\title{
Timo Schmidt \\ Der Rücktritt vom versuchten Unterlassungsdelikt durch weiteres Unterlassen
}



Timo Schmidt

Der Rücktritt vom versuchten Unterlassungsdelikt durch weiteres Unterlassen

Dieses Werk ist lizenziert unter einer

Creative Commons

Namensnennung - Weitergabe unter gleichen Bedingungen

4.0 International Lizenz.

(c) $\underset{\mathrm{BY}}{(1)}$ (2) 
erschienen in der Reihe der Universitätsdrucke im Universitätsverlag Göttingen 2018 
Timo Schmidt

Der Rücktritt

vom versuchten

Unterlassungsdelikt

durch weiteres Unterlassen

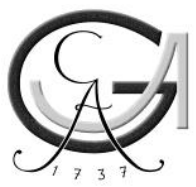

Universitätsverlag Göttingen 2018 


\section{Bibliographische Information der Deutschen Nationalbibliothek}

Die Deutsche Nationalbibliothek verzeichnet diese Publikation in der Deutschen Nationalbibliographie; detaillierte bibliographische Daten sind im Internet über $<$ http://dnb.dnb.de $>$ abrufbar.

Autorenkontakt

Timo Schmidt

E-Mail: tmhschmidt@gmx.de

Dieses Buch ist auch als freie Onlineversion über die Homepage des Verlags sowie über den Göttinger Universitätskatalog (GUK) bei der Niedersächsischen Staats- und Universitätsbibliothek Göttingen (http://www.sub.uni-goettingen.de) erreichbar. Es gelten die Lizenzbestimmungen der Onlineversion.

Satz und Layout: Timo Schmidt

(C) 2018 Universitätsverlag Göttingen https://univerlag.uni-goettingen.de ISBN: 978-3-86395-353-9

DOI: https://doi.org/10.17875/gup2018-1083 
Meiner Mutter 



\section{Vorwort}

Diese Arbeit wurde im Sommersemester 2016 von der Juristischen Fakultät der Georg-August-Universität Göttingen als Dissertation angenommen.

Mein Dank gilt an erster Stelle meinem Doktorvater, Professor Dr. Uwe Murmann, für die schnelle Begutachtung der Arbeit und vor allem für die angenehme und erhellende Zeit am Lehrstuhl. Insbesondere die Mitarbeit hat maßgeblich zu meinem juristischen Fortkommen beigetragen und nicht zuletzt den Grundstein für meine berufliche Entwicklung gelegt.

Dr. Manuel Ladiges, LL.M. möchte ich für unsere unzähligen Diskussionen und das „Versorgen“ mit aktuellen Problemen danken. Der Austausch war immer eine willkommene Abwechslung und hat manche Wissenslücke geschlossen. Ich wünsche ihm für seine Zukunft alles Gute.

Unserer Sekretärin Thekla Bollensen danke ich für die gute Zusammenarbeit und vor allem für ihre Hilfsbereitschaft.

Ein großer Dank gilt auch meinen Eltern, Barbara und Manfred Schmidt. Beide haben stets großes Vertrauen in mich gesetzt und meine Entscheidungen unterstützt. Durch sie konnte ich meinen Lebensweg frei ausgestalten und schließlich meine Ziele erreichen. Die Arbeit widme ich meiner Mutter.

Meiner Verlobten, Studienrätin Kristine Suchanek, bin ich insbesondere für das Verständnis während der beiden Staatsexamina und die vielen schönen Momente dankbar. Ich freue mich auf unsere gemeinsame Zukunft. 
Ebenso möchte ich meinen zukünftigen Schwiegereltern, Biserka und Peter Suchanek, für die Aufnahme in die Familie und das stets so herzliche und liebevolle Verhältnis danken.

Anne Krüger danke ich für die Durchsicht der Arbeit und ihre konstruktive Unterstützung.

Dr. Philipp-Alexander Hirsch, Katharina Lüse, Xenia Tukuser und Sascha Warnecke sind abschließend nicht nur wegen ihrer juristischen Unterstützung zu erwähnen, sondern haben vor allem in privater Hinsicht besonderen Dank verdient. Ohne sie wäre so mancher Abschnitt in den vergangenen Jahren nicht nur trister, sondern vor allem auch schwerer zu bewältigen gewesen.

Goslar, im Februar 2018

Timo Schmidt 


\section{Inhaltsverzeichnis}

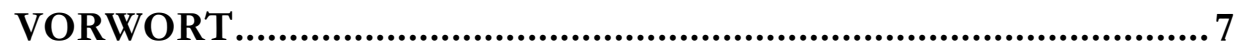

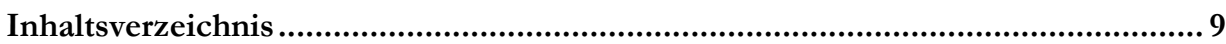

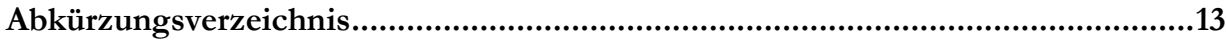

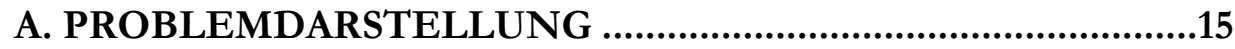

B. EINFÜHRUNG/BEWERTUNGSRAHMEN ..........................17

I. Der Tatbegriff des $\ 24$ Abs. 1 StGB ...........................................................17

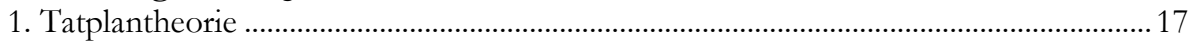

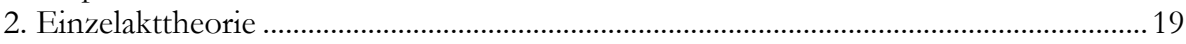

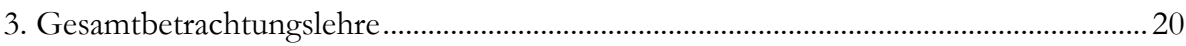

4. Streitentscheid Gesamtbetrachtungslehre/Einzelakttheorie............................................ 20

a. Argumente für ein enges Tatverständnis i.S. der Einzelakttheorie ............................2 21

b. Argumente für die Gesamtbetrachtungslehre .............................................................. 22

aa. Bewertung der für die Einzelakttheorie vorgebrachten Argumente .................... 22

bb. Argumente für die Gesamtbetrachtungslehre...................................................... 24

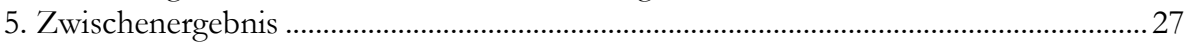

II. Die Reichweite des Tatbegriffs............................................................... 27

1. Natürliche Handlungseinheit/Einheitlicher Lebensvorgang ......................................... 27

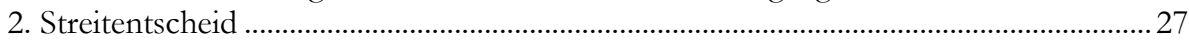

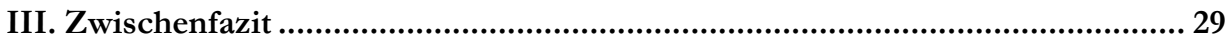

\section{DER RÜCKTRITT VOM VERSUCHTEN}

UNTERLASSUNGSDELIKT DURCH WEITERES

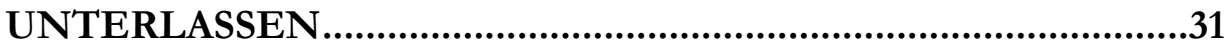

I. Einführung/Folgen eines begehungsformunabhängigen Tatbegriffs ................31

II. Der Begehungsformwechsel im Rahmen des

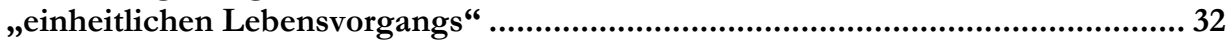

1. Vergleich des Begehungsformwechsels mit einem Tatmittelwechsel.............................. 32

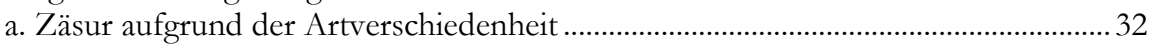

b. Zäsur aufgrund unterschiedlicher Geeignetheit und Gefährlichkeit.......................... 36

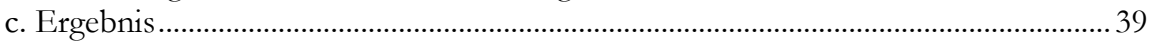

2. Zäsur aufgrund geänderten Unrechtsgehalts ...................................................................... 39 


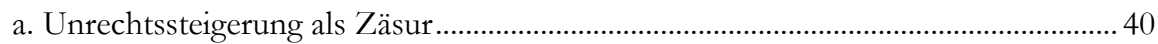

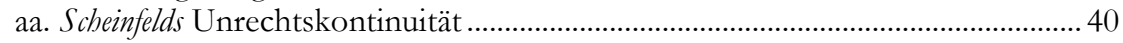

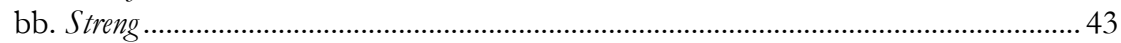

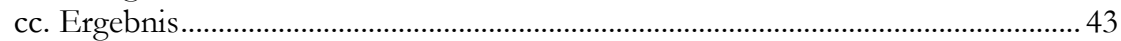

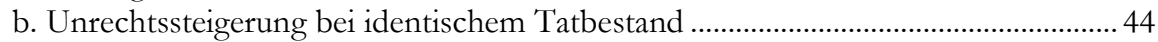

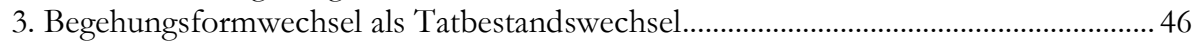

a. Auswirkungen eines Tatbestandswechsels auf die einheitliche Tat i.S. des

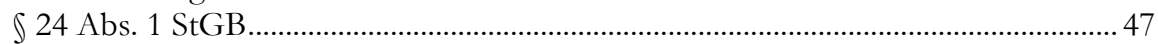

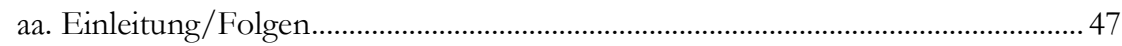

bb. Vertretene Ansichten........................................................................................... 49

(1.) BGH und Teil der Lehre: Die Tat i.S. des $\int 24$ StGB entspricht dem

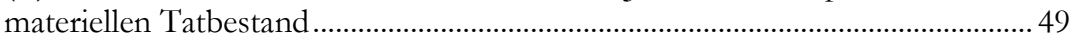

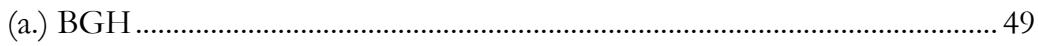

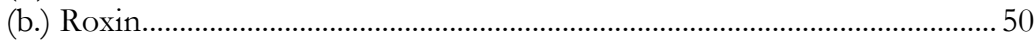

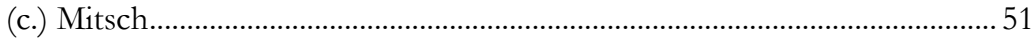

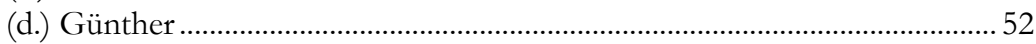

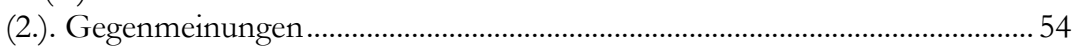

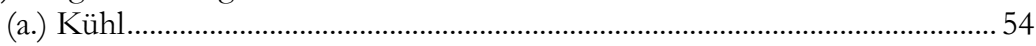

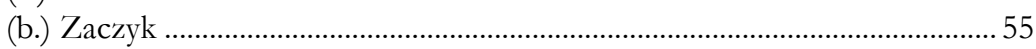

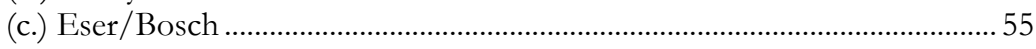

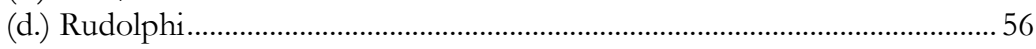

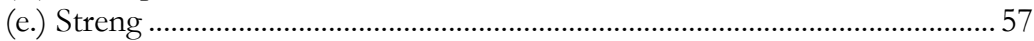

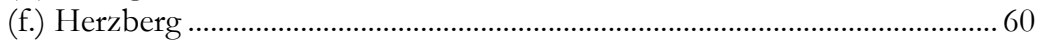

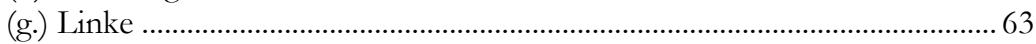

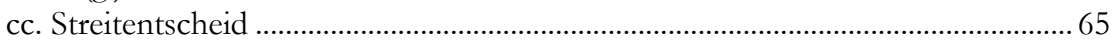

(1.) Allgemeine Würdigung der Entscheidung des BGH ...................................... 66

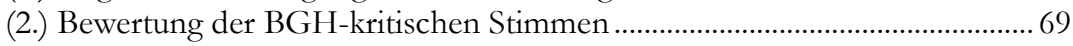

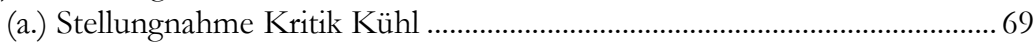

(b.) Stellungnahme Kritik Zaczyk ...................................................................... 70

(c.) Stellungnahme Kritik Eser/Bosch............................................................... 70

(d.) Stellungnahme Kritik Rudolphi ............................................................... 72

(aa.) Allgemeine Würdigung........................................................................... 72

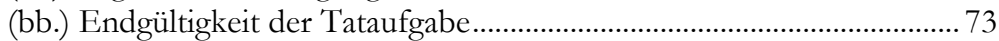

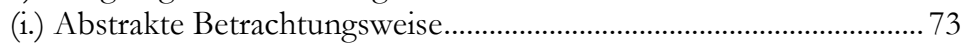

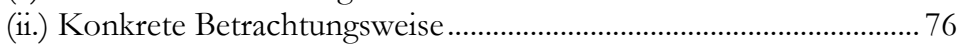

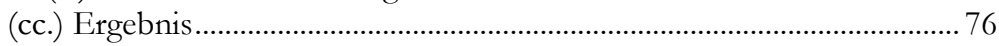

(e.) Stellungnahme Kritik Streng .......................................................................... 77

(aa.) Strengs Kritik im Hinblick auf die Herleitung ........................................ 77

(bb.) Strengs Kritik im Hinblick auf die Folgen .............................................. 78

(i.) Bewertung des Tresorbeispiels........................................................... 79

(ii.) Ergebniskongruenz trotz abweichender Begründung .................... 80

(iii.) Bewertung der weiteren Einwände .................................................... 82

(f.) Stellungnahme Kritik Herzberg .................................................................. 84

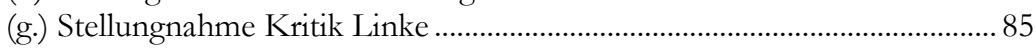

(3.) Weitere Argumente für die Auffassung des BGH.......................................... 88

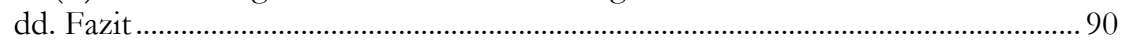

b. Bestimmung der Tatbestandsqualität der unechten Unterlassungsdelikte ............... 91 
aa. Auffassung des BGH

bb. Die Unterlassungsstrafbarkeit vor Einführung des $\int 13 \mathrm{StGB} / \mathrm{Sinn}$ und Zweck der Einführung des $\ 13$ StGB (= Verfassungsmäßigkeit der Strafbarkeit des „Begehens durch Unterlassen“ ohne besondere gesetzliche Ausgestaltung)

(1.) Verfassungsmäßigkeit der Unterlassungsstrafbarkeit bei Fehlen des $\int 13 \mathrm{StGB}$ .94

(a.) Verstoß gegen das Analogieverbot .95 (aa.) Ergründung des Bewertungsmaßstabs anhand des $₫ 212$ StGB und die dortige Tatbestandsmäßigkeit des Unterlassens ............................. 97

(bb.) \ 223 StGB Körperverletzung ………………........................................ 100

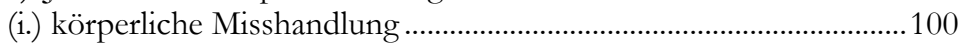

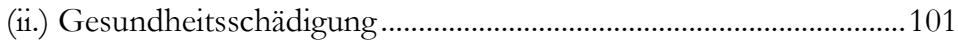

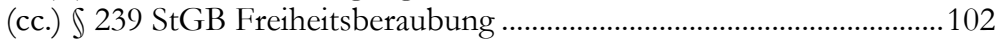

(i.) Erste Verhaltensvariante: „einsperren“ .............................................102

(ii.) Zweite Verhaltensvariante: ,auf andere Weise der Freiheit

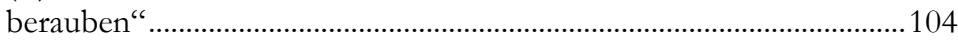

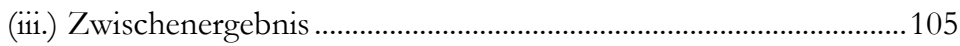

(dd.) Verstoß gegen das Analogieverbot: Ergebnis ....................................105

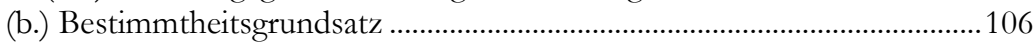

(aa.) Charakter der Garantenstellung........................................................... 107

(i.) Maurach/Unterlassung als Handlung ..............................................108

(ii.) Bestimmung anhand des Wortlauts....................................................111

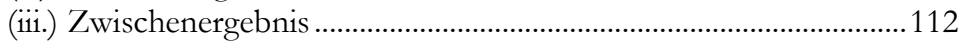

(bb.) Verletzung des Bestimmtheitsgebots...................................................113

(i.) Die Garantenstellung und der Wortlaut des konkreten

Begehungsdelikts ........................................................................................ 113

(ii.) Herleitung der Handlungspflicht nach Böhm ................................115

(iii.) Herleitung der Handlungspflicht nach Schönke/Schröder .........118

(iv.) Herleitung der Handlungspflicht nach Meyer-Bahlburg ..............119

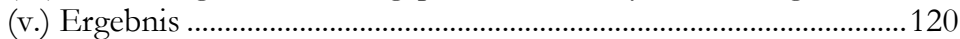

(c.) Verfassungsmäßigkeit des unechten Unterlassungsdelikts ohne

besondere gesetzliche Ausgestaltung aufgrund von faktischen

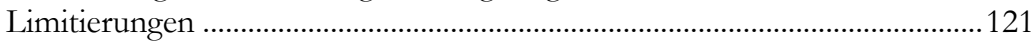

(2.) Konsequenzen für den Charakter des $\int 13$ StGB ........................................123

cc. Wortlaut des $₫ 13$ Abs. 1 StGB/Betrachtung der

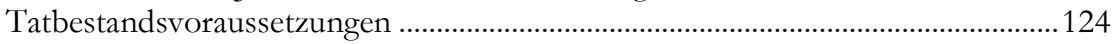

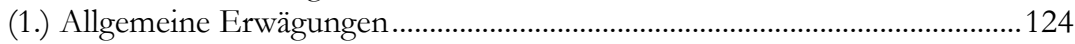

(2.) Eigenständigkeit aufgrund des Garantenerfordernisses ..............................126

(3.) Eigenständigkeit aufgrund der Kausalitätsanforderungen...........................129

(4.) Eigenständigkeit aufgrund der Entsprechungsklausel.................................130

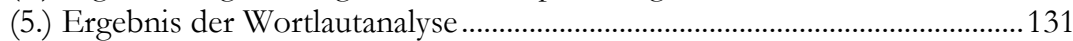

dd. Die fakultative Strafmilderung ( $(13$ Abs. 2 StGB)............................................. 132

(1.) Rückschluss von der Milderungsmöglichkeit bzw. deren Rechtsgrund

auf die deliktische Eigenständigkeit .......................................................................... 132

(2.) Anwendungsumfang des $\int 13$ Abs. 2 StGB im Fall eines

Begehungsformwechsels bei Fortbestehen derselben Tat. 
(3.) Vergleich der Verweise auf $\int 49$ Abs. 1 StGB ............................................... 135

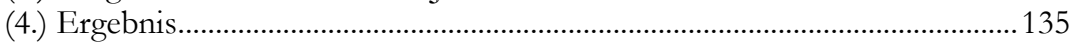

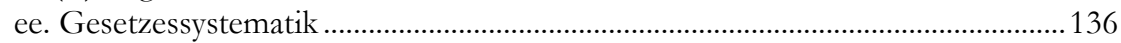

(1.) Vergleich mit den echten Unterlassungsdelikten ......................................... 136

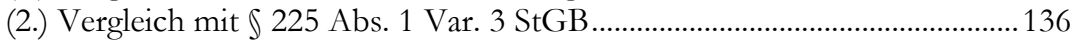

ff. Strafrechtlicher Vorwurf..................................................................................... 138

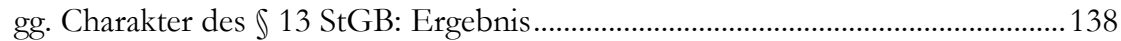

c. Folgen für die Einheitlichkeit des Geschehens bei einem

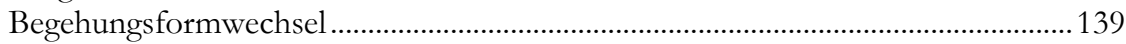

4. Begehungsformübergreifende sukzessive/iterative Tatbestandserfüllung .................139

5. Vereinbarkeit einer Rücktrittserweiterung mit den Grundsätzen des Rücktritts .......142

a. Mangelnde Distanzierung von der Unterlassungspassage ....................................... 142

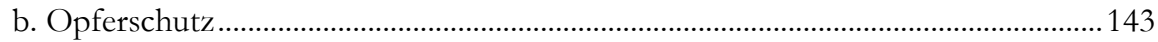

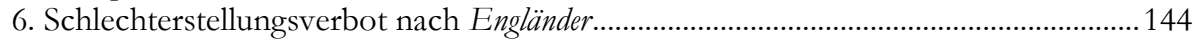

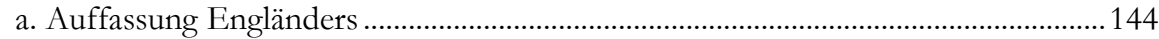

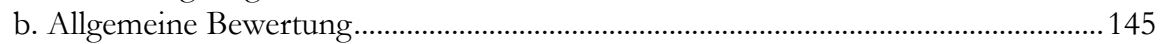

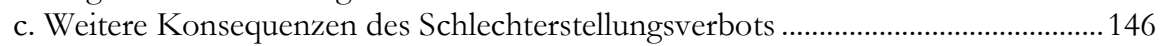

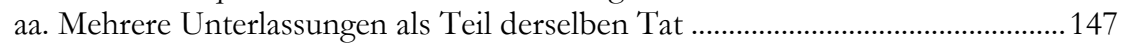

(1.) Grundsätzliche Möglichkeit einer mehraktigen Unterlassung .................... 147

(2.) Zäsuren im Rahmen der mehraktigen Unterlassung .................................. 148

(a.) Zäsur aufgrund des zwischenzeitlichen Scheiterns ................................. 149

(b.) Zäsur aufgrund des Zufallsmoments ....................................................... 149

(c.) Zäsur durch Aufgabe des Tatentschlusses bzw. durch mangelnde

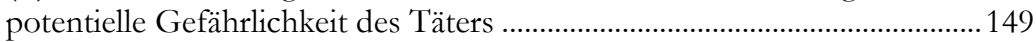

(d.) Zwischenergebnis .......................................................................................... 150

bb. Fehlschlagsnegation durch eine weitere Unterlassungsmöglichkeit.................150

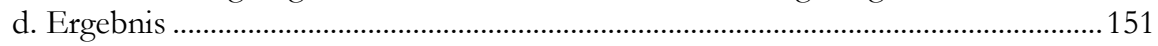

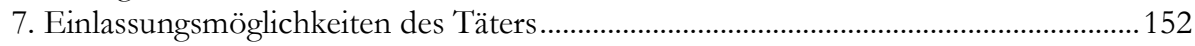

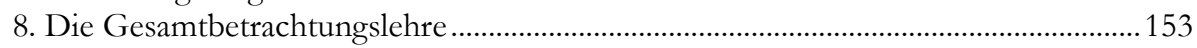

a. Bewertungsgrundlage ................................................................................................ 153

aa. Rechtliche Bedeutung eines sich an ein aktive Handlung anschließenden

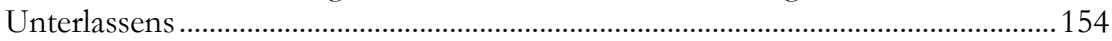

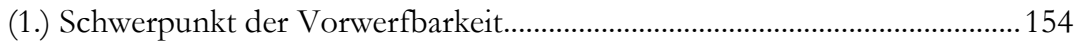

(2.) Garantenstellung bei einem vorsätzlichen Vorverhalten...............................154

(3.) Unzumutbarkeit der Hilfeleistung ................................................................. 156

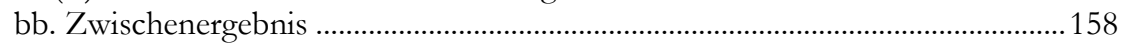

b. Konsequenzen für die Gesamtbetrachtungslehre ................................................... 158

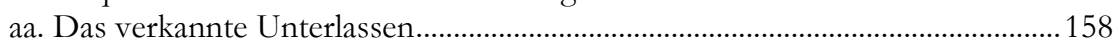

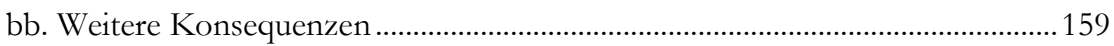

dd. Modifikation der Gesamtbetrachtungslehre........................................................ 161

ee. Folgen für die begehungsformübergreifende Mehraktigkeit.............................. 162

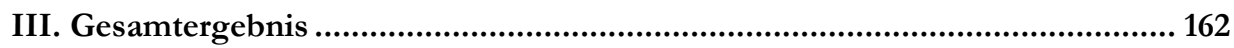

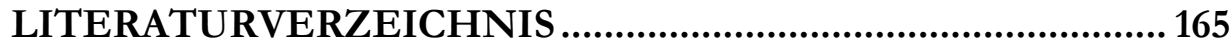




\section{Abkürzungsverzeichnis}

\begin{tabular}{|l|l|}
\hline a.F. & alte Fassung \\
\hline aaO & am angegebenen Ort \\
\hline Abs. & Absatz \\
\hline Art. & Artikel \\
\hline AT & Allgemeiner Teil \\
\hline Aufl. & Auflage \\
\hline Bd. & Band \\
\hline BGH & Bundesgerichtshof \\
\hline BGHSt & $\begin{array}{l}\text { Entscheidungen des Bundesgerichtshofs } \\
\text { in Strafsachen }\end{array}$ \\
\hline Bsp. & Beispiel \\
\hline bspw. & beispielsweise \\
\hline BT & Besonderer Teil \\
\hline BVerfG & Bundesverfassungsgericht \\
\hline BVerfGE & $\begin{array}{l}\text { Entscheidungen des Bundesverfas- } \\
\text { sungsgerichts }\end{array}$ \\
\hline bzw. & beziehungsweise \\
\hline dens. & denselben \\
\hline ders. & derselbe \\
\hline Diss. Jur. & juristische Dissertation \\
\hline f./ff. & folgend/folgende \\
\hline Fn. & Fußnote \\
\hline FS & Festschrift \\
\hline GA & Goltdammer's Archiv für Strafrecht \\
\hline gem. & gemäß \\
\hline GerS & Gerichtssaal \\
\hline GG & Grundgesetz \\
\hline ggf. & gegebenenfalls \\
\hline GK & Grundkurs \\
\hline grds. & grundsätzlich \\
\hline GS & Gedächtnisschrift \\
\hline
\end{tabular}




\begin{tabular}{|l|l|}
\hline HK-GS & $\begin{array}{l}\text { Gesamtes Strafrecht, StGB, StPO, Ne- } \\
\text { bengesetze, Handkommentar }\end{array}$ \\
\hline Hrsg. & Herausgeber \\
\hline i.S. & im Sinne \\
\hline i.S.v. & im Sinne von \\
\hline JR & Juristische Rundschau \\
\hline Jura & Juristische Ausbildung \\
\hline JuS & Juristische Schulung \\
\hline JZ & JuristenZeitung \\
\hline LK & Leipziger Kommentar \\
\hline MDR & Monatsschrift für Deutsches Recht \\
\hline MK & Münchener Kommentar \\
\hline NJW & Neue Juristische Wochenschrift \\
\hline NK & Nomos Kommentar \\
\hline NStZ & Neue Zeitschrift für Strafrecht \\
\hline Rn. & Randnummer \\
\hline S. & Seite \\
\hline SK & Systematischer Kommentar \\
\hline SSW & Satzger/Schluckebier/Widmaier \\
\hline StGB & Strafgesetzbuch \\
\hline StV & Strafverteidiger \\
\hline u.a. & unter anderem \\
\hline v. & von \\
\hline Var. & Variante \\
\hline wistra & $\begin{array}{l}\text { Zeitschrift für Wirtschafts- und Steuer- } \\
\text { strafrecht }\end{array}$ \\
\hline z.B. & zum Beispiel \\
\hline ZStW & $\begin{array}{l}\text { Zeitschrift für die gesamte Strafrechts- } \\
\text { wissenschaft }\end{array}$ \\
\hline & \\
\hline
\end{tabular}




\section{A. Problemdarstellung}

Wendet sich ein Unterlassungstäter von seinem Vorhaben ab, so sind die Anforderungen, die an das Rücktrittsverhalten gestellt werden, vermeintlich eindeutig. Unkritisch wird hierbei stets ein entgegengesetztes Handeln gefordert. ${ }^{1}$ Dies erscheint auf den ersten Blick schlüssig. Der Täter, der gerade durch das Unterlassen tatbestandlich handelt, muss den Kausalverlauf ändern, mithin also tätig werden. Zu beachten ist jedoch, dass diese Frage meist nur im Rahmen der Unterlas-

1 U.a. BGH, NStZ 1997, 485: „Damit sind die Rücktrittsvoraussetzungen beim Versuch des Unterlassungsdelikts dieselben wie beim beendeten Versuch des Begehungsdelikts."; BGH, NJW 2000, 1730, 1732; BGH, NStZ 2003, 252, 253; NK-StGB/Zacryyk, \ 24 Rn. 47; Schönke/Schröder/Eser/Bosch, \24 Rn. 27, 30; SSW-StGB/Kudlich/Schubr, \24 Rn. 40; LKStGB/Lilie/Albrecht, \24 Rn. 467; Küper, ZStW 112 (2000), 1, 3 f.; Kübl, AT, \} 1 8 \text { Rn. 152; Ro- } xin, AT II, \29 Rn. 269; Freund, AT, \8 Rn. 67; MK-StGB/Heræyerg/Hoffmann-Holland, \24 Rn. 83; so auch Ahmed, Rücktritt vom versuchten unechten Unterlassungsdelikt, S. 85 f., der zwar zwischen einem unbeendeten und beendeten Versuch unterscheidet, hieran jedoch allein die Anforderungen für das entgegengesetzte Handeln festmacht. Beim unbeendeten Versuch solle es ausreichen, die ursprüngliche Handlung nachzuholen, wobei bei einem beendeten Versuch zusätzliche „Sondermaßnahmen“ für eine Strafbefreiung erforderlich sind; Kudlich/Hannich, StV 1998, 369, 370; Kudlich, JR 2003, 379, 381; anders Engländer, JZ 2012, 130, 133. Nach Engländer ergibt sich aus $₫ 13 \mathrm{StGB}$ ein Scblechterstellungsverbot. Dies führe dazu, dass auch bei einem versuchten Unterlassen das bloße Ablassen von einer weiteren Ausführungsmöglichkeit zur Straflosigkeit führen muss, wenn dies auch im Rahmen eines aktiven Versuchs gilt; ebenso abweichend Wessels/Beulke/Satzger, AT, Rn. 1046 und 1048. 
sung an sich erörtert wird. Der Vater, der seine Tochter ertrinken sieht und vorsätzlich nicht eingreift, kann in diesem Rahmen durch bloßes Zuwarten freilich nicht zurücktreten. Anders könnte es sich aber dann darstellen, wenn die Tochter sich selbst rettet und der Vater die Möglichkeit erkennt, die Tochter wieder zurück ins Wasser zu stoßen, dies jedoch unterlässt. ${ }^{2}$ Fraglich erscheint dann, ob das Ablassen von einer weiteren aktiven Ausführungsmodalität tauglich ist, um insgesamt zurückzutreten. ${ }^{3}$

Anders als somit stets angenommen, bestehen für den Rücktritt vom versuchten Unterlassungsdelikt zwei Anknüpfungspunkte. Neben der isolierten Betrachtung der Unterlassung könnten auch weitere mögliche Akte Einfluss auf die Rücktrittsfähigkeit des Unterlassungsversuchs besitzen. Klärungsbedürftig ist somit, ob das Absehen von weiteren Tatmitteln zur vollständigen Straflosigkeit führt. Dies wäre der Fall, wenn die Voraussetzungen des $₫ 24$ Abs. 1 StGB vorliegen würden. Um die möglichen Handlungen berücksichtigen zu können, müssten diese Teil derselben Tat i.S. des $₫ 24$ Abs. 1 StGB sein. ${ }^{4}$ Scheidet dies aus, so läge im Zeitpunkt des Scheiterns der Unterlassung mangels weiterer Ausführungsmöglichkeiten ein Fehlschlag vor. ${ }^{5}$

Fraglich ist somit, ob ein Unterlassen und ein aktives Tun Teil derselben Tat i.S. des $\$ 24$ Abs. $1 \mathrm{StGB}$ sein können.

2 Engländer, JZ 2012, 130, 131; Murmann, GA 2012, 711, 712; siehe auch Wessels/Beulke/Satzger, AT, Rn. 1048.

3 Frage so bei Engländer, JZ 2012, 130, 131, der dies auf S. 133 bejaht; für eine einheitliche Tat trotz eines Begehungsformwechsels auch Wessels/Beulke/Satzger, AT, Rn. 1046: „Auch ein Unterlassungsversuch kann fehlgeschlagen sein. Davon ist in erster Linie auszugehen, wenn der Täter erkennt, dass er den tatbestandsmäßigen Erfolg allein durch das Unterlassen nicht mehr bewirken könnte und ihm auch keine Mittel zur Verfügung stehen, den Erfolg durch positives Tun herbeizuführen." Zudem sei es erforderlich, zwischen einem unbeendeten und beendetem Unterlassungsversuch zu differenzieren, denn „Ausnahmsweise kann ein rein passives Aufgeben der weiteren Tatausführung gem. \24 I 1 Alt. 1 auch bei unechten Unterlassungsdelikten einen Rücktritt bewirken.“ (Rn. 1048); siehe auch Murmann, Grundkurs, \ 29 Rn. 116, der hier das Problem der Mehraktigkeit erkennt, jedoch trotzdem einen Fehlschlag annimmt, da „[...] der Übergang von einem Unterlassen zum Tun eine Zäsur im Geschehensablauf und damit eine neue Tat i. S. v. \$ 24 StGB dar[stellt]“; ders., GA 2012, 711, 712 ff., wobei Murmann hier versucht, den Zäsurmoment zu präzisieren und schließlich das Problem am eigenen Tatverständnis misst; MK-StGB/Herz̨erg/Hoffmann-Holland, \24 Rn. 83 verkennen diesen Anknüpfungspunkt.

4 Siehe Murmann, GA 2012, 711; Engländer, JZ 2012, 130, 131.

5 Siehe allgemein zum Fehlschlag nur Murmann, Grundkurs, $\ 28$ Rn. 109. 


\section{B. Einführung/Bewertungsrahmen}

\section{Der Tatbegriff des $\$ 24$ Abs. 1 StGB}

Wie weit der Tatbegriff im Allgemeinen reichen soll und welche Handlungsakte von ihm noch erfasst sind, ist umstritten.

\section{Tatplantheorie}

Nach der Tatplantheorie ${ }^{6}$ sind einzelne Ausführungsakte solange Teil einer Tat i.S. des $\int 24$ Abs. 1 StGB, wie sie auf dem vom Täter gefassten Tatplan beruhen. Sobald alle dort vorgesehenen Ausführungsarten aufgebraucht sind, schlägt der Versuch fehl und der Täter kann nicht mehr strafbefreiend zurücktreten. ${ }^{7}$

Für die vorliegende Problematik bedeutete dies, dass eine abstrakte Rücktrittsmöglichkeit davon abhinge, was der Täter sich zu Beginn der Tat vorgestellt hat. Der Vater, der seine Tochter ertrinken sieht und sich entschließt, nichts zu

So BGH früher. U.a. BGHSt 10, 129, 131; BGHSt 14, 76, 79.

7 BGHSt 10, 129, 131: „Die nach dem Fehlschlag des ersten Mittels unmittelbar anschließende Verwirklichung desselben Tötungsentschlusses mit einem anderen Mittel könnte nur dann als im natürlichen und rechtlichen Sinne selbständige Handlung gesondert gewertet werden, wenn der Täter seinen Tötungswillen ursprünglich $\mathrm{n}$ u r mit einem b e s t i m m t e n Mittel hätte verwirklichen wollen $[\ldots]$. . 
unternehmen, müsste sich somit bereits zu diesem Zeitpunkt Handlungsalternativen bereitlegen, um einen Fehlschlag bei Fehlgehen der Unterlassung zu vermeiden. Ob der Vater jedoch tatsächlich straffrei würde, kann dahinstehen, wenn die Tatplantheorie für die Bestimmung der Tat nicht fruchtbar gemacht werden kann. In Bezug auf die Tatplantheorie erscheint bereits problematisch, dass der Täter, der sich im Vorfeld viele Ausführungsakte vorbehalten hat, gegenüber dem Täter mit einem geringeren Repertoire bevorzugt würde. Der planende Täter wird aufgrund des später einsetzenden Fehlschlags besser gestellt als der „Amateur“. 8 Zudem könnte der Täter, der sich über die Ausführungsarten überhaupt keine Gedanken macht, insgesamt strafbefreiend zurücktreten. ${ }^{9}$ Auch ist das von Otto vorgetragene Argument der ungünstigen Einlassung im Strafverfahren stichhaltig. Ein Täter, der um die juristischen Hintergründe nicht weiß, wird auf die Frage hin, ob er einmal oder mehrmals auf das Opfer einstechen wollte, stets behaupten, dass er es von Anfang an bei einem Stich bewenden lassen wollte, selbst wenn dieser sich diesbezüglich gar keine Gedanken gemacht hat. Die Strafbarkeit würde mithin nicht zuletzt von Zufällen abhängen. ${ }^{10}$ Wäre der Täter hingegen anwaltlich gut beraten, so wird dieser das vorherige Einplanen weiterer Handlungsmöglichkeiten einräumen. ${ }^{11}$ Somit ist festzustellen, dass die Tatplantheorie versucht, dem einzelnen Täter individuell gerecht $\mathrm{zu}$ werden, was separiert betrachtet wohl gelingt. Erst im Zusammenspiel und im Vergleich dieser individuellen Lösungen wird klar, dass es zu unbegründeten Privilegierungen kommt.

Gössel wendet gegen die Tatplantheorie des Weiteren ein, dass die Tat i.S. des $\int 24$ Abs. 1 S. 1 StGB als "Tatplan“ verstanden würde. Dies führte dazu, dass allein die Aufgabe des gefassten Tatplans relevant wäre und „,nicht die objektiv rechtsgutsbeeinträchtigende Straftat“..12 Nach Gössel hätte dies eine „,kriminalpolitisch unvertretbar[e]“" Erweiterung der Rücktrittsmöglichkeit zur Konsequenz. So schiene es grundsätzlich denkbar, dass ein Rücktritt auch dann möglich sei, wenn abweichend von dem Tatplan vor dessen gänzlicher Realisierung schon eine Rechtsgutsbeeinträchtigung eintritt. ${ }^{13}$ Neben diesem Umstand führt Gössel an, dass strafrechtliche Relevanz allein ,ins Werk gesetəte Pläne“ besitzen können und nicht der bloße Plan an sich. „[D]eshalb kann Gegenstand der Aufgabe nicht bloß die

8 SK-StGB/Rudolphi, \ 24 Rn. 12 a; Geilen, JZ 1972, 335, 336; Murmann, Grundkurs, \ 28 Rn. 116; Jescheck/Weigend, AT, \51 II 3; Otto, GA 1967, 144 f.; Puppe, NStZ 1986, 14, 15.

9 „Robrzangenfall" BGHSt 22, 176, 177; siehe auch BGHSt 10, 129, 131; Roxin, AT II, \30 Rn. 201; Fabrenhorst, Jura 1987, 291, 292.

10 Otto, GK, \& 19 Rn. 13.

11 Roxin, AT II, $₫ 30$ Rn. 201; ders., JuS 1981, 1, 7; siehe hierzu auch ders., JR 1986, 424, 425 f.; Dreher, JR 1969,105, 106; Fahrenhorst, Jura 1987, 291, 292.

12 Maurach/Gössel, AT, 7. Aufl. 1989, \ 41 Rn. 50.

13 Maurach/Gössel, AT, 7. Aufl. 1989, \41 Rn. 50; Roxin, JR 1986, 424, 425 weist zudem darauf hin, dass es nicht einleuchte, „,warum Strafbarkeit oder Straflosigkeit davon abhängen sollen, ob der Täter geglaubt hat, mit einem Handlungsakt oder möglicherweise nur mit mehreren zum Ziel zu kommen“, mithin also, warum überhaupt an den Tatplan angeknüpft wird. 
subjektive Vorstellung eines Tatplans sein, sondern das aus subjektiven und objektiven Elementen bestehende strafbare rechtsgutsbeeinträchtigende Verhalten, soweit es das Stadium des Versuchs noch nicht verlassen hat."14

Folglich gilt die Tatplantheorie zu Recht als überholt und kann zur Bestimmung der Tat i.S. des $\int 24$ Abs. 1 StGB nicht herangezogen werden. ${ }^{15}$

\section{Einzelakttheorie}

Nach der Einzelakttheorie ${ }^{16}$ stellt jede Handlung eine neue Tat dar, sodass bei einem mehraktigen Geschehen nicht nur ein Versuch vorliegt, sondern jede Handlung für sich genommen ein eigenständiger Versuch ist. Dies führt dazu, dass nach dem Fehlgehen einer Handlung der Versuch als fehlgeschlagen angesehen werden muss, selbst wenn noch weitere Handlungsmöglichkeiten bestehen. ${ }^{17}$ Es wäre dem Täter folglich nicht möglich, durch Ablassen von weiteren Ausführungshandlungen, strafbefreiend zurückzutreten.

Auf das vorliegende Problem bezogen bedeutete dies, dass das Unterlassen eine eigenständige Tat i.S. des $\ 24$ Abs. 1 StGB darstellen würde. Nachdem der Vater erkannt hatte, dass sein Unterlassen zur Erfolgsherbeiführung nicht mehr tauglich ist, schlug der Versuch fehl. Ob er hierbei ggf. Fortsetzungsmöglichkeiten sah, hätte für die Bewertung des Fehlschlags keine Relevanz.

Folglich kann nach der Einzelakttheorie ein Rücktritt nur innerhalb der tatbestandlichen Unterlassung erfolgen. Hier ist jedoch eindeutig, dass nur ein entgegengesetztes Handeln des Täters zu dessen Straflosigkeit führt. Ein Rücktritt vom versuchten Unterlassungsdelikt durch weiteres Unterlassen ist mit der Einzelakttheorie somit nicht denkbar. ${ }^{18}$

14 Maurach/Gössel, AT, 7. Aufl. 1989, \41 Rn. 50.

15 Auch der BGH ist von dieser Auffassung abgekommen und vertritt nunmehr die Gesamtbetrachtungslehre. Siehe u.a. BGHSt 31, 170; BGHSt 34, 53, 56 f.; BGHSt 35, 90, 93; BGHSt 39, 221, 227.

16 Vertreten u.a. von Bergmann, ZstW 100 (1988), 329, 351: „Die ,besten Karten“ scheint mir dabei doch die überwiegend abgelehnte strenge Einzelaktstheorie zu haben."; Jakobs, AT, 26/16; Schönke/Schröder/Eser/Bosch, \24 Rn. 21; Paeffgen, FS Puppe, 2011, S. 791; Heckler, Rücktrittsleistung, S. 196 ff.; Burkhardt, Der „Rücktritt“ als Rechtsfolgenbestimmung, in: Strafrechtliche Abhandlungen Bd. 23, 1975, S. 94.

17 Bergmann, ZstW 100 (1988), 329, 332; Schönke/Schröder/Eser/Bosch, \ 24 Rn. 21; Burkhardt, Der „Rücktritt“ als Rechtsfolgenbestimmung, in: Strafrechtliche Abhandlungen Bd. 23, 1975, S. 94.

18 Siehe hierzu Murmann, GA 2012, 711, 712. 
Einführung/Bewertungsrahmen

\section{Gesamtbetrachtungslehre}

Die heute wohl herrschende Auffassung ist die Gesamtbetrachtungslehre. ${ }^{19}$ Es erfolgt eine Gesamtbetrachtung der Handlungen des Täters. ${ }^{20}$ Welche Handlungen dem Täter zur Verfügung stehen, bemisst sich nach dem Rücktrittshorizont, sodass es für etwaige weitere Ausführungsmodalitäten unerheblich ist, ob der Täter sich diese schon zu Beginn zurechtgelegt hat oder ob sich deren Möglichkeit spontan ergibt. ${ }^{21}$ Solch eine Annahme determiniert aber allein die grundsätzliche Möglichkeit eines mehraktigen Geschehens, wobei fraglich bleibt, wann die einzelnen Handlungen tatsächlich Teil derselben Tat sind.

Nach einer Auffassung bestimmt sich die Einheitlichkeit der einzelnen Akte nach der Einheitlichkeit des Lebensvorganges 22 , wohingegen andere die Bestimmung an der natürlichen Handlungseinheit festmachen wollen ${ }^{23} .^{24}$

Festzustellen ist, dass nach der Gesamtbetrachtungslehre, zumindest abstrakt betrachtet, die Möglichkeit besteht, auch mehrere Handlungen zu einer Tat i.S. des $\int 24$ Abs. 1 StGB zusammenzufassen. Somit erscheint es mit der Gesamtbetrachtungslehre nicht ausgeschlossen, dass auch bei einem Wechsel vom Unterlassen zum aktiven Tun dieselbe Tat fortbesteht, was dazu führen könnte, dass ein Rücktritt vom versuchten Unterlassungsdelikt durch weiteres Unterlassen möglich wäre. ${ }^{25}$

\section{Streitentscheid Gesamtbetrachtungslehre/Einzelakttheorie}

Die Tatdefinition entscheidet, ob im Fall einer weiteren möglichen Handlung ein unbeendeter Versuch vorliegt, der Täter somit durch Ablassen von dieser Ausführungsmöglichkeit strafbefreiend zurücktreten kann oder ob der Versuch durch das Scheitern des ersten Aktes als fehlgeschlagen angesehen werden muss, was einen Rücktritt ausschließt. ${ }^{26}$ Bereits hieraus ist ersichtlich, dass sich das Problem des

19 U.a. BGHSt 34, 53, 56 f.; BGHSt 35, 90, 93; BGHSt 39, 221, 227 f.; MKStGB/Herz̧berg/Hoffmann-Holland, \ 24 Rn. 61; Kühl, AT, 』16 Rn. 22; Krey/Esser, AT, Rn. 1277; Rengier, AT, \ 37 Rn. 46; SSW-StGB/Kudlich/Schubr, \24 Rn. 19; HK-GS/Ambos, \ 24 Rn. 7.

20 Siehe nur BGHSt 34, 53, 56 f.; BGHSt 35, 90, 93; BGHSt 39, 221, 228.

21 U.a. BGHSt 31, 170, 175 f.; BGHSt 33, 295, 298; BGHSt 35, 90, 91 f.; BGHSt 36, 224, 225; BGHSt, 39, 221, 227 f.; BGH NStZ 2002, 427, 428; BGH NStZ 2008, 393; BGH NStZ 2009, 25; NK-StGB/Zaczyk, \24 Rn. 12.

22 BGHSt 40, 75, 77; NK-StGB/Zaczyk, 』 24 Rn. 17; LK-StGB/Lilie/Albrecht, \ 24 Rn. 115 f.; MK-StGB/Herzberg/Hoffmann-Holland, J 24 Rn. 62.

23 So wohl Roxin, JuS 1981, 1, 7; Dreher, JR 1969, 105, 107; SK-StGB/Rudolphi, \ 24 Rn. 14; Schmidhäuser, AT, Lehrbuch, 15/78; siehe hierzu Baumann/Weber/Mitsch, AT, \27 Rn. 31.

24 Siehe zum Streitentscheid S. 27.

25 Siehe hierzu auch Murmann, GA 2012, 711, der darauf hinweist, dass es sich bei der hier gestellten Frage um ein Problem der Gesamtbetrachtungslehre handelt.

26 Roxin, AT II, \30 Rn. 175; siehe auch Murmann, Grundkurs, \ 28 Rn. 112 ff. 
Rücktritts vom versuchten Unterlassungsdelikt durch weiteres Unterlassen allein mit der Gesamtbetrachtungslehre stellen kann. Nur wenn weitere Akte in die Tat einbezogen werden können, besteht die Möglichkeit, auf eine weitere denkbare aktive Handlung Bezug zu nehmen.

\section{a. Argumente für ein enges Tatverständnis i.S. der Einzelakttheorie}

Für die Einzelakttheorie spreche, dass in den Fällen des Fehlgehens des ersten Aktes die mangelnde Erfolgsrealisierung allein zufälliger Art sei. Dass der Erfolg nicht eingetreten ist, beruhe auf glücklichen Umständen und basiere gerade nicht auf einer Leistung des Täters. ${ }^{27}$ Dies lasse sich mit Jakobs auch nicht dadurch ausgleichen, dass der Täter etwas Zusätzliches erbringt, da auf objektiver Ebene diesbezüglich nichts möglich sei und ein alleiniges Abstellen auf die subjektive Ebene dem auch objektiven Versuch zuwiderlaufe, was den Rücktritt zudem unpraktikabel ausgestalten würde. ${ }^{28}$ Ein weiter Tatbegriff (so wie ihn die Gesamtbetrachtungslehre vertritt) führe zudem dazu, dass der Täter, der sich eine Vielzahl an Ausführungsmodalitäten zurechtlegt, bevorzugt würde, da bei diesem ein Fehlschlag erst sehr viel später vorliege. ${ }^{29}$ Auch aufgrund des Sinn und Zwecks der Strafe sei eine separate Betrachtung geboten, denn sofern der Täter gehandelt hat und es ihm nicht mehr möglich ist, diese Handlung rückgängig zu machen (Bsp.: fehlgegangener Schuss auf das Opfer), habe dieser „damit massive generalpräventive Bedürfnisse verursacht". Gleiches gelte für die Spezialprävention, da der Täter durch den fehlgegangenen Akt gezeigt habe, dass er in der Lage war, gegen das Recht zu verstoßen. ${ }^{30}$ Heckler bringt zudem vor, dass ein einfaches Ablassen von weiteren Handlungen an sich schon nicht ausreiche. „Denn der Rücktritt als Spiegelbild und »actus contrarius« des Versuchs muß die für die Strafbarkeit des Versuchs maßgeblichen Gründe paralysieren, in diesem Sinne eine >Umkehrleistung des Täters sein, und eine solche ist in dem bloßen Verzicht auf einen »neuen Anlauf« fürwahr nicht zu sehen.“ Es handele sich hierbei lediglich um „ein konsequentes Haltmachen an der Grenze zur noch schwereren Rechtsverletzung [...].“31

Paeffgen verweist für die Einordnung des Tatbegriffs auf den Sonderausschuss für die Strafrechtsreform. ${ }^{32}$ In der Sitzung vom 29.11.1967 vertrat Dreher die Auffassung, dass bei einem Vorbehalt von mehreren Schüssen der Täter vom ver-

27 Jakobs, AT, 26/16.

28 Jakobs, AT, 26/16.

29 Schönke/Schröder/Eser/Bosch, $\$ 24$ Rn. 18 a, der auf Mayer, MDR 1984, 187 f. verweist; Geilen, JZ 1972, 335, 338.

30 Bergmann, ZStW 100 (1988), 329, 344; siehe zu diesem Argument auch Heckler, Rücktrittsleistung, S. 197 f., der ebenfalls davon ausgeht, dass die general- und spezialpräventive Strafbedürftigkeit, nur weil der Täter von einer weiteren Handlung ablässt, ,auf keinen Fall so weit beseitigt [wird] (nämlich bis auf Null), daß der Delinquent Straffreiheit verdient.“

31 Heckler, Rücktrittsleistung, S. 197; auch Bauer, wistra 1992, 201, 206 verwendet in diesem Zusammenhang den Begriff, ,actus contrarius“.

32 Paeffen, FS Puppe, S. 806 Fn. 66. 
Einführung/Bewertungsrahmen

suchten Mord strafbefreiend zurücktreten könne, wenn er nach den ersten untauglichen Schüssen von der weiteren Ausführung ablässt. ${ }^{33}$ Hiergegen sprach sich jedoch Arndt namens des gesamten Ausschusses aus. Schon der erste Schuss sei ein Mordversuch, von dem nicht zurückgetreten werden könne. ${ }^{34}$ Der Sonderausschuss präferierte scheinbar eine Einzelbetrachtung.

\section{b. Argumente für die Gesamtbetrachtungslehre}

aa. Bewertung der für die Einzelakttheorie vorgebrachten Argumente

Gegen das Argument des zufälligen Fehlgehens trägt Rudolphi vor, dass der strafbefreiende Rücktritt häufig auf Zufällen beruhe. Die Zufälligkeit des Fehlgehens ändere „nichts daran, daß der Täter durch sein (wenn ihm auch erst durch Zufall ermöglichtes) Verhalten auf den Boden des Rechts zurückgekehrt und wertbewahrend tätig geworden ist. “35 Mit Rengier stelle es eine Umkehrleistung dar, wenn der Täter darauf verzichtet, die Tat zu vollenden. ${ }^{36}$ Der Einwand, dass die Rücktrittsleistung das Spiegelbild des Versuchs sei und somit ein Ablassen von weiteren Handlungen dem gerade nicht entspreche, trägt hierbei nicht. Freilich ist der Rücktritt das Spiegelbild des Versuchs, allerdings nur insoweit als der Versuch die Strafbarkeit begründet und der Rücktritt diese wiederum aufhebt. Eine Kongruenz in dem Sinne, dass der Täter für eine Straflosigkeit genau das Entgegengesetzte zu tun hat, besteht nicht. Anderenfalls müsste der Heckenschütze, nachdem die Kugel subjektiv totbringend getroffen hat, das Opfer nicht durch medizinische Maßnahmen retten bzw. Hilfe verständigen, sondern den Schuss rückgängig machen. Dass das Rücktrittsverhalten keinen „actus contrarius“ erfordert, zeigt zudem $₫ 24$ Abs. 1 S. 1 Var. 1 StGB, wonach die bloße Aufgabe zur Straflosigkeit führt.

Gegen den Einwand, dass die Gesamtbetrachtungslehre den umsichtigen/skrupellosen Täter bevorzuge, spricht, dass es vorzugswürdig ist, den Umfang der Tat nicht gänzlich zu abstrahieren. Nur so können die Vorstellungen des Täters einfließen, wodurch diesem individuell entsprochen werden kann. Im Gegensatz zur Tatplantheorie gelingt dies hier, da es auf die Vorstellung des Täters nach seiner letzten Ausführungshandlung ankommt und die Tat daher nicht von vornherein definiert ist. Zwar ist es zutreffend, dass hierdurch der intelligentere und brutalere Täter zumeist weitere Handlungsalternativen erkennt, die der einfältige Täter nicht sieht, allerdings kann dies erstem nicht zum Nachteil gereichen. Es muss beachtet werden, dass es dem gerissenen Täter tatsächlich noch möglich

33 Dreher, Beratung des Sonderausschusses für die Strafrechtsreform, 5. Wahlperiode, 88. Sitzung, S. 1758.

34 Arndt, Beratung des Sonderausschusses für die Strafrechtsreform, 5. Wahlperiode, 88. Sitzung, S. $1758 \mathrm{f}$.

35 SK-StGB/Rudolphi, \24 Rn. 14.

36 Rengier, AT, \37 Rn. 57; siehe zur „Gefährdungsumkehr“ auch Roxin, AT II, \30 Rn. 187. 
gewesen wäre, sein Ziel zu erreichen, wohingegen eine Erfolgsrealisierung durch den anderen Täter mangels weiterer Ausführungsmöglichkeiten ausscheidet. ${ }^{37}$

Für einen engen Tatbegriff i.S. einer Einzelaktbetrachtung könnten aber die benannten general-/spezialpräventiven Erwägungen angeführt werden. Hiergegen lässt sich gleichwohl vorbringen, dass die Spezialprävention zwar die Besserung, Abschreckung und Sicherung umfasst ${ }^{38}$, jedoch der Täter bereits durch das Ablassen von weiteren Handlungsmöglichkeiten beweist, dass er sich noch nicht vollständig der Illegalität hingegeben hat und sich zum Recht bekennt. Feuert der Täter, obschon er es könnte, keine weiteren Schüsse auf das Opfer ab, ,so hat er damit gezeigt, daß er freiwillig auf die ihm noch mögliche Verwirklichung seines Handlungsziels verzichtet hat und nicht über die zur Vollendung erforderliche verbrecherische Energie verfügt. “39 Durch dieses Ablassen liegt gerade eine Rückkehr zur Legalität vor und der „,böse[...] Eindruck seines ,Erstversuchs“ “ findet hierdurch eine Kompensation. ${ }^{40}$ Auch Roxin stellt fest: „Wer die Tat - durch weitere Schüsse - noch zum Erfolg führen kann und darauf freiwillig verzichtet, erbringt eine Umkehrleistung, die das general- und spezialpräventive Strafbedürfnis erheblich reduziert, während der endgültig Gescheiterte keinerlei honorierungsfähiges Verdienst hat.“41 Des Weiteren arbeitet Kühl heraus, dass gerade nicht die Strafe den Täter zur Umkehr gebracht hat, sondern seine individuelle eigene Entscheidung. ${ }^{42}$ Zudem wird durch das Ablassen von weiteren Handlungen auch der negative Eindruck beseitigt, sodass es gleichfalls einer Generalprävention nicht bedarf. 43

Eindeutig erscheint allerdings der Hinweis auf den Sonderausschuss und die dortige scheinbare Einzelaktsnähe. Zu erkennen ist hierbei jedoch, dass sich der Ausschuss zwar gegen die von Dreher vorgeschlagene Auslegungsmöglichkeit ausgesprochen hat, als Konsequenz dies aber nur im Protokoll vermerk.t wurde. Hätten die Beteiligten im Ergebnis tatsächlich ein Interesse an der Manifestation der Einzelakttheorie gehabt, so hätte sich dies wohl in einer anderen Reaktion geäußert. Vor allem eine Änderung des Gesetzestextes dahingehend, dass ein Rücktritt nur von einzelnen Handlungen möglich ist, wäre dann zu erwarten gewesen. Allein hierdurch hätte die vermeintlich falsche Interpretation Drehers beim Rechtsanwender vermieden werden können. Ob eine Änderung des Gesetzes nicht vorgenommen wurde, weil die Beteiligten den Vermerk im Protokoll für ausreichend erachteten oder die Auslegung von Dreher als zu abwegig empfanden, erscheint

37 Roxin, JR 1986, 424, 425; vgl. LK-StGB/Lilie/Albrecbt, \ 24 Rn. 109; anders z.B. Geilen, JZ 1972, 335, 338; anders Schönke/Schröder/Eser/Bosch, $₫ 24$ Rn. 18 a.

38 Kindhäuser, AT, \2 Rn. 12.

39 SK-StGB/Rudolphi, \$2 24 Rn. 14.

$40 \quad \mathrm{SK}-\mathrm{StGB} / \mathrm{Rudolphi,} \int 24 \mathrm{Rn} .14$.

41 Roxin, AT II, $₫ 30$ Rn. 203.

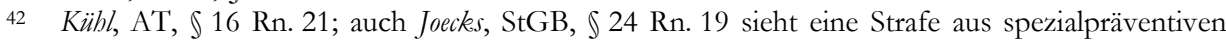
Gründen nicht unbedingt als geboten an.

43 Joecks, StGB, \24 Rn. 19; siehe auch SK-StGB/Rudolpbi, \24 Rn. 14. 
fraglich. Überzeugender ist, dass dieser Regelungsbereich absichtlich offengelassen wurde, um die Lösung der Lehre/Rechtsprechung zu überlassen. Vor allem der heutige Streitstand beweist, dass sich die Tatreichweite nicht so unkritisch definieren lässt, wie Arndt es vorgab. Es ist vor allem auch aufgrund der mangelnden Diskussionsbereitschaft davon auszugehen, dass zu diesem Zeitpunkt noch kein Problembewusstsein bestand. Dies verdeutlichen auch die Worte Arndts („,Wenn der Täter mehrere Schüsse abgeben wolle, dann aber nur einen Schuss abgebe, der nicht treffe, so sei der erste Schuß ein Mordversuch, von dem der Täter nicht mehr zurücktreten könne“"44), denn ein Argument gegen Dreher enthält diese Ausführung nicht.

\section{bb. Argumente für die Gesamtbetrachtungslehre}

Für die Gesamtbetrachtungslehre und somit gegen eine isolierte Betrachtung der einzelnen Handlungen wird vorgebracht, dass durch einen Bewertungsmaßstab im Sinne der Einzelakttheorie ein einheitlicher Lebensvorgang auseinandergerissen werde. ${ }^{45}$ Dies trifft insoweit zu, als dass die Versuchseinheit nach der Einzelakttheorie, unabhängig von dem Bild des Täters, nur aus einer Handlung bestehen kann. Erkennt der Delinquent weitere Handlungen, so liegt ein neuer Versuch vor, der mit dem Vorangegangenen in keiner Verbindung steht. Das einheitliche Geschehen, welches die Handlungen umfasst, die auf Verwirklichung des Tatbestands gerichtet sind, wird mithin separiert. Aus diesem Grund vermag auch der Einwand Hecklers, dass ,[...] die Einzelakttheorie den Versuch nicht wie ihr Name nahelegen mag, naturalistisch-kausal und willkürlich in irgendwelche Elementarhandlungen [zerlegt] ${ }^{\text {"46 }}$, nicht $\mathrm{zu}$ überzeugen, da, wie er selbst erkennt ${ }^{47}$, stets allein die individuelle Handlung des Täters Maßstab für die Rücktrittsmöglichkeit ist.

Bergmann führt gegen die Einzelakttheorie an, dass hiernach eigentlich auch dem Täter eine Rücktrittsmöglichkeit abzusprechen sei, der nach einer erfolgstauglichen Handlung den Erfolg abwendet. ${ }^{48}$ Dies verstieße jedoch gegen $\ 24$ Abs. 1 S. 1 Var. 2 StGB, der den Rücktritt von einem beendeten Versuch positiv erfasst, und ist somit unzulässig. ${ }^{49}$ Als Konsequenz könne der Täter bei einem Verletzungserfolg zurücktreten, wohingegen dies ausscheide, wenn der Täter das Opfer verfehlt. Die Einzelakttheorie honorierte folglich die besondere Nähe zur

44 Arndt, Beratung des Sonderausschusses für die Strafrechtsreform, 5. Wahlperiode, 88. Sitzung, S. $1758 \mathrm{f}$.

45 U.a. BGHSt 34, 53, 57; Wessels/Beulke/Satzger, AT, Rn. 891 a.E.; LK-StGB/Lilie/Albrecht, \ 24 Rn. 97; MK-StGB/Herzberg/Hoffmann-Holland, \24 Rn. 60; Heinrich, AT, Rn. 820; HKGS/Ambos, \24 Rn. 7; Krey/Esser, AT, Rn. 1277.

46 Heckler, Rücktrittsleistung, S. 198; Puppe, NStZ 1986,14, 16.

47 Heckler, Rücktrittsleistung, S. 198.

48 Bergmann, ZStW 100 (1988), 329, 345; so auch Roxin, JR 1986, 424, 425.

49 So Bergmann, ZStW 100 (1988), 329, 345. 
Tatbestandsverwirklichung. ${ }^{50}$ Dem entgegnet Heckler, dass sich der Rücktritt des Täters, der das Opfer getroffen hat, allein auf die versuchte Straftat beziehe. Die daneben verwirklichte vollendete Körperverletzung bliebe indes bestehen. Zudem sei die aktive Verhinderung mit dem Nichtweiterhandeln nicht vergleichbar, da dies kein deutlicher actus contrarius sei. ${ }^{51}$ Gegen das Argument des actus contrarius' spricht schon das oben Gesagte. ${ }^{52}$ Ein actus contrarius im Sinne einer tatsächlichen Handlungsumkehr wird von \24 Abs. 1 StGB nicht gefordert. Des Weiteren trifft es zwar zu, dass der Täter wegen der vollendeten Körperverletzung zu bestrafen ist, allerdings geht es bei dem Vergleich darum nicht. Vielmehr steht die Versuchsstrafbarkeit im Vordergrund. Hier lässt sich schwerlich leugnen, dass dem Täter einmal eine Rücktrittsmöglichkeit gewährt wird und im anderen Fall nicht. Dass der Täter diese Möglichkeit aber gerade dann erlangen soll, wenn seine Handlung den tatbestandlichen Erfolg beinahe herbeigeführt hat, erscheint widersprüchlich.

Für einen weiten Tatbegriff könnten zudem Opferschutzgesichtspunkte geltend gemacht werden. Schlägt der Versuch mit der Einzelakttheorie bereits nach der ersten Handlung fehl, so könnte der Täter den Gedanken fassen, das Versuchsopfer zu töten, um sich des Zeugen zu entledigen. ${ }^{53}$ Auch wenn es mit Kübl „wenig wahrscheinlich ist, dass sich der Täter sagt, ,wenn ich nach diesem Fehlschlag aufhöre, komme ich ungestraft aus dieser Situation heraus, "“ so besteht zumindest die Möglichkeit eines entsprechenden Gedankengangs. Dies darf nicht verkannt werden, um das Opfer nicht weiteren Gefahren auszusetzen. ${ }^{54}$ Heckeler begegnet dieser Überlegung damit, dass ein solcher Verzicht nach der Einzelakttheorie zwar nicht zur Straffreiheit führt, jedoch bei der Strafzumessung Berücksichtigung findet. Der Täter solle sich „,wohl überlegen“, „ob das Töten des Opfers für ihn vorteilhafter ist als das Aufhören". 55 Zudem stelle sich dasselbe Problem auch bei der Gesamtbetrachtungslehre. Sobald die räumlich und zeitliche

50 Heinrich, AT, Rn. 820; Kühl, AT, \ 16 Rn. 19; Roxin, JR 1986, 424, 425; ders., AT II, \ 30 Rn. 205; siehe zu diesem Widerspruch Rengier, AT, $₫ 37$ Rn. 45, 57; Freund, AT, $₫ 9$ Rn. 29; Murmann, Grundkurs, \28 Rn. 119.

51 Heckler, Rücktrittsleistung, S. 200.

52 S. 22 f.

53 Kübl, AT, \16 Rn. 20; Roxin, AT II, \30 Rn. 188; Heinrich, AT, Rn. 821; zum Opferschutz auch SSW-StGB/Kudlich/Schubr, $\$ 24$ Fn. 19.

54 Kübl, AT, $\ 16$ Rn. 20; zum Opferschutz: BGH NStZ 1986, 264, 265; siehe auch Murmann, Grundkurs, \28 Rn. 119; HK-GS/Ambos, \24 Rn. 7; Roxin, AT II, \30 Rn. 188, 207; Heinrich, AT, Rn. 821. Das Argument des Opferschutzes kann jedoch nur solange angedacht werden, wie der Täter es überhaupt für erforderlich hält, einen Zeugen auszuschalten. Handelt der Täter aus dem Hinterhalt heraus und ist für das Opfer nicht erkennbar, so besteht seitens des Delinquenten auch nicht die Motivationslage, das Opfer nach dem Fehlgehen des ersten Aktes nunmehr endgültig zu beseitigen. Durch den Tod des Opfers würde sich die Strafverfolgungsgefahr für den Täter nicht verändern. Siehe zu dieser Überlegung im Rahmen des Unterlassens S. $143 \mathrm{f}$.

55 Heckler, Rücktrittsleistung, S. 200; gegen die Überlegung des Opferschutzes auch Paeffen, FS Puppe, 2011, S. 791, 800 f. 
Grenze überschritten ist und eine neue Tat vorliegt, könne der Täter gleichfalls nicht mehr zurücktreten. Auch hier liege aus den gleichen Gründen ein „Anreiz“ vor, das Opfer im Folgenden auszuschalten. ${ }^{56}$ Nach Heckler kann in Entsprechung zu Herzberg 57 ,,in jeder Begrenzung des Rücktrittsprivilegs ein Anreiz für den Täter zur Tatvollendung gesehen werden.“58 Gegen Hecklers Einwand spricht, dass die Aussicht auf eine mildere Strafe nicht den gleichen Anreiz schafft, wie Straffreiheit. Für den Täter ist es völlig unklar, in welchem Maße das Ablassen auf Rechtsfolgenseite durch das Gericht Berücksichtigung findet. Zudem wird der Täter zu diesem Zeitpunkt solche differenzierten Überlegungen nicht vornehmen, sondern sich allein von einem Entfall der Strafe leiten lassen. Allerdings trifft es zu, dass sich das Problem der Opfergefährdung nicht nur im Rahmen der Einzelakttheorie ergibt. So kann auch auf Basis der Gesamtbetrachtungslehre ein Versuch

fehlschlagen und den Täter aus den gleichen Gründen wie bei der Einzelakttheorie motivieren, das Opfer auszuschalten. Insoweit hat Heckler recht: „Letztendlich kann in jeder Begrenzung des Rücktrittsprivilegs ein Anreiz für den Täter zur Tatvollendung gesehen werden. "59 Hierbei ist aber zu berücksichtigen, dass das Gefährdungspotential des Betroffenen geringer ist, als im Rahmen der engen zeitlichen und räumlichen Ausführung. Das Opfer kann sich bei einer Zäsur auf die neue Gefährdungssituation einstellen und Schutzmaßnahmen treffen.

Neben den inhaltlichen Einwänden ist zudem auffällig, dass die Einzelakttheorie $\ 24$ Abs. 1 S. 1 Var. 1 StGB fast gänzlich unanwendbar machen würde. Allein im Stadium des unmittelbaren Ansetzens, vor einer Einwirkung auf das Opfer, verbliebe Raum für die Anwendung. Nur hier können kumulativ die Vorstellung des Täters, noch nicht alles Erforderliche getan zu haben, und die fortwährende Erfolgstauglichkeit des ersten Aktes vorliegen. Hat der Täter hingegen auf das Opfer eingewirkt und glaubt, erfolgstauglich gehandelt zu haben, so liegt ein beendeter Versuch vor bzw. ein Fehlschlag, wenn der Akt subjektiv nicht erfolgreich war.

56 Heckler, Rücktrittsleistung, S. 200 f.

57 Herzberg, FS Blau, 1985, S. 97, 112.

58 Heckler, Rücktrittsleistung, S. 201. Anzumerken ist, dass in diesem Kontext der Begriff „Tatvollendung" ungenau ist. Diese Begrifflichkeit lässt den Eindruck entstehen, als ob die versuchte Tat weiterhin vollendet werden kann. Richtig ist jedoch, dass der Täter aufgrund des Fehlschlags und der Zäsur den tatbestandlichen Erfolg allein durch eine neue/ andere Tat herbeiführen kann.

59 Heckler, Rücktrittsleistung, S. 201; siehe auch Heræzberg, FS Blau, 1985, S. 97, 112. 


\section{Zwischenergebnis}

Im Ergebnis muss für die Gesamtbetrachtungslehre votiert werden. Zu beachten ist hierbei, dass diese Feststellung allein besagt, dass grundsätəlich mehrere Akte zu einer Tat zusammengefasst werden können. Welche Anforderungen an dieselbe Tat gestellt werden, wird hierdurch hingegen noch nicht definiert. ${ }^{60}$

\section{Die Reichweite des Tatbegriffs}

Im Hinblick auf die Tatreichweite im Sinne der Gesamtbetrachtungslehre haben sich zwei Meinungen herausgebildet. ${ }^{61}$

\section{Natürliche Handlungseinheit/Einheitlicher Lebensvorgang}

Nach der natürlichen Handlungseinheit ${ }^{62}$ liegt eine einheitliche Tat i.S. des $\int 24$ Abs. 1 StGB dann vor, ,wenn zwischen einer Mehrheit gleichartiger strafrechtlich erheblicher Verhaltensweisen ein derart unmittelbarer räumlicher und zeitlicher Zusammenhang besteht, daß das gesamte Handeln des Täters objektiv auch für einen Dritten als ein einheitliches zusammengehöriges Tun erscheint, und wenn die einzelnen Betätigungsakte auch durch ein gemeinsames subjektives Element miteinander verbunden sind." 63

Die Gegenauffassung bemisst die Einheitlichkeit anhand eines einheitlichen Lebensvorgangs. ${ }^{64}$ Dieser sei dann gegeben, „wenn die einzelnen Handlungen in engem räumlichen und zeitlichen Zusammenhang stehen. “65

\section{Streitentscheid}

Der Streitentscheid hat Auswirkungen auf den Rücktritt vom versuchten Unterlassungsdelikt durch weiteres Unterlassen. So muss im Folgenden bewertet werden, ob die weitere aktive Ausführungsmöglichkeit noch Teil eines „einheitlichen Lebensvorgangs“ bzw. einer ,natürlichen Handlungseinheit“ ist.

\footnotetext{
60 Vgl. MK-StGB/Herzberg/Hoffmann-Holland, \$24 Rn. 62.

61 Siehe hierzu zusammenfassend MK-StGB/Herzberg/Hoffmann-Holland, \$24 Rn. 62.

62 BGHSt 10, 129, 131; BGHSt 21, 319, 322; BGH, NStZ 2001, 315; SK-StGB/Rudolphi, \ 24 Rn. 14; Puppe, NStZ 1986, 14, 16; Schmidhäuser, AT, Lehrbuch, 15/78; Dreher, JR 1969, 105, 107; Kindhäuser, AT, \ 32 Rn. 13; Lenckner, FS Gallas, 1973, S. 281, 303 f.

63 BGHSt 41, 368.

64 BGHSt 34, 53, 57; BGHSt 40, 75, 77; BGHSt 41, 368, 369; siehe Fischer, StGB, \24 Rn. 17; Jescheck/Weigend, AT, $\ 51$ II 4.

65 BGHSt 41, 368, 369.
} 
Gegen die natürliche Handlungseinheit als Bewertungsmaßstab spricht, dass sie als Teil der Konkurrenzen die Rechtsfolgenseite und somit einen gänzlich anderen Regelungsbereich betrifft. „Die Konkurrenzregeln wollen eine Antwort auf die Frage der Strafbemessung im Falle des Zusammentreffens mehrerer Gesetzesverletzungen durch eine Person geben. Über die sachliche Einheit des Gesamtgeschehens geben sie keine Auskunft [...]. “66

Augenfällig ist zudem, dass zur Tatdefinition allein die natürliche Handlungseinheit maßgeblich sein soll, die juristische Handlungseinheit hingegen ausgeklammert wird. ${ }^{67}$ So könnte vor allem eine Verklammerung für das Fortbestehen der Einheitlichkeit sorgen. ${ }^{68}$ Dies führte allerdings zu einer umfassenden Ausweitung der Rücktrittsmöglichkeit und hätte eine unberechtigte Privilegierung zur Folge, weswegen im Ergebnis zu Recht von der Berücksichtigung abgesehen wurde. Jedoch verdeutlicht diese eingeschränkte Tatbegriffsgleichschaltung zum einen eine gewisse Inkonsequenz dieser Auffassung und zeigt zugleich die unterschiedliche Reichweite beider Tatbegriffe.

Herzberg weist des Weiteren auf die Inkongruenz beider Normierungen hinsichtlich des divergierenden Terminus' hin. So liege Tateinheit i.S. des \52 StGB im Fall derselben Handlung vor, wohingegen $\ 24$ StGB an „die Tat" anknüpfe. ${ }^{69}$ Diesbezüglich räumt Heræ̧berg allerdings ein, dass es sich hierbei auch um Zufall handeln könne und bildet einen weiteren Anknüpfungspunkt in der Form, dass ein Zusammenfügen der einzelnen Teile schon deshalb schwierig sei, ,weil sie auf den verschiedenen Ebenen der Aktualität und der Potentialität liegen. Man könne daraus, daß ein real getätigter Einzelakt eventuell, d. h. im Fall der Realisierung auch des geplanten weiteren Handelns, seine Eigenbedeutung verlieren würde, nicht schließen, daß er schon jetzt nur unselbstständiger Teil einer Handlungseinheit ist. ${ }^{\text {"770 }}$

66 LK-StGB/Lilie/Albrecht, \24 Rn. 114; Murmann, Versuchsunrecht und Rücktritt, S. 45: Es ,[...] bleibt unklar, warum ein die Strafzumessung tatsächlich begangener Taten vorbereitender Gesichtspunkt auch für das Rücktrittsverhalten relevant sein soll.“; LK-StGB/Vogler, 10. Aufl. 1985, \ 24 Rn. 63; so auch Fabrenborst, Jura 1987, 291, 294; NK-StGB/Zacrylk, \ 24 Rn. 17; Bawer, wistra 1992, 201, 206, der nochmals verdeutlicht, dass \24 StGB und \52 StGB unterschiedliche Zielsetzungen besitzen und somit eigenständig zu betrachten sind; siehe auch Jakobs, JuS 1980, 714, 716 Fn. 24: „Bei der Lehre von der Handlungseinheit geht es - neben anderem - darum, wann der bei Handlungsmehrheit notwendige Auswurf von Einzelstrafe nach \54 I sinnvoll ist und wann nicht; zentral ist auch die Erweiterung des Limits nach $₫ 54$ II."; Grünwald, FS Welzel, 1974, S. 701, 714: „Doch sind die beiden Begriffe keineswegs gleichzusetzen, da sie Rechtssätzen angehören, die ganz unterschiedliche Problemlagen betreffen.“; siehe auch Linke, Rücktritt, S. 110.

67 Anders wohl z.B. Baumann/Weber/Mitsch, AT, \27 Rn. 31, da Mitsch bei der Darstellung der Meinung auf die Heranziehung der gesamten „Regeln der Handlungseinheit“ verweist.

68 Siehe zur Klammerwirkung nur Murmann, Grundkurs, \& 31 Rn. 41 ff.

69 Herzberg, GS H. Kaufmann, 1986, 709, 722.

70 Herzberg, GS H. Kaufmann, 1986, S. 709, 722. 
Die Reichweite der Tat i.S. des $\int 24$ Abs. 1 StGB mittels der konkurrenzrechtlichen Regeln definieren zu wollen, gelingt nicht. Die Bestimmung der Einheitlichkeit des Geschehens ist nach dem einheitlichen Lebensvorgang vorzunehmen.

\section{Zwischenfazit}

Mit der Gesamtbetrachtungslehre können auch mehrere Akte Teil einer Tat i.S. des $\int 24$ Abs. 1 StGB sein. Die Einheitlichkeit des Geschehens bemisst sich nach dem einheitlichen Lebensvorgang. Rahmt dieser die Handlungen ein, so bilden sie eine einheitliche Tat. ${ }^{71}$

In Bezug auf den Rücktritt vom versuchten Unterlassungsdelikt durch weiteres Unterlassen besteht somit abstrakt die Möglichkeit, dass ein weiteres mögliches Handeln den Fehlschlag des Unterlassungsversuchs beseitigt und der Täter durch einfaches Absehen von dieser Handlung Straffreiheit erlangt. Ob ein Unterlassen und ein aktives Tun jedoch tatsächlich Teil derselben Tat sein können, knüpft an den einheitlichen Lebensvorgang an. Nur dann wenn trotz eines Begehungsformwechsels ein einheitlicher Lebensvorgang fortbesteht, ist die weitere denkbare aktive Handlung im Rahmen des Fehlschlags zu berücksichtigen und ein Rücktritt möglich.

71 Auch wenn vorliegend für die Gesamtbetrachtungslehre votiert wurde, erweist sich die Gesamtbetrachtungslehre im Hinblick auf die Rücktrittsmöglichkeit als äußerst großzügig. Ob dem Täter tatsächlich in diesem Umfang Straffreiheit zugebilligt werden soll, erscheint fraglich. Insoweit kommt eine Begrenzung des Tatbegriffs nach der Auffassung Murmanns, Versuchsunrecht und Rücktritt, S. 44 ff. in Betracht. Dies soll hier aber dahinstehen. Nur so kann festgestellt werden, ob mit der Gesamtbetrachtungslebre der Täter straffrei werden kann, wenn er nach einem gescheiterten Unterlassungsversuch eine mögliche aktive Handlung nicht ausführt (zu diesem Problem im Rahmen der Konzeption Murmanns Murmann, GA 2012, 711, 715 ff.). Siehe zur Gesamtbetrachtungslehre S. $153 \mathrm{ff}$. 



\section{Der Rücktritt vom versuchten Unterlassungsdelikt durch weiteres Unterlassen}

Ob mehrere Akte Teil derselben Tat sein können, bemisst sich nach dem einheitlichen Lebensvorgang. Wäre diese Einheitlichkeit zwischen der gescheiterten versuchten Unterlassung und der möglichen aktiven Handlung gegeben, so wäre ein Rücktritt mangels Fehlschlags möglich. ${ }^{72}$

\section{Einführung/Folgen eines begehungsformunabhängigen Tatbegriffs}

Ein begehungsformübergreifender Tatbegriff hätte zur Folge, dass der gescheiterte Unterlassungstäter Straffreiheit erlangen würde, wenn er von einer möglichen weiteren aktiven Handlung ablässt. Gleichfalls führt diese Tatdefinition dazu, dass der Täter bezüglich aller Akte straffrei würde, wenn er von einem Unterlassen zu

72 Siehe hierzu BGH, NStZ 2010, 690, 691. Der BGH verneinte in dieser Entscheidung einen Fehlschlag des Unterlassungsversuchs aufgrund eines weiteren möglichen aktiven Tuns. Die Einheitlichkeit besteht folglich über den Begehungsformwechsel hinaus fort. Zu dieser Entscheidung mit entsprechender Kritik S. 91. 
einem aktiven Tun übergeht und sodann im Rahmen der aktiven Ausführung sich wieder der Legalität zuwendet. Negativ für den Täter wäre es allerdings, dass der Wechsel von einem fortwährend tauglichen Unterlassen zu einem Tun bzgl. des versuchten Nichthandelns keinen Rücktritt darstellen kann. Dieselbe Tat bliebe in diesem Fall bestehen und durch den Begehungsformwechsel läge kein Rücktritt vor. Die Strafbarkeit bzgl. der ersten Passage wäre an die weitere aktive Begehung gekoppelt und der Täter würde nur dann straffrei, wenn er im Rahmen des weiteren Aktes zurücktreten würde. ${ }^{73}$

\section{Der Begehungsformwechsel im Rahmen des „einheitlichen Lebensvorgangs“}

Fraglich ist, ob sich aus dem Begehungsformwechsel Zäsuren ergeben, die zu einer Trennung des einheitlichen Lebensvorgangs führen. Im Folgenden gilt es somit, mögliche Zäsurmomente zu extrahieren und deren Trennungscharakter zu ergründen.

1. Vergleich des Begehungsformwechsels mit einem Tatmittelwechsel

Der Wechsel des Tatmittels im Rahmen desselben Geschehens ist dem Begehungsformwechsel ähnlich. Sofern die Änderung des Tatmittels eine Zäsur begründet, könnten hieraus Rückschlüsse auf den Wechsel von einem Unterlassen zu einem Tun gezogen werden.

\section{a. Zäsur aufgrund der Artverschiedenheit}

Werden die Begehungsformen miteinander verglichen, so zeigt sich eine abweichende Risikoart. Beruht im einen Fall das Risiko auf einem Nichteinschreiten, so ist es beim Tun gerade das aktive Handeln des Täters, das die Rechtsgüter des Opfers bedroht. Es liegt eine Artverschiedenheit vor, die eine Zäsur begründen könnte. Diese mögliche Zäsur besteht gleichfalls im Rahmen des allein aktiven Tuns, sofern der Täter versucht, den tatbestandlichen Erfolg auf unterschiedliche Arten herbeizuführen.

73 Zur Vereinbarkeit dieser Folgen mit den Grundsätzen des Rücktritts S. 142 ff. 
BGH: Der Täter T versucht das Opfer mit seinem PKW zu überfahren. Als dies misslingt, fängt $T$ an, das Opfer zu würgen, lässt hiervon jedoch ab. ${ }^{74}$

Ranft knüpft an den Strafgrund des Versuchs an. Er stellt fest, dass die Bestrafung des Versuchs aus der „Erschütterung des Vertrauens in die Geltung der Rechtsordnung und die damit einhergehende Gefährdung des Rechtsfriedens durch Beeinträchtigung des Gefühls der Rechtssicherheit“" resultiere. ${ }^{75}$ Dieser Tatsache entspreche auch der Rechtsgedanke des Rücktritts, wonach „der rechtserschütternde Eindruck, den die Tat in der Rechtsgemeinschaft erzeugt, durch den Rücktritt wenigstens nachhaltig vermindert wird.“76 Hieraus folge, dass dieser ,rechtserschütternde Eindruck" gerade dann nicht verringert würde und daraus resultierend ein Rücktritt nicht vorliege, ,wenn der Täter nach Fehlschlagen eines Tatmittels und eindeutiger Zäsur der Ausführungshandlungen ein neues selbständiges und arteigenes Risiko begründet". ${ }^{77}$ In solch einer Situation setze der Täter zu einem neuen Versuch an. Der Täter könne in diesem Fall nur von dem neuen Versuch zurücktreten. ${ }^{78}$ In Bezug auf die geschilderte Konstellation seien das versuchte Überfahren und das Würgen artverschieden, weswegen eine Zäsur gegeben sei. ${ }^{79}$ Es handele sich um zwei eigenständige Taten, sodass der Täter durch das Ablassen vom Würgen allein diesbezüglich zurücktreten könne. Auf den versuchten Totschlag durch das Überfahren hätte dies keine Auswirkungen. ${ }^{80}$ Gleiches gelte im Benzinfall ${ }^{81} .{ }^{2}$ Nachdem es dem Täter dort misslang das Opfer durch Verbrennen zu töten und er im Anschluss vom Würgen abließ, könne er hierdurch nur vom zweiten Akt zurücktreten. Der versuchte Mord durch Verbrennen (grausam) ${ }^{83}$ bliebe vollumfänglich bestehen. ${ }^{84}$

Im Hinblick auf den Begehungsformwechsel hätte dies zur Konsequenz, dass aufgrund der Artverschiedenheit eines Nichteinschreitens und eines aktiven Han-

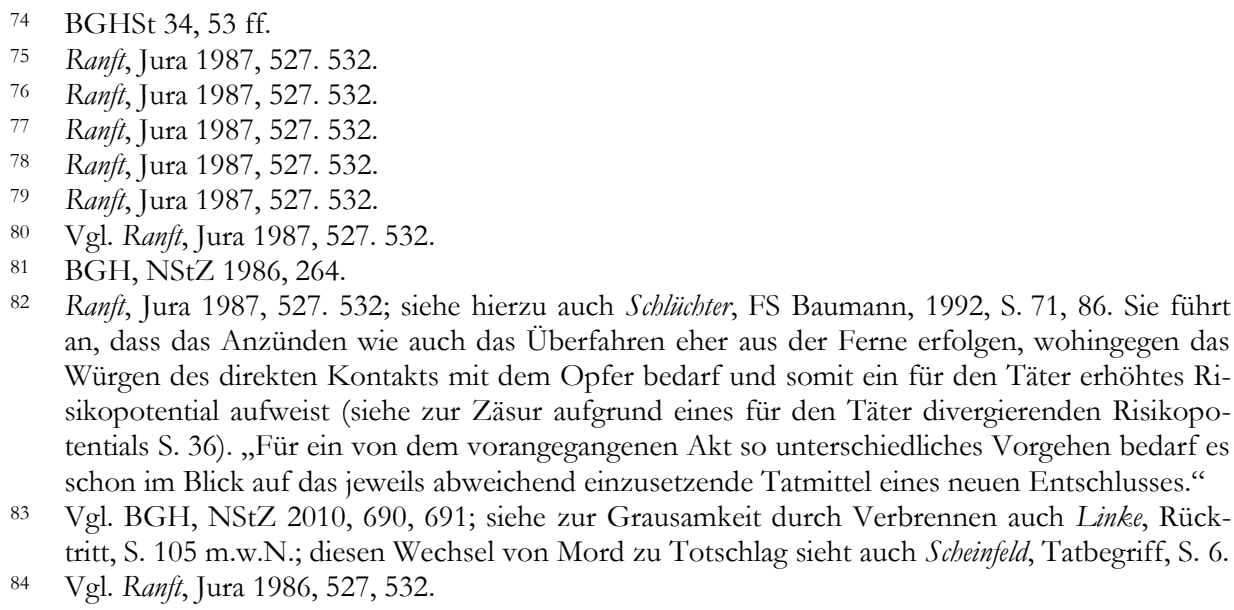
an, dass das Anzünden wie auch das Überfahren eher aus der Ferne erfolgen, wohingegen das Würgen des direkten Kontakts mit dem Opfer bedarf und somit ein für den Täter erhöhtes Risikopotential aufweist (siehe zur Zäsur aufgrund eines für den Täter divergierenden Risikopotentials S. 36). „Für ein von dem vorangegangenen Akt so unterschiedliches Vorgehen bedarf es schon im Blick auf das jeweils abweichend einzusetzende Tatmittel eines neuen Entschlusses."

83 Vgl. BGH, NStZ 2010, 690, 691; siehe zur Grausamkeit durch Verbrennen auch Linke, Rücktritt, S. 105 m.w.N.; diesen Wechsel von Mord zu Totschlag sieht auch Scheinfeld, Tatbegriff, S. 6.

84 Vgl. Ranft, Jura 1986, 527, 532. 
delns eine Zäsur begründet würde. Ein Unterlassen und ein Tun könnten somit nicht Teil derselben Tat i.S. des $\int 24$ Abs. 1 StGB sein.

Für Ranft sprechen die Einleitung des Problems und das Fundament der Auffassung. ${ }^{85}$ Jedoch scheint dieses Verständnis zu unstimmigen Ergebnissen zu führen, was das Beispiel von Rengier verdeutlicht.

Bsp.: Der Täter T versucht das Opfer mit einem Messer zu töten. Als der erste
Stich den gewünschten Erfolg nicht herbeiführen konnte, (a) sticht T weitere
Male auf das Opfer ein, (b) fängt T an, das Opfer zu würgen. Beide Male lässt
$T$ vor Erfolgseintritt von dem Betroffenen ab und leitet erfolgreich
Gegenmaßnahmen ein.

Mit Ranft hieße dies für (a), dass aufgrund der bestehenden Artgleichheit zwischen dem ersten und den weiteren Stichen eine Tat i.S. des $\ 24$ Abs. 1 StGB vorläge. In Variante (b) hingegen ergibt sich durch den Wechsel vom Messereinsatz zum bloßen Würgen mangels Artgleichheit eine Zäsur. Es existierten folglich zwei Taten, sodass der Täter durch die aktiven Rettungsbemühungen, in Abweichung zur ersten Fallvariante, nur von dem zweiten Akt straffrei zurücktreten könnte. Hierbei ist nicht eindeutig, warum im Hinblick auf die Rücktrittsmöglichkeit unterschiedliche Bewertungen erforderlich sein sollen. ${ }^{87}$ In beiden Konstellationen wendet sich der Täter vom Unrecht ab und es erscheint sehr technisch, hier eine Differenzierung anhand des Tatmittels vornehmen zu wollen. Ranft misst dem Tatmittel somit ein zu großes Gewicht bei, was zu widersprüchlichen Ergebnissen führt. ${ }^{88}$ Es zeigt sich ein ähnliches Problem wie bei der Tatplantheorie. Erst im Vergleich verschiedener Ergebnisse fällt auf, dass die vorgenommene Differenzierung nicht dem angestrebten Differenzierungsziel entspricht und Unstimmigkeiten begründet.

Neben dieser Widersprüchlichkeit ist zudem ungeklärt, was unter Artgleichheit $\mathrm{zu}$ verstehen ist und welche Kriterien den Maßstab bilden sollen. ${ }^{89}$ Dies erkennt auch Linke. So „gibt es bei den Schusswaffen von der kleinsten Pistole bis hin zum Maschinengewehr eine erhebliche Anzahl von Variationen, so dass man be-

85 Siehe zum Strafgrund des Versuchs nur Wessels/Beulke/Satzger, AT, Rn. 843 m.w.N.; siehe zusammenfassend zum Rechtsgrund des Rücktritts nur Wessels/Beulke/Satgger, AT, Rn. 887 mit entsprechenden Nachweisen.

86 Rengier, JZ 1988, 930, 933.

87 Rengier, JZ 1988, 930, 933; Feltes, GA 1992, 395, 405; Freund, AT, $\ 9$ Rn. 37; so auch Linke, Rücktritt, S. $111 \mathrm{f}$.

88 Rengier, JZ 1988, 930, 932; dem zustimmend Feltes, GA 1992, 395, 405; Freund, AT, \ 9 Rn. 37; Kübl, AT, $\$ 16$ Rn. 36, der zudem darauf hinweist, dass „ein sehr formales Kriterium für die Straffreiheit entscheidend“" wäre; Roxin, AT II, \ 30 Rn. 209; Linke, Rücktritt, S. 111.

89 Feltes, GA 1992, 395, 405. 
reits schon Artungleichheit annehmen könnte." ${ }^{\circ 0}$ Feltes schlägt als konsequente Lösung die subjektive Sicht des Täters vor, sodass entscheidend sei, was dieser noch als artgleich ansieht. ${ }^{91}$ Diese subjektive Sichtweise würde der Problematik jedoch nicht abhelfen. Denn die Schwierigkeit der Bedeutungsergründung wird nicht dadurch verringert, dass das Problem von der objektiven auf die subjektive Ebene verschoben wird. Es tritt durch die subjektive Betrachtung allenfalls eine Verifikations- bzw. Falsifizierungsschwierigkeit hinzu. So wird es dem Täter schwerlich nachzuweisen sein, dass subjektiv keine Artgleichheit vorgelegen hat, obschon er dies vorgibt. Dies bedeutete, dass der Täter sich stets darauf einlassen wird, von einer Artgleichheit ausgegangen zu sein. Feltes merkt zudem an, dass der skrupellose Täter durch eine Orientierung anhand der Artgleicheit privilegiert würde und die Verwendung von Tatmitteln, die nur auf eine Art und Weise angewendet werden können (z.B. Gift), den Täter benachteiligten, weswegen mit dem BGH nur danach gefragt werden könne, „ob das Mittel ,zur Hand“ war, als der Täter die Versuchshandlung aufgab. “92

Linke wendet des Weiteren ein, dass Erfolgsdelikte nicht festlegen, wie der Erfolg herbeizuführen ist, sondern die Begehungsart tatbestandlich gänzlich offen gelassen wird. „Das Erfordernis einer Abgrenzung zwischen verschiedenen artungleichen Tatmitteln lässt sich so nicht am Deliktstatbestand festmachen." ${ }^{\text {"93 }}$ Zudem lasse sich die Auffassung Ranfts ,auch nicht mit einer Steigerung des Unrechts bei verschiedenen Angriffsmitteln begründen", sofern das weitere Angriffsmittel nicht zu einer Qualifizierung führe. ${ }^{94}$ Würde durch das neue Tatmittel jedoch tatsächlich eine Qualifikation verwirklicht, so sei auch nach der von Ranft kritisierten Rechtsprechung ein Rücktritt ausgeschlossen. ${ }^{95}$

Im Ergebnis ist der Rechtsprechung 96 und herrschenden Lehre ${ }^{97}$ dahingehend zu folgen, dass artverschiedene Mittel einer Einheitlichkeit nicht entgegenstehen. Insoweit gilt Gleiches auch für den Begehungsformwechsel. Selbst wenn das Unterlassen und das aktive Tun gänzlich artverschieden sind, ergibt sich hieraus keine Zäsur.98

\footnotetext{
90 Linke, Rücktritt, S. 112.

91 Feltes, GA 1992, 395, 405.

92 Feltes, GA 1992, 395, 405; zum Problem der Privilegierung des planenden Täters auch Linke, Rücktritt, S. 111.

93 Linke, Rücktritt, S. 112; gleichfalls weist auch Engländer, JZ 2012, 130, 132 darauf hin, dass „beim reinen Erfolgsdelikt die Tatbestandsverwirklichung eben nicht verhaltensgebunden ist, es insoweit also auf die nähere Art und Weise der Erfolgsverursachung gerade nicht ankommt."

94 Linke, Rücktritt, S. 112.

95 Linke, Rücktritt, S. 112.

96 Siehe u.a. BGHSt 34, 53, 57; BGHSt 35, 90, 94 f.; BGHSt 40, 75, 77; BGH, NStZ 1986, 264, 265; BGH, NStZ 2007, 399 f.; BGH, StV 1987, 529; BGH, StV 2003, 216.

97 Rengier, JZ 1988, 930, 932 f.; Feltes, GA 1992, 395, 405; Freund, AT, \ 9 Rn. 37; SSWStGB/Kudlich/Schubr, \24 Rn. 19; LK-StGB/Lilie/Albrecbt, \24 Rn. 121, 123; Kübl, AT, \16 Rn. 36; NK-StGB/Zaczyk, \24 Rn. 17; Lackner/Kübl, StGB, \24 Rn. 12.

98 So explizit auch Engländer, JZ 2012, 130, 132.
} 


\title{
b. Zäsur aufgrund unterscbiedlicher Geeignetheit und Gefäbrlichkeit
}

Werden die Begehungsformen bzgl. des Entdeckungsrisikos und der Gefährlichkeit verglichen, so erscheint das Unterlassen für den Täter vorteilhafter. Der Unterlassungstäter muss nicht aktiv tätig werden, weswegen er bei der Ausführung unerkannt bleibt. Während der Unterlassung ist er folglich nahezu „unsichtbar“", sodass ein Einschreiten Dritter gegen ibn selbst zudem nicht zu erwarten ist. Aufgrund der Distanz zum Opfer muss der Täter auch nicht mit konkreter Gegenwehr seitens des Betroffenen rechnen, sodass das Gefährdungspotential neben dem Entdeckungsrisiko gegenüber einer aktiven Begehung vermindert ist.

Ob sich hieraus eine Zäsur ergibt, ist anhand eines Beispiels von Hillenkamp zu ergründen:

\begin{abstract}
Bsp.: Der Täter T versucht das Opfer mit einem schwer nachzuweisenden Gift zu töten, was misslingt. T erkennt sodann, dass er den Erfolg noch durch einen Stich mit einem herumliegenden Brotmesser erreichen könnte. Aufgrund des erhöhten Entdeckungsrisikos lässt $T$ jedoch von dieser Tatmodalität ab und gibt sein Vorbaben gänzlich auf. ${ }^{99}$
\end{abstract}

Beide Ausführungspassagen unterscheiden sich hinsichtlich der Tätergefährdung und des Entdeckungsrisikos. So ist der Einsatz des Brotmessers mit einem höheren Risiko für den Täter verbunden, wobei das Verabreichen des Gifts zudem den Vorteil der unentdeckten Erfolgsherbeiführung bietet. Die Entscheidung des Täters, den Erfolg durch ein heimliches Vorgehen zu erreichen, steht somit der weiteren Handlungsmöglichkeit konträr gegenüber. Durch den Einsatz des Messers setzte sich der Täter in eine konkrete Verbindung zum Opfer.

Rudolphi will eine Einheitlichkeit nur dann zulassen, wenn die weiteren möglichen Tatmittel das gleiche Risikopotential besitzen und gleich geeignet sind. ${ }^{100}$ Dies begründet Rudolphi damit, dass durch Ablassen von ungleichwertigen Tatmit-

99 Hillenkamp, Probleme aus dem Strafrecht, S. 143 Nr. 2 mit Darstellung der unterschiedlichen Lösungen; Fall so auch bei Kübl, AT, \16 Rn. 37; ebenfalls bei Kübl, JuS 1981, 193, 195; LKStGB/Lilie/Albrecht, \24 Rn. 119; siehe hierzu auch SK-StGB/Rudolphi, 24 Rn. 14.

100 SK-StGB/Rudolphi, \24 Rn. 14; Fabrenhorst, NStZ 1987, 277, 279; Rengier, JZ 1988, 930, 933, der grundsätzlich davon ausgeht, dass der Tatmittelwechsel eine Zäsur nach sich ziehen kann und in Fn. 30 darauf hinweist, dass dies bei riskanteren oder weniger geeigneten Mitteln der Fall sei; Fischer, StGB, $₫ 24$ Rn. 12: es ,„...] liegt aber kein Fehlschlag vor, wenn dem Täter andere, gleichwertige Mittel nach seiner Kenntnis so zur Verfügung stehen, dass er die Tat in unmittelbarem Fortgang des Geschehens vollenden könnte, ohne dass durch eine erforderliche wesentliche Änderung des Tatplans eine Zäsur einträte.“; Schmidbäuser, AT, Lehrbuch, 15/78 bejaht wohl dann eine Zäsur und damit einen Fehlschlag, wenn der Täter psychisch nicht dazu in der Lage ist, die weitere Handlung auszuführen. 
teln die „mangelnde Gefährlichkeit“ des Täters noch nicht hervortrete. ${ }^{101}$ Zudem solle die Gleichwertigkeit anhand des Tatplans des Täters bestimmt werden. ${ }^{102}$ So sei eine Zäsur nicht pauschal dann gegeben, wenn bezüglich der Tatmittel eine Ungleichheit vorliege, sondern es müssen auch auf subjektiver Ebene die Vorteile des ersten fehlgeschlagenen Mittels von dem Täter gewollt sein. Ist die Heimlichkeit des Tatmittels „Gift“ für den Täter unerheblich, komme es bei einem Wechsel gerade zu keiner Unterbrechung des einheitlichen Ablaufs und eine Rücktrittsmöglichkeit bestünde. ${ }^{103}$ Anders sei es dann, wenn es dem Delinquenten gerade auf diese Heimlichkeit ankam. In diesem Fall sei ein Fehlschlag des Versuchs gegeben, selbst wenn noch weitere Tatmittel verfügbar wären. ${ }^{104}$

Schlüchter spricht sich auch für eine Zäsur aus. Wie bereits angemerkt, greift sie im Benzin- und Überfahrfall wohl die unterschiedliche Art der Tatmittel auf, denn einmal sei das Mittel auf die Ferne und im anderen Fall auf die Nähe ausgelegt. ${ }^{105}$ Hieraus resultierte ein unterschiedliches Risikopotential für den Täter. Vor allem bei Tatmitteln, die den Erfolg distanzwahrend herbeiführen können, reduziert sich das Risiko für den Täter beträchtlich. Im Überfahrfall wird deutlich, dass das Überfahren für den Täter ein viel geringeres Risiko darstellt als die direkte Konfrontation durch Würgen. Nach Schlüchter divergieren die beiden Tatmittel so sehr, dass es allein schon aus diesem Grund eines neuen Entschlusses bedürfe. ${ }^{106}$

Herzberg weist darauf hin, dass keine Aufgabe/kein Verzicht vorliege, wenn die unterlassene Handlung des Täters ,außerhalb der Grenzen seiner Zweckverfolgung lag. “107 Misslingt es einem Jungen durch den Einsatz eines Giftköders einen

101 SK-StGB/Rudolphi, \ 24 Rn. 14; so ähnlich auch Fabrenhorst, NStZ 1987, 277, 279: „Sieht der Täter davon ab, diese Mittel [(die weniger geeigneten und riskanteren)] einzusetzen, heißt das nicht, daß er sich von seiner Tat distanziert und sich erneut rechtstreu verhält, so daß eine Bestrafung entbehrlich erscheinen könnte."; siehe auch Feltes, GA 1992, 395, 405.

102 Vgl. hierzu BGHSt 10, 129, 131; SK-StGB/Rudolphi, \24 Rn. 14; siehe auch Rengier, JZ 1988, 930, 933 der ebenfalls auf die Vorstellung des Täters abstellt: ,[...] weil es hier der Täterin offenbar nicht auf eine schwere nachweisbare, gerade durch Gift erfolgende Tötung ankam."; ebenfalls stellt LK-StGB/Lilie/Albrecht, \ 24 Rn. 119 auf die subjektive Komponente ab; gleichfalls Fischer, StGB, \24 Rn. 12; Kübl, AT, \16 Rn. 37.

103 Vgl. BGHSt 10, 129, 131; vgl. SK-StGB/Rudolphi, \24 Rn. 14; Rengier, JZ 1988, 930, 933; LK-StGB/Lilie/Albrecht, \24 Rn. 119; anders wohl Kübl, AT, \16 Rn. 37, der zwar grundsätzlich auf den Tatplan des Täters abstellt, „obwohl auch der Einsatz eines schwer nachweisbaren Giftes schon für ein heimliches Geschehen spricht.“

104 BGHSt 10, 129, 131; SK-StGB/Rudolphi, \24 Rn. 14; LK-StGB/Lilie/Albrecht, \24 Rn. 119; so im Ergebnis auch Roxin, AT II, $\ 30$ Rn. 210, der herausstellt, dass eine Einheitlichkeit fortbesteht, wenn der Täter zu der weiteren Handlung übergegangen ist. Roxin stützt seine Auffassung auf die Überlegung, dass das weitere Tatmittel nicht nur rein faktisch zugänglich sein muss, sondern für den Täter auch eine tatsächliche Alternative ist: „Denn wer eine Vergiftung fertigbringt, ist deswegen nicht ohne weiteres zu Gewaltakten disponiert[...]." (Roxin, AT II, \30 Rn. 196); siehe auch Scheinfeld, Tatbegriff, S. 133 Fn. 367, komme es dem Täter auf die Heimlichkeit an, „dann beschränkt dieser [...] gesetzte Rahmen die Tat“, siehe auch S. 134 f.

105 Siehe hierzu schon Fn. 82.

106 Schlüchter, FS Baumann, 1992, S. 71, 86.

107 MK-StGB/Herzberg, 2003, \24 Rn. 83. 
Hund zu töten und lehnt er das Töten mittels eines Messers ab, so könne ein Rücktritt durch das Abstandnehmen von dem Messereinsatz nicht begründet werden. ${ }^{108}$ „Bot sich $[\ldots]$ dem Täter nur noch ein neuer Weg und ein anderes Mittel an, dann ist grds. anzunehmen, dass sie außerhalb der selbstgesetzten Grenzen lagen und der Täter mit der Nichtnutzung nichts aufgegeben hat.“ Nur wenn der nächste Akt tatsächlich in Betracht gezogen werde, was bedeute, dass der Täter tatsächlich begonnen hat, diesen Weg zu beschreiten und sich so dem Erfolgseintritt nähert, könne bei einem Nichtausführen von einem Verzicht gesprochen werden. ${ }^{109}$

Den Auffassungen ist zuzugestehen, dass es befremdlich anmutet, dem Täter das Unterlassen von riskanteren Ausführungshandlungen zugutezuhalten. So drängt sich die Vermutung auf, dass die Aufgabe allein dem erhöhten Risiko geschuldet ist. Deutlich wird dies im „Giftfall“. Kommt es dem Täter gerade darauf an, aus dem Verborgenen heraus zu handeln, so steht von vornherein fest, dass aus der Täterperspektive andere Tatmittel nicht in Betracht kommen. Objektiv stünden zwar weitere Mittel zur Verfügung, jedoch befänden diese sich abseits der subjektiven Handlungsgrenzen. Dass der Täter aber zwangsläufig aufgrund solcher Motivation die weitere Ausführung aufgibt, ist ungewiss, denn auch Scham, Reue oder andere Beweggründe können Ursache für das Ablassen sein. Um hier unbillige Ergebnisse zu vermeiden, müsste die Vorstellung des Täters maßgeblich sein, denn nur so kann flexibel auf die Frage reagiert werden, warum die Tat nicht weiter ausgeführt wurde..$^{110}$

Gegen solch eine subjektive Tatmittelbegrenzung spricht allerdings das zum Tatmittelwechsel Gesagte. Die Strafnormen in ihrer Grundform beschreiben die Art der Ausführung nicht, sondern definieren den Erfolg. So setzt z.B. $\ 212$ StGB allein voraus, dass ein Mensch getötet wurde, wobei die übrigen Tatumstände für die Strafbarkeit an sich keine Relevanz besitzen. ${ }^{111}$ „[W]enn $\ 212$ prinzipiell keinen Unterschied in bezug auf das Tatmittel macht, dann ist auch eine entsprechende Differenzierung beim Versuch zumindest problematisch." ${ }^{112}$ Feltes stellt zudem fest, dass auch das Ablassen von einem Mittel, das riskanter bzw. weniger geeignet ist, „objektiv als Aufgabe der weiteren Tatausführung zu sehen ist. Der Täter entscheidet sich in der konkreten Situation dafür, die geplante Rechtsgutverletzung nicht zu realisieren, obwohl ihm dies zumindest prinzipiell noch möglich wäre. Er distanziert sich dabei auch insofern von der Tat, als er das Tatziel nicht weiter verfolgt." "113 Anmerkend fügt Feltes hinzu, dass das Abwenden von einem

108 MK-StGB/Herzergerg, 2003, § 24 Rn. 83.

109 MK-StGB/Heržberg, 2003, § 24 Rn. 85.

110 Freund, AT, $\int 9$ Rn. 38 kritisiert eine Objektivierung der Geeignetheit und des Risikos, denn es gebe schließlich ,[...] risikofreudige Täter und solche Täter [...], die an sich bereit sind, auch auf geringe Erfolgschancen zu setzen."

111 Fn. 93.

112 Feltes, GA 1992, 395, 406; siehe im Übrigen zu dieser Argumentation schon zuvor.

113 Feltes, GA 1992, 395, 406. 
riskanteren oder weniger geeigneten Tatmittel nicht zwangsläufig ,gegen eine Rückkehr des Täters zur Rechtstreue“ spricht. ${ }^{114}$ Des Weiteren können auch hier Opferschutzgesichtspunkte geltend gemacht werden. ${ }^{115}$ Schlägt der Versuch fehl, weil der Täter den Erfolg nicht mehr heimlich herbeiführen kann, so bestünde für den Täter kein Anreiz von der weiteren Tatausführung abzulassen. Der Täter könnte auch hier aus den gleichen Gründen motiviert werden, das Opfer, nunmehr mit anderen Tatmitteln, auszuschalten, selbst wenn diese Mittel seiner einstigen Vorstellungen nicht entsprechen.

Zudem ergibt sich dieselbe Problematik, wie sie sich bereits bei der Tatplantheorie und der Auffassung von Ranft abgezeichnet hat. Eine Bewertung nach subjektiven Kriterien überzeugt dahingehend, dass der Tatvorstellung des Täters entsprochen wird. Jedoch führt dies auch hier dazu, dass der Täter privilegiert werden würde, dem der Weg, etwaige Entdeckungsrisiken und Gefahren gleich sind.

Zuletzt erschweren Abgrenzungsschwierigkeiten zur Freiwilligkeit die Begründung einer Zäsur. So erkennt der Täter trotz des individuellen Reglements eine tatsächliche Vollendungsmöglichkeit. Anstatt durch die Vorstellung des Täters die Reichweite der Tat zu begrenzen, scheint auch die Frage legitim, ob der Täter die weitere Tatausführung tatsächlich freiwillig aufgegeben hat, wenn allein wegen des Risikos abgelassen wurde. ${ }^{116}$

\section{c. Ergebnis}

Weder die Andersartigkeit, die abweichende Geeignetheit, noch die Änderung der Gefahrträchtigkeit des Tatmittels führen für sich genommen zu einer Separierung des einheitlichen Vorgangs. Selbst wenn eine Zäsur angenommen werden sollte, liegt die Trennung nur dann vor, wenn es dem Täter zwingend auf die Vorzüge des einen Tatmittels ankam. Eine allgemeingültige Aussage bzgl. einer Zäsur ließe sich somit auch in diesem Falle durch den hiesigen Anknüpfungspunkt nicht treffen.

\section{Zäsur aufgrund geänderten Unrechtsgehalts}

Wie \13 Abs. 2 StGB erkennen lässt, kann dem Unterlassen auf Rechtsfolgenseite mit einer Strafrahmenverschiebung entsprochen werden. Nach dem Zweiten Schriftlichen Bericht des Sonderausschusses für die Strafrechtsreform beruht $\int 13$ Abs. 2 StGB darauf, dass „das Unterlassen der Abwendung des tatbestandsmäßigen Erfolges regelmäßig weniger schwer wiege als die Herbeiführung dieses Er-

114 Feltes, GA 1992, 395, 406.

115 Hierzu schon S. 25 f.

116 Freund, AT $₫ 9$ Rn. 38. 
folges durch ein positives Tun[...]." ${ }^{117}$ Konkret bedeute dies einen geringeren Unrechtsgehalt und eine kumulativ bzw. alternativ vorliegende Abweichung der Schuld. ${ }^{118}$ Zwischen der Erfolgsherbeiführung durch ein Unterlassen und der aktiven Realisierung kann folglich eine Unrechtsdifferenz vorliegen, woraus sich eine Zäsur ergeben könnte. ${ }^{119}$

Ob eine einheitliche Tat trotz abweichenden Unrechts fortbestehen kann, ist keine spezifische Frage im Rahmen des Begehungsformwechsels, sondern besitzt gleichfalls bei mehreren aktiven Handlungen unterschiedlichen Unrechts Relevanz, sodass die diesbezüglichen Meinungen zu berücksichtigen sind.

\section{a. Unrechtssteigerung als Zäsur}

\section{aa. Scheinfelds Unrechtskontinuität}

Nach Scheinfeld liegt eine neue Tat vor, ,wenn der Täter zu einem Mittel greift oder zur Erreichung seines Ziels greifen müsste, das einen Sprung in der Unrechtsqualität mit sich brächte, dessen Einsatz also in eine andere Unrechtsdimension führte“".120 So sei keine Tatidentität gegeben, wenn ein Messerstich erfolglos bleibt und der Tod erst durch Verbrennen erreicht werden kann. Im zweiten Akt trete das Mordmerkmal „grausam“ hinzu. „Dieses neue Unrechtselement verbietet es, die Akte als Einheit anzusehen." ${ }^{21}$ Gleiches soll auch dann gelten, wenn das Verabreichen von Abführtropfen misslingt und der Täter dem Opfer sodann Säure ins Gesicht schüttet. In diesem Fall stelle sich der Täter ,zwei völlig verschiedene

117 BT-Drs. V/4095, S. 8; noch gegen eine Milderungsmöglichkeit BT-Drs. IV/650, S. 126.

118 Siehe hierzu MK-StGB/Freund, \13 Rn. 295 m.w.N.; LK-StGB/Weigend, \13 Rn. 98 der neben dem Unrechtsmoment auch die Schuld als Bewertungsmaßstab heranzieht; ders. verweist in $₫ 13$ Rn. 98 Fn. 314 auf LK-StGB/Jescheck, 11. Aufl. 2003, \13 Rn. 61 und das dortige Hervorheben des veränderten Schuldgehalts; HK-GS/Tag, \13 Rn. 35, hebt den „Unrechtsgehalt und die kriminelle Energie“ hervor; Murmann, Grundkurs, $₫ 29$ Rn. 8 stellt fest, dass „ein positives Tun häufig eine größere kriminelle Energie zum Ausdruck bringt als ein Nichtstun"; Roxin, AT II, \31 Rn. 239, der auf den Unrechts- und Schuldgehalt abstellt; ders. verweist in $\$ 31 \mathrm{Rn} .239$ Fn. 281 auf Jescheck/Weigend, AT, $\ 58$ V 1, 2 und die dortige Schwerpunktsetzung auf den geringeren Schuldgehalt. Allein ausnahmsweise sei der Unrechtsgehalt des Unterlassens gegenüber der aktiven Begehung vermindert. „Trotz Garantenpflichtverletzung kann nämlich beim Erfolgsdelikt das ,Handlungsunrecht' des Unterlassungsdelikts weniger Gewicht haben als beim entsprechenden Begehungsdelikt (das Handlungsunrecht ist größer, wenn der Ehemann die Frau mit Tötungsabsicht ins Wasser stößt, als wenn er sich nur nicht rettet) [...].“; siehe zudem Roxin, JuS 1973, 197, 200 f. und die dortigen Verweise auf Jescheck, AT, 2. Aufl. 1972, \58 V. 1. f. und Maurach, AT, 4. Aufl. 1971, \46 III A 3. a) f., gegen die sich Roxin jedoch zu Recht wendet; siehe zu $\int 13$ Abs. 2 StGB auch Metzen, Strafmilderung, S. 139 ff.

119 Für eine Zäsur im Rahmen eines Begehungsformwechsels aufgrund des unterschiedlichen Unrechtsgehalts Murmann, GA 2012, 711, 715: „Die mit einem Wechsel vom Unterlassen zu einem positiven Tun zumindest regelmäßig verbundene Unrechtssteigerung spricht also gegen einen einheitlichen Lebensvorgang."; vorliegend wird für die Frage nach einer Zäsur allein an das Unrecht angeknüpft. Zu \13 Abs. 2 StGB an sich siehe S. 132 ff.

120 Scheinfeld, Tatbegriff, S. 132.

121 Scheinfeld, Tatbegriff, S. 98 f., siehe auch S. 132 f. 
Körperverletzungserfolge vor. Der Grund dafür, dass eine Verschmelzung zu einer Tat ausscheidet, ist das Divergieren der Unrechtsdimensionen. " Die Diarrhö wiege im Vergleich weit weniger schwer. ${ }^{122}$ Die Unrechtsdivergenz zwischen den einzelnen Tathandlungen führte folglich zu einer separierten Betrachtung, sodass der Versuch fehlgeschlagen wäre, wenn die einzige weitere mögliche Handlung einen erhöhten Unrechtsgehalt besitzt. Etwas anderes soll aber dann gelten, wenn sich eine Gefahrkontinuität ausgebildet hat. ${ }^{123}$ Gelingt es dem Täter nicht, das Opfer zu verprügeln und setzt er dazu an, das mitgeführte Messer zu verwenden, so trete der Täter zurück, wenn er von dem Messereinsatz ablässt. ${ }^{124}$ Denn wäre der Fall vollendet, so würde das Geschehen als einheitlich bewertet werden müssen. „Das ist nur angemessen, wenn schon die Situation, in die ihn der Versuch geführt hat, die konkrete Gefahr einer gefährlichen Körperverletzung innewohnte; nur dann besteht die nötige Gefahrkontinuität." Denn hier liege die Gefahr des Einsatzes des Messers schon vor, bevor der Entschluss zum Messereinsatz tatsächlich gefasst wurde. Dies folge aus einem Vergleich mit $\int \mathbb{} 177$ Abs. 3 Nr. 1, 244 Abs. 1 Nr. 1a, 250 Abs. 1 Nr. 1a StGB.125 „Wegen dieser Gefahrkontinuität ist die [...] erwogene Fortsetzung der Körperverletzung mit den ursprünglichen Faustschlägen verbunden. Die Gefahrkontinuität bewirkt weiter, dass die im Messereinsatz liegende Steigerung im Unrecht die Tatidentität nicht zerschlägt [...]." ${ }^{126}$ Entscheidend für die Einheitlichkeit sei das „Beisichführen“, i.S. der benannten Vorschriften, allerdings nicht im originären Sinne. „Beim Rücktritt [...] geht es nur darum, ob zum Rücktrittszeitpunkt noch die ursprüngliche Gefahr der Fortsetzung besteht.“ Daher solle es ausreichen, wenn die Tatmittel dem Täter „, zur Hand liegen" “, dieser also eine Zugriffsmöglichkeit besitzt. ${ }^{127}$ Ein weiteres Tatmittel ist somit dann Teil derselben Tat, „wenn seine Verwendung in der konkreten Situation der Vorstellung des Täters von der Tat entsprach, das heißt, wenn es - unter Berücksichtigung einer etwaigen Selbstbeschränkung - einer zweckgemäBen Tatbestandsverwirklichung diente. “128

Eine Unrechtssteigerung führte somit nur dann zu einer Zäsur, wenn die Steigerung im ersten Akt noch nicht angelegt war, wobei für das „Angelegtsein“ bereits das bloße „zur Hand liegen“ ausreichen soll. ${ }^{129}$ Offen bleibt aber, ob diese konkrete Zugriffsmöglichkeit objektiv oder subjektiv zu bestimmen ist. Zudem gründet Scheinfeld seine Überlegungen auf einen allein statischen Geschehensablauf. Will A den B verprügeln und liegt genau an diesem Ort ein Stein, so besteht die Gefahr

\footnotetext{
122 Scheinfeld, Tatbegriff, S. 98, siehe auch S. $132 \mathrm{f}$.

123 Siehe Scheinfeld, Tatbegriff, S. 135.

124 Zum Fall Scheinfeld, Tatbegriff, S. 132 f.; zum Ergebnis ders., Tatbegriff, S. 135.

125 Scheinfeld, Tatbegriff, S. $133 \mathrm{f}$.

126 Scheinfeld, Tatbegriff, S. 135.

127 Scheinfeld, Tatbegriff, S. 134.

128 Scheinfeld, Tatbegriff, S. 134.

129 Scheinfeld, Tatbegriff, S. 134.
} 
des Steineinsatzes von Beginn an. Anders jedoch dann, wenn sich der Geschehensort verlagert:

\begin{abstract}
Bsp.: $A$ will den $B$ verprïgeln und sucht diesen zu Hause auf. Als B öffnet schlägt $A$ auf $B$ ein, der den Attacken jedoch ausweicht. Der Kampf setzt sich sodann im Wohnzimmer fort, wobei es $A$ auch bier nicht gelingt, $B$ zu verletzen. Nachdem B immer weiter zurückweicht, führt es sie durch zwei weitere Räume in das Büro des B. Als A gerade realisieren muss, dass seine Fäuste dem B nichts anhaben werden, erkennt er auf dem Schreibtisch einen Brieföfner. A ergreift diesen und will damit zustechen. In diesem Moment erscheint ihm ein Stich jedoch als überzogen, er lässt den Brieföffner fallen und verlässt das Haus.
\end{abstract}

Der Einsatz des Brieföffners war dem Täter erst mit dem Betreten des Büros möglich. Hierdurch bestand zwischen den einzelnen Passagen keine Gefahrkontinuität, sodass die Abschnitte getrennt voneinander bewertet werden müssten. Das Geschehen umfasste zwei eigenständige Taten und folglich zwei Versuche, wobei der erste Versuch fehlgeschlagen und der Täter bzgl. des weiteren Versuchs strafbefreiend zurückgetreten wäre.

Der Täter also, der die Aussichtslosigkeit des Verletzungsvorhabens ohne Hilfsmittel erkennt und sodann unmittelbar zur Erfolgsrealisierung mit dem mitgefübrten bzw. zur Hand liegenden Werkzeug ansetzt, könnte aufgrund der bestehenden Gefahrkontinuität insgesamt zurücktreten, wenn er hiervon ablässt. Greift der Täter hingegen zu einem Werkzeug, das zu Beginn des Handlungsstranges noch nicht zur Verfügung stand, lägen mangels Gefahrkontinuität zwei Taten vor. Ließe der Täter in diesem Fall ebenfalls vom Werkzeugeinsatz ab, könnte er nur bzgl. dieses Versuchs zurücktreten, wobei der vorangegangene fehlgeschlagene Versuch bestehen bliebe. Unstimmig erscheint, dass beide Fallkonstellationen sich in Bezug auf das bereitliegende Tatmittel allein im Zeitpunkt des Auffindens der Sache unterscheiden, es aber zu einer gänzlich anderen rechtlichen Bewertung kommt. Für den Täter wäre es folglich von Vorteil, bereits zu Beginn seiner Ausführungen abstrakt eine große Gefahr zu begründen.

Auch überzeugt Scheinfelds Lösungsvorschlag dann nicht, wenn aus Sicht des Täters kein Fehlschlag vorliegt, er jedoch trotzdem ein nicht von Beginn an zur Verfügung stehendes Hilfsmittel einsetzt. Der Versuch ohne Werkzeug wäre nicht fehlgeschlagen und durch den Wechsel zum Versuch mit Tatmittel und der sich hieraus ergebenden Zäsur hätte der Täter die erste Tat aufgegeben. Dies führt zu der Auffälligkeit, dass der Täter, obschon dieser zu einer weiteren Körperverletzung ansetzt, von der ersten versuchten Körperverletzung strafbefreiend zurück- 
getreten wäre. ${ }^{130}$ Der Täter würde somit etwas aufgeben, was er tatbestandlich unmittelbar im Anschluss bzw. sogar in demselben Moment wiederum versucht.

bb. Streng 131

Streng stellt im Fall einer Unrechtssteigerung fest, dass ,,[es] [b]eim Rücktritt [...] ja um die - auch nach außen sichtbar werdende - innere Distanzierung vom ursprünglich geplanten Unrecht [geht]. Wer nun aber zur Steigerung dieses Unrechts übergeht, tut nichts, was unter dem Rücktrittsaspekt eine Neubewertung der Auflehnung des Täters gegen die Rechtsordnung nahelegt; im Hinblick auf $\ 24$ fehlt es daher an einer Zäsur." ${ }^{132}$ Hiergegen wendet Günther zutreffend ein, dass die Negation eines Rücktritts bei einer Unrechtssteigerung allein dann die richtige Konsequenz ist, wenn sich an das versuchte Grunddelikt eine vollendete Qualifikation anschließt. „Infolge des Spezialitätsverhältnisses der gesetzlichen Strafbestände [sic!] und des Subordinationsverhältnisses der Sachverhalte schließt die letztlich verübte Straftat den ursprünglichen Deliktsversuch logisch-begrifflich als ein Minus ein. Auch für einen tatbestandsbezogenen rücktrittsrechtlichen Tatbegriff handelt es sich deshalb nicht um verschiedene Taten."133 Aufgrund dieser „tatbestandsbedingten Spezialitäts- und Subordinationsbeziehung zwischen ursprünglicher und späterer Tat" sei dieses Beispiel untauglich zu beweisen, dass eine Zäsur allein dann eintritt, wenn der Täter das Unrecht reduziert. ${ }^{134}$ Auch wenn ein Täter von einem Betrugsversuch zu einem Raub wechselt, erscheine es unschlüssig, warum bei Raubvollendung die Strafbarkeit wegen versuchten Betrugs verbleibt, obschon der Delinquent hiervon gänzlich Abstand genommen hat. ${ }^{135}$

cc. Ergebnis

Die dargestellten Auffassungen überzeugen nicht. Bereits der Versuch, die Zäsurwirkung einer Unrechtssteigerung anhand von Beispielen zu ergründen, die durch Grunddelikt und Qualifikation gekennzeichnet sind, erscheint unglücklich. ${ }^{136} \mathrm{Im}$ Folgenden soll daher allein an die Unrechtsänderung ohne eine tatbestandliche Abweichung angeknüpft werden.

\footnotetext{
130 Dies freilich nur, wenn keine vollständige Rückkehr in die Legalität gefordert wird.

131 Strengs Auffassung ist an dieser Stelle auf den Unrechtsbezug reduziert. Zur vollständigen Meinungsdarstellung siehe S. 57 ff. Zur Diskussion siehe S. $77 \mathrm{ff}$.

132 Streng, JZ 1984, 652, 655.

133 Günther, GS Armin Kaufmann, 1989, S. 541, 550.

134 Günther, GS Armin Kaufmann, 1989, S. 541, 550.

135 Günther, GS Armin Kaufmann, 1989, S. 541, 550.

136 Diese Kritik bzgl. Streng Günther, GS Armin Kaufmann, 1989, S. 541, 550.
} 


\section{b. Unrechtssteigerung bei identischem Tatbestand}

Ändert sich das Unrecht in einem Geschehensablauf, ohne dass dies tatbestandliche Auswirkungen besitzt, so kann die Unrechtsabweichung sich im Erfolg 137 niederschlagen, an die Qualität der Handlung138 anknüpfen oder durch die Motive ${ }^{139}$ des Täters bestimmt sein. Im Vergleich zum Begehungsformwechsel weist die Unrechtsänderung aufgrund geänderter unrechtsintensiverer Handlung die größte Parallele auf, da sich allein der Unwertgehalt der Begehungsweise ändert, das angestrebte Ziel jedoch dasselbe bleibt. Besonders deutlich tritt eine solche Unrechtsänderung dann hervor, wenn von einer Drohung zur tatsächlichen Umsetzung des in Aussicht gestellten Übels übergegangen wird.

Bsp.: $T$ drobt $O$ damit, ibn zu verprïgeln, wenn er nicht das tue, was von ibm verlangt wird. Als $O$ sich hiervon jedoch nicht beeindrucken lässt, setzit $T$ seine Drohung in die Tat um und macht $O$ durch Schläge gefingig.

Mangels Integritätsverletzung verkörpert das Drohen geringeres Unrecht als die aktive Einwirkung auf die körperliche Unversehrtheit des Opfers, sodass eine Unrechtsänderung zu bejahen ist. ${ }^{140}$ Fraglich ist, ob zwei Taten, eine fehlgeschlagene versuchte Nötigung und eine vollendete Nötigung, vorliegen oder das gesamte Geschehen als eine vollendete Nötigung anzusehen ist. Sommer stellt fest:

137 Der Täter entwendet anstatt der geplanten $10 € 500 €$.

138 Siehe folgendes Beispiel im Text.

139 Der Täter T nötigt Millionär M, um Geld zu erhalten. Er will das Geld einsetzen, um seiner Schwester eine teure lebenswichtige Operation zu bezahlen. Währenddessen stirbt die Schwester, was T telefonisch erfährt. T erpresst das Geld sodann für den Eigenbedarf.

140 Sommer, NJW 1985, 769, 771 weist darauf hin, dass sich bei der Realisierung der Drohung eine „,...] Unrechtssteigerung im Hinblick auf die durch die Drohung beeinträchtigte Willensbetätigungsfreiheit keinesfalls auf[drängt]. Im Gegenteil: Realisiert der Drohende seine Androhung und hält dabei keine weitergehenden Drohungen aufrecht, begibt er sich u. U. des effektivsten Druckmittels auf den zu Nötigenden." Besitzt der Täter durch die Realisierung der Drohung kein taugliches Drohmittel, so trifft die Auffassung Sommers zu. Nach Ausführung der Drohung besteht für den Betroffenen kein Grund, sich dem Willen des Täters unterzuordnen, da insoweit eine weitere Verschlechterung nicht zu erwarten ist. Dies gilt so aber nur dann, sofern die Drohung einen allein singulären Charakter besitzt, mithin durch die Ausführung entfällt, wie z.B. bei der Preisgabe einer Information. Anders ist dies jedoch im vorliegenden Fall (S. 44). Hier sind die Schläge fortwährend tauglich das Opfer gefügig zu machen. Anders als in dem von Sommer angeführten Zerkratzen des Autolacks bzw. im Fall des Drohens mit der Informationsweitergabe, welches einmalige Akte darstellen und nach Realisierung dieser Drohung ,aufgebraucht" sind, kann durch die fortgesetzte Einwirkung auf die körperliche Integrität, da das Interesse des Opfers an der Beendigung des Rechtsgutsangriffs fortbesteht, die Bedrohungslage aufrechterhalten und durch das Hinzutreten von körperlichen Schmerzen sogar noch verstärkt werden; allgemein zum unterschiedlichen Unrechtsgehalt von Drohung und Gewalt Sommer, NJW 1985, 769, 772. 
„Auch wenn der Täter unter Beibehaltung des Nötigungsziels zunächst mit Gewaltanwendung droht und diese anschließend realisiert, $[\ldots]$ so vermag doch diese besondere Sachverhaltskonstellation ihre Kontinuität allein aus einer gewissen Üblichkeit der Vorbereitung und Anwendung gewaltsamer Nötigung abzuleiten. Der als einheitlich erfaßte Geschehensablauf beruht auf sozialer Erfahrung, nicht auf einer tatbestandlichen Unrechtskontinuität." "141 Sommer entkoppelt die Einheitlichkeit des Geschehens somit von dem Unrecht und stellt auf die „Üblichkeit“ und die „soziale Erfahrung“ ab. Zuzustimmen ist Sommer dahingehend, dass es nur stringent und schlüssig ist, erst mit einer bestimmten Handlung zu drohen und im Fall des Fehlgehens der Drohung diese, wenn auch ggf. nur teilweise, um sich der Drohkulisse nicht insgesamt zu begeben, umzusetzen. Daher ist es zu recht wenig überzeugend, das Geschehen künstlich aufzuspalten und unabhängig voneinander zu bewerten.

Wird zur Ergründung der Einheitlichkeit bei einer bestehenden Unrechtsdivergenz konkret auf die Definition des Fehlschlags nach der Gesamtbetrachtungslehre Bezug genommen, wonach der Versuch dann nicht fehlgeschlagen ist, „wenn der Täter, wie er weiß, im unmittelbaren Anschluss an sein bisheriges Tun erneut zum Angriff ausholen oder ein neues bereitstehendes Mittel einsetzen kann" "142, so scheint es zudem so, als ob der Unrechtsänderung in diesem Rahmen keine Bedeutung beigemessen wird und gar nicht beigemessen werden kann. Wird mit der Gesamtbetrachtungslehre das Ziel verfolgt, einen weiten Tatbegriff zu etablieren, so würde eine Zäsur aufgrund geänderten Unrechtsgehalts dies konterkarieren, denn eine Änderung der Ausführungsart bringt zumeist auch eine Unrechtsänderung mit sich. Für sich genommen ist dies freilich kein Argument gegen eine Zäsur, im Zusammenspiel mit dem Umstand jedoch, dass eine weitere Handlung in den seltensten Fällen den gleichen Unrechtsgehalt besitzt wie die Handlung zuvor, käme es durch solch eine Begrenzung zu einer faktischen Einzelakttheorie und gleichfalls zu deren Schwächen. Zudem ist festzustellen, dass das Erfordernis einer Unrechtskonsistenz eine Parallele zu der Auffassung Ranfts aufweist, wonach eine Einheitlichkeit nur beim Einsatz von artgleichen Tatmittel besteht. ${ }^{143}$ Denn ist das weitere einsetzbare Tatmittel nicht artgleich zu dem ersten, so wird auch die Unrechtsqualität eine andere sein. Übertragen auf Rengiers Beispielsfall ${ }^{144}$ hätte dies zur Folge, dass der Täter dann nicht insgesamt zurücktreten könnte, wenn das Messer durch den ersten Stich beschädigt wurde und er von dem anschließenden Würgen ablässt. Dem Würgen müsste aufgrund des erhöhten Leidens und dem langsameren Todeseintritt ein größerer Unrechtsgehalt beigemessen werden als ein weiteres Zustechen. Es handelte sich um zwei Taten, sodass ein fehlgeschlagener und ein weiterer versuchter Totschlag vorlägen, von

\footnotetext{
141 Sommer, NJW 1985, 769, 772.

142 Wessels/Beulke/Satzger, AT, Rn. 891.

143 Siehe zu Ranft S. 33.

144 Siehe S. 34.
} 
dem der Delinquent allerdings durch Einleiten von Rettungsmaßnahmen strafbefreiend zurückgetreten ist. Hätte der Täter hingegen ein weiteres bereitliegendes Messer eingesetzt, um nach dem erneuten Stechen zurückzutreten, so hätte dies, aufgrund der Unrechtsidentität, Auswirkungen auf das gesamte Geschehen. ${ }^{145}$ Neben dieser unbegründeten Ungleichbehandlung könnte sich der Täter aufgrund der feststehenden Strafbarkeit zudem motiviert sehen, die Tat zum Erfolg zu führen. Insoweit ist aufgrund der beengten Tatreichweite die Opferschutzproblematik ebenso präsent wie bei der Einzelakttheorie selbst.

Nicht zuletzt käme es bei einer Zäsur aufgrund geänderten Unrechtsgehalts z.B. bei mehreren Faustschlägen darauf an, wo diese platziert worden sind. Schläge gegen den Kopf könnten aufgrund des höheren Unrechtsgehalts mit Schlägen gegen die Beine nicht zusammengefasst werden. Die Einheitlichkeit der Tat hinge mithin nicht zuletzt davon ab, wie der Täter das Tatmittel eingesetzt hat bzw. wie dieser sich vorstellte, das Mittel noch zu verwenden. Die Art und Weise des Einsatzes bedingte folglich auch die Reichweite der Tat, wobei geschickte Einlassungen es dem Täter ermöglichten, die Tat nach seiner Vorstellung und dem konkreten Bedürfnis nach einer geringen Strafe bzw. Straffreiheit zu formen.

Festzustellen ist somit, dass ein den Tathandlungen anhaftender unterschiedlicher Unwertgehalt für sich genommen eine Zäsur des einheitlichen Lebensvorgangs nicht zu begründen vermag. Anders könnte dies jedoch dann sein, wenn das Unrecht so stark abweicht, dass das Verhalten einem anderen Tatbestand zugeordnet werden muss.

\section{Begehungsformwechsel als Tatbestandswechsel}

Betrachtet man Unterlassen und aktives Tun, so stehen diese beiden Ausführungsformen sich konträr gegenüber. Im Rahmen des Unterlassens ist gerade das Nichtstun Anknüpfungspunkt für die Strafe, wohingegen beim aktiven Tun die Handlung das vorwerfbare Verhalten darstellt. Dieser Umstand legt die Vermutung nahe, dass es sich beim Unterlassen und aktiven Tun um eigenständige Tatbestände handeln könnte. ${ }^{146}$ Entscheidend ist somit, ob der Wechsel von einem Unterlassen zu einem Tun allein gleich einem Tatmittelwechsel zu behandeln ist oder ob der Begehungsformwechsel zwei Tatbestände umfasst. ${ }^{147}$ Wäre dies der Fall, so könnte dies für eine Zäsur und mithin gegen einen einheitlichen Lebensvorgang sprechen.

\footnotetext{
145 Vgl. S. 34.

146 Gemeint ist hier nur die Strafbarkeit des Unterlassens nach \13 StGB.

147 Siehe zu beiden Auslegungsmöglichkeiten Murmann, GA 2012, 711, 713 f.; für einen neuen Tatbestand z.B. Welzel, Strafrecht, 11. Aufl. 1969, S. 210 f.
} 
Für die Einordnung ist maßgeblich, ob $\int 13$ StGB einen konstitutiven oder deklaratorischen Charakter besitzt. ${ }^{148}$

a. Auswirkungen eines Tatbestandswechsels auf die einheitliche Tat i.S. des $\int 24$ Abs. 1 StGB

Bevor jedoch auf die Einordnung bzw. den Charakter des $\int 13$ StGB eingegangen wird, sollen zunächst die Folgen eines Tatbestandswechsels im Allgemeinen dargestellt werden. Führt nämlich schon im Rahmen der aktiven Begehung ein Tatbestandswechsel nicht zu einer Zäsur des einheitlichen Geschehens, so könnte die Prüfung der Eigenständigkeit des $\int 13$ StGB dahinstehen.

\title{
aa. Einleitung/Folgen
}

Wie bereits angedeutet, ist die Zäsurwirkung eines Tatbestandswechsels für die Tat i.S. des $\int 24$ Abs. 1 StGB über den Begehungsformwechsel hinaus relevant ${ }^{149}$ :

\begin{abstract}
(1) Der Täter T versucht Delikt $A$ zu verwirklichen, was jedoch fehlschlägt. In diesem Moment erkennt er die Möglichkeit, ein weiteres Deliket zu realisieren. (Der versuchte Betrug schlägt fehl, nun erkennt T, dass er auch mit Gewalt an das Geld gelangen könnte150). T lässt jedoch von diesem Vorhaben ab und verlässt unverrichteter Dinge den Tatort.
\end{abstract}

Verneint man in diesem Zusammenhang eine Zäsur zwischen zwei Delikten und lässt einen Tatbestandswechsel innerhalb eines Geschehensablaufs zu, so wäre der Versuch des ersten Delikts für sich genommen zwar gescheitert, jedoch könnte ein Fehlschlag abgewendet werden, wenn der Täter noch einen anderen Tatbestand

148 Zu der Abgrenzung siehe Murmann, GA 2012, 711, 714.

149 Alle folgenden Konstellationen knüpfen an denselben Tatbegriff wie der Begehungsformwechsel an. Insoweit muss dieselbe Tatreichweite gelten, sodass auf diese Fälle Bezug genommen werden kann. Siehe hierzu Weinhold, Rettungsverhalten und Rettungsvorsatz, S. 61 ff., insbesondere S. 63 ff. Weinhold verweist auf Küper, der eine unterschiedliche Definition der Tat zulässt, da die Begrifflichkeit der Regelungsmaterie anzupassen sei (Küper, JZ 1979, 780). Hiergegen wendet Weinhold auf S. 64 ein: „Das Prinzip der rechtsbegrifflichen Relativität erlaubt, sogar innerhalb eines Gesetzes einen Begriff verschieden zu verwenden. So erlaubt es der Einzelaktstheorie den Tatbegriff beim Rücktritt anders zu bestimmen als bei den Konkurrenzen. Rechtsbegriffliche Relativität innerhalb eines einzigen Paragraphen aber gibt es nicht und noch weniger innerhalb zweier Fallgruppen, die unter dasselbe Merkmal eines Halbsatzes desselben Paragraphen subsumiert werden. »Aufgeben der Tat« bei \ 24 I 1. Alt StGB kann nicht einmal dies und einmal jenes bedeuten.“

150 Vgl. Günther, GS Armin Kaufmann, 1989, S. 541, 543. 
verwirklichen könnte. Allein diese Realisierungsmöglichkeit eines anderen Delikts eröffnete dem Täter die Rücktrittsmöglichkeit. ${ }^{151}$

Diese vorteilhafte Folge kann auch bei einer weiteren Sachlage beobachtet werden:

(2) Wie zuvor schlägt Delikt A febl. Nun erkennt T aber nicht nur das weitere Delikt, sondern versucht dieses zu verwirklichen, besinnt sich sodann aber eines Besseren und tritt wirksam zurück.

Die Wirkung des Rücktritts würde aufgrund der Einheitlichkeit nicht nur den zweiten Abschnitt, sondern das gesamte Geschehen erfassen. T wäre in solch einem Fall insgesamt straflos. ${ }^{152}$

Eine Straflosigkeit müsste allerdings mangels Zäsur dann verneint werden, wenn der Täter von einem versuchten Delikt ablässt und einen anderen Tatbestand vollendet.

(3) Der Täter $T$ versucht Delikt $A$ zu verwirklichen, vollendet sodann aber Deliket $B$.

Der Täter könnte durch das Ablassen von Delikt A nicht zurücktreten. Delikt A und Delikt B stellten dieselbe Tat dar, weswegen der Täter die Tat durch das Umschwenken auf das weitere Delikt noch nicht aufgegeben hätte. Ein Aufgeben der Tat kann freilich dann nicht vorliegen, wenn dieselbe Tat noch fortbesteht. ${ }^{153}$

151 Vgl. hierzu Günther, GS Armin Kaufmann, 1989, S. 541, 543 f. Dieselbe Problematik zeigt sich auch beim Unterlassen (die Eigenständigkeit des $₫ 13$ StGB vorausgesetzt) und der Frage, ob das bloße Erkennen eines weiteren aktiven Delikts zur Beseitigung des Fehlschlags ausreicht.

152 Siehe Scheinfeld, Tatbegriff, S. 4. Entsprechendes findet sich wiederrum im Rahmen des Unterlassens. Schlägt das Unterlassen fehl und geht der Täter zu einer aktiven Handlung über, wobei er hiervon ablässt, so ist bei einer deliktischen Eigenständigkeit des $₫ 13$ StGB entsprechend fraglich, ob der Rücktritt von der aktiven Handlung gleichsam das Geschehen insgesamt erfasst.

153 Vgl. Scheinfeld, Tatbegriff, S. 3; Roxin, AT II, \30 Rn. 421 und vgl. das Beispiel Rn. 424, der auf Günther verweist; vgl. hierzu auch Günther, GS Armin Kaufmann, 1989, S. 541, 543 und S. 553; siehe auch Walter, Der Rücktritt vom Versuch als Ausdruck des Bewährungsgedankens im zurechnenden Strafrecht, 1980, S. 100. 


\section{bb. Vertretene Ansichten}

(1.) BGH und Teil der Lehre: Die Tat i.S. des $\int 24$ StGB entspricht dem materiellen Tatbestand

\section{(a.) $B G H$}

\begin{abstract}
BGH: Der Täter T will das Opfer O vergewaltigen. O flüchtet, wobei T es mit einem Messer verletzt. Als $O$ die Wunde im Bad reinigt, versucht er $O$ zum Mundverkehr zu zwingen. Als sich das Opfer dem jedoch widersetæt, lässt $T$ ab, nicht jedoch wegen der Unmöglichkeit der Fortsetzung dieses Vorhabens, sondern weil er wiederum den Geschlechtsverkehr vollziehen will. T vergewaltigt sodann die 0.154
\end{abstract}

Fraglich ist, ob der Täter durch das Ablassen von dem versuchten Mundverkehr diesbezüglich strafbefreiend zurückgetreten ist, obwohl sich aus dem weiteren Fortgang eine vollendete Strafbarkeit ergibt. Dies bildete den Anknüpfungspunkt für die Frage, inwieweit sich die Tat i.S. des $\ 24$ Abs. 1 StGB mit dem Tatbestand deckt. ${ }^{155}$

154 BGHSt 33, $142 \mathrm{ff}$.

155 Wie der BGH richtig erkennt (BGHSt 33, 142, 145), hätte die Entscheidung, ob ein Tatbestandswechsel dem Täter die Möglichkeit des Aufgebens eröffnet, hier dahinstehen können. Der durch den ersten Abschnitt versuchte $₫ 178$ StGB a.F. wirkt auch in der Vergewaltigung fort, sodass hier derselbe Tatbestand bzgl. beider Teile vorliegt und eine Aufgabe der Tat ausscheiden muss. Allein eine anderweitige Zäsur im einheitlichen Ablauf könnte für ein Ablassen von der Tat sprechen. De lege lata müsste zudem auf einer anderen strafrechtlichen Basis entschieden werden. Die Vergewaltigung ist in der heutigen Fassung allein als Regelbeispiel im Rahmen der sexuellen Nötigung ausgestaltet ( $\mathbb{1} 177$ Abs. 2 S. 1 Nr. 1 StGB). Heute ergibt sich in dieser Konstellation folglich kein Tatbestandswechsel mehr, sondern es stellt sich die Frage, ob zwei getrennte Strafbarkeiten gem. $\ 177$ Abs. 1 StGB und $\ 177$ Abs. 1 u. 2 Nr. 1 StGB vorliegen, wobei von der ersten zurückgetreten worden sein könnte, oder ob beide Akte zu einer Tat zusammenzufassen sind, sodass die Strafbarkeit nur aus $\ 177$ Abs. 1 u. 2 StGB folgte, wobei hiernach freilich ein Rücktritt ausscheiden muss. (Abseits der Vergewaltigung kommen noch $\ 177$ Abs. 3 und 4 in Betracht); Freund, AT, $\ 9$ Rn. 49 stellt fest, dass die Rspr. ,[...] z. T. einen recht weiten Begriff der Tat im materiellstrafrechtlichen Sinne zugrunde [legt]", wobei Freund auf die hiesige Entscheidung und den Umstand verweist, dass ein Rücktritt von der sexuellen Nötigung nach dem BGH dann nicht möglich sei, wenn der Entschluss das Opfer zu vergewaltigen fortbesteht (ders., AT, $\$ 9$ Rn. 49 Fn. 56). Warum es sich hierbei jedoch um einen weiten Tatbegriff handeln soll, erscheint fraglich. Stellt der Täter sich im Zeitpunkt des Ablassens vor, sofort zur Vergewaltigung überzugehen, so enthält die Entscheidung zugleich auch den Entschluss, das Opfer sexuell zu nötigen, da durch die Vergewaltigung auch die sexuelle Nötigung verwirklicht wird. Der Täter hätte somit im Zeitpunkt der Aufgabe den Tatentschluss nicht aufgegeben, sondern allein geändert, wobei diese Änderung den ursprünglichen Entschluss inkludiert; zu der 
Der BGH führt diesbezüglich aus, dass „Tat im Sinne des $₫ 24$ StGB [...] eine Straftat im Sinne eines materiellrechtlichen Straftatbestandes [ist]. " 156 Dies wird damit begründet, dass anderenfalls der Täter, dessen Versuchshandlung mehrere Tatbestände verwirklicht, das Vorhaben insgesamt aufgeben müsste, um straffrei zu werden. Versucht der Täter einen „Raub mit Mitteln des Mordes“, so könne dieser von dem versuchten Mord nur dann zurücktreten, wenn der Delinquent neben dem Mord auch vom Raub ablässt. Ein solches Ergebnis stehe nicht im Einklang mit \24 StGB. ${ }^{157}$ Diese Überlegung widerspreche auch nicht dem Grundsatz, dass für einen Rücktritt „der Täter die Durchführung seines Verbrechensentschlusses im ganzen und endgültig $[\ldots]^{\text {“ }}$ aufzugeben habe ${ }^{158}$, denn dies beziehe sich gerade nur auf den einen Straftatbestand. ${ }^{159}$

Dass der Tatbegriff des $\int 24$ StGB mit dem materiellen Straftatbestand kongruent sei, ergebe sich zudem schon aus der „Verknüpfung des $\ 24$ StGB mit den $\iint 22,23$ StGB, in denen die Frage der Strafbarkeit des Versuchs von Straftaten ( $\left.\int 22 \mathrm{StGB}\right)$ - nämlich von Verbrechen und Vergehen in dem bezeichneten Sinne (vgl. \ 23 StGB) - geregelt ist. "'160

\section{(b.) Roxin}

Roxin stimmt der Auffassung des BGH zu, möchte diese jedoch dahingehend erweitern, dass dieselbe Tat auch dann vorliege, wenn „der Täter vom versuchten Grunddelikt zu einer Qualifikation oder zu einem qualifizierten selbständigen Tatbestand übergeht, indem er z. B. bei einem Diebstahl ( $\int 242$ StGB) Gewalt

Entscheidung und der Frage, warum sich die Gerichte überhaupt mit der freiwilligen Aufgabe auseinandersetzen Herzberg, GS H. Kaufmann, 1986, S. 709.

156 BGHSt 33, 142, 144; bestätigt durch BGHSt 35, 184, 186 f. und BGHSt 39, 221, 230, die auf die Ausgangsentscheidung verweisen; dem zustimmend Roxin, AT II, \30 Rn. 421 f.; ebenso Günther, GS Armin Kaufmann, 1989, S. 541, 554 passim; Wessels/Beulke/Satzger, AT, Rn. 904 (in Wessels, AT, 14. Aufl. 1984, \14 IV 4 hingegen versagte Wessels dem Täter noch einen Rücktritt bzgl. des ersten Abschnitts, wenn dieser von einem versuchten Betrug zu einem Raub wechselt); LK-StGB/Lilie/Albrecbt, \24 Rn. 218; ebenso Baumann/Weber/Mitsch, AT, \27 Rn. 29 a; MKStGB/Heræ̧berg/Hoffmann-Holland, \$2 4 Rn. 96: „Zurücktreten kann der Täter immer nur von einem konkret versuchten Delikt, also von einer Tat im materiell-rechtlichen Sinn, was auch im Wortlaut von Abs. 1 S. 1 1. Alt. zum Ausdruckt gebracht wird, da der Täter hiernach die weitere Ausführung der Tat aufgeben muss." (meine Unterstreichung); Fischer, StGB, $\$ 24$ Rn. 26; vgl. auch Stratenwerth/Kublen, Strafrecht, AT I, 6. Aufl. 2011, 2. Kap. \11 Rn. 82 in Fn. 101; Grünwald, FS Welzel, 1974, S. 701, 713 „Andererseits steht außer Zweifel, daß die Identität nicht nur dann zu verneinen ist, wenn ein anderer Tatbestand vollendet wird [...]“. BGHSt 33, 142, 144; so auch Günther, GS Armin Kaufmann, 1989, S. 541, 548, passim. So BGH in BGHSt 7, 296, 297; BGH, NJW 1980, 602.

159 BGHSt 33, 142, 145.

160 BGHSt 33, 142, 145; so auch Günther, GS Armin Kaufmann, 1989, S. 541, 543 f.; siehe allgemein zur Verknüpfung von $\$ 22$ StGB und der erforderlichen Aufgabe MK-StGB/Herzberg/Hoffmann-Holland, \$24 Rn. 89. 
anwendet und dadurch den Tatbestand des Raubes ( $\int 249$ StGB) verwirklicht."161 Diesbezüglich stellt Roxin aber sogleich klar, dass es sich hierbei eigentlich um keine Ausnahme der zuvor festgesetzten Regel handelt, denn der Raub enthalte den Diebstahl, sodass der Tatbestand gleich bleibe. ${ }^{162}$

\section{(c.) Mitsch}

Auch Mitsch spricht sich für eine Identität von Tat und Tatbestand im Rahmen des $\int 24$ Abs. 1 StGB aus. Schon der Versuch könne sich immer nur auf einen konkreten Tatbestand beziehen. ${ }^{163}$ „Strafbarkeit wird nicht abstrakt wegen , versuchter Straftat', sondern konkret wegen ,versuchten Totschlags', ,versuchten Diebstahls“ usw. begründet.“164 „Tat“ stelle allein die tatsächlichen Umstände dar, durch die der Tatbestand verwirklicht wird und zur Strafbarkeit führt. Gleiches gelte für den Rücktritt. Der Rücktritt gewähre dem Täter nur bzgl. des Tatbestands Straffreiheit, auf den bezogen ein tatsächlicher Rücktritt auch vorliege. Insoweit müsse eine Übereinstimmung zwischen dem versuchten Tatbestand und den Wirkungen des Rücktritts bestehen. ${ }^{165}$

161 Roxin, AT II, $₫ 30$ Rn. 422.

162 Roxin, AT II, $\$ 30$ Rn. 422.

163 Baumann/Weber/Mitsch, AT, \27 Rn. 29 a.

164 Baumann/Weber/Mitsch, AT, \$2 27 Rn. 29 a.

165 Baumann/Weber/Mitsch, AT, $\$ 27$ Rn. 29 a; zur Deckungsgleichheit von Tat i.S. des $\ 22$ und i.S. des $\ 24$ Abs. 1 Alt. 1 StGB Schlüchter, FS Baumann, 1992, S. 71, 82: „Zunächst interessiert die ,weitere Ausführung der Tat' als Gegenstand der Rücktrittshandlung nach der 1. Alt. von $₫ 24$ Abs. 1 S. 1 StGB. Gemeint ist die Tat, zu deren Ausführung der Täter gemäß $\ 22$ StGB unmittelbar angesetzt hat."; zu dieser Deckungsgleichheit siehe auch Maurach/Gössel, AT, 7. Aufl. 1989, \ 41 Rn. 51: „Die Tat, deren weitere Ausführung der Täter aufgibt, kann folglich nur jenes aus objektiven und subjektiven Elementen bestehende rechtsgutsbeeinträchtigende Verhalten sein, mit dem der Täter jene Schwelle überschritten hat, welche den strafbaren Versuch von der Vorbereitung trennt.“ Weiterhin wird festgestellt, dass „Gegenstand des Aufgebens [...] damit jene Straftat und also die tatbestandliche strafbare Rechtsgutbeeinträchtigung [ist], die zu erreichen der Täter bereits versucht hat."; siehe zu dem Rückschluss aus $\$ 22$ StGB auch Günther, GS Armin Kaufmann, 1989, S. 541, 553, „Wenn der Entschluß zur Tat den Vorsatz zur Verwirklichung eines bestimmten (und nicht irgendeines) Straftatbestandes kennzeichnet, muß gleiches auch für den actus contrarius gelten, für die Aufgabe des Entschlusses zur Tat.“ 


\section{(d.) Günther}

Günther schließt sich der Tatdefinition des BGH an. ${ }^{166}$ Wenn schon Änderungen im Rahmen des deliktischen Sachverhalts zu einer Änderung der „Tat“ führen, so sei es schlüssig, dass dies erst Recht dann gelten müsse, wenn Abweichungen vorliegen, die eine gänzlich andere strafrechtliche Bewertung nach sich ziehen. ${ }^{167}$ Jedoch sei zwischen diesen beiden Umständen zu differenzieren. Durch das Erfordernis der Tatbestandsidentität werde eine notwendige Bedingung festgesetzt. Gehören zwei Abschnitten unterschiedlichen Straftatbeständen an, so folge allein aus diesem Umstand heraus, dass eine Identität zwischen diesen beiden Passagen nicht vorliegen kann, selbst wenn eine zeitlich und räumliche Zusammengehörigkeit gegeben ist. 168

Die mangelnde Aufarbeitung dieses Problemkreises beruhe nach Günther vor allem auf dem Umstand, dass eine Zubilligung von Straffreiheit dem Rechtsgrund des Rücktritts zu widersprechen scheint, wenn der Täter deliktisch weiterhandelt. ${ }^{169}$ Versucht der Täter jedoch einen Diebstahl, um sodann eine räuberische Erpressung zu begehen, so müsse ihm hier ein Rücktritt bzgl. des ersten Teils gewährt werden. Dies folge allein schon daraus, dass der Gesetzgeber beide Strafbarkeiten von gänzlich anderen Voraussetzungen abhängig gemacht hat. Dieser Umstand könne nicht überwunden werden. „,Wenn der Täter den Diebstahl nicht mehr vollenden will (obwohl er es könnte und dies weiß), wie sollte sich allein aus dem Umstand, daß er eine räuberische Erpressung begeht, rechtfertigen lassen, er habe auch die Diebstahlstat fortgesetzt und sei deshalb zusätzlich wegen Diebstahlsversuchs strafbar?" 170

Auch könne das vorliegende Problem auf die tätige Reue übertragen werden. Zündet ein Täter ein Haus an, um, nachdem er dieses wieder gelöscht hat, die darin enthaltenen Sachen zu entwenden, so wäre der \310 StGB a.F. wohl trotz des Umstands des Weiterhandelns nach einhelliger Auffassung anzuwenden. ${ }^{171}$

Zudem sei das vorliegende Problem mit einer Konstellation im Rahmen des $\int 24$ Abs. 2 StGB vergleichbar. So kann der Exzess eines Tatbeteiligten nicht zugerechnet werden, da es sich insoweit um eine andere Tat handelt. ${ }^{172}$ Solch ein

166 Günther, GS Armin Kaufmann, 1989, S. 541, 554 und 552: „Es zeigt sich mithin auf Schritt und Tritt, daß die höchstrichterliche These vom Tatbestandsbezug des rücktrittsrechtlichen Tatbegriffs mit ihren tätergünstigen Konsequenzen für einen Teilrücktritt trotz Deliktswechsels offenbar den berühmten Nagel auf den Kopf getroffen hat.“

167 Günther, GS Armin Kaufmann, 1989, S. 541, 544 f.

168 Günther, GS Armin Kaufmann, 1989, S. 541, 545.

169 Günther, GS Armin Kaufmann, 1989, S. 541, 546.

170 Günther, GS Armin Kaufmann, 1989, S. 541, 549.

171 Günther, GS Armin Kaufmann, 1989, S. 541, 549.

172 Günther, GS Armin Kaufmann, 1989, S. 541, 551 der in seinem Beitrag auf Otto, JA 1980, 707, 710 und Haft, JA 1979, 306, 310 verweist. 
Exzess soll gerade bei einem Tatbestandswechsel stets gegeben sein. ${ }^{173}$ Wechselt ein Beteiligter mithin abredewidrig das Delikt, so können die anderen Beteiligten, trotz einer ansonsten ggf. vorliegenden Einheitlichkeit, von dem ersten Abschnitt zurücktreten ${ }^{174}$, weswegen sich nunmehr die Frage stelle, warum im Rahmen des \24 Abs. 1 StGB etwas anderes gelten soll als bei \ 24 Abs. 2 StGB. ${ }^{175}$ „Soll der Sinneswandel des Täters den Beteiligten zugutekommen, muß Gleiches doch erst recht für den Täter selbst zutreffen, sofern jeweils auch die übrigen Rücktrittsvoraussetzungen vorliegen." ${ }^{176}$

Auch könne eine vollständige Rückkehr in die Legalität gar nicht gefordert werden, da anderenfalls dem Täter der Rücktritt vom Mord verwehrt werden müsse, weil er das Opfer z.B. im Anschluss beleidigt. ${ }^{177}$ Obschon dieser allein „partiellen“ Rechtskonformität werde der Rechtsgrund des Rücktritts gewahrt. Beziehe man sich immer nur auf ein konkretes Delikt, so sei der Rechtsgrund des Rücktritts auch hier gegeben. Verwirklicht der Täter im weiteren Fortgang ein anderes Delikt, so spreche dies nicht dagegen, dass dieser von dem zuvor versuchten Delikt durch Rücktritt in die Legalität zurückgekehrt ist. ${ }^{178}$

Zudem sei zu beachten, dass „das Strafrecht [...] die Handlung des Täters auch auf allen übrigen Ebenen des Straftatsystems ausnahmslos immer nur unter dem Aspekt der Mißachtung einer Verbots- oder Gebotsnorm [würdigt]. Das gilt für den Straftatbestand, die Rechtfertigungsfrage, die Schuldprüfung, für objektive Bedingungen der Strafbarkeit und persönliche Strafaufhebungsgründe. " ${ }^{179}$

Dieselbe Schlussfolgerung ergebe sich zudem aus der Legaldefinition in $\ 11$ Abs. 1 Nr. 5/6 StGB und der Verbindung von $\int 22$ mit $\int 24$ StGB $^{180}$. Denn muss sich der Versuch auf einen konkreten Tatbestand beziehen, so müsse dies für die Kehrseite, hier also den Rücktritt, ebenfalls gelten. ${ }^{181}$

Bestärkt werde diese Auffassung durch $\int 46$ Nr. 2 StGB a.F., der die Abwendung des Erfolgs des Verbrechens bzw. Vergehens für einen wirksamen Rücktritt voraussetzte. ${ }^{182}$

Aber auch, dass der Täter bei mehreren gleichzeitig versuchten Tatbeständen individuell zurücktreten kann, hier also die Tat i.S. eines Tatbestands verstanden

173 Günther, GS Armin Kaufmann, 1989, S. 541, 551. Ders. verweist auf Schönke/Schröder/Eser/Bosch, \24 Rn. 93 und auf Grünwald, FS Welzel, 1974, S. 701, 713, der feststellt, dass eine Identität nicht nur dann nicht mehr vorliege, „,wenn ein anderer Tatbestand vollendet wird, sondern auch dann, wenn ein Wechsel im Tatobjekt eintritt.“

174 Günther, GS Armin Kaufmann, 1989, S. 541, 551.

175 Günther, GS Armin Kaufmann, 1989, S. 541, 551.

176 Günther, GS Armin Kaufmann, 1989, S. 541, 551.

177 Günther, GS Armin Kaufmann, 1989, S. 541, 552.

178 Günther, GS Armin Kaufmann, 1989, S. 541, 552.

179 Günther, GS Armin Kaufmann, 1989, S. 541, 552.

180 Diesbezüglich BGHSt 33, 142, 145.

181 Günther, GS Armin Kaufmann, 1989, S. 541, 553; siehe auch Baumann/Weber/Mitsch, AT, $₫ 27$ Rn. 29 a.

182 Günther, GS Armin Kaufmann, 1989, S. 541, 553. 
wird, spreche dafür, dass für eine aufeinanderfolgende Versuchskette nichts anderes gelten dürfe. ${ }^{183}$

Zuletzt verdeutlichten auch die Folgen eines übertatbestandlichen Tatbegriffs das Erfordernis einer Identität von „Tat“ und Tatbestand. Versucht der Täter einen Betrug und geht sodann zu einer versuchten räuberischen Erpressung über, so könne der Täter bei diesem Tatverständnis von dem versuchten Betrug nur durch das Ablassen von der räuberischen Erpressung zurücktreten. Ebenfalls sei es auffällig, dass ein Fehlschlag z.B. dann ausscheiden und der Täter straffrei würde, wenn dieser eine sich als Mann herausstellende Frau zu vergewaltigen versucht und er das Opfer, obschon er es könnte, sodann nicht tötet. ${ }^{184}$

(2.). Gegenmeinungen

\section{(a.) Kühl}

Der BGH habe nach Kübl zwar den Wortlaut („Tat=Tatbestand“) auf seiner Seite, jedoch sei dies nicht so eindeutig, wie es auf den ersten Blick erscheine. ${ }^{185}$ Zudem sei der Anspruch, dass derselbe Tatbestand verwirklicht werden müsse, „zu formal, denn ein ,Tatbestandswechsel' ergibt sich oft aus mehr oder weniger zufälligen Differenzierungen der Tatbestände. "“186 Des Weiteren sei das Verständnis des BGH zu eng. Es müssen auch weitere Akte einbezogen werden, sofern sich diese für den Täter ,als einheitliche Fortsetzung desselben Angriffs auf das [sic!] dasselbe Rechtsgut ohne wesentliche planwidrige Abweichungen im Hinblick auf Angriffsobjekt und Angriffsmodalitäten darstellt, sich der Tatbestandswechsel also aus mehr oder weniger zufälligen Differenzierungen der Tatbestände ergibt, wie das zB beim Übergang vom Trickdiebstahl zum Betrug oder vom Raub zur räuberischen Erpressung zutrifft." ${ }^{187}$

183 Günther, GS Armin Kaufmann, 1989, S. 541, 553; siehe hierzu bereits oben, BGHSt 33, 142, 144 (worauf Günther in Fn. 74 auch verweist).

184 Günther, GS Armin Kaufmann, 1989, S. 541, 553.

185 Kübl, AT, \$16 Rn. 46.

186 Kübl, AT, \16 Rn. 46; nach Lackner/Kübl, StGB, \24 Rn. 9 sei dies z.B. bei dem Wechsel von einem Trickdiebstahl zu einem Betrug bzw. von einem Raub zu einer räuberischen Erpressung der Fall; auch Schönke/Schröder/Eser/Bosch, \ 24 Rn. 40; Linke, Rücktritt, S. 103 f.; siehe hierzu auch Streng, NStZ 1985, 358, 360: „Entscheidend würden für Versuchsstrafbarkeit oder Straflosigkeit dogmatische Konstruktionen, denen man unter dem Aspekt von Sinn und Zweck des \24 nur das Prädikat 'zufällig' zuerkennen kann."

187 Lackner/Kübl, StGB, \24 Rn. 9; bzgl. der Wesentlichkeit auch Kübl, AT, \16 Rn. 46. 


\section{(b.) Zaczyk}

Ob der Täter die Tat aufgegeben hat, müsse sich nach Zaçyyk zwar an der Tat im materiell-rechtlichen Sinne orientieren, „,[d]och darf dies nicht als formal eingeschränkt auf den einzelnen Tatbestand verstanden werden, sondern es muss ergänzend auch die Technik der Tatbestände berücksichtigt werden." "188

Stellt die weitere Handlung eine Qualifikation zu dem bereits verwirklichten Delikt dar und ist die Einheitlichkeit des Lebensvorgangs gewahrt, so könne der Täter nicht zurücktreten. Allerdings komme im umgekehrten Fall bei einem Wechsel von der Qualifikation zum Grundtatbestand ein Teilrücktritt in Betracht. Liegen verschiedene Tatbestände vor, dann sei eine Einheitlichkeit, abweichend von der zu formalen Bestimmung anhand des Rechtsguts, zu bejahen und ein Rücktritt folglich zu verwehren, sofern eine Wahlfeststellung möglich ist, also eine „rechtsethische und -psychologische“ Vergleichbarkeit vorliegt. ${ }^{189}$ Im Falle der parallelen Realisierung unterschiedlicher Delikte sei ein individueller und deliktsbezogener Rücktritt möglich. ${ }^{190}$

\section{(c.) Eser/Bosch}

Der Täter müsse die Illegalität verlassen, was erst dann zutreffe, wenn das Ziel des deliktischen Handelns aufgegeben werde. Andererseits seien die Anforderungen an den Rücktritt durch $\int 24$ Abs. 1 StGB und den dortigen Bezug zur „Tat“ begrenzt, wobei die Tat sich durch das Tatobjekt und die beabsichtige Begehungsweise ausgestaltet. ${ }^{191}$ Das Erfordernis einer Aufgabe jedweden weiteren Handlungsinteresses scheide schon aus Gründen der Beweisbarkeit aus. ${ }^{192}$ Für das Aufgeben könne somit nur gefordert werden, dass der Täter ,von dem versuchten und einem etwaigen äquivalenten Angriff auf das gleiche Tatobjekt" Abstand nimmt; dies sei „erforderlich, aber auch ausreichend.“193 „[A]n einer Abstandnahme fehl[t es], wenn der Täter bei Festhalten am Entschluss nur die

\footnotetext{
188 NK-StGB/Zaczy/k, \ 24 Rn. 51.

189 NK-StGB/Zaczyk, \ 24 Rn. 51.

190 NK-StGB/Zaczyk, \ 24 Rn. 51.

191 Schönke/Schröder/Eser/Bosch, \24 Rn. 40.

192 Schönke/Schröder/Eser/Bosch, \ 24 Rn. 40; so auch LK-StGB/Vogler, 10. Aufl. 1985, \ 24 Rn. 79.

193 Schönke/Schröder/Eser/Bosch, \ 24 Rn. 40; so für die Aufgabe bei fortgesetztem deliktischen Handeln auch LK-StGB/Vogler, 10. Aufl. 1985, \ 24 Rn. 79, der auf Küper verweist. Küper, JZ 1979, 775, 780, ,...] [sieht] den einheitsbegründenden Zusammenhang jenseits des raumzeitlichen Handlungskonnexes wesentlich in der qualitativen Gleichartigkeit von Angriffsobjeket und Ausführungsweise [...].“
} 
konkrete Verwirklichungsform aufgibt", was beim Umschwenken vom versuchten Mundverkehr zur Vergewaltigung der Fall sei. ${ }^{194}$

Zudem kritisieren Eser/Bosch wie Kühl195 und Zacsylk ${ }^{196}$ die Formalität der Auffassung des BGH.197

\section{(d.) Rudolphi}

Rudolphi fordert für eine wirksame Aufgabe, dass der Täter es unterlässt, sein angestrebtes Tatziel zu realisieren, wobei der „Gegenstand der Tataufgabe [...] dabei allein die von dem Täter geplante und bereits begonnene konkrete Tat sein [muß]. Eine Tataufgabe ist daher auch dann zu bejahen, wenn der Täter von der weiteren Ausführung seiner geplanten konkreten Tat nur deshalb endgültig Abstand nimmt, um später eine a n d e r e, d. h. in ihrem Angriffsziel oder ihrer Begehungsweise davon wesentlich abweichende Tat zu begehen." "198

Die Endgültigkeit der Tataufgabe bedeute hingegen nur, ,dass die der weiteren Tatverwirklichung entgegenstehenden Motive ein Übergewicht über die zur weiteren Tatverwirklichung hindrängenden Motive gewinnen." "199 Dies reiche aus, denn in solch einem Fall habe der Täter seinen Entschluss zur Tatverwirklichung aufgegeben. ${ }^{200}$ Lässt der Täter hingegen von der konkreten Ausführungshandlung nur $a b$, ,weil der Täter glaubt, daß er sein Tatziel an einem anderen Ort oder zu einer anderen Zeit leichter oder mit geringerem Risiko erreichen kann, so hat er nämlich seine Entscheidung für die Verwirklichung der von ihm geplanten konkreten Tat gerade noch nicht revidiert und sich nunmehr gegen diese entschieden." ${ }^{201}$ Ein Rücktritt müsste somit verneint werden. Im Unterschied hierzu sei jedoch dann eine Aufgabe anzunehmen, wenn den Täter der Mut verlässt und sich deswegen von der weiteren Ausführung distanziert, in der Hoffnung am nächsten Tag die erforderliche mentale Kraft aufzubringen. Hier sei aufgrund des Überwiegens der entgegenstehenden Motive ein Rücktritt zu bejahen. ${ }^{202}$ Vor allem „die ratio des $\$ 24$, derzufolge danach zu differenzieren ist, ob der Täter durch die Aufgabe der konkreten Tatausführung wieder auf den Boden des Rechts zurückgekehrt ist und

194 Schönke/Schröder/Eser/Bosch, \24 Rn. 40; in Schönke/Schröder/Eser, 28. Aufl. 2010, \24 Rn. 40 sollte Gleiches für den Fall gelten, wenn das Geschehen von einem Gesamtvorsatz getragen ist und der Täter nur von einer Handlung absieht, um sich einer schon festgesetzten ähnlichen Ausführungsmodalität zu bedienen.

195 Siehe S. 54 f.

196 Siehe S. 55.

197 Schönke/Schröder/Eser/Bosch, \ 24 Rn. 40.

198 SK-StGB/Rudolphi, \24 Rn. 18.

199 SK-StGB/Rudolphi, \24 Rn. 18 a.

200 SK-StGB/Rudolphi, \24 Rn. 18 a.

201 SK-StGB/Rudolphi, \$24 Rn. 18 a.

202 SK-StGB/Rudolphi, \24 Rn. 18 a. 
sich damit als ungefährlich erwiesen hat und daher eine Strafe weder aus spezialnoch aus generalpräventiven Gründen erforderlich ist" rechtfertige diese dahingehend differenzierte Auffassung. ${ }^{203}$

Sieht der vom Täter gefasste Tatplan mehrere Tatbestandsverwirklichungen vor, so komme es nach Rudolphi für einen Rücktritt darauf an, ob dieser individuell auf den jeweiligen Tatbestand bezogen vorliegt. Für das Beispiel des $\mathrm{BGH}^{204}$, dass ein Raub mit Mordmitteln versucht wird, der Täter bzgl. des Mordes jedoch ablässt, kommt bzgl. des Mordes ein Rücktritt in Betracht. ${ }^{205}$ Auch eröffnet Rudolphi dem Täter einen Teilrücktritt von einer Qualifikation. ${ }^{206}$

Hierneben sei die Freiwilligkeit des Rücktritts zudem dann nicht pauschal ausgeschlossen, wenn der Täter im Versuchsstadium das Delikt wechselt. Denn obwohl der Täter weiterhin deliktisch handele, erkenne der Delinquent die zuvor durch den Versuch verletzte Strafrechtsnorm wieder an. Einer Bestrafung bedürfe es diesbezüglich somit nicht. ${ }^{207}$

\section{(e.) Streng}

Ebenso spricht sich auch Streng gegen den BGH aus. ${ }^{208}$ Er kritisiert die Position des BGH dahingehend, dass die Begründung dieser Annahme u.a. auf die Verknüpfung des $\int 24$ mit $\iint 22,23$ StGB gestützt wird. „Denn daß es im Ergebnis beim Rücktritt immer um die Straflosigkeit bezüglich eines konkreten Verbrechens oder Vergehens - d. h. bezüglich eines bestimmten gesetzlichen Straftatbestandes - geht, versteht sich von selbst und bedarf keiner weiteren Absicherung durch Verweis auf die $\iint 22,23 . " 209$ Zudem sei es nicht fruchtbar, die Bestimmung des $\int 24$ StGB durch weitere Normen vorzunehmen, da die Voraussetzungen des Rücktritts aus der Vorschrift selbst resultieren müssen. ${ }^{210}$ Ebenfalls sei zu erkennen, dass der Tatbegriff des $\int 24$ StGB in den $\iint 22,23$ StGB „keine derart eindeutige Entsprechung [besitzt], daß sich daraus eine Klärung des Tatbegriffs ergeben könnte. “211 Denn in $\int 22$ StGB werde sowohl auf den Tatbestand an sich, als auch auf die Vorstellung des Täters von der Tat abgestellt. Gerade dieser subjektive Bezug könne auch dahingehend verstanden werden, dass hiermit ein Geschehensablauf gemeint ist, der auch mehrere Tatbestände umfasst. ${ }^{212}$

\footnotetext{
203 SK-StGB/Rudolphi, 』 24 Rn. 18 a.

204 Siehe S. 49 f.

205 SK-StGB/Rudolphi, \ 24 Rn. 18 b.

206 SK-StGB/Rudolphi, \ 24 Rn. 18 b.

207 SK-StGB/Rudolphi, S 24 Rn. 18c.

208 Streng, NStZ 1985, 358, 359 ff.

209 Streng, NStZ 1985, 358, 359.

210 Streng, NStZ 1985, 358, 359.

211 Streng, NStZ 1985, 358, 359.

212 Streng, NStZ 1985, 358, 359.
} 
Nicht zuletzt sprächen die sich aus der Auffassung des BGH ergebenen Folgen gegen dessen Lösung:

\section{Bsp.: Einbrecher E versucht einen verschlossenen Tresor zu öffnen, lässt jedoch aufgrund der biermit verbundenen Mühen ab, um auf den nächsten Morgen zu warten, an dem er, wie geplant, den Eigentümer zum Öffnen des Schranks mit Waffengewalt zwingt.213}

Der Täter würde mit dem BGH in Bezug auf den versuchten ersten Abschnitt straffrei, da durch die weitere Handlung nicht noch einmal ein Diebstahl verwirklicht würde. ${ }^{214}$ Hingegen müsste mit der Auffassung des BGH dann anders entschieden werden, wenn der Täter anstatt zu einer räuberischen Erpressung zu einem Raub übergegangen wäre. Ein Rücktritt scheide dann aus, da im Rahmen des Raubs auch der Diebstahl verwirklicht ist. ${ }^{215}$

Diese Differenzierung sei vor allem unter Berücksichtigung des Sinn und Zwecks des \24 StGB ein befremdliches Ergebnis. Denn der Rücktritt setze doch voraus, dass der Täter die Rechtsordnung wiederum anerkennt. „Für einen Rücktritt fehlt es bei Steigerung des Unwerts, d.h. bei nahtloser Fortführung des Rechtsgutsangriffs auf höherem Niveau, folglich immer an der wichtigsten Grundvoraussetzung." ${ }^{216}$ Die vom BGH vorgesehene Differenzierung nach dem Fortsetzen desselben Tatbestands ,ist somit schon im Ansatz verfehlt" “.217

Des Weiteren führe im Beispiel die räuberische Erpressung den durch den Diebstahlsversuch begonnenen Rechtsgutsangriff auf das Vermögen fort. ${ }^{218}$ Das erste Delikt sei gegen Eigentum und Gewahrsam gerichtet, wobei der zweite Akt das Vermögen und die persönliche Freiheit verletze, jedoch gleichermaßen, im Verhältnis zum Wechsel von einem Diebstahl zu einem Raub, dieselbe Angriffsrichtung auf das Eigentum und den Gewahrsam an den im Tresor verwahrten Werten fortbestehe. ${ }^{219}$

213 Streng, NStZ 1985, 358, 359, wobei Streng von einem räumlichen und zeitlichen Zusammenhang zwischen den Akten ausgeht.

214 Streng, NStZ 1985, 358, 359.

215 Streng, NStZ 1985, 358, 359; dieser Umstand wird auch von Linke, Rücktritt, S. 104 aufgegriffen. Insoweit verweist Linke, Rücktritt, Fn. 642 auf Wessels, AT, 15. Aufl. 1985, \14 IV 4. Wessels stellt heraus, dass ein Rücktritt bei einem Wechsel von einem Betrugsversuch zu einem Raub ausscheiden müsse. Dass dies der Fall sei, „dürfte einleuchten.“

216 Streng, NStZ 1985, 358, 359 f.; siehe hierzu auch Linke, Rücktritt, S. 104, die die Rückkehr in die Legalität herausstellt.

217 Streng, NStZ 1985, 358, 359 f.

218 Streng, NStZ 1985, 358, 359.

219 Streng, NStZ 1985, 358, 360. 
Ebenfalls könne es durch die Auffassung des BGH zu einer vollständigen Straflosigkeit kommen. Dies wäre der Fall, wenn die zweite geplante Tat noch im Vorbereitungsstadium stecken bleibe. Dann nämlich sei der Täter bzgl. der ersten Tat strafbefreiend zurückgetreten, wohingegen das weitere Verhalten noch keine strafrechtliche Relevanz entfalte. Den Sinn und Zweck des Rücktritts gänzlich ausgeblendet, werde allein der Tatbestandswechsel honoriert. Ob eine Versuchsstrafbarkeit vorliegt, hinge allein von „dogmatische[n] Konstruktionen [ab], denen man unter dem Aspekt von Sinn und Zweck des \ 24 nur das Prädikat 'zufällig' zuerkennen kann. “220

Aber nicht nur diese Bedenken sprechen nach Streng gegen die Auffassung des BGH. So bleibe zudem der Umstand des „raum-zeitlichen Handlungskonnexes“ gänzlich außen vor, wobei dieser Umstand für die Bewertung der Einheitlichkeit selbst vom BGH nicht abgelehnt werde. Denn liegt ein materieller Tatbestand vor und ist ein Zusammenhang in diesem Sinne gegeben, so handele es sich um eine Tat i.S. des $\int 24$ StGB. ${ }^{221}$

Dem Argument, der Tatbegriff des BGH sei erforderlich, um dem Raubmörder einen Rücktritt vom versuchten Mord zuzubilligen, tritt Streng damit entgegen, dass hierfür ein ,'Teilrücktritt“ ausreiche. ${ }^{222}$

Trotz der Kritik kommt Streng im Vergewaltigungsfall zu demselben Ergebnis wie der BGH. So habe der Täter durch den Wechsel zu der Vergewaltigung nicht gezeigt, dass er das durch die erste Handlung angegriffene Rechtsgut wieder anerkennt, weswegen ihm ein Rücktritt nicht zu Gute kommen könne. Der Umstand, dass der Täter im konkreten Fall den äußerst belastenden und erniedrigenden Mundverkehr nicht erzwungen hat, könne aber positiv in die Strafzumessung einfließen. ${ }^{223}$ Eine Strafschärfung hingegen scheide aus, da der Mundverkehr und somit die besonders belastende Situation tatsächlich nicht entstanden ist und die Rechtsgutsverletzung „,voll über die Strafe der Vergewaltigung erfasst wird.“ Es müsse in solchen Konstellationen beachtet werden, dass belastende Umstände nicht doppelt in die Strafzumessung einfließen. ${ }^{224}$

\footnotetext{
220 Streng, NStZ 1985, 358, 360.

221 Streng, NStZ 1985, 358, 360.

222 Streng, NStZ 1985, 358, 360 der zugleich auf LK-StGB/Vogler, 10. Aufl. 1985, 』 24 Rn. 208 verweist; siehe auch Scheinfeld, Tatbegriff, S. 4, m.w.N. in Fn. 9.; zum Teilrücktritt schon Rudolphi S. 57.

223 Streng, NStZ 1985, 358, $360 \mathrm{f}$.

224 Streng, NStZ 1985, 358, 361; siehe auch BGHSt 33, 142, 146 f.
} 


\section{(f.) Herzberg}

Im Ergebnis gleichlaufend zur Auffassung des BGH eröffnet Herz̧berg dem Täter bei einem Wechsel von einem versuchten Betrug zu einem Raub225 die Möglichkeit eines Rücktritts von dem versuchten ersten Delikt. ${ }^{226}$

Zur Verdeutlichung, dass diese Entscheidung richtig sei und eine vollständige Rückkehr in die Legalität nicht gefordert werden könne, wandelt Herz̧berg den Fall $\mathrm{ab}$ :

\section{Bsp.: Der Täter will anstatt durch den bereits versuchten Betrug lieber durch einen Raub zum Erfolg kommen. Von diesem Vorbaben lässt er jedoch schon vor Eintritt in den Raubversuch ab. ${ }^{227}$}

Würde aufgrund des Deliktvorbehalts der Rücktritt verneint, so führte allein die Vorstellung von einem weiteren deliktischen Verhalten zu einer Strafbarkeit, was eine „getarnte Bestrafung des bösen Willens“ zur Folge hätte. ${ }^{228}$ Im Übrigen könne eine „Rückkehr in die Legalität“ nicht gefordert werden. Denn wird dem Täter der Rücktritt vom versuchten ersten Delikt aufgrund des Versuchs eines anderen Tatbestands verwehrt, so sei dies dann problematisch, wenn von dem zweiten Versuch strafbefreiend zurückgetreten wird. Die Strafbarkeit wegen des ersten Versuchs bliebe dann, obschon sich der Täter wieder vollständig rechtstreu verhält, bestehen. ${ }^{29}$ Zudem sei das Erfordernis einer Rückkehr in die Legalität oder äquivalenter Voraussetzungen schon an sich bedenklich. Anstatt einem Gesetz eine Ratio zu unterstellen und diese sodann auf problematische Konstellationen zu übertragen, müsse gerade umgekehrt verfahren werden. „Erst aus sachgerechten Lösungen von Fall zu Fall, die streng am Gesetzeswortlaut zu messen sind, kann man, unter dem Vorbehalt jederzeitiger Korrektur, die ratio langsam erschließen und genauer bestimmen. " ${ }^{230}$ Für $\int 24$ StGB bedeute dies, dass die unterstellte Ratio nur noch in einer äußerst eingeschränkten Form erhalten bleiben kann. So könne eine Rückkehr in die Legalität weiterhin gefordert werden, jedoch müsse es ausreichen, dass bezüglich des einen Delikts in die Rechtmäßigkeit zurückgefunden wurde und nicht insgesamt. ${ }^{231}$

225 Wessels, AT, 14. Aufl. 1984, \ 14 IV 4.

226 Herzberg, GS H. Kaufmann, 1986, S. 709, 714.

227 Herzberg, GS H. Kaufmann, 1986, S. 709, 714.

228 Herzberg, GS H. Kaufmann, 1986, S. 709, 714 f.

229 Herzberg, GS H. Kaufmann, 1986, S. 709, 714 f. Diese Kritik bezieht sich jedoch nicht auf den Tatbegriff, sondern richtet sich vielmehr gegen eine abstrakte Betrachtungsweise.

230 Herzberg, GS H. Kaufmann, 1986, S. 709, 716.

231 Herzberg, GS H. Kaufmann, 1986, S. 709, 716. 
Im Folgenden grenzt sich Herz̧berg weiter vom BGH ab, denn „[d]ie Beachtlichkeit auch eines Verzichtes mit Deliktsvorbehalt erklärt sich nicht daraus und ist nicht darauf beschränkt, daß die versuchte Tat und das neu beschlossene Delikt verschiedenen Tatbeständen unterfallen“.232 Gleiches könne auch dann auftreten, wenn der Täter zweimal hintereinander dasselbe Delikt anstrebt.

\section{Bsp.: Reinigungskeraft P versucht ein Schmuckstück ibrer Dienstherrin D qu entwenden, lässt jedoch aus Scham ab, um sich hierfür später mit einem Griff in D's Geldbörse zu belohnen. 233}

Auch hier erscheine ein Rücktritt fraglich. Es müsse das Gleiche gelten wie bei einem Deliktswechsel. „Die Skrupel beim ersten Ansetzen zum Diebstahl haben P freiwillig in den straffreien Bereich bloßer Tatentschlossenheit und damit auch (zwar nicht der Gesinnung, wohl aber) dem äußeren Verhalten nach ,in die Legalität' zurückkehren lassen. “234 Ob die Reinigungskraft versucht, eine andere Sache an sich zu nehmen, um diese für sich zu behalten, habe für den Rücktritt vom vorangegangenen Akt keine Auswirkungen, selbst dann nicht, wenn zwischen diesen Akten eine Handlungseinheit besteht. Anderenfalls wäre P gleich einer Täterin zu behandeln, der die Vollendung, etwa durch Entdeckung, nicht mehr möglich ist. ${ }^{235}$ Solch ein Verständnis hätte zur Konsequenz, dass allein „unter dem Deckmantel der Bestrafung eines vergangenen Versuchs ein übriggebliebener böser Wille bestraft wird, der sich in keiner Handlung manifestiert hat."236 Zudem würde P, sofern sie einen weiteren Diebstahl versucht oder vollendet, so bestraft, „als habe sie Geld und Schmuck gestohlen oder zu stehlen versucht.“"237

Gegen die Berücksichtigung einer weiteren Handlung sprächen zudem die „verschiedenen Ebenen der Aktualität und der Potentialität [...]. Man kann daraus, daß ein real getätigter Einzelakt eventuell, d. h. im Fall der Realisierung auch des geplanten weiteren Handelns, seine Eigenbedeutung verlieren würde, nicht schließen, daß er schon jetzt nur unselbständiger Teil einer Handlungseinheit ist.“238

Zudem ergäben sich „schwere Mängel“. Es mache keinen Sinn und stelle keinen Gewinn dar, an einer „Strafbarkeit trotz des freiwilligen Zurückweichens“ festzuhalten. Wird der Vorbehalt des weiteren Handelns realisiert, so falle gegenüber der versuchten oder vollendeten weiteren Straftat der vorherige Versuch

\footnotetext{
232 Herzberg, GS H. Kaufmann, 1986, S. 709, 718.

233 Zum Fall Heraberg, GS H. Kaufmann, 1986, S. 709, 718.

234 Herzberg, GS H. Kaufmann, 1986, S. 709, 718.

235 Herzberg, GS H. Kaufmann, 1986, S. 709, 719.

236 Herzberg, GS H. Kaufmann, 1986, S. 709, 719.

237 Herzberg, GS H. Kaufmann, 1986, S. 709, 719.

238 Herzberg, GS H. Kaufmann, 1986, S. 709, 722.
} 
nicht ins Gewicht. Dies dürfe die Strafhöhe betreffend keine Nachteile für den Täter haben, wohingegen ein erfolgter Rücktritt auf beide Abschnitte Auswirkungen besäße. ${ }^{239}$ Bliebe der Vorbehalt der weiteren Ausführung jedoch nur eine Idee des Täters, so käme es für die Aufgabe allein auf seine diesbezüglichen Einlassungen an. Gibt er an, dass er ,zu einem neuen Anlauf nur [...] geneigt, aber noch nicht ,entscblossen ${ }^{6}[. .$.$] [war], so wird die Bestrafung fast immer daran scheitern, daß die$ Grundvoraussetzung für die Annahme eines Versuchs, die Tatentschlossenheit, unbeweisbar ist.“240 Räumt der Täter den Tatentschluss aber ein oder wird dieser nachgewiesen, so folge eine strafrechtliche Relevanz und eine „materielle[...] Ungerechtigkeit [...]. Denn ein Versuchstäter, der freiwillig in den Bereich bloßer Vorbereitung zurückgekehrt ist, würde behandelt wie jemand, der mit seinem Versuch gescheitert ist oder ihn unfreiwillig abgebrochen hat.“241

Aus diesen Gründen sei für den Rücktritt allein entscheidend, „ob der Rückzug den Täter aus der Versuchssituation wieder herausfübrt.“242 „Denn der Rücktritt ist gewissermaßen die Umkehrung des Versuchs. So, wie trotz fester Deliktsentschlossenheit erst das ,Ansetzen ' den Verlust der Straffreiheit bewirkt, so muß umgekehrt das freiwillige, die unmittelbare Gefahr beendende ,Absetzen “ auch die Wiedererlangung der Straffreiheit bedeuten.“243

Ein Ablassen und somit ein Rücktritt wäre folglich gegeben, wenn sich der Täter bzgl. des nächsten Aktes noch in einem „Vorbereitungsstadium“ befindet. Hat der Täter hingegen die Versuchsphase betreten, so müsse ein Rücktritt verneint werden. ${ }^{244}$

Herzberg stellt sodann bezogen auf die Entscheidung des BGH fest, dass dieser ein falscher „Maßstab der Handlungseinheit (zwischen aufgegebenem und geplantem Handeln)“" zugrunde liege. Das Ergebnis sei jedoch trotzdem richtig, denn subjektiv bestand das Ziel der Befriedigung des Geschlechtstriebs unentwegt fort, was der Täter durch die Anwendung von Gewalt kontinuierlich zu realisieren versuchte. Der Täter sei durch das Ablassen vom Oralverkehr mithin nicht strafbefreiend zurückgetreten und habe sich gem. $\iint 178,22,23$ Abs. 1 StGB strafbar gemacht. 245

239 Herzberg, GS H. Kaufmann, 1986, S. 709, 722

240 Her₹berg, GS H. Kaufmann, 1986, S. 709, 722.

241 Herzberg, GS H. Kaufmann, 1986, S. 709, 723.

242 Herzberg, GS H. Kaufmann, 1986, S. 709, 723.

243 Herzberg, GS H. Kaufmann, 1986, S. 709, 723 f.

244 Herzeberg, GS H. Kaufmann, 1986, S. 709, 723 f. (mit Beispielen; siehe auch S. 725), 735; siehe hierzu auch Murmann, Versuchsunrecht und Rücktritt, S. 46 ff., der im Rahmen des vorläufig fehlgeschlagenen Versuchs eine einheitliche Tat bejaht, wenn der Täter im Zeitpunkt des Fehlschlags schon unmittelbar zum nächsten Akt angesetzt hat (S. 47 f.); ders., GA 2012, 711, 721. Die Zäsurwirkung eines Deliktswechsels lässt Murmann jedoch offen. 


\section{(g.) Linke}

Auch nach Linke sei die Herleitung des Tatbegriffs aus der Verbindung von $\ 24$ mit den $\iint 22,23$ StGB kritisch zu sehen, da dort keine Definition der Tat vorhanden sei. Vor allem $\int 22$ StGB könne nicht herangezogen werden, da die Tat hier durch die Vorstellung des Täters subjektiviert werde. ${ }^{246}$ Des Weiteren kritisiert Linke gleichfalls, dass das Kriterium des Tatbestandswechsels zu formal sei und sich der Tatbestandswechsel häufig ,,aus mehr oder weniger zufälligen Differenzierungen“ ergebe. ${ }^{247}$ Abgestellt werden solle vielmehr ,auf den engen räumlichen und zeitlichen Zusammenhang, die ähnliche Angriffsrichtung und das im Wesentlichen gleiche Tatobjekt. "248 Hiergegen könne nicht angeführt werden, dass dadurch der Opferschutz, Strafzwecke oder Schuldausgleichsaspekte umgangen würden, denn der Täter befinde sich fortwährend im Versuchsstadium. ${ }^{249}$ Die Vorstellungen des Täters, die den Vorsatz begründen, müssten zudem keinen konkreten Deliktsbezug aufweisen, sodass auch aus diesem Grund die Auffassung des BGH abzulehnen sei. „Für den Vorsatz ist nicht erforderlich, dass die Vorstellung des Täters mehr umfasst als eine in ihren Grundzügen, das heißt in ihrem Unrechtsgehalt und ihrer Angriffsrichtung bestimmte Tat; die genaue Kenntnis des zu verletzenden Straftatbestands ist nicht erforderlich, weswegen geringfügigen Modifikationen, die mitunter unintendiert erfolgen, nicht unbedingt ein unrechtsreduzierender Zweck innewohnt, mag er auch objektives Ergebnis sein. "250

Auch komme es zu unberechtigten Privilegierungen. So könne der Täter von dem ersten versuchten Delikt allein dann zurücktreten, wenn dieses von dem zweiten Delikt nicht umfasst wird. „,[A]llein der Wechsel von einem Tatbestand zum anderen [wird] privilegiert, ohne zu beachten, dass durch die Strafbefreiung beim Rücktritt (auch) die Rückkehr in die Legalität belohnt werden soll.“251 Es komme hierdurch zu „zufälligen Differenzierungen“, sofern das weitere Delikt nicht ins Versuchsstadium gelangt. ${ }^{252}$

Mit dem BGH könne es für die Einheitlichkeit sodann auch nicht mehr auf einen zeitlichen und räumlichen Zusammenhang ankommen und das, „obwohl sich ein solcher streng genommen aus der Begründung über $\iint 22,23$ ergibt, da für das unmittelbare Ansetzen eine (aus Sicht des Täters) unmittelbare Gefährdung des geschützten Rechtsgut verlangt wird." 253

Ebenfalls sei es widersprüchlich, dass der BGH einen zwischenzeitlichen Rücktritt aufgrund eines einheitlichen Entschlusses ablehnt, obschon ein Tatbe-

\footnotetext{
246 Linke, Rücktritt, S. 103; zu diesem Argument bereits Streng (S. 57).

247 Linke, Rücktritt, S. 103 f.; so schon Kühl (S. 54), Zaczyk (S. 55), Eser/Bosch (S. 56).

248 Linke, Rücktritt, S. 104.

249 Linke, Rücktritt, S. 104.

250 Linke, Rücktritt, S. 104.

251 Linke, Rücktritt, S. 104; siehe Streng (S. 58).

252 Linke, Rücktritt, S. 104.

253 Linke, Rücktritt, S. 105.
} 
standswechsel vorliegt. Nach Auffassung des BGH hätte der Täter durch den Wechsel vom Vergewaltigungsversuch zum Versuch des zwangsweisen Mundverkehrs zurücktreten müssen. ${ }^{254}$ „Indem der BGH jedoch verdeckt davon ausgeht, fordert er letztendlich nicht [sic!] anderes als eine Unterbrechung des räumlichzeitlichen Handlungskonnexes. "255

Zudem würden die eigenen Grundsätze vom BGH missachtet:

BGH: Der Täter wollte das Opfer verbrennen und übergoss es mit Benzin. Als das Anzünden misslang und sich das Opfer in den Garten retten konnte, würgte er das Opfer, ließ hiervon jedoch nach kurzer Zeit ab.256

Der BGH bewertet beide Abschnitte als einheitliche Tat, sodass der Täter durch das Ablassen vom Würgen vollständig zurücktreten konnte. ${ }^{257}$ Dies widerspreche nach Linke allerdings dem grundsätzlichen Verständnis des BGH. Durch den ersten Akt sei das Mordmerkmal ,grausam“ erfüllt, sodass sich der Täter wegen versuchten Mords gem. $\int \$ 211$ Abs. 2, 22, 23 Abs. 1 StGB strafbar gemacht hätte. Hingegen stelle das Würgen allein einen versuchten Totschlag dar, sodass, unter der Annahme der deliktischen Eigenständigkeit, ein Deliktswechsel vorliege.258 Eine Einheitlichkeit scheide aus. ${ }^{259}$ Folglich sei der versuchte Mord durch das Übergießen mit dem Benzin fehlgeschlagen und ein Rücktritt nicht möglich. ${ }^{260}$ Sofern dem Täter hier jedoch trotzdem ein vollständiger Rücktritt aufgrund bestehender Einheitlichkeit eingeräumt wird, so dürfe für den Wechsel von einem Betrug zu einer Erpressung nichts anderes gelten. Die Einheitlichkeit bestehe trotz des Tatbestandswechsels fort, „da das Vorhaben des Täters das ,SichVerschaffen eines Vermögensvorteils" das gleiche geblieben ist, und lediglich die Art der Verschaffung von Täuschung zur Drohung oder Gewaltanwendung wechselt.“261

Neben diesen Kritikpunkten sei der Argumentationsweg in einem weiteren Urteil , unnötig kompliziert und widersprüchlich“.262 So bejahte der BGH die Aufgabe im Rahmen des $₫ 31$ Abs. 1 Nr. 3 StGB, obschon der weiteren Ausführung des

\footnotetext{
254 Linke, Rücktritt, S. 105.

255 Linke, Rücktritt, S. 105.

256 BGH, NStZ 1986, $264 \mathrm{f}$.

257 BGH, NStZ 1986, 264, 265; siehe auch Linke, Rücktritt, S. 105 f.

258 Linke, Rücktritt, S. 105, die zum Verhältnis von Mord und Totschlag auf BGHSt 1, 368 und BGHSt 22, 375 verweist.

259 Linke, Rücktritt, S. 105 f.

260 Linke, Rücktritt, S. 106.

261 Linke, Rücktritt, S. 106.

262 Linke, Rücktritt, S. 106.
} 
Mittäters, aufgrund eines Exzesses. ${ }^{263}$ Durch die vom BGH vorausgesetzte Kongruenz zwischen dem Tatbegriff des $\int 24$ und $\int 31$ StGB wäre es hingegen nach Linke nur konsequent gewesen, die Zäsur mit dem vorhandenen Deliktswechsel zu begründen. „Hier hat wohl der BGH erkannt, dass insbesondere bei Beteiligung Mehrerer das Abstellen allein auf den Begriff der Tat im materiellrechtlichen Sinne für den Rücktritt nicht zu adäquaten Ergebnissen führt. Ausdrücklich genannt hat er aber die zu beachtenden Unterschiede von \ 24 I und \ 24 II nicht. "264

Des Weiteren widerspreche es der Gleichsetzung von Tat und Tatbestand, wenn im Fall des Eintritts der Erfolgsqualifikation des \ 251 StGB „das Aufgeben der Diebstahls- (bzw. Raubkomponente)“ für einen Rücktritt ausreiche. ${ }^{265}$ Es fehle am erforderlichen Tatbestandswechsel. Durch \ 11 Abs. 2 StGB würden das Grunddelikt und die Erfolgsqualifikation zu einer neuen Tat vereinigt, sodass ein insgesamt wirkender Rücktritt sich auch auf beide Komponenten beziehen müsse. Dafür, dass allein das Grunddelikt maßgeblich sei, spreche weder $\int 24$ StGB noch ergebe sich dies aus Art. 103 Abs. 2 GG. ${ }^{266}$ Der Rücktritt ließe sich allein mit der Feststellung Strengs rechtfertigen, dass zu den Theorien des 19. Jahrhunderts zurückgekehrt werden müsse, wonach durch die Tataufgabe auch das Versuchsunrecht entfällt. ${ }^{267}$ Dies sei jedoch mit $\int 24$ StGB und dessen Selbstständigkeit ,gegenüber dem vorangegangenen Versuch" nicht zu vereinbaren. Anderenfalls sei auch $\int 24$ Abs. 2 StGB sinnlos, da jeder Teilnehmer selbst zurücktreten muss und der Rücktritt eines Haupttäters auf diese gerade keine Auswirkung besitzt. ${ }^{268}$

\section{cc. Streitentscheid}

Wie sich aus dem dargestellten Meinungsspektrum ergibt, ist die von dem BGH vorgenommene Gleichschaltung von Tat und materiell-rechtlichem Tatbestand in der Literatur stark umstritten. Insoweit ist es geboten, sich mit den einzelnen Auffassungen im Detail auseinanderzusetzen, um die individuelle Überzeugungskraft zu prüfen.

\footnotetext{
263 BGH, NStZ 1992, 537 f.; vgl. Linke, Rücktritt, S. 106.

264 Linke, Rücktritt, S. 106 f.

265 Linke, Rücktritt, S. 107; so BGHSt 42, 158, 160.

266 Linke, Rücktritt, S. 107; \11 Abs. 2 führt auch Bacher, Versuch und Rücktritt vom Versuch beim erfolgsqualifizierten Delikt, S. 210 für das Vorliegen einer Tat an.

267 Siehe Streng, FS Küper, 2007, S. 629, 635 auf den Linke, Rücktritt, S. 107 verweist.

268 Linke, Rücktritt, S. 107; siehe auch Streng, FS Küper, 2007, S. 629, 653: „Die Rechtstheorien und auch deren moderne Ableger des 20. Jahrhunderts verfielen schon deshalb der Kritik, weil bei deren Zugrundelegung ein Rücktritt des Haupttäters durch Eliminierung der ,rechtswidrigen Tat' auch zur Straflosigkeit der nicht zurückgetretenen Teilnehmer führen musste.“
} 


\section{(1.) Allgemeine Würdigung der Entscheidung des $\mathrm{BGH}^{269}$}

Der BGH beschäftigt sich primär mit dem Rücktritt von dem versuchten Mundverkehr (\$ 178 StGB a.F.). Ob der Täter jedoch durch den Wechsel zum Mundverkehr von dem vorherigen Abschnitt zurückgetreten ist, bleibt unbeachtet. ${ }^{270}$

Richtig wäre dies, wenn das vorangegangene Geschehen keine strafrechtliche Relevanz hätte. Vorliegend fasste der Täter den Entschluss, mit dem Opfer den Geschlechtsverkehr durchzuführen und wenn nötig, dies mit Gewalt und Bedrohung mit einem Messer zu ermöglichen, ${ }^{271}$ sodass bereits zu diesem Zeitpunkt der Tatentschluss, bezogen auf eine Vergewaltigung, vorlag. Daneben müsste für die Strafbarkeit des Versuchs aber auch gem. \22 StGB unmittelbar zur Tat angesetzt worden sein. „Dafür ist nicht erforderlich, dass der Täter bereits ein Tatbestandsmerkmal verwirklicht. Es genügt, dass er Handlungen vornimmt, die nach seinem Tatplan der Erfüllung eines Tatbestandsmerkmals vorgelagert sind und in die Tatbestandshandlung unmittelbar einmünden, die mithin - aus der Sicht des Täters - das geschützte Rechtsgut in eine konkrete Gefahr bringen. Dementsprechend erstreckt sich das Versuchsstadium auf Handlungen, die im ungestörten Fortgang unmittelbar zur Tatbestandserfüllung führen sollen oder die im unmittelbaren räumlichen und zeitlichen Zusammenhang mit ihr stehen. Dies ist der Fall, wenn der Täter subjektiv die Schwelle zum, jetzt geht es los'überschreitet und objektiv zur tatbestandsmäßigen Angriffshandlung ansetzt, so dass sein Tun ohne Zwischenakte in die Tatbestandserfüllung übergeht.“272 Vorliegend hat der Täter das Opfer mit einem Messer gejagt, um den Geschlechtsverkehr vollziehen zu können. Die Handlung sollte unmittelbar und ohne wesentliche Zwischenschritte in die Vergewaltigung und somit in die Tatbestandsverwirklichung einmünden. Durch das Jagen mit dem Messer reduzieren sich die Widersetzungsmöglichkeiten im Hinblick auf den sexuellen Übergriff, weswegen hierdurch die sexuelle Selbstbestimmung konkret gefährdet wird. Ein unmittelbares Ansetzen ist gegeben. In Verbindung mit dem bestehenden Tatentschluss hat der Täter sich bereits durch das Verfolgen mit dem Messer wegen versuchter Vergewaltigung strafbar gemacht.

Aufgrund des folgenden Wechsels zum versuchten Mundverkehr ist zu entscheiden, ob der Täter hierdurch von der Vergewaltigung zurücktreten konnte. Hierauf geht der BGH jedoch nicht ein. Überzeugen kann die Lösung des BGH sodann nur noch, wenn davon ausgegangen wird, dass das Gericht zwischen diesem Versuch und der späteren vollendeten Vergewaltigung einen einheitlichen Lebensvorgang annahm und eine isolierte Versuchsstrafbarkeit deswegen unbeachtet ließ.

\footnotetext{
269 BGHSt 33, 142 ff.

270 Siehe hierzu Linke, Rücktritt, S. 105.

271 BGHSt 33, 142, 143.

272 BGH, NStZ 2013, 156, 157.
} 
Abseits dieses Aspekts bietet die versuchte sexuelle Nötigung einen weiteren Anknüpfungspunkt für eine kritische Betrachtung. Der BGH problematisiert, ob der Täter durch den Übergang zur vollendeten Vergewaltigung die Tat aufgegeben hat, wobei zutreffend erkannt wird, dass keine Aufgabe vorliegt, wenn eine im Anschluss vorgenommene Handlung Teil derselben Tat i.S. des $\int 24$ Abs. 1 StGB ist. ${ }^{273}$ Unbeachtet bleibt hierbei allerdings die Vollendung des Delikts. Wird die Aufgabe der Tat verneint, weil der Täter dieselbe Tat fortsetzt, so muss sich bei späterer Vollendung bereits zuvor die Frage stellen, ob überhaupt ein separierter Versuch vorliegt, was weit vor der Rücktrittsfrage hätte entschieden werden müs$\operatorname{sen}^{274}$. Wie nämlich richtig erkannt wurde, verwirklicht der Täter durch die Vergewaltigung ebenfalls den Tatbestand der sexuellen Nötigung gem. \178 StGB a.F.275 Wird deswegen eine Aufgabe verneint, so kann schon, aufgrund der Tatidentität, gar kein eigenständiger Versuch vorliegen. Auf diesen Umstand geht der BGH nicht ein, wobei die zuständige Staatsanwaltschaft das Problem der Mehraktigkeit gänzlich verkennt und allein die Freiwilligkeit im Rahmen des Ablassens verneint. ${ }^{276}$

Auch wenn in dieser Entscheidung die Ausführungen zur Einheitlichkeit falsch verortet wurden, ändert dies nichts an der eigentlichen Tatbestimmung. Die so determinierte Tatreichweite müsste bei gleicher Sachlage auch in anderen Konstellationen wiederzufinden sein: ${ }^{277}$

273 BGHSt 33, 142, 144 ff.

274 Siehe zur Prüfung der Nichtvollendung Murmann, Grundkurs, \ 28 Rn. 35; LKStGB/Hillenkamp, \ 22 Rn. 10: „Anlass zu einer Versuchsprüfung besteht nur dann, wenn es zur [...] Vollendung der Tat nicht gekommen ist."

275 BGHSt 33, 142, 145. Vor allem im Hinblick auf den „Dagobert-Fall“ (siehe insoweit Murmann, Grundkurs, J 31 Rn. 21 [mit Fn. 33] und den dortigen Verweis auf BGHSt 41, 368 ff. [= BGH, NJW 1996, 936 ff.]), hätte das Vorliegen eines „sukzessiven Versuchs“ bzw. einer sukzessiven Tatbestandserfüllung erörtert werden müssen; geht der erste Schuss fehl und tötet der zweite Schuss das Opfer (so Beispiel bei Murmann, Grundkurs, \ 31 Rn. 19), so ist „,nicht etwa zuerst eine Versuchsprüfung vorzunehmen, denn zum ,töten“ gehören - wenn man der Gesamtbetrachtungslehre folgt [...] - alle Handlungen, die innerhalb eines Ausführungsstadiums von einem einheitlichen Vorsatz getragen in unmittelbarem zeitlichen und räumlichen Zusammenhang auf die Herbeiführung des Erfolges zielen.“ (Murmann, Grundkurs, \ 31 Rn. 22.).

276 Siehe hierzu BGHSt 33, 142, 144.

277 Hinweis auf die abweichende Entscheidung des BGH bei Schönke/Schröder/Eser/Bosch, \ 24 Rn. 40. 
BGH: Täter T will das Opfer zum Oralverkehr nötigen. Als dies misslingt, da sich das Opfer „,mit beiden Händen gegen seinen Oberkörper stemmt [...] “, lässt er ab, berührt das Opfer am Unterkörper und dringt mit der Hand in die Scheide ein. Im Anschluss vollzieht er gewaltsam den Geschlechtsverkehr. ${ }^{278}$

Dem Ausgangsfall und dieser Konstellation ist gemein, dass der Täter zunächst den Oralverkehr beabsichtigt, um im Versuchsstadium die sexuelle Befriedigung doch im Geschlechtsverkehr zu suchen. Entgegen der ersten Entscheidung bejaht der BGH hier jedoch einen strafbefreienden Rücktritt: „Das LG hat in dem Verlangen nach Oralverkehr zu Recht eine versuchte sexuelle Nötigung gesehen, die im Gegensatz zu den Manipulationen am Unterkörper und an der Scheide der Frau nicht nur eine typische Vorbereitungshandlung für die Verwirklichung des erzwungenen Geschlechtsverkehrs war. Der Tatrichter hat aber nicht berücksichtigt, daß der Angekl. dieses Verlangen aufgegeben hat. Daß er dabei nicht freiwillig i.S. von \24 I StGB handelte, ist nicht ersichtlich. Für die Beurteilung der Rücktrittsfrage ist es unerheblich, daß der Angekl. seine geschlechtliche Befriedigung dann durch den erzwungenen Geschlechtsverkehr zu erlangen suchte. ${ }^{\text {" } 279}$ Es besteht eine Ergebnisdivergenz. ${ }^{280}$

Unbeachtet vom BGH bleibt hierbei bereits, dass durch die Vergewaltigung zugleich \178 StGB a.F. verwirklicht wird, sodass der Täter durch den Wechsel zu \ 177 StGB a.F. auch die sexuelle Nötigung fortsetzte. ${ }^{281}$ Hierdurch läge eine Aufgabe vom ersten Akt allein im Fall einer anderweitigen Zäsur vor, die sich so jedoch nicht ergibt. Somit verkannte der BGH offenbar das Vorliegen der sexuellen Nötigung im zweiten Abschnitt. Anderenfalls würde ein noch engerer Tatbegriff postuliert als in der ersten Entscheidung. Das stünde der grundsätzlichen Gleichsetzung von Tat und Tatbestand allerdings nicht entgegen, da dies allein eine Obergrenze der Tat darstellt, Zäsuren diese Reichweite aber nicht erreichen müssen. Insoweit kann diese Ergebnisabweichung hier dahinstehen. Vielmehr ist zu entscheiden, ob die Gleichsetzung von Tat und Tatbestand tatsächlich überzeugt.

278 BGH, NStZ 1997, 385.

279 BGH, NStZ 1997, 385 (meine Unterstreichung).

280 Hierauf wurde auch in der Urteilsanmerkung hingewiesen (BGH, NStZ 1997, 385 f.).

281 BGHSt 33, 142, 145. 
(2.) Bewertung der BGH-kritischen Stimmen

\section{(a.) Stellungnahme Kritik Kühl ${ }^{282}$}

Dass der Wortlaut „Tat“ nur auf den ersten Blick für eine Auslegung fruchtbar gemacht werden könne, bestätigt auch Scheinfeld, da der Sprachgebrauch eine Eingrenzung des Begriffs „Tat" nicht vornehme. Der Begriff würde sowohl eine weite, als auch eine enge Auslegung decken.283 Scheinfeld versucht durch $\int 24$ Abs. 1 S. 1 Var. 2 StGB den Bedeutungsgehalt zu ermitteln. Hiernach muss der Täter die Vollendung der Tat verhindern, sodass durch Auslegung der „Vollendung der Tat“ möglicherweise die Reichweite bestimmt werden könne. ${ }^{284}$ Nach Bacher „[kann] die Vollendung, einer Tat ${ }^{6}[\ldots]$ nur auf die Verwirklichung eines bestimmten Tatbestandes bezogen werden"285. Zwar findet Scheinfeld diese Interpretation Bachers naheliegend, jedoch weist er darauf hin, dass auch eine anderweitige Auslegung in Betracht komme. Die Vollendung der Tat könne sich ebenso auf das Erreichen des vom Täter angestrebten Ziels beziehen, unabhängig davon durch welchen Tatbestand ihm dies gelungen ist. ${ }^{286}$ Dass aber die Tatbestandsverwirklichung gemeint sei, ergebe sich aus $\int 23$ Abs. 2 StGB, ,wo von der, vollendeten Tat gesprochen wird, die bestraft wird. Bestraft wird aber nur die Tatbestandserfüllung. Sie meint der Gesetzgeber also wohl mit der, Vollendung der Tat'. Demnach scheint es die Tatbestandsverwirklichung, also die Realisierung der vom Versuchstäter geschaffenen Gefahr, zu sein, die er i.S.d. 2. Alternative verhindern muss, damit er wegen des Versuchs nicht bestraft wird. " 287

Es verbleibt in Bezug auf den Wortlaut ein Interpretationsspielraum. Wenn auch die kongruente Sichtweise mit Scheinfeld näher liegt, so erwächst hieraus kein Argument für die Identität von Tat und Tatbestand, ${ }^{288}$ was allerdings zugleich bedeutet, dass der Wortlaut auch nicht gegen dieses Verständnis vorgebracht werden kann.

Unabhängig hiervon überzeugt Kübls Argument nicht, dass ein Tatbestandswechsel häufig auf zufälligen Tatbestandsdifferenzierungen beruhe. Wird zutref-

282 Zu Kühl S. 54.

283 Scheinfeld, Tatbegriff, S. 35 f.

284 Scheinfeld, Tatbegriff, S. 36.

285 Bacher, Versuch und Rücktritt vom Versuch beim erfolgsqualifizierten Delikt, S. 210 in Fn. 562 in Bezug auf $\int 11$ Abs. 1 Ziff. 6 StGB.

286 Scheinfeld, Tatbegriff, S. 36.

287 Scheinfeld, Tatbegriff, S. 36.

288 Scheinfeld, Tatbegriff, S. 36: „Die Beschränkung des Begriffs ,Tat‘ auf den materiellen Straftatbestand, den zu verwirklichen der Täter versucht hat, liegt entschieden näher als die extensive Sicht, welche das Merkmal ,Tat" über den Begriff der Straftat hinaus erstrecken möchte." Bzgl. der Unergiebigkeit des Wortes „Vollendung“ ebenda: „Das bedeutet jedoch nur, dass das Wort ,Vollendung' nicht dazu zwingt, das Merkmal ,Tat' zu verstehen als Verwirklichung des Tatbestandes." 
fend mit Lilie/Albrecht erkannt, dass ein Versuch vorsätzliches Handeln voraussetzt, so muss „der Täter hinsichtlich der tatbestandsbegründenden Umstände wissentlich und willentlich handel[n]. Erfüllt die vorbehaltene Handlungsweise einen anderen, wenn auch in der Angriffsart ähnlichen, selbstständigen Tatbestand als die bisher verwirklichten Handlungsweisen, ändert sich auch die den Vorsatz begründenden Vorstellungen des Täters, weil diese immer nur deliktsbezogen sind. " 289

Zuletzt verlässt Kübl bei seiner Kritik am BGH auch das eigene Tatverständnis. Denn es „,[...] bleibt die rhetorisch gemeinte Frage, welche Veränderungen konkreter Tatumstände noch äquivalent bzw. unwesentlich sein sollen, obwobl sie den Gesetzgeber zu einer anderen tatbestandlichen Bewertung der Handlung und zur Eröffnung eines anderen Strafrahmens bewogen haben?" 290 Folglich müsste auch mit Kübl aus einem Tatbestandswechsel eine Zäsur folgen.

\section{(b.) Stellungnahme Kritik Zaczyk ${ }^{291}$}

Verneint Zaçy k bei einem Wechsel vom Grundtatbestand zur Qualifikation die Tataufgabe, so verdient dies Zustimmung. Dies bedarf allerdings keiner besonderen Erwähnung, da durch die Qualifikation auch das Grunddelikt verwirklicht wird, sodass auch nach Auffassung des BGH hier dieselbe Tat fortwirkt. ${ }^{292}$

Unklar ist hingegen, warum die Wahlfeststellungskriterien auch mehrere Tatbestände zu einer Tat zusammenfassen sollen. So besteht bereits keine Verknüpfung dieser beiden Regelungsbereiche, die solch einen Rückgriff legitimieren würde. Ähnlich wie bei der Bezugnahme auf die konkurrenzrechtliche Tatdefinition bedarf es für jeden Regelungsbereich einer individuellen Betrachtung, wobei die abstrakte Heranziehung anderweitiger vermeintlich identischer Definitionen die Gefahr birgt, dass die eigentliche Reichweite des fraglichen Tatbestandsmerkmals verkannt wird.

\section{(c.) Stellungnahme Kritik Eser/Bosch ${ }^{293}$}

Insoweit Eser/Bosch einen gleichwertigen Angriff für die Einheitlichkeit fordern, ist bereits unklar, was hierunter zu verstehen ist. Wird diese Auslegung trotz dieser Unschärfe akzeptiert, so muss die Grenze der Einheitlichkeit aber auch hier ein Tatbestandswechsel sein. Denn in Entsprechung zu Kübl lässt sich mit Günther

289 LK-StGB/Lilie/Albrecht, 』 24 Rn. 218.

290 Günther, GS Armin Kaufmann, 1989, S. 541, 549.

291 Zu Zaczy/k S. 55.

292 Dies gilt so freilich nur dann, wenn keine anderweitige Zäsur die Einheitlichkeit aufspaltet.

293 Zu Eser/Bosch S. 55 f. 
einwenden, dass die Gleichwertigkeit der Angriffe spätestens dann endet, wenn der Täter eine Handlung vornimmt, die einem anderen Tatbestand zuzuordnen ist. ${ }^{294}$ Diesbezüglich besteht somit eine Kongruenz zum BGH. Dem steht auch nicht entgegen, dass nach Eser/Bosch für eine Zäsur der weitere Angriff nicht gegen das gleiche Tatobjekt erfolgen darf. Denn wendet sich der Täter einem anderen aber gleichen Tatobjekt zu und wählt dieselbe Ausführungsart, so ist derselbe Tatbestand gegeben, weswegen sich auch nach dem BGH eine Zäsur allein hieraus nicht ergibt. Zielt der Täter hingegen auf das gleiche Tatobjekt ab, begeht aber einen anderen Angriff, so folgt aus der unterschiedlichen Angriffsart ein Tatbestandswechsel und mit dem BGH eine Zäsur, wobei aufgrund des nicht äquivalenten Angriffs Gleiches auch für Eser/Bosch gelten muss.

Wenngleich Eser/Bosch feststellen, dass der BGH der eigenen Ansicht zumindest nahekomme, so übersehen sie doch die Identität. Einzig in der Vorgehensweise sind die Meinungen dahingehend divergent, dass der BGH auf den Tatbestandswechsel abstellt, Eser/Bosch hingegen die Angriffsart und das Tatobjekt heranziehen, wobei diese beiden Umstände in einem Tatbestandswechsel aufgehen. Anstatt den Oberbegriff „Tatbestandswechsel“" zu nennen, grenzen Eser/Bosch nach Kriterien ab, welche diesen gerade ausmachen.

Positiv anzumerken ist, dass Eser/Bosch versuchen, die Rückkehr in die Legalität und somit die Aufgabe weiterer Handlungen in der Rücktrittsprüfung zu verorten, hierbei jedoch erkennen, dass „,von Gesetzes wegen nicht mehr gefordert werden [kann] als das Aufgeben der ,Tat" “. 295 Gem. \ 24 Abs. 1 Var. 1 StGB ist entscheidend, was Teil derselben Tat ist. Wird der Tatbegriff einem Straftatbestand gleichgesetzt, so kommt es allein darauf an, ob von diesem Delik.t abgelassen wurde. Forderte man sodann für einen Rücktritt die vollständige Rückkehr in die Legalität, so wäre dies eine die Anforderung des Gesetzes übersteigende Auslegung. ${ }^{296}$ Dem Täter würden für die Strafaufhebung nach \ 24 Abs. 1 Var. 1 StGB höhere Hürden auferlegt, als vom Gesetzgeber vorgesehen.

Folglich deckt sich die Auffassung von Eser/Bosch mit dem Verständnis des BGH und kann diesem somit nicht entgegengehalten werden.

294 Günther, GS Armin Kaufmann, 1989, S. 541, 549.

295 Schönke/Schröder/Eser/Bosch, \ 24 Rn. 40.

296 Siehe zur konkreten/abstrakten Betrachtungsweise im Zusammenhang mit Rudolphi S. 73 ff. 


\section{(d.) Stellungnahme Kritik Rudolphi ${ }^{297}$}

\section{(aa.) Allgemeine Würdigung}

Trotz der Erkenntnis, dass die Tat Bezugspunkt für die Aufgaben ist, stellt Rudolphi vermeintlich hohe Anforderungen an das Vorliegen einer Zäsur. Liegt mit Rudolphi eine Aufgabe erst dann vor, wenn das weitere Geschehen in Bezug auf das Angriffsziel/die Begehungsweise wesentlich von dem vorherigen Akt abweicht, so erscheint es möglich, dass auch mehrere Tatbestände Teil derselben Tat sein könnten. Wechselt der Täter von einem versuchten Betrug zu einer räuberischen Erpressung, um an eine bestimmte Sache zu gelangen, so bliebe zumindest das Ziel der Bemühungen dasselbe. In Parallele zu Kübls Wesentlichkeitsmaß$\operatorname{stab}^{298}$ und der von Eser/Bosch geforderten Gleichwertigkeit ${ }^{299}$ ist hier aber ebenso fraglich, was unter einer „wesentlichen“ Abweichung zu verstehen ist. Auch wenn bei einem Wechsel von einem Betrug zu einer räuberischen Erpressung das Ziel unverändert bleibt, dürfte sich bei fortbestehender Einheitlichkeit ebenfalls die Begehungsweise nicht wesentlich geändert haben. Spätestens dann jedoch, wenn der Täter zu einem anderen Tatbestand ansetzt, wird diese Wesentlichkeitsschwelle überschritten sein. Denn wie bereits festgestellt, kann eine Abweichung, die zur Verwirklichung eines anderen Tatbestands führt, mit dem vorherigen Abschnitt weder gleichwertig sein, noch kann dies eine unwesentliche Veränderung darstellen. 300 Folglich muss auch bei Rudolpbi spätestens der Tatbestandswechsel eine Zäsur einleiten. Ähnlich wie bei Eser/Bosch ist auch bei Rudolphi zu erkennen, dass augenscheinlich eine gewisse Zurückhaltung dahingehend besteht, dem Tatbestandswechsel eine limitierende Wirkung zuzusprechen. Anstatt konkret auf den Tatbestandswechsel abzustellen, werden Abgrenzungskriterien herangezogen, die diesen gerade ausmachen. Insoweit besteht Deckungsgleichheit zu der Auffassung des BGH. Des Weiteren ist es auffällig, dass Rudolphi zunächst einen vermeintlich weiten Tatbegriff entwirft, der wohl auch andere Tatbestände erfassen soll, im Fall von mehreren parallelen Tatbeständen aber unproblematisch die Möglichkeit eines eigenständigen Rücktritts angenommen wird. Zwar trifft es zu, dass in solch einer Konstellation der Rücktritt für jedes Delikt separat zu prüfen ist, allerdings ist hierbei das gesamte Geschehen zu berücksichtigen. Versucht der Täter einen Raubmord und lässt vom Mord ab, um den Raub auf anderem Wege zu vollenden, so ist der Rücktritt vom versuchten Mord freilich eigenständig zu bewerten. Wird jedoch ein weiter Tatbegriff zugrunde gelegt, sodass auch mehrere Tatbestände Teil derselben Tat sein können, so müssen im Rahmen der Aufgabe auch

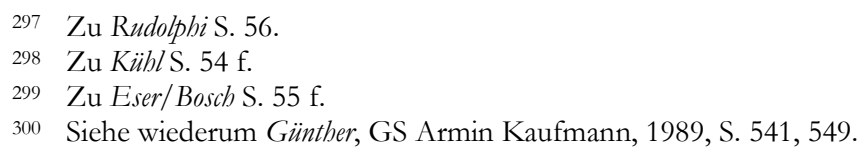


weitere Delikte berücksichtigt werden, sofern diese derselben Tat angehören. Zumindest ist bei einer extensiven Sichtweise an dieser Stelle Problembewusstsein angebracht und die Aufgabe des versuchten Mords müsste hier vor allem im Hinblick auf die Vollendung des Raubs besonders erörtert werden. Durch die pauschale Behauptung Rudolphis, ein separierter Rücktritt bei Vollendung eines weiteren Delikts sei möglich, wird von ihm die nach seinem Verständnis wohl mögliche Mehrtatbestandlichkeit der Tat ausgeblendet.

\section{(bb.) Endgültigkeit der Tataufgabe}

Des Weiteren bieten sich auch bei der Endgültigkeit der Tataufgabe Anknüpfungspunkte für eine genaue Betrachtung. Eine Aufgabe müsste nach Rudolphi verneint werden, wenn der Täter nur ablässt, um das Ziel später auf gefahrlosere Weise zu erreichen. Dieses pauschale Ergebnis scheint jedoch der vorherigen Feststellung Rudolphis zu widersprechen, wonach es für einen Rücktritt, selbst bei fortgesetztem deliktischen Handeln und Verwirklichung einer anderen Tat, ausreicht, wenn sich der Täter von der konkreten Tat distanziert. Denn auch bei beständigem Willen des Täters, dasselbe Ziel zu erreichen, ist es nicht zwingend, dass stets dieselbe Tat vorliegt. Sind die einzelnen Ausführungsakte durch eine Zäsur getrennt, so könnte sich der Täter von der vorangegangenen Tat selbst dann vollständig abwenden, wenn er den deliktischen Willen nie aufgegeben hat. Neben diesem Umstand erscheint es zudem fraglich, wie Rudolphi diese Rücktrittseinschränkung in den Kontext des $₫ 24$ Abs. 1 S. 1 Var. 1 StGB einbeziehen will.

\section{(i.) Abstrakte Betrachtungsweise}

Die Auffassung Rudolphis könnte zunächst so verstanden werden, dass die Endgültigkeit der Tataufgabe abstrakt und somit ohne konkreten Bezug zur Tat zu bestimmen ist. ${ }^{301}$ Unabhängig von dem Ablassen von der konkreten Tat müsste ein

301 Solch eine abstrakte Sichtweise vertrat auch RGSt 72, 349, 350 f.: „Hier hatte die Angeklagte jedenfalls ihren Vorsatz, den erstrebten einheitlichen und unteilbaren Erfolg herbeizuführen, nämlich den P zu töten, in keinem Augenblick endgültig aufgegeben. Sie gab nur eine bestimmte Ausführungsweise auf, war aber nach wie vor bestrebt, denselben Erfolg auf anderem Wege zu erreichen. Sie verwirklichte ihn auch demnächst in unmittelbarer Fortwirkung ihres Tötungsvorsatzes. Bei einer solchen Sachlage, d. h. bei einem bloßen Ändern der Tatmittel, die zu dem unverändert gewollten Enderfolg führen sollen, kann keinesfalls von einem Rücktritt vom Versuche i.S. des \46 StGB. die Rede sein.“; BGHSt 7, 296, 297 zu \46 Nr. 1 StGB: „Diese Vorschrift setzt zunächst voraus, daß der Täter die Durchführung seines Verbrechensentschlusses im ganzen und endgültig a u fgibt [...] auch wenn im Gesetz das Wort,endgültig' nicht enthalten ist [...].“; siehe ausführlich zum damaligen Meinungsstand bzgl. konkreter/abstrakter Betrachtungsweise Bottke, Strafrechtswissenschaftliche Methodik und Systematik bei der Lehre vom strafbefreienden und strafmildernden Täterverhalten, 1979, S. 373 ff. 
Rücktritt versagt werden, wenn sich der Täter für einen späteren Zeitpunkt ein deliktisches Verhalten vorbehält. Zäsuren, wie z.B. eine räumliche und zeitliche Trennung, hätten hierauf keine Auswirkungen, da nicht die Tat den Anknüpfungspunkt bildet, sondern abstrakt die Endgültigkeit der Aufgabe. ${ }^{302}$

Durch dieses Verständnis würde dem Täter für einen Rücktritt nicht nur auferlegt, von der begangenen Tat abzulassen, sondern ihm wird auch abverlangt, ,,von Verhaltensweisen Abstand zu nehmen, die mit seinen bisherigen Handlungen in keinerlei Zusammenhang stehen und die voraussetzen, dass er nach seiner Vorstellung von der Tat ein weiteres mal unmittelbar zur Tatbestandsverwirklichung ansetzt, also ein eigenständiges Versuchsunrecht verwirklicht. “303 Auch widerspricht das abstrakte Endgültigkeitserfordernis dem Gesetz. Gem. \24 Abs. 1 S. 1 Var. 1 StGB wird für einen Rücktritt gefordert, dass der Täter von der Tat abgelassen haben muss. Es ist somit allein entscheidend, ob das weitere Vorhaben des Täters derselben Tat angehört oder eigenständig zu betrachten ist. ${ }^{304}$ Günther gibt zu bedenken, dass bei bestehender Zäsur und hieraus folgender Tatdivergenz das Versagen des Rücktritts aufgrund einer weiteren möglichen tatfremden Handlung, welche sich im Vorbereitungsstadium befinden, ein „Verstoß gegen die nullumcrime-sine-lege-scripta-Maxime“ vorliegen könnte. „Denn die Strafbarkeit des Versuchs der einen Tat läßt sich nicht mit der gesetzlich angeordneten Straflosigkeit der Vorbereitung einer anderen Tat begründen. “305

Herzberg weist zudem darauf hin, dass bei diesem Verständnis ein Täter, der aus Scham von einem Betrug ablässt, um das Ziel durch einen Raub zu begehen ${ }^{306}$, selbst dann zu bestrafen wäre, wenn es allein bei dieser theoretischen Vorstellung bliebe. Obwohl der Täter durch sein Schamgefühl geleitet wurde, bestehe die Betrugsstrafbarkeit. Der strafrechtlich ansonsten unbeachtliche bloße Verbrechensentschluss würde hier zur Verwehrung des Rücktritts führen. ${ }^{307}$ So trifft die Aussage Heræ̧bergs, dass hierdurch der Wille des Täters bestraft würde ${ }^{308}$, die Prob-

302 Siehe zur abstrakten Sichtweise kurz Streng, JZ 1984, 652.

303 MK-StGB/Herzberg/Hoffmann-Holland, \ 24 Rn. 96.

304 Vgl. hierzu MK-StGB/Herzberg/Hoffmann-Holland, J 24 Rn. 96, die zwar auch am Wortlaut des $\int 24$ Abs. 1 StGB anknüpfen, jedoch bereits hier dahingehend argumentieren, dass der Rücktritt sich stets nur auf ein konkretes Delikt beziehe, da der Täter ,die weitere Ausführung der Tat aufgeben muss.“; vgl. Herzberg, GS H. Kaufmann, 1986, S. 709, 714: „Wer wegen des gleichzeitig gefaßten Raubentschlusses entweder das ,Aufgeben der weiteren Tatausführung' oder die ,Freiwilligkeit‘ verneint, setzt die eigene Hypothese, was der Sinn des Gesetzes zu sein habe, über das Gesetz selbst.“"

305 Günther, GS Armin Kaufmann, 1989, S. 541, 547; vgl. zum Verstoß gegen die nullum-crimesine-lege-scripta-Maxime Herzberg, GS H. Kaufmann, 1986, S. 709, 714: „Die Versagung der Straffreiheit wäre geradezu eine Rechtsverweigerung."

306 So Beispiel von Wessels, AT, 14. Aufl. 1984, \ 14 IV 4.

307 Herzberg, GS H. Kaufmann, 1986, S. 709, 714.

308 Herzberg, GS H. Kaufmann, 1986, S. 709, 715. 
lematik recht gut. ${ }^{309}$ Freilich wird rein rechtlich nicht der Wille bestraft, sondern der begangene Versuch, tatsächlich führte jedoch dieser Wille zur Verneinung der Aufgabe und somit zum Ausschluss des Rücktritts, sodass im Ergebnis die Strafbarkeit auf den „bösen Willen“ des Täters zurückzuführen wäre.

Auch wenn es nicht nur beim bloßen Täterwillen bleibt, sondern der Täter tatsächlich zum nächsten Delikt unmittelbar ansetzt und sodann zurücktritt, komme es zu unbilligen Ergebnissen. Durch die Aufgabe könne der Täter allein vom zweiten Versuch zurücktreten. Die Strafbarkeit wegen des ersten versuchten Tatbestands bliebe hiervon unberührt bestehen. Obwohl der Täter insgesamt in die Legalität zurückgefunden hat, müsse er sich trotzdem strafrechtlich verantworten. ${ }^{310}$

Würde einem Täter der Rücktritt von einer versuchten Sachbeschädigung abgesprochen, weil er auf einen Mord umschwenkt, so würde ignoriert, „daß unsere Täter die Deliktsvollendung aus Scham bzw. aus Achtung vor wirtschaftlichen Werten unterlassen haben, und tut [sic!], als seien ihre Versuche fehlgeschlagen oder unfreiwillig abgebrochen worden." "311

Die abstrakte endgültige Aufgabe führt zu unbilligen Ergebnissen und überschreitet zudem den Gesetzeswortlaut. Gefordert werden kann allein, dass der Täter endgültig von der konkereten Tat Abstand nimmt. ${ }^{312}$ Herz̧berg erkennt zudem, dass ,abstrakte Rücktrittsschranken“, wie das Erfordernis der vollständigen Rückkehr in die Legalität, schon vom Grunde her fraglich sind. Diese Einschränkungen basieren allein auf einer dem Gesetz unterstellten Ratio. Man könne aber problematische Einzelfälle nicht mit dem unterstellten Sinn der Norm lösen, sondern müsse gerade ,aus sachgerechten Lösungen von Fall zu Fall, die streng am Gesetzeswortlaut zu messen sind,“ den Zweck der Vorschrift ergründen. ${ }^{313}$ „Beibehal-

309 Diese Kritik Heræbergs trägt jedoch nur bei einer abstrakten Beurteilung der Endgültigkeit. Lehnt man dies ab und stellt allein, auf Basis eines übertatbestandlichen Tatbegriffs, auf die Tat ab, so führte dieser Einwand nicht weiter. Die Vorstellung des Täters, durch Gewalt an das Geld zu gelangen, wäre dann, mangels räumlicher und zeitlicher Trennung, darauf bezogen, dieselbe Tat fortzuführen. Zu diesem Zeitpunkt müsste eine Aufgabe folglich verneint werden. Zu entscheiden wäre jedoch dann, ob der Täter durch das Unterlassen der weiteren Ausführung straffrei wird, was an einem Fehlschlag oder an mangelnder Freiwilligkeit scheitern könnte. Allein wenn der Rücktritt tatsächlich zu versagen ist, käme es aufgrund des Deliktsvorbehalts zu einer Bestrafung.

310 Herzberg, GS H. Kaufmann, 1986, S. 709, 714 f. An diesem Punkt wird nochmals deutlich, dass Heržberg sich mit seinen Ausführungen gegen eine abstrakte Betrachtung wendet bzw. seine Kritik nur in diesem Fall greift. Denn beruhte hier die Rücktrittsversagung nicht auf abstrakten Erwägungen, sondern auf der Annahme, dass beide Delikte Teil derselben Tat sind und somit durch den Tatbestandswechsel keine Aufgabe gegeben ist, so könnte der Täter durch Aufgabe des zweiten Delikts insgesamt und nicht nur partiell zurücktreten. Durch das Abstandnehmen von dem zweiten Straftatbestand ließe der Täter von der gesamten Tat ab und wäre folglich insgesamt straflos.

311 Herzberg, GS H. Kaufmann, 1986, S. 709, 715.

312 So auch MK-StGB/Herzberg/Hoffmann-Holland, \24 Rn. 97.

313 Herzberg, GS H. Kaufmann, 1986, S. 709, 716. 
ten kann man die Redeweise [,Rückkehr des Täters in die Legalität'] allenfalls in einem so formalen Sinne, daß sie nahezu wertlos erscheint. Denn gewiß, ein bißchen sind die Täter unserer Beispiele zur Legalität zurückgekehrt, weil sie speziell auf den Betrug und die Sachzerstörung verzichtet haben." 314

\section{(ii.) Konkrete Betrachtungsweise}

Rudolphi könnte auch dahingehend verstanden werden, dass die Einheitlichkeit der Tat nicht länger an einem räumlichen und zeitlichen Zusammenhang festgemacht werden soll, sondern dessen Kriterien eimbeitsstiftend sind. Dann läge solange eine einheitliche Tat vor, wie der Täter noch zur Tat hindrängende Motive aufweist. Dies führte dazu, dass dieselbe Tat aufgrund des Entschlusses des Täters auch über lange Zeiträume hinweg fortbestehen würde, wobei der Täter sich fortwährend im Versuchsstadium befände:

Bsp.: T will O töten und legt seine Waffe an. Kurz vor dem Erreichen des Abrugdruckpunkts entspannt er den Finger und verschiebt das Vorbaben auf übernächstes Jahr.

Aufgrund der zur Tat hindrängenden Motive müsste die Aufgabe und folglich der Rücktritt verneint werden. Zugleich bedeutete dies, dass der Versuch ab diesem Zeitpunkt fortwirken würde und sich T auch zwei Jahre später im noch andauernden selben Versuch befände. Ginge T zwei Jahre später tatsächlich zu dem nächsten Akt über, so hätte der Täter zu der Tat bereits zwei Jahre zuvor mit dem Ziehen des Abzugs angesetzt. Hierdurch wird deutlich, dass es einer zeitlichen Begrenzung zwingend bedarf, sei es durch einen räumlichen und zeitlichen Zusammenhang oder mit Murmann, dass der Täter zum nächsten Akt unmittelbar angesetzt haben muss ${ }^{315}$.

\section{(cc.) Ergebnis}

Dem rücktrittswilligen Versuchstäter für eine Strafbefreiung gem. \24 StGB eine vollständige Rückkehr in die Legalität abzufordern, geht somit fehl. So spricht $\int 24$ StGB allein davon, dass der Täter die weitere Ausführung der Tat aufzugeben habe, was eine ausnahmslose Rechtstreue nicht erkennen lässt. Gleichsam überzeugt der deliktische Wille als tatausdehnender Umstand nicht. Zwar erscheint es

314 Herzberg, GS H. Kaufmann, 1986, S. 709, 716.

315 Murmann, Versuchsunrecht und Rücktritt, S. 47 f. 
auf den ersten Blick widersinnig, einem Täter einen Rücktritt zuzusprechen, der im Zeitpunkt des Ablassens deliktisch weiterhandeln möchte, ${ }^{316}$ jedoch dürfen solche Gedanken eine konsequente Gesetzesanwendung nicht überlagern. Bei der „Aufgabe“ kommt es nur auf das Ablassen von der konkreten Tat an, sodass allein die Reichweite der Tat Raum für differenzierte Auffassungen bietet.

Mit dem BGH muss im Ergebnis auch Rudolphi darauf erkennen, dass bei einem Deliktswechsel, aufgrund der hierbei eintretenden wesentlichen Änderungen, eine andere Tat vorliegt, weswegen eine verdeckte Deckungsgleichheit mit der Auffassung des BGH besteht.

\section{(e.) Stellungnahme Kritik Streng ${ }^{317}$}

\section{(aa.) Strengs Kritik im Hinblick auf die Herleitung}

Insoweit Streng an dem Argument der Verknüpfung von $\iint 22,23$ StGB mit $\int 24$ StGB Kritik übt, muss ihm dahingehend zugestimmt werden, dass sich der Rücktritt stets nur auf einen Tatbestand bezieht. Dies muss auch dann gelten, wenn zwei Tatbestände eine Tat darstellen würden. Denn umfasst die Tat auch mehrere Delikte, so stellt sich für jeden Tatbestand allein, jedoch bezogen auf das gesamte Geschehen, die Frage, ob ein Rücktritt vorliegt. Dies sollte durch den Verweis auf die $\iint 22,23$ StGB allerdings gar nicht belegt werden. Vielmehr geht es darum, festzustellen, ob im Rahmen der $\iint 22,23$ StGB stets nur ein Delikt Teil eines Versuchs sein kann, um das gewonnene Ergebnis auf den Rücktritt zu übertragen. Dieses Vorgehen hält Streng aber für unzulässig, da für eine Auslegung allein die fragliche Norm heranzuziehen sei. Warum Streng diese Einschränkung vornimmt, ist unklar. Betreffen Normen denselben Regelungsbereich, so ist es widersprüchlich, unterschiedliche Auslegungen etablieren $\mathrm{zu}$ wollen. Anders ist es freilich dann, wenn die Vorschriften gänzlich andere Bezugspunkte aufweisen. ${ }^{318}$ Hier jedoch ist der Rücktritt die Kehrseite des Versuchs. „\$ 22 StGB verbindet die »Vorstellung von der Tat« mit der»Verwirklichung des Tatbestandes«. Wenn der Entschluß zur Tat den Vorsatz zur Verwirklichung eines bestimmten (und nicht irgendeines) Straftatbestandes kennzeichnet, muß Gleiches auch für den actus contrarius gelten, für die Aufgabe des Entschlusses zur Tat. “319 Könnte sich schon

\footnotetext{
316 Zu den Rücktrittsformeln Günther, GS Armin Kaufmann, 1989, S. 541, 547: „Sie erklären das zunächst gefühlsmäßige Unbehagen, einem unverändert kriminellen Delinquenten hinsichtlich der versuchten Tatbestandsverwirklichung Strafbefreiung zu gewähren."

317 Zu Streng S. 57 ff.

318 So z.B. \ 24 StGB und \ 52 StGB.

319 Günther, GS Armin Kaufmann, 1989, S. 541, 553.
} 
der Versuch nur auf ein Delikt beziehen, so müsste dies für den Rücktritt gleichfalls gelten.

Ob sich der Versuch allerdings tatsächlich nur auf ein Delikt bezieht oder ob auch mehrere Tatbestände Teil desselben Versuchs sein können, lasse sich nach Streng hieraus aber nicht ableiten. \22 StGB stelle zwar auf den konkreten Tatbestand $\mathrm{ab}$, jedoch werde auch auf die Tat nach der Vorstellung des Täters Bezug genommen, „wobei dann Tat etwa als faktisches Gesamtgeschehen verstanden werden kann." 320

Auf den ersten Blick ist Strengs Einwand schlüssig. Vor allem trägt seine Überlegung, dass nach der damaligen herrschenden Meinung auf den Tatplan des Täters abzustellen war ${ }^{321}$, wobei dies in ähnlicher Form auch bei der heutigen Gesamtbetrachtungslehre zutrifft. Denn ausschlaggebend für die Reichweite der Tat ist auch hier die subjektive Sicht des Täters. Dies spricht aber dann nicht gegen die Auffassung des BGH, wenn sich aus dem Gesetz eine Begrenzung des Versuchs auf denselben Tatbestand ergibt. Gem. \22 StGB versucht derjenige eine Straftat, der nach seiner Vorstellung von der Tat zur Verwirklichung des Tatbestands unmittelbar ansetzt. Aufgrund des Wortlauts „des Tatbestandes“ wird vorausgesetzt, dass es sich bei einem Versuch nur um einen Tatbestand handeln kann. Anderenfalls hätte der Gesetzgeber es an dieser Stelle deutlich machen müssen, indem er das unmittelbare Ansetzen zur Verwirklichung „eines Tatbestandes“ oder das Ansetzen „zu einem der Tatbestände“ gefordert hätte.

Solch eine Auslegung deckt sich auch mit der „Vorstellung des Täters von der Tat". Denn hierbei handelt es sich gerade um den Tatentschluss, der alle subjektiven Merkmale des Tatbestands umfasst. ${ }^{322}$

Folglich beschränkt bereits $\int 22$ StGB den Versuch und den damit in unmittelbarer Verbindung stehenden Rücktritt auf einen Tatbestand.

\section{(bb.) Strengs Kritik im Hinblick auf die Folgen}

Streng weist aber nicht nur die Herleitung des BGH als unstimmig zurück, sondern auch die aus solch einem Verständnis resultierenden Folgen.

\footnotetext{
320 Streng, NStZ 1985, 358, 359.

321 Siehe Streng, NStZ 1985, 358, 359, Fn. 4.

322 NK-StGB/Zaczyk, \ 22 Rn. 13.
} 


\section{(i.) Bewertung des Tresorbeispiels}

Warum Streng das Ergebnis seines Tresorbeispiels als so befremdlich ansieht, erscheint fraglich. So weist der Diebstahl gegenüber einer Erpressung gänzlich abweichende Tatbestandsvoraussetzungen auf. ${ }^{323}$ Anders ist es aber dann, wenn der Täter anstatt der Erpressung einen Raub gem. \249 StGB erfüllt. Richtig erkennt Streng, dass in diesem Fall ein Rücktritt vom versuchten Diebstahl ausscheidet. Dies stellt allerdings keinen Widerspruch zu dem zuvor Gesagten dar, da der Raub den Diebstahl gänzlich einschließt. Durch den Raub wird auch der Diebstahl vollendet, sodass keine Zäsur existiert, die einen Rücktritt rechtfertigen würde.

Sofern Streng des Weiteren anmerkt, dass es keinen Unterschied mache, ob der Täter mit einem Raub oder eine räuberischen Erpressung fortfährt, da sich der Täter in beiden Fällen gegen Gewahrsam und Eigentum wende, ist ihm dahingehend zuzustimmen, dass gänzlich losgelöst von strafrechtlichen Vorschriften dies freilich zutrifft. Unabhängig vom konkreten Tatbestand versucht der Täter an den Inhalt des Safes zu gelangen. Im Ergebnis besteht rein tatsächlich zwischen diesen beiden Fallvarianten keine Abweichung, was für eine Einheitlichkeit im Ausgangsfall sprechen könnte. Hierbei darf jedoch nicht vergessen werden, dass der Täter trotzdem einen gänzlich anderen Weg beschreitet, um die Beute zu erhalten. Nur weil in dieser Konstellation der Nötigungserfolg und die Wegnahme das gleiche Ergebnis erzielen, hilft dies nicht über den Umstand hinweg, dass die Ausführungsart eine gänzlich andere ist.

Gegen die Aussage Strengs, dass durch die räuberische Erpressung der Unrechtsgehalt ansteige und hierdurch der Sinn und Zweck des Rücktritts verfehlt würde, wendet Herzberg ein, dass eine festgelegte Ratio nicht auf unbekannte Konstellationen angewendet werden könne, die bei der Bildung des Sinn und Zwecks der Vorschrift nicht mitgewirkt haben. ${ }^{324}$ Der Anspruch, dass der Täter für einen wirksamen Rücktritt in die Legalität zurückgefunden haben muss, könne nur dahingehend beibehalten werden, dass der Täter zumindest bzgl. des ersten Delikts in die Legalität zurückgekehrt ist. ${ }^{325}$ Fraglich erscheint zudem, warum Streng diese Kritik überhaupt vorträgt, denn für ihn ist der „Privilegierungsgrund des Rücktritts [...] doch das freiwillige Anerkennen - zumindest von Teilen - der Rechtsordnung durch Abstandnehmen von Rechtsgutsangriffen.“"326 Indem der Täter von dem versuchten Diebstahl ablässt und nunmehr die räuberische Erpressung begeht, wendet er sich von der Verwirklichung des $\int 242$ StGB ab und erkennt doch zumindest diese Norm, und nach Streng mithin auch einen Teil der Rechtsordnung, wiederum an.

\footnotetext{
323 Günther, GS Armin Kaufmann, 1989, S. 541, 549.

324 Herzberg, GS H. Kaufmann, 1986, S. 709, 716.

325 Herzberg, GS H. Kaufmann, 1986, S. 709, 716; Günther, GS Armin Kaufmann, 1989, S. $541,552$. Siehe zum Erfordernis einer endgültigen Aufgabe S. 73 ff.

326 streng, NStZ 1985, 358, 359.
} 
Abschließend kann Streng mit Günther entgegengehalten werden, dass es unstimmig erscheint, dem Täter den versuchten Diebstahl, obwohl er diesen gar nicht mehr vollenden möchte, allein deswegen anzulasten, weil dieser im Anschluss noch eine räuberische Erpressung begeht. ${ }^{327}$

\section{(ii.) Ergebniskongruenz trotz abweichender Begründung}

Auf den Vergewaltigungsfall bezogen verneint Streng mit dem BGH die Rücktrittsmöglichkeit vom Versuch des $\int 178$ StGB a.F. Die Begründung, dass im Anschluss auf dasselbe Rechtsgut unrechtsintensiver eingewirkt wurde und es somit an einer Rechtsgutsanerkennung mangele, überzeugt aber insoweit nicht, als dass es dieser Rechtsgutsabstrahierung gar nicht bedarf. Auch wenn $\int 177$ StGB a.F. gegenüber $\int 178$ StGB a.F. spezieller ist, so liegt die sexuelle Nötigung auch im Rahmen der Vergewaltigung vor. Dadurch, dass der Täter durch die Vergewaltigung die sexuelle Nötigung mitverwirklicht, hat er von der versuchten sexuellen Nötigung nicht abgelassen und ist diesbezüglich somit nicht zurückgetreten. Wie jedoch bereits in der Würdigung des BGH-Urteils gesehen, ist die Verortung des Problems verspätet. ${ }^{328}$ Schon zu Beginn der Prüfung der versuchten sexuellen Nötigung hätte gefragt werden müssen, ob die versuchte Tat vollendet ist. Aufgrund der Zusammengehörigkeit der einzelnen Akte, welche in die Vollendung der sexuellen Nötigung mündeten, liegt nur eine Tat vor, sodass kein Raum für eine eigenständige versuchte sexuelle Nötigung verbleibt.

Gegen Streng spricht Günthers Argumentation im Hinblick auf den Fehlschlag hingegen nicht. So führt nach Streng ein übertatbestandlicher Tatbegriff nicht da$\mathrm{zu}$, dass ein fehlgeschlagener Vergewaltigungsversuch durch eine Tötungsmöglichkeit rücktrittsfähig bliebe. ${ }^{329}$ Streng will nämlich nicht jedweden weiteren Tatbestand in die Einheitlichkeit einfließen lassen, sondern nur solche Delikte, durch die der Angriff auf das Rechtsgut fortgesetzt wird. ${ }^{330}$ Im Beispiel schützt $\int 177$ StGB jedoch „die freie sexuelle Selbstbestimmung einer Person“331, wohingegen $\int 212 \mathrm{StGB}$ das Leben schützt ${ }^{332}$. Auch wird nicht im weiteren Sinne durch den Totschlag der Angriff auf die freie sexuelle Selbstbestimmung fortgesetzt, sodass auch mit Streng keine einheitliche Tat vorliegt und der Vergewaltigungsversuch fehlgeschlagen ist.

Aber auch die Einschränkung Strengs scheint nicht ohne Widerspruch zu bleiben:

327 Günther, GS Armin Kaufmann, 1989, S. 541, 549.

328 Siehe S. $67 \mathrm{f}$.

329 Siehe bzgl. des Arguments Günther, GS Armin Kaufmann, 1989, S. 541, 553.

330 Siehe Streng, NStZ 1993, 257, 261; ders., NStZ 1985, 358, 359 f.

331 Schönke/Schröder/Eisele, \ 177 Rn. 2.

332 NK-StGB/Neumann, J 212 Rn. 1. 


\begin{abstract}
Bsp.: Täter $T$ begibt sich in die Villa des O, um dessen kostbares Fabergé-Ei zu entwenden. Als $T$ die Kostbarkeit in seinen Händen hält, wird er von $O$ und dessen Sicherheitskräften entdeckt. T sieht sich nunmehr nicht mehr in der Lage, das Ei wegzunehmen. Gleichfalls will er es dem verhassten $O$ aber auch nicht überlassen. T schmeißt das Ei sodann in die Luft, damit es auf dem Boden zerschellt. Kurz vor dem Aufschlag reut $T$ jedoch sein Verhalten, wirft sich auf den Boden und fängt das Ei im letzten Moment.
\end{abstract}

Obschon der versuchte Diebstahl mangels Wegnahmemöglichkeit gescheitert ist, muss dies nicht zu einem Ausschluss des Rücktritts führen. Wären der versuchte Diebstahl und die versuchte Sachbeschädigung Teil derselben Tat, so hätte der Rücktritt von der versuchten Sachbeschädigung gleichfalls Auswirkungen auf den versuchten Diebstahl. Sowohl \242 StGB ${ }^{333}$ als auch \ 303 StGB $^{334}$ schützen das Eigentum, sodass aufgrund dieser fortgesetzten Rechtsgutsverletzung nach Streng dieselbe Tat vorliegen müsste. Hierdurch würde sich aber die gleiche Problematik wie in Günthers Beispielen stellen. ${ }^{335}$ Der Fehlschlag eines versuchten Tatbestands würde durch die Realisierungsmöglichkeit eines anderen Delikts beseitigt. Zudem hätte der Rücktritt von einem versuchten eigenständigen Tatbestand auch bzgl. eines anderen Tatbestandsversuchs strafbefreiende Wirkung. Da diese Konsequenzen insbesondere nur für den Täter gelten, der sich gegen ein Rechtsgut wendet, das durch mehrere Tatbestände geschützt ist, käme es gleichfalls zu einer zufälligen und unbegründeten Privilegierung des Täters, der ein Rechtsgut zu verletzen beabsichtigt, das im Rahmen der Strafgesetze besonders prominent ist.

Da es nach Streng jedoch noch nicht einmal erforderlich ist, dass die tateinheitlichen Delikte dem Schutz desselben Rechtsguts dienen, sondern für eine einheitliche Tat allein abstrakt der Angriff auf dasselbe Rechtsgut fortgesetzt werden muss, kommt es zu den von Günther aufgezeigten Schwächen. So könnte der Täter von einem versuchten Betrug zurücktreten, wenn er zu einem Mord umschwenkt, wohingegen ihm dies verwehrt wäre, wenn er sich für einen Raub entscheidet. ${ }^{336}$ „Daß sich der Täter eines Betrugsversuchs besser stellen sollte, weil er zum Mord umschwenkt, statt sich für einen Raub zu entscheiden, könnte jedenfalls nicht das letzte Wort zum Tatbegriff des $₫ 24$ StGB und zum Rücktritt bei Deliktswechsel bleiben." 337

\footnotetext{
333 Schönke/Schröder/Eser/Bosch, \ 242 Rn. 1/2.

334 Schönke/Schröder/Stree/Hecker, \ 303 Rn. 1.

335 Günther, GS Armin Kaufmann, 1989, S. 541, 553.

336 Günther, GS Armin Kaufmann, 1989, S. 541, 550.

337 Günther, GS Armin Kaufmann, 1989, S. 541, 551.
} 


\section{(iii.) Bewertung der weiteren Einwände}

Entgegen Streng ist es kein Widerspruch, dass ein Täter, der freiwillig zu einer anderen Tat wechselt und diesbezüglich bereits vor Versuchsbeginn scheitert, nach dem BGH straffrei wird, wenn der ursprüngliche Deliktsentschluss aufgegeben wurde. Anderenfalls hieße dies für das Tresorbeispiel ${ }^{338}$, dass der Rücktritt vom versuchten Diebstahl schon deswegen scheitert, weil der Täter sich vorstellt, noch eine räuberische Erpressung durchzuführen. Allein die Vorstellung des Täters führte nach Streng zur Strafbarkeit. Dem könnte nunmehr wieder mit Herzberg entgegengehalten werden, dass dies „eine getarnte Bestrafung des bösen Willens“ sei. ${ }^{339}$ Außerhalb dieser besonderen Konstellation reichte allein eine Vorstellung für eine Strafbarkeit nicht aus. Selbst wenn der Tatentschluss hinreichend gefestigt wäre, liegt zumindest noch kein unmittelbares Ansetzen des Täters vor. ${ }^{340}$ „Er [der Verbrechensentschluss] rechtfertigt für sich allein weder die Bestrafung wegen eines Versuchs des geplanten Verbrechens, noch darf er herangezogen werden, um einen vorangegangenen Rücktritt zu entwerten." ${ }^{\text {“341 }} \mathrm{Zu}$ beachten ist hierbei jedoch, dass Streng keine abstrakte Rücktrittsbeschränkung anstrebt, sondern sich gegen die Gleichschaltung von "Tat“ i.S. des \24 StGB und dem materiellrechtlichen Tatbestand ausspricht. Insoweit fordert Streng wohl einen übertatbestandlichen Tatbegriff. ${ }^{342}$ Dies hat zur Folge, dass die Bestrafung zwar auf dem „bösen Willen" beruht, allerdings in der Form, dass mit diesem Willen die konkrete Tat fortgesetzt werden würde. Aufgrund dieser angenommenen Übertatbestandlichkeit der Tat ist der Tatbestandswechsel genauso zu bewerten, als wenn der Täter einen Diebstahl versucht, hiervon ablässt, die Fortsetzung aber weiterhin beabsichtigt. Sofern keine Zäsur besteht, müsste die Aufgabe in diesem Zeitpunkt verneint werden. Dadurch, dass der Täter sich fortwährend in derselben Tat befindet und somit keine Tataufgabe vorliegt, führt zwar dieser konkrete Fortsetzungswille zur Versagung des Rücktritts und somit zur Strafbarkeit des Täters, weswegen der „,böse Wille“ bestraft würde, jedoch mit der Abweichung, dass der Täter sich schon gar nicht von der konkreten Tat distanziert hat.

Des Weiteren zieht Streng aus der Gleichsetzung von Tat und Tatbestand auch die falschen Konsequenzen in Bezug auf den zeitlichen und räumlichen Zusammenhang, wenn er dem BGH dessen Missachtung vorwirft. Wird vertreten, dass für eine einheitliche Tat ein Tatbestand vorliegen muss, so wird hierdurch mit

338 S. 58

339 Herzberg, GS H. Kaufmann, 1986, S. 709, 715, 724; dem zustimmend Günther, GS Armin Kaufmann, 1989, S. 541, 547.

340 Herzberg, GS H. Kaufmann, 1986, S. 709, 714.

341 Herzberg, GS H. Kaufmann, 1986, S. 709, 714.

342 Daher trägt hier auch der Hinweis auf den nullum crimen sine lege scripta Grundsatz (Günther, GS Armin Kaufmann, 1989, S. 541, 547) nicht. Das Argument Günthers greift nur dann, wenn über die Tat hinaus Umstände für die Tataufgabe berücksichtigt würden (zur abstrakten/konkreten Betrachtungsweise S. 73 ff.). 
Günther eine notwendige Bedingung aufgestellt. Fehlt dieses Erfordernis, so scheitert die Einheitlichkeit der Tat bereits an diesem Punk.t. ${ }^{343}$ Streng verwechselt hier eine notwendige mit einer hinreichenden Bedingung. „Ein Sachverhalt der die notwendige Bedingung erfüllt, ist damit noch nicht hinreichend als identische Tat ausgewiesen.“344 Zudem müsste Streng auch jedweden anderen Umstand kritisieren, der zu einer Zäsur führt und so eine räumliche und zeitliche Verknüpfung aufspaltet. Denn hierdurch würde dieser Zusammenhang gleichfalls missachtet.

In Bezug auf den letzten Einwand, dass im Fall eines Raubmords, der durch ein anderes Nötigungsmittel vollendet wird, für einen Rücktritt von dem versuchten Mord ein Teilrücktritt ausreiche und somit eine Gleichsetzung von Tat und Tatbestand nicht erforderlich sei, ist fraglich, warum Streng in dieser Konstellation das Argument des Teilrücktritts überhaupt vorträgt. Dies wäre nur dann zutreffend, wenn nach seiner Auffassung eine Tat i.S. des \ 24 Abs. 1 StGB vorliegen würde. Wie festgestellt, ist es nach Streng für einen strafbefreienden Rücktritt erforderlich, dass „,- zumindest für den gegebenen zeiträumlichen Zusammenhang auch von sonstigen strafrechtlich pönalisierten Angriffen gegen das in jenem Tat-

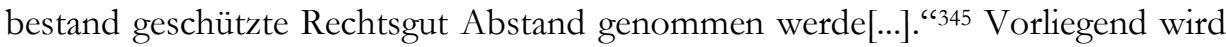
durch den fortgesetzten Raub der Angriff gegen das Leben jedoch nicht weitergeführt ${ }^{346}$, sodass nach Streng schon aus diesem Grund unterschiedliche Taten i.S. des $\int 24$ Abs. 1 StGB vorliegen müssten. Die Fortsetzung des Raubs kann somit für den Rücktritt vom versuchten Mord nicht schädlich sein, sodass es auf einen Teilrücktritt gar nicht ankommt. Allein wenn durch das fortgesetzte Delikt auch weiterhin auf das geschützte Rechtsgut des anderen Tatbestands eingewirkt worden wäre, hätte die Frage nach einem Teilrücktritt Relevanz besessen.

Unabhängig hiervon und allgemein betrachtet spricht gegen einen Teilrücktritt bereits eine gewisse Inkonsequenz. Sind zwei Tatbestände Teil derselben Tat und lässt der Täter allein von einem der beiden Delikte ab, so führt der Täter dieselbe Tat fort und ein Rücktritt muss ausscheiden. Indem durch die Annahme eines Teilrücktritts dieses Ergebnis verändert wird, wird der Wortlaut des \24 Abs. 1 StGB umgangen und damit die Übertatbestandlichkeit des Tatbegriffs konterkariert. Es würde ein übertatbestandlicher Tatbegriff postuliert, wobei die hieraus folgenden Konsequenzen sodann durch Ergebniskorrekturen wider der ursprünglichen Definition modifiziert würden.

Neben dieser Inkonsequenz ist zudem fraglich, warum ein partieller Rücktritt allein bei einer parallelen Tatbestandsverwirklichung angedacht wird, bei einer sukzessiven Begehung hingegen dieser keine Relevanz besitzt. ${ }^{347}$ Sollte der Teil-

343 Günther, GS Armin Kaufmann, 1989, S. 541, 545.

344 Günther, GS Armin Kaufmann, 1989, S. 541, 545.

345 Streng, NStZ 1993, 257, 261.

346 Der Mord schützt das Leben (MK-StGB/Schneider, S 211 Rn. 1), wohingegen der Raub das Eigentum, den Gewahrsam und den Willen schützt (MK-StGB/Sander, \249 Rn. 2).

347 Vgl. Günther, GS Armin Kaufmann, 1989, S. 541, 553: „Wenn bei gleichzeitiger Verwirklichung verschiedener Straftatbestände (z. B. Raub- und Mordversuch, Diebstahls- und Sachbeschädi- 
rücktritt auch in diesen Konstellationen Anwendung finden, so erfolgte eine vollständige Ergebnisgleichschaltung mit der Auffassung des BGH. Zwar könnten dann auch zwei Tatbestände eine Tat bilden, allerdings wäre unabhängig hiervon stets ein separater Teilrücktritt möglich.

\section{(f.) Stellungnahme Kritik Herzberg ${ }^{348}$}

Herzberg erkennt zu Recht, dass sich die Frage nach der Aufgabe und mithin nach einer Zäsur nicht allein im Rahmen des Tatbestandswechsels, sondern auch innerhalb eines Delikts stellen kann. Gegen die Gleichsetzung von Tat und Tatbestand spricht dies allerdings nicht. Aus der Deckungsgleichheit der Begriffe folgt allein, dass spätestens im Zeitpunkt des Deliktwechsels eine Zäsur vorliegt, die zu einer Trennung des einheitlichen Ablaufs führt, nicht jedoch, dass bei nur einem Delikt eine einheitliche Tat stets zwingend vorliegen muss. ${ }^{349}$

Nach Heræ̧berg führt weder ein Deliktsvorbehalt noch die spätere Ausführung eines anderen Delikts zur Negation des Rücktritts, sofern der Täter bezüglich der weiteren Ausführung noch nicht ins Versuchsstadium gelangt ist. Günther weist sodann darauf hin, dass die Auffassung Herz̧bergs ,in Fällen eines Deliktwechsels [...] bei sukzessiver Tatbestandsverwirklichung zu gleichen Ergebnissen wie die höchstrichterliche These vom Tatbestandsbezug des Tatbegriffs" kommt. ${ }^{350}$ Das trifft so aber nur zu, wenn auch nach Herzberg auf einen Tatbestandswechsel stets eine Zäsur folgen würde. Dies wäre dann der Fall, wenn der Täter sich in Bezug auf das nächste Delikt stets in einer bloßen Vorbereitungshandlung befindet und nie sofort das Versuchsstadium erreicht.

Bsp.: Täter $T$ will sich an $O$ rächen. Er schleicht sich von binten an den sitzenden $O$ an, um ibn mit einem Strick zu erdrosseln. Als T bierzu unmittelbar angesetżt hat, hält er es jedoch für ausreichend, Os Hals mit dem Seil am Stubl zu fixieren und ibn nicht zu töten.

Aufgrund der Tatbestandsdivergenz könnte der Täter mit dem BGH vom Mord zurücktreten. Nach Heržberg hingegen liegt hier ein nahtloser Übergang vor, da sich der Täter im Zeitpunkt der Aufgabe des Mords schon im Versuchsstadium

gungsversuch) die versuchte Tat jeweils tatbestandsbezogen zu verstehen ist, der Täter also von dem einen Versuch freiwillig zurücktritt ohne Rücksicht darauf, ob er den anderen vollendet, kann auf die Fälle sukzessiver Ausführungshandlungen schwerlich etwas anderes zutreffen [...].“

Zu Herzberg S. 60 ff.

Siehe hierzu Günther, GS Armin Kaufmann, 1989, S. 541, 545.

Günther, GS Armin Kaufmann, 1989, S. 541, 548. 
einer Freiheitsberaubung und Nötigung befindet. Der Täter hätte die Versuchssituation nie verlassen und ein Rücktritt müsste ausscheiden. Insoweit trifft Günthers Feststellung in Bezug auf die sukzessive Tatbestandverwirklichung nicht zu. Richtig hingegen ist dessen Erkenntnis, dass bei einer parallelen Ausgestaltung Herzberg vom BGH abweicht. Wechselt der Raubmörder vom versuchten Mord zu einem anderen Nötigungsmittel, so müsste ein Rücktritt ausscheiden, da sich der Täter weiterhin im Raubversuch befinde. ${ }^{351}$

Unabhängig von dieser Ergebnisabweichung, was eine faktische Kongruenz der beiden Meinungen ausschließt, ist zu erkennen, dass Herz̧berg ein äußerst ansprechendes Kriterium geschaffen hat, um die Aufgabe der Tat und somit auch die Einheitlichkeit des Geschehens zu bestimmen. Allerdings kann dies nicht über die fehlende Begrenzung der Tat durch einen Tatbestandswechsel und die damit verbundenen aufgezeigten Unstimmigkeiten hinweghelfen. Vor allem im Fall des parallelen Versuchs mehrerer Tatbestände erscheint es unbillig, dem Räuber den Rücktritt vom versuchten Mord allein deswegen zu verwehren, weil er sich weiterhin im Raubversuch befindet. Bezüglich des Mords hat der Täter sich der Rechtsordnung wieder insgesamt zugewandt, sodass eine diesbezügliche Straffreiheit die konsequente Folge sein müsste. ${ }^{352}$

Somit ist festzustellen, dass zwar die einheitsstiftenden Kriterien Herzbergs durchaus ansprechend ausgestaltet sind, allerdings der Umstand der übertatbestandlichen Einheitlichkeit zu unbilligen Ergebnissen führt, weswegen dieser Auffassung nicht gefolgt werden kann.

\section{(g.) Stellungnahme Kritik Linke $\mathrm{353}^{3}$}

Der Hinweis Linkes, dass es vorzugswürdig sei, die Tat anhand eines zeitlichen und räumlichen Zusammenhangs, der wesentlichen Gleichheit des Tatobjekts und der Angriffsrichtung zu bestimmen, verfängt nicht. So wurde durch den BGH allein eine Begrenzung der Einheitlichkeit eingeführt, wobei die grundsätzliche Bestimmung unverändert bleibt. Zwar können zwei Tatbestände einen zeitlichen und räumlichen Zusammenhang aufweisen, jedoch liegt trotz dieser Konnexität eine

351 Günther, GS Armin Kaufmann, 1989, S. 541, 548.

352 Vgl. Günther, GS Armin Kaufmann, 1989, S. 541, 550 in Bezug auf Betrug und Raub; dass die Tat durch einen Tatbestandswechsel begrenzt wird, hat Herz̧berg zu einem späteren Zeitpunkt allerdings wohl doch noch überzeugt, denn in einer späteren Veröffentlichung schließt er sich den Ausführungen des BGH an: „Zurücktreten kann der Täter immer nur von einem konkret versuchten Delikt, also von einer Tat im materiell-rechtlichen Sinn, was auch im Wortlaut von Abs. 1 S. 1 1. Alt. zum Ausdruck gebracht wird, da der Täter hiernach die weitere Ausführung der Tat aufgeben muss." (MK-StGB/Herzberg/Hoffmann-Holland, \ 24 Rn. 96, meine Unterstreichung).

353 Zu Linke S. 63 ff. 
Trennung aufgrund des Deliktswechsels vor. ${ }^{354}$ Auch kann Linke in Bezug auf die Rückkehr in die Legalität entgegnet werden, dass sich der Täter bei einem Tatbestandswechsel zumindest partiell und bezogen auf das vorangegangene Delikt wieder zum Recht bekennt. ${ }^{355}$

Der weitere Einwand, dass das Verständnis des BGH sich auch nicht aus dem Vorsatz ergebe, da es ausreiche, dass die Tätervorstellung die Grundzüge der Tat, also Unrechtsgehalt und Angriffsrichtung, umfasse, erscheint fraglich. So muss der Vorsatz dem objektiven Tatbestand doch gerade entsprechen. ${ }^{356}$ Warum allein eine grobe Vorstellung ausreichen soll, erschließt sich nicht.

Neben diesen Kritikpunkten sei der BGH in der Rechtsanwendung auch selbst inkonsequent. So hätte im Vergewaltigungsfall bereits der Wechsel von der versuchten Vergewaltigung zum Mundverkehr einen Rücktritt darstellen müssen. Dies erscheint auf den ersten Blick schlüssig. Wie jedoch in der kritischen Würdigung des Urteils festgestellt, ist davon auszugehen, dass der BGH aufgrund der räumlichen und zeitlichen Verknüpfung mit der vollendeten Vergewaltigung eine eigenständige versuchte Vergewaltigung durch das Verfolgen mit dem Messer abgelehnt hat. ${ }^{357}$ Insoweit liegt hier keine Inkonsequenz sondern im Gegenteil eine schlüssige Rechtsanwendung vor. Dass der BGH seine eigenen Vorgaben aber selbst nicht einhalte, soll sich nach Linke zudem aus dem Benzin-Fall ${ }^{358}$ ergeben. $\mathrm{Zu}$ Recht ist mit Linke durch den Verbrennungsversuch das Mordmerkmal der Grausamkeit zu bejahen. Der Täter wechselte somit von einem versuchten Totschlag zu einem versuchten Mord, was mit der Rechtsprechung einen Tatbestandswechsel ${ }^{359}$ und folglich eine Zäsur zur Folge hätte. Der BGH bejahte hingegen die Einheitlichkeit zwischen dem versuchten Anzünden und dem Würgen, sodass der Täter durch das Ablassen vom Würgen vollständige Straffreiheit erlangen konnte. Dies erscheint nunmehr im Widerspruch zu den vorherigen Erkenntnissen des BGH zu stehen. Allerdings ist zu erkennen, dass der BGH mit der Vorinstanz das Mordmerkmal der Grausamkeit im Rahmen des Verbrennungsversuchs ablehnte. So hätte sich der Täter nach dem BGH durch den Versuch, das Opfer zu verbrennen, wegen versuchten Totschlags strafbar gemacht, wenn keine weiteren Ausführungsakte verfügbar gewesen wären. ${ }^{360} \mathrm{Da}$ es sich nach Auffas-

354 Siehe Günther, GS Armin Kaufmann, 1989, S. 541, 545, der die Tatbestandsidentität zu Recht als notwendige Bedingung versteht.

355 Günther, GS Armin Kaufmann, 1989, S. 541, 552. Zur Unzulässigkeit von abstrakten Rücktrittsbeschränkungen S. $73 \mathrm{ff}$.

356 Siehe hierzu nur Murmann, Grundkurs, \24 Rn. 8.

357 Siehe S. $66 \mathrm{f}$.

358 BGH, NStZ 1986, $264 \mathrm{f}$.

359 Siehe zum Verhältnis Mord/Totschlag nach Auffassung der Rechtsprechung u.a. BGHSt 1, 368, 370; 22, 375, 377; 36, 231, 233; BGH, NStZ 2006, 288, 290.

360 BGH, NStZ 1986, 264, 265: „Der Senat verkennt nicht, daß ein Täter, dem nach dem mißlungenen Brandanschlag ein weiteres Tatmittel nicht zur Verfügung gestanden hätte, wegen beendeten Totschlagsversuchs zu bestrafen ist.“ (meine Unterstreichung). 
sung des BGH folglich in beiden Fällen um einen versuchten Totschlag handelt und der Tatbestand mithin nicht gewechselt wurde, sind beide Abschnitte aufgrund der räumlichen und zeitlichen Verknüpfung zu einer Tat zusammenzufassen. Das Ablassen von der weiteren Tötungshandlung besitzt somit gleichfalls Auswirkungen auf den ersten Abschnitt. Die von Linke vorgetragene Unstimmigkeit der BGH-Rechtsprechung ist durch diese Entscheidung nicht auszumachen. Allenfalls das Verneinen der Grausamkeit bezogen auf das Verbrennen kann hier kritisiert werden. Auch ist der Schluss Linkes, das von ihr gewonnene Ergebnis auf den Wechsel von einem Betrug zu einer Erpressung zu übertragen, vorschnell. Denn allein aus dem Umstand, dass die Tat nicht auf denselben Tatbestand begrenzt ist, folgt noch nicht, dass stets eine Einheitlichkeit gegeben ist. Erst wenn zwischen den Akten eine Zusammengehörigkeit besteht, bildeten diese auch eine Tat.

Soweit Linke im Weiteren darauf verweist, dass in einer Entscheidung ${ }^{361}$ „unnötig kompliziert und widersprüchlich argumentiert" wurde ${ }^{362}$, so kann dem allein dahingehend zugestimmt werden, dass das Gericht nicht auf die deliktische Divergenz sondern auf ein anderes Zäsurmoment rekurrierte. Setzte man den Tatbegriff des $₫ 31$ StGB tatsächlich mit dem des $₫ 24$ StGB gleich, so wäre es aufgrund des Charakters einer notwendigen Bedingung ${ }^{363}$ hingegen geboten gewesen, zunächst auf den Umstand des abweichenden Tatbestands und die sich ggf. hieraus ableitende Zäsur einzugehen. Ob die Tat i.S. des $\ 31$ StGB und des $\int 24 \mathrm{StGB}$ jedoch tatsächlich insgesamt gleich auszulegen sind, bleibt seitens Linke offen und wird ohne Nachweis behauptet. Augenfällig ist diesbezüglich bereits der abweichende Strafgrund. So bestraft $\int 30$ StGB eine Vorbereitungshandlung, wohingegen $\iint 22$, 23 StGB die konkrete Nähe zur Deliktsrealisierung unter Strafe stellen. ${ }^{364}$ Es erscheint im Hinblick auf die Rücktrittsmöglichkeit somit zumindest möglich, divergente Tatbegriffe zugrunde zu legen. Selbst wenn dies abgelehnt werden sollte, so könnte die Zäsur aufgrund der geänderten deliktischen Ausführung durch den $\mathrm{BGH}$, auch wenn dies unwahrscheinlich ist, einfach übersehen worden sein. Dies würde allerdings nicht bedeuten, dass die Gleichsetzung von Tat und Tatbestand konterkariert werden würde, sondern zeigte allein eine Unzulänglichkeit des Urteils auf. Aufgrund der bestehenden Variablen lässt sich aus dieser Entscheidung entgegen Linke kein Argument für eine widersprüchliche gerichtliche Praxis ableiten.

Die Inkonsequenz des BGH ergebe sich abschließend noch aus einer weiteren Entscheidung ${ }^{365}$, in der der BGH den Rücktritt von einem erfolgsqualifizierten

361 BGH, NStZ 1992, 537 f.

362 Linke, Rücktritt, S. 106.

363 Günther, GS Armin Kaufmann, 1989, S. 541, 545.

364 Siehe nur MK-StGB/Joecks, \30 Rn. 1; BGH, NJW 2005, 2867, 2868; vgl. BGH, NStZ-RR 2003, 137, 138.

365 BGHSt 42, $158 \mathrm{ff}$. 
Versuch bejahte. 366 Diesbezüglich erscheint jedoch schon fraglich, was Linke mit dem Einwand meint, dass es ,nach der Tatdefinition des BGH [...] am nötigen Tatbestandswechsel“" mangele. ${ }^{367}$ Festzustellen sei nochmals, dass aus der Identität von Tat und Tatbestand nicht grundsätə̧lich ein Deliktswechsel für den Rücktritt erforderlich ist, sondern hierdurch nur die Einheitlichkeit des Geschehens begrenzt wird. Unabhängig hiervon und bezogen auf die Entscheidung ist im Zusammenhang mit der Identität von Tat und Tatbestand allein auffällig, dass bei einer Erfolgsqualifikation die Tat gerade nicht mit dem Tatbestand insgesamt gleichgesetzt wird. Allein eine partielle Kongruenz bezogen auf das Grunddelikt besteht. Insoweit kann aber nicht von einem Widerspruch gesprochen werden, da sich die hier fragliche Situation von den Fallkonstellationen im Übrigen unterscheidet. So liegt eine Vorsatz-Fahrlässigkeits-Kombination vor, die eine abweichende Betrachtung rechtfertigt. Der von Linke diesbezüglich vorgebrachte Verweis auf $\int 11$ Abs. 2 StGB und die daraus gezogene Schlussfolgerung, dass das Grunddelikt und die Erfolgsqualifikation eine Tat darstellen, ist zumindest dahingehend angreifbar, dass ungeklärt bleibt, ob \11 Abs. 2 StGB und \24 StGB denselben Tatbegriff zugrunde legen. Folgte man hier Linke, so käme es des Weiteren zu prüfungsbezogenen Unstimmigkeiten. Würde der versuchte Raub eigenständig geprüft, so existierte kein Anknüpfungspunkt, um die Strafaufhebung gem. \24 StGB zu verwehren. Hingegen müsste der Rücktritt im Rahmen der Erfolgsqualifikation ausscheiden, sodass das Grunddelikt nur im Rahmen der Erfolgsqualifikation strafend wirkte, allein jedoch keine Strafbarkeit begründete. ${ }^{368}$

\section{(3.) Weitere Argumente für die Auffassung des BGH}

Wie festgestellt, konnten die vorgebrachten Bedenken den Standpunkt des BGH nicht widerlegen. Allerdings trägt die Auffassung des BGH nicht nur aus Gründen der Unwiderlegbarkeit, sondern es sprechen über dies noch weitere Argumente für sie.

So ist mit Mitsch festzustellen, dass die Versuchsstrafbarkeit nicht aus abstrakten Erwägungen folgt, sondern ein konkreter Bezug zu dem jeweiligen Tatbestand besteht, was gleichfalls für den Rücktritt als Kehrseite gelten muss. ${ }^{369}$

Günther führt für eine Gleichsetzung zutreffend an, dass Abweichungen, die zu einem anderen Tatbestand führen, eine Zäsur begründen müssen, wenn bereits Änderungen im Rahmen desselben Tatbestands die Einheitlichkeit des Gesche-

366 Jäger, NStZ 1998, 161, 163 auf den Linke, Rücktritt, S. 107 u.a. in Fn. 662 verweist. Nach Jäger, der sich gegen die in dem Urteil vorgenommene Gleichsetzung von Tat und Grundtatbestand ausspricht, sei das Ergebnis des BGH unter dieser Prämisse schlüssig. Durch diese Deckungsgleichheit beziehe sich die Tat i.S. des $₫ 24$ Abs. 1 StGB nur auf das Grunddelikt, sodass ein diesbezügliches Ablassen für eine vollständige Straflosigkeit ausreiche.

367 Linke, Rücktritt, S. 107.

368 Vgl. hierzu Bacher, Versuch und Rücktritt vom Versuch beim erfolgsqualifizierten Delikt, S. $216 \mathrm{f}$.

369 Baumann/Weber/Mitsch, AT, $\$ 27$ Rn. 29 a; Günther, GS Armin Kaufmann, 1989, S. 541, 553. 
hens trennen. ${ }^{370}$ Richtig ist ebenfalls Günthers Verweis auf die Exzessproblematik im Rahmen des $\int 24$ Abs. 2 StGB. Begeht ein Mittäter abredewidrig ein anderes Delikt, so erfolgt keine Zurechnung und die Mittäter könnten von dem ursprünglichen Delikt weiterhin zurücktreten. Warum für den Einzeltäter eine andere Bewertung gelten soll, erscheint fraglich. ${ }^{371}$ Dass die Einheitlichkeit des Geschehens spätestens bei einem Tatbestandswechsel ihre Grenze findet, ergibt sich mit Günther auch aus einem Vergleich mit $\int 46 \mathrm{Nr}$. 2 StGB a.F. Hier musste zur Straffreiheit der konkrete Deliktserfolg abgewendet werden, wobei nicht verlangt wurde, dass der Täter sich im Übrigen rechtstreu verhält. ${ }^{372}$ Auch ist der Umstand anzuführen, dass bei paralleler Deliktsverwirklichung ein Rücktritt möglich ist, weswegen dies auch bei einem sukzessiven Versuch der Fall sein muss. ${ }^{373}$

Ein übertatbestandlicher Tatbegriff führte des Weiteren dazu, dass der Mörder im Versuchsstadium nicht zurücktreten könnte, wenn er sich vorbehält, im räumlichen und zeitlichen Zusammenhang eine Sache des Opfers zu entwenden. ${ }^{374}$ Dass der Vorbehalt ein gänzlich anderes Rechtsgut betrifft und hierbei der Unwert viel geringer ist, fände keine Beachtung. Obwohl der Täter sich gegen das Töten ausspricht, müsste er doch hierfür einstehen. Auch der Strafgrund kann solch eine Lösung nicht tragen. Durch den Diebstahlsvorbehalt zeigt der Täter doch nicht, dass er weiterhin zur Tötung des Opfers bereit ist. Vielmehr beweist er, dass er dieses Rechtsgut respektiert und es diesbezüglich einer Strafe nicht bedarf, sodass es mithin geboten ist, beide Abschnitte, trotz ihrer räumlichen und zeitlichen Zusammengehörigkeit, getrennt zu bewerten. ${ }^{375}$

Gleichfalls beeinflusste ein übertatbestandlicher Tatbegriff die Rücktrittsreichweite und stellte hierdurch besondere Anforderungen an das Rücktrittsverhalten. Versucht der Täter ein Delikt und geht sodann zu dem Versuch eines anderen Tatbestands über, von dem er jedoch zurücktritt, so hätte dies bei einer einheitlichen Tat Auswirkungen auf beide Versuchsstrafbarkeiten. Der Delinquent könnte somit erst durch das Ablassen von dem zweiten Delikt von dem ersten Versuch zurücktreten. ${ }^{376}$ Warum aber die Abstandnahme vom zweiten Delikt auch den Rücktritt vom versuchten ersten Tatbestand tragen soll, erscheint zu-

370 Günther, GS Armin Kaufmann, 1989, S. 541, 544 f.

371 Günther, GS Armin Kaufmann, 1989, S. 541, 551.

372 Günther, GS Armin Kaufmann, 1989, S. 541, 553.

373 Günther, GS Armin Kaufmann, 1989, S. 541, 553.

374 Vgl. den Fall bei Günther, GS Armin Kaufmann, 1989, S. 541, 552, bei dem der Täter von einem Mord zu einer Beleidigung wechselt und ebenso die Fälle bei Heræz̨erg, GS H. Kaufmann, 1986, S. $709,714 \mathrm{f}$.

375 Siehe Günther, GS Armin Kaufmann, 1989, S. 541, 549, der kritisiert, warum der Täter für einen versuchten Diebstahl allein aus dem Grund einzustehen hätte, weil er im weiteren Fortgang eine räuberische Erpressung begeht; siehe hierzu auch Herz̧berg, GS H. Kaufmann, 1986, S. 709, 716, der feststellt, dass die Täter solch einer Konstellation „ein bißchen [...] zur Legalität zurückgekehrt" seien.

376 Günther, GS Armin Kaufmann, 1989, S. 541, 553. 
mindest fragwürdig. Der Täter hat durch dieses Verhalten in keinster Weise gezeigt, dass er einer dahingehenden Straffreiheit würdig ist.

Nicht zuletzt müssten bei einer vom BGH abweichenden Auffassung auch weitere Tatbestände in die Fehlschlagsbewertung einfließen. Scheitert ein Betrug, weil das Opfer den Schwindel durchschaut, so bliebe der Versuch trotzdem rücktrittsfähig, wenn der Täter erkennt, dass er den Sachwert bspw. noch durch eine räuberische Erpressung erlangen könnte. Ausreichend wäre es aber auch, wenn der Täter eine Körperverletzung für möglich hält. Diese mangelnde Verknüpfung veranschaulicht Günther an einem Beispiel, wonach auf Basis eines übertatbestandlichen Tatbegriffs eine versuchte Vergewaltigung nicht gescheitert wäre, wenn der Täter das Opfer noch töten könnte. ${ }^{377}$ Der Fehlschlag dürfte mit diesem Verständnis keine Relevanz mehr besitzen. So wird es stets die Möglichkeit einer weiteren Deliktsbegehung geben, die bei entsprechender Vorstellung des Täters einen Fehlschlag verhindert.

Abschließend ist zu erkennen, dass immer dann, wenn eine Inkongruenz zwischen dem Tatbegriff und dem materiell-rechtlichen Tatbestand angenommen wird, zwei Maßstäbe aufeinandertreffen. Der Rücktritt knüpft stets an das konkret versuchte Delikt an, wobei danach zu fragen ist, ob der Täter von diesem zurückgetreten ist. ${ }^{378}$ Im Rahmen der Rücktrittsprüfung wird hingegen gem. \24 Abs. 1 StGB auf die Tat abgestellt, wobei fraglich ist, ob der Täter die Tat aufgegeben hat. Wird hier nunmehr ein übertatbestandlicher Tatbegriff zugrunde gelegt, so führt dies dazu, dass der Täter zwar von dem konkreten Delikt abgelassen haben könnte, er jedoch die Tat durch ein anderes Delikt fortsetzt. In diesem Fall müsste ein Rücktritt mangels Aufgabe ausscheiden. Dies ist allerdings dahingehend widersprüchlich, dass der Rücktritt sich zwar nur auf ein konkretes Delikt bezieht, hierbei aber nicht entscheidend ist, ob von diesem Delikt abgelassen wurde, sondern das vollständige Ablassen von rechtsfeindlichem Verhalten erforderlich ist $\mathrm{t}^{379}$. Vielmehr muss hier doch eine Deckungsgleichheit bestehen, sodass für den Rücktritt von einer versuchten Straftat darauf abzustellen ist, ob der Täter die Verwirklichung dieses konkreten Delikts auch tatsächlich aufgegeben hat.

\section{dd. Fazit}

Die vom BGH vorgenommene Gleichsetzung der Tat i.S. des $₫ 24$ StGB mit dem materiell-rechtlichen Tatbestand überzeugt. Die vorgebrachten Einwände tragen nicht, wobei vor allem die aus einem übertatbestandlichen Tatbegriff folgenden Widersprüchlichkeiten zu einer Identität der beiden Begriffe zwingen.

377 Günther, GS Armin Kaufmann, 1989, S. 541, 553.

378 Dies erkennt auch Streng, NStZ 1985, 358, 359 bzw. siehe S. 58.

379 Zumindest solche Vorstellungen, die in einem räumlichen und zeitlichen Zusammenhang stehen. 


\section{b. Bestimmung der Tatbestandsqualität der unechten Unterlassungsdelikte}

Ein Deliktswechsel führt zu einer Trennung des einheitlichen Geschehens, sodass spätestens dann eine andere Tat i.S. des $₫ 24$ Abs. 1 StGB vorliegt. Für den Rücktritt vom versuchten Unterlassungsdelikt durch weiteres Unterlassen hätte dies dann Konsequenzen, wenn $\int 13$ StGB eine deliktische Eigenständigkeit besäße. Dann folgte aus einem Begehungsformwechsel zugleich ein Tatbestandswechsel und mithin stets eine Zäsur. Die dem Täter nach dem Scheitern des Unterlassens mögliche aktive Handlung wäre nicht mehr Teil derselben Tat, sodass ein Rücktritt durch das Unterlassen dieser Ausführungsmöglichkeit ausscheiden müsste.

Entscheidend ist somit, ob der Begehungsformwechsel zu einem Tatbestandswechsel führt, was an die Tatbestandsqualität des $₫ 13$ StGB i.V.m. dem entsprechenden aktiven Delikt anknüpft. Konstitutiv ist hierbei eine Vorschrift immer dann, wenn sich aus ihr eine neue Rechtspflicht ergibt ${ }^{380}$, wohingegen sie deklaratorisch ist, wenn eine bestehende Rechtspflicht lediglich aufgezeigt wird ${ }^{381}$.

\section{aa. Auffassung des BGH}

Nach Auffassung des BGH ,[brachte] [d]iese Bestimmung [( 13 StGB)] [...] keine Änderung des bis dahin geltenden Strafrechts, sie begründete nicht erst die Strafbarkeit für unechte Unterlassungsdelikte. [...] Die Aufnahme der Vorschrift in den Allgemeinen Teil bezweckte auch keine Änderung der bisherigen Handhabung der unechten Unterlassungsdelikte. Sie beruhte überwiegend auf rechtsstaatlichen Erwägungen. Vor allem sollte dem Bestimmtheitsgebot des Art. 103 Abs. 2 GG Rechnung getragen werden." ${ }^{382}$ Der BGH verneint folglich die strafbegründende und somit konstitutive Wirkung des $\ 13$ StGB. ${ }^{383}$ Diesen deklaratorischen Charakter bestätigte der BGH auch in einer späteren Entscheidung:

380 Siehe Murmann, GA 2012, 711, 714; vgl. auch Köbler, Deutsches Rechts-Lexikon, Arloth/Tilch (Hrsg.), 3. Aufl. 2001, Bd. 2, S. 2558.

381 Siehe Murmann, GA 2012, 711, 714; vgl. auch Köbler, Deutsches Rechts-Lexikon, Arloth/Tilch (Hrsg.), 3. Aufl. 2001, Bd. 1, S. 1036.

382 BGH, NJW 1990, $332 \mathrm{f}$.

383 Siehe zur Auffassung des BGH MK-StGB/Freund, \ 13 Rn. 298; siehe zudem Freund aaO, \ 13 Rn. 14, der $\int 13$ StGB eine allein deklaratorische Wirkung zukommen lässt: „Dass eine Tatbestandsverwirklichung nicht nur durch die Verhaltensform des aktiven Tuns, sondern auch durch Unterlassen möglich ist, war in der Sache nie ernsthaft umstritten. Insofern kommt $\int 13$ lediglich eine Klarstellungsfunktion zu." 
BGH: T zündet das Opfer an. Die zwei Nebentäter $N_{1}$ und $N_{2}$ akezeptieren dies zunächst, als das Feuer jedoch schon fast erloschen ist, schreiten sie ein und ersticketen die restlichen Flammen. ${ }^{384}$

Mangels gemeinsamen Tatplans wurde bzgl. $\mathrm{N}_{1}$ und $\mathrm{N}_{2}$ auf versuchten Totschlag durch Unterlassen erkannt. Bzgl. eines möglichen Rücktritts stellten die Richter fest, dass kein Fehlschlag vorliege, da ,nach dem Ersticken des Brandes [...] für sie [(die Unterlassungstäter)] kein ersichtlicher Grund [bestand] anzunehmen, sie könnten den ursprünglich in Kauf genommenen Taterfolg nicht mehr - im Zusammenwirken mit den anderen Angeklagten - herbeiführen. “385 Der Fehlschlag des versuchten Totschlags durch Unterlassen wurde folglich allein durch eine mögliche aktive Erfolgsherbeiführung abgelehnt, was bedeutet, dass trotz eines Begehungsformwechsels die Einheitlichkeit der Tat fortbesteht. ${ }^{386}$ Aufgrund des Umstands, dass der BGH bei einem Tatbestandswechsel eine Zäsur annimmt, kann dies nur dann zutreffen, wenn von einer deklaratorischen Wirkung des \ 13 StGB und mithin einer deliktischen Unselbstständigkeit ausgegangen wird.

Unabhängig von dieser Einschätzung des BGH zeichnet sich in dem Urteil bereits eine Unstimmigkeit dahingehend ab, warum für die Frage des Fehlschlags auf den Zeitpunkt nach dem Löschen der Flammen abgestellt wurde. „Für die Angeklagten [...] lag nach dem Löschen des Brandes kein Fehlschlag des Versuchs vor. “387 Dies wäre nur dann konsequent, wenn die Täter erkannten, dass das Unterlassen für sich genommen nicht mehr dazu in der Lage war, den Tod des Opfers noch herbeizuführen. Indem sie allerdings rettend einschritten und „die letzten Flammen“ löschten, spricht vieles dafür, dass aus ihrer Perspektive auch nach dem „Welzen“ des Opfers die Todesgefahr andauerte. Folglich scheint es so, als ob die Delinquenten zum Zeitpunkt ihres Einschreitens fortwährend von der Tauglichkeit des Unterlassens ausgingen und sich somit in einem beendeten Versuch befanden, sodass schon aus diesem Grund ein Fehlschlag nicht vorläge. Welchen Eindruck die Täter in der konkreten Situation jedoch tatsächlich hatten, lässt sich dem Urteil nicht entnehme.

Wird aber der Fehlschlag des Unterlassens mit dem BGH bejaht, so stellt sich die sodann vom BGH vorgenommene Abgrenzung vom unbeendeten/beendeten Versuch nicht. Denn geht der Täter davon aus, dass sein erster Ausführungsakt fehlgeschlagen ist, so kann dieser nicht gleichzeitig annehmen, durch diesen Akt bereits alles Erforderliche getan zu haben, um den Erfolg herbeizuführen. Insoweit sind die diesbezüglichen gerichtlichen Ausführungen nicht erforderlich.

\footnotetext{
384 BGH, NStZ 2010, 690 ff.

385 BGH, NStZ 2010, 690, 691.

386 Siehe hierzu auch Murmann, GA 2012, 711, 713.

387 BGH, NStZ 2010, 690, 691.
} 
Hiervon losgelöst bleibt allerdings weiterhin fraglich, ob es überzeugt, den Begehungsformwechsel als reinen Tatmittelwechsel zu begreifen oder dem Unterlassen vielmehr eine deliktische Eigenständigkeit zukommen zu lassen. 388

bb. Die Unterlassungsstrafbarkeit vor Einführung des $₫ 13$ StGB/Sinn und Zweck der Einführung des $\$ 13$ StGB (= Verfassungsmäßigkeit der Strafbarkeit des „Begehens durch Unterlassen“ ohne besondere gesetzliche Ausgestaltung)

Rechtshistorisch war eine besondere Normierung der unechten Unterlassungsdelikte dem Strafgesetzbuch stets fremd. \13 StGB erlangte erst am 01. Januar 1975 im Zuge des 2. Strafrechtsreformgesetzes ${ }^{389}$ Rechtskraft. ${ }^{390}$ Zuvor war ein Unterlassen jedoch nicht etwa straflos, sondern neben normierten Unterlassungsdelikten wurde die Strafbarkeit im Übrigen aus den Begehungsdelikten ${ }^{391}$ abgeleitet bzw. ohne nähere Begründung angenommen. ${ }^{392}$

Dies könnte nunmehr den Schluss zulassen, dass Begehungsdelikte auch fortwährend immanent die Unterlassung umfassen, sodass die Strafbarkeit eines Unterlassens und des aktiven Pendants auf demselben Straftatbestand beruhen würden. ${ }^{393}$ In diesem Fall läge durch einen Begehungsformwechsel, mangels konstitutiver Wirkung des $₫ 13$ StGB, kein Tatbestandswechsel und somit, zumindest aus diesem Grund, auch keine Zäsur des einheitlichen Geschehens vor.

388 Siehe hierzu Murmann, GA 2012, 711, 713 f.

389 BGBl. Teil I Nr. 56, Zweites Gesetz zur Reform des Strafrechts (2. StrRG) vom 4. Juli 1969.

390 Siehe hierzu BGBl. Teil I Nr. 63, Gesetz über das Inkrafttreten des Zweiten Gesetzes zur Reform des Strafrechts vom 30.07.1973, S. 909.

391 Siehe zum Begehungsdelikt Murmann, Grundkurs, $\ 14$ Rn. 27.

392 Siehe u.a. Petters/Preisendan₹, StGB, 28. Aufl. 1974, C I. 1. c) S. 29: „Die unechten Unterlassungsdelikte sind daher nichts anderes als besondere Erscheinungsformen d e r B e g e h u n g s d e li k t e.“; Preisendanz, StGB, 29. Aufl. 1975, \13 I: „Erklärtes Anliegen der Vorschrift [ $₫ 13 \mathrm{StGB}]$ ist es, die bisher nur gewohnheitsrechtlich entwickelte Strafbarkeit der sog. unechten Unterlassungsdelikte auf eine festere Rechtsgrundlage zu stellen [...].; siehe Moser, AT, 2. Aufl. 1953, \$21 II: „Das Wort Handlung umfasst nach dem Sprachgebrauch des StGB auch Unterlassungen."; Kohlrausch-Lange, StGB, 43. Aufl. 1961, system. Vorb. II II, der einfach feststellt, dass ,auch eine Unterlassung [...] sozial erhebliches Verhalten sein [kann].“; Schönke/Schröder, 17. Aufl. 1974, Vorbem. 77, wonach die unechten Unterlassungsdelikte anerkannt seien; LK-StGB/Nagler/Mezger, 7. Aufl. 1954, Bd. 1, Anhang 2 B.I.1., die bzgl. der unechten Unterlassungsdelikte feststellen: „Sie sind lediglich Erscheinungsformen des durch ein bestimmtes Verbot substantiell begründeten Begehungsverbrechens (si fugienda facis), weil hier die Unterlassung infolge der unmittelbar fühlbaren Einflußnahme auf die Gestaltung des äußeren Kausalverlaufs der positiven tatbestandsmäßigen Tätigkeit g l e i c h gestellt werden muß.“; Wessels, AT, 1. Aufl. 1970, \14 I 2: „Für die rechtliche Bewertung der Tat macht es aber keinen Unterschied, ob eine Mutter ihr Kleinkind nun vorsätzlich vergiftet oder verhungern oder im Swimmingpool ertrinken läßt.“ Zudem wird ebenda auf eine „gewohnheitsrechtlich anerkannte Ableitung der unechten Unterlassungsdelikte aus den Begehungstatbeständen“ erkannt; Berner, Lehrbuch des Deutschen Strafrechts, 18. Aufl. 1898, S. 118 \63, der absichtliche Unterlassungen als „n e g a t i v e H a n d l u n g e n“ beschreibt; Mezger/Blei, Strafrecht AT, 14. Aufl. 1970, \$ 23 III 2. b) die gleichsam die Möglichkeit der Realisierung durch Unterlassen annehmen. 
Fraglich erscheint aber dann, warum es des $\int 13$ StGB bei solch einer Auslegung überhaupt bedarf. Wenn sich die Strafbarkeit des Unterlassens ganz selbstverständlich als eine besondere Ausprägung der Begehungsdelikte darstellt, so könnte auf eine spezielle gesetzliche Ausformung gänzlich verzichtet werden.

Entscheidend ist somit, welche Gründe den Gesetzgeber dazu bewogen haben, $\mathbb{1} 13 \mathrm{StGB}$ in das Strafgesetzbuch aufzunehmen. Im zweiten schriftlichen Bericht des Sonderausschusses für die Strafrechtsreform heißt es: „Aus rechtsstaatlichen Erwägungen, insbesondere im Hinblick auf Artikel 103 Abs. 2 GG, empfiehlt sich die Aufnahme dieser Vorschrift. Durch sie wird im Gesetz selbst zum Ausdruck gebracht, daß Straftatbestände auch durch ein Unterlassen verwirklicht werden können. “394 Dem schließt sich, wie bereits dargestellt, auch der BGH an, der als Motivation für die Einführung des $\int 13$ StGB das Bestimmtheitsgebot ansieht. ${ }^{395}$ Roxin erkennt, dass vor der gesetzlichen Ausgestaltung die Herleitung der Unterlassungsstrafbarkeit in einem Spannungsverhältnis zum Analogieverbot und zum Bestimmtheitsgebot stand. ${ }^{396}$ Dem stimmt im Ergebnis auch Weigend zu, der davon ausgeht, dass , $\ 13[\ldots]$ deshalb eingeführt [wurde], weil man es für notwendig hielt, eine rechtliche Grundlage dafür zu schaffen, dass die Strafgesetze nicht nur auf aktives Tun, sondern auch auf Unterlassen angewendet werden.“397

\section{(1.) Verfassungsmäßigkeit der Unterlassungsstrafbarkeit bei Fehlen des $₫ 13$ StGB}

Fraglich ist somit, ob eine Strafbarkeit des Unterlassens im Rahmen der Begehungsdelikte obne den $\ 13$ StGB zulässig wäre, mithin also, inwieweit die vor Einführung des $₫ 13$ StGB geübte Praxis Verfassungskonformität aufweist. ${ }^{398}$ Stände dies in Einklang mit dem Grundgesetz, so müsste der Strafgrund in den Begehungsdelikten gesehen werden und, da es gerade einer weiteren gesetzlichen Aus-

394 BT-Drs. V/4095, S. 8; siehe auch BT-Drs. IV/650, S. 124: „Eine ausdrückliche gesetzliche Regelung [...] empfiehlt sich aus rechtsstaatlichen Gründen, um die Praxis auf feste Grundlagen zu stellen und Zweifel, die immer wieder auch im Hinblick auf den Grundsatz der gesetzlichen Bestimmtheit der Straftatbestände (Artikel 103 Abs. 2 GG) geäußert werden, zu beseitigen.“ ders., Die Dogmatik der Unterlassungsdelikte, 2. Aufl. 1988, S. 281 f. der gleichfalls ein Spannungsverhältnis zu ,nullum crimen sine lege“ erkennt.

397 LK-StGB/Weigend, \ 13 Rn. 12 Fn. 32, der auf Gallas, Niederschriften über die Sitzungen der Großen Strafrechtskommission, 1959, 12. Bd., S. 79 f. verweist.

398 Anzumerken sei, dass es im Rahmen dieser Prüfung und im Folgenden nicht darauf ankommt, ob frühere Stimmen versuchten die Begehung durch Unterlassung auf andere Weise zu legitimieren, als es der $\int 13$ StGB heute tut. So hat sich der Gesetzgeber mit Einführung des $\int 13$ StGB dazu entschieden, die Gleichstellung von Tun und Unterlassen an der Garantenstellung festzumachen, sodass für die vorliegende Frage Auffassungen dahinstehen können, die diese Gleichstellung anderen Kriterien unterordneten. Wichtig ist hier allein, ob der Inhalt des \ 13 StGB sich auch eigenständig aus den Begehungsdelikten ergibt. Bei dieser Betrachtung sind jedoch freilich frühere Stimmen zu berücksichtigen, soweit sie versuchten, die Voraussetzungen des heutigen $\int 13 \mathrm{StGB}$ auf andere Weise zu begründen. 
gestaltung nicht bedürfe, wäre der $\int 13$ StGB rein deklaratorisch, denn er verweist auf das, was das Gesetz bereits ohne diese besondere Normierung konstituiert. $\int 13$ StGB stellte in diesem Fall eine überobligatorische Vorschrift dar, die dem Bürger die bestehende Unterlassungsstrafbarkeit verdeutlichen soll.

Klärungsbedürftig ist somit, ob eine sich allein aus den Begehungsdelikten ergebene Unterlassungsstrafbarkeit einen Verstoß gegen das Gesetzlichkeitsprinzip gem. Art. 103 Abs. 2 GG bedeutet. Aus dem Gesetzlichkeitsprinzip folgen vier Regeln: das Analogieverbot, das Rückwirkungsverbot, das Verbot des Gewohnheitsrechts und das Bestimmtheitsgebot. 399

Indem nunmehr davon ausgegangen wird, dass sich die Strafbarkeit der Unterlassungsdelikte direkt aus den Begehungsdelikten ergibt, könnte ein Verstoß gegen das Analogieverbot ${ }^{400}$ und das Bestimmtheitsgebot ${ }^{401}$ vorliegen.

\section{(a.) Verstoß gegen das Analogieverbot}

Das Analogieverbot verbietet eine Anwendung des Rechts, „die über den Inhalt einer gesetzlichen Sanktionsnorm hinausgeht.“402 „Der mögliche Wortsinn des Gesetzes markiert die äußerste Grenze zulässiger richterlicher Interpretation" "403, wobei es zur Bestimmung des Wortsinns auf die Sicht des Bürgers ankomme. ${ }^{404}$

Für die vorliegende Frage, ob die Begehungsdelikte auch das Unterlassen umfassen, bedeutet dies somit, dass zu ergründen ist, ob der Wortsinn der Begehungsdelikte ein Unterlassen einschließt. Es kommt somit auf den konkreten Wortlaut jedes einzelnen Tatbestands an.

Schon diesen konkreten Anknüpfungspunkt übergeht Böhm indem er feststellt, dass das Strafgesetzbuch Unterlassungsstrafbarkeiten enthalte und daraus geschlossen werden könne, „daß der Gesetzgeber im Strafrecht ebensowenig wie in anderen Rechtsgebieten sich nur auf die aktive Seite menschlichen Verhaltens beschränken wollte." Ein Mensch bestimme sowohl durch aktives Tun als auch durch Unterlassen den Geschehensablauf, weswegen „die Rechtsordnung vernünftigerweise überall und auch im Strafrecht Rechtsfolgen an beide Arten menschlichen Verhaltens anknüpfen [wird]. Da unerwünschte Erfolge sowohl auf einem Tun als auch auf einem Unterlassen beruhen können, erscheint es wenig sinnvoll, mit großem Scharfsinn darzutun, durch Unterlassen könne nichts verursacht werden. " ${ }^{405}$ Freilich mögen die Aussagen Böhms schlüssig erscheinen. Jedoch

\footnotetext{
399 Siehe hierzu nur Nolte, in: v. Mangoldt/Klein/Starck, GG III, 6. Aufl. 2010, Art. 103 Rn. 96.

400 Zum Analogieverbot S. 95 ff.

401 Zum Bestimmtheitsgebot S. $106 \mathrm{ff}$.

402 BVerfG, NJW 1986, 1671, 1672; BVerfG, NStZ 2009, 560, 561.

403 BVerfG, NJW 1986, 1671, 1672; BVerfG, NStZ 2009, 560, 561.

404 BVerfGE 71, 108, 115; BVerfG, NJW 1986, 1671, 1672.

405 Böhm, JuS 1961, 177, 178; siehe hierzu auch Jescheck, AT, 2. Aufl. 1972, S 58 IV 5.a), der feststellt, „[d]aß jedenfalls der Gesetzgeber mit dem Merkmal der Erfolgsverursachung unter gewissen $\mathrm{Vo}_{\mathrm{O}}$
} 
darf Interpretation nur im Rahmen der verfassungsrechtlichen Grenzen Anwendung finden. Selbst wenn die Überlegungen Böhms somit sogar als folgerichtig angesehen werden müssten, Maßstab bleibt weiterhin der Wortlaut des konkreten Delikts. Was nunmehr vernünftig ist oder worauf sich der Gesetzgeber nicht beschränken wollte, besitzt hier keine Relevanz. Entscheidend ist allein, was sich aus dem konkreten Gesetz ergibt, hier ob der Wortlaut der Tatbestandsmerkmale auch ein Unterlassen umfasst. ${ }^{406}$ Ist dies nicht der Fall, so können selbst die überzeugendsten Überlegungen darüber nicht hinweghelfen.

Hieran ändert auch der Vorschlag Maurachs nichts, wonach ein Unterlassen eine Handlung sei und somit die aktiven Delikte dieses Verhalten umfassen.. ${ }^{407}$ Die Wortlautgrenze kann durch diese Auslegung nicht umgangen werden. Denn selbst wenn es abstrakt zuträfe, dass das Unterlassen eine Handlung ist, so muss dies nicht bedeuten, dass jedes Begehungsdelikt auch jede Handlung pönalisieren will. Somit kann und muss Maßstab allein das individuelle Delikt sein, sodass auch bei diesem Verständnis ungeklärt bleibt, ob der konkrete Tatbestand das Verhalten des Täters erfasst. 408

Fraglich ist somit, ob der Wortsinn der Begehungsdelikte ein Unterlassen einbezieht, was im Folgenden exemplarisch anhand von ausgewählten aktiven Delikten untersucht werden soll. Maßstab hierfür ist die Sicht des Bürgers und somit ob dieser erkennen kann, dass neben aktiven Handlungen auch eine Erfolgsrealisierung durch ein Unterlassen Tatbestandsqualität besitzt. ${ }^{409}$ Fasst dieser unter ein

raussetzungen auch die Nichtabwendung des Erfolgs gemeint hat[...]“. Dies folge z.B. aus \223 b StGB, der konkret auf ein Unterlassen abstelle. Dies nunmehr zu verallgemeinern sei richtig, „denn es wäre mit gesetzgeberischer Logik unvereinbar, wenn zwar die Gesundheitsschädigung, nicht aber die Tötung durch Unterlassen erfaßt werden sollte.“

406 Vgl. Meyer-Bablburg, GA 1966, 203.

407 Maurach, AT, 3. Aufl. 1965, \46 III A 4.; Moser, AT, 2. Aufl. 1953, \ 21 II unterstellt, dass Handlung aufgrund des Sprachgebrauchs auch das Unterlassen umfasse.

408 So pauschal will auch Nickel, Die Problematik der unechten Unterlassungsdelikte, S. 27 ff. die Frage nach der Reichweite des Wortlauts lösen. Handele es sich bei dem fraglichen Delikt nicht um ein reines Unterlassungs- bzw. Begehungsdelikt, so stelle es ein „unterlassungsoffenes Delikt" dar und sei dem Unterlassen aus diesem Grund weder verschlossen noch geöffnet. Hierdurch wird jedoch missachtet, dass jeder Tatbestand andere Tatbestandsmerkmale determiniert, die unterschiedliche Bedeutungsreichweiten umfassen können. Folglich ist diese Schematisierung für die Frage, ob das Unterlassen im Rahmen der Begehungsdelikte Relevanz entfaltet, untauglich. Die konkrete Auslegung lässt sich auch nicht mit dem Hinweis übergehen, dass bei einer Verneinung der Unterlassungsstrafbarkeit im Rahmen der Begehungsdelikte eine ,willkürliche Lückenhaftigkeit des Rechtsgüterschutzes“ entstünde (ebenda S. 30). Resultiert aus der individuellen Reichweitenbestimmung der einzelnen Tatbestände, dass das Unterlassen vereinzelt oder insgesamt nicht tatbestandsmäßig ist, so ist es Aufgabe des Gesetzgebers diese Lücken zu schließen und nicht den Gerichten auferlegt, die Tatbestände so zu erweitern, dass das als strafbar erachtete Verhalten von dem Delikt doch noch erfasst wird.

409 Zur Betrachtungsperspektive BVerfGE 71, 108, 115: „Wenn, wie gezeigt, Art. 103 Abs. 2 GG Erkennbarkeit und Vorhersehbarkeit der Straf- oder Bußgeldandrohung für den Normadressaten verlangt, so kann das nur bedeuten, daß dieser Wortsinn aus der Sicht des Bürgers zu bestimmen ist.“; ebenso BVerfG, NJW 1986, 1671, 1672; BVerfG, NJW 2007, 1666: „Der mögli- 
Verhalten im Rahmen eines Begehungsdelikts auch ein Unterlassen, so läge kein Verstoß gegen das Analogieverbot vor. Dies erscheint unter dem Aspekt schlüssig, dass der Täter nicht schutzwürdig wäre, wenn er um die genauen Folgen seines Verhaltens weiß.410 Solch ein individueller Maßstab kann aber freilich nicht Maßstab der Verfassungsmäßigkeit sein, da die Verfassungsmäßigkeit anderenfalls davon abhinge, wie der Einzelne die gesetzlichen Voraussetzungen interpretiert. Insoweit kann nur das Verständnis der Gesellschaft im Allgemeinen zur Ergründung des Wortsinns Bedeutung besitzen. ${ }^{411}$

Unzulässig ist es hingegen, den Sinn der Vorschrift für die Auslegung heranzuziehen. ${ }^{412}$ „Denn der Sinn eines Tatbestands ergibt sich erst auf Grund dessen Auslegung. "413 Insoweit muss Radbruch einräumen, dass das Unterlassen im Rahmen der Begehungsdelikte keine deliktische Relevanz besitzen kann, wenn er feststellt, dass man, „,wenn auch nicht dem Wortlaute, so doch dem Sinn des Gesetzes gerecht [wird], wenn wir, obgleich eine Verursachung in unserem Sinne nicht vorliegt, auch im Falle der Nichtverursachung des Nichteintritts des Todes strafen." 414

Somit steht fest, dass allein im Fall eines weiten Wortverständnisses der Allgemeinheit das Unterlassen Teil der aktiven Tatbestände ist, anderenfalls würde bei einer strafrechtlichen Relevanz des Unterlassens ein Verstoß gegen das Analogieverbot vorliegen.

\section{(aa.) Ergründung des Bewertungsmaßstabs anhand des $\S 212$ StGB und die dortige Tatbestandsmäßigkeit des Unterlassens}

Im Rahmen des $₫ 212$ Abs. 1 StGB ist entscheidend, ob „Wer einen Menschen tötet" auch die Erfolgsherbeiführung durch ein Unterlassen umfasst.

Schünemann führt hierzu an, dass sich eine Beschränkung auf eine allein aktive Tötung nicht ergebe. So folge schon aus dem allgemeinen Sprachgebrauch, dass „töten“ gerade nicht mit „den Tod verursachen“ gleichzusetzen sei. Ernährt eine

che Wortsinn des Gesetzes markiert die äußerste Grenze zulässiger richterlicher Interpretation. Da Art. 103 II GG die Vorhersehbarkeit der Strafandrohung für den Normadressaten garantieren will, ist die Grenze aus dessen Sicht zu bestimmen.“

410 Hierzu auch Grünwald, ZStW 1958, 412, 417 f.: „Ist es allgemeine Auffassung - und war es auch die Auffassung des Gesetzgebers -, daß auch der Unterlassende töte, so ist keine Garantie des Staatsbürgers verletzt, wenn man ihn wegen Totschlags bestraft."; siehe auch Grünwald, Das unechte Unterlassungsdelikt, S. $68 \mathrm{f}$.

411 Vgl. MK-StGB/Schmitz, \1 Rn. 63. Insoweit ist der Verweis Schmitz' in ebenda $\int 1$ Rn 73 Fn. 278 auf BGH, NJW 2007, 524 ff. fruchtbar. In dieser Entscheidung hatte der BGH unter Pflanze auch Pilze subsumiert (siehe hierzu auch die Anmerkung von Schmitz ebenda $\int 1 \mathrm{Rn} .73$ ).

412 MK-StGB/Schmitz, $\int 1$ Rn. 63.

413 MK-StGB/Schmitr, $\int 1$ Rn. 63.

414 Radbruch, Der Handlungsbegriff, S. 142 f.; auf diesen verweist Grünwald, Das unechte Unterlassungsdelikt, S. 69 Fn. 1. 
Mutter ihr Kind nicht und stirbt es deswegen, so habe „die Mutter [...] ihr Kind durch Nichternähren [getötet]. “415 Bremst ein Zugführer nicht und erfasst der Zug ein auf den Schienen spielendes Kind, so habe der ,Zugführer [...] das Kind auf den Schienen durch Nichtbremsen [...] getötet."416 Schünemann stellt zudem fest, dass mit „tötet“ auch nicht allein gemeint sei „den Tod nicht abwenden“, weswegen die Grenzen zwischen diesen beiden Extremen verlaufe, wobei jedoch eine Sache sicher sei: „Eine vernünftige Garantentheorie wird auch vom Gesetzeswortlaut gedeckt werden, das Nichtretten durch den Garanten wird immer als Töten verstehbar sein; gerade weil der Umgangssprachgebrauch keine exakte Grenzziehung zwischen den Extremen ermöglicht, deckt er praktisch jede nicht schlechthin unvernünftige Garantentheorie!“417

Nach der Argumentation von Schünemann erfasst \212 StGB somit auch ein Unterlassen. Man wird einer Mutter stets vorwerfen, ihr Kind getötet zu haben, wenn dieses durch mangelnde Ernährung verstirbt. Der Wortsinn im Allgemeinen lässt eine Verwendung in diesem Rahmen dem Anschein nach zu. Problematisch erscheint jedoch, den Sinn eines Wortes von der Seite des Verwendens im Kontext zu ergründen und nicht von der Seite des alleinigen Verstehens. Es ist doch zunächst vielmehr danach zu fragen, ob ein gesetzliches Tatbestandsmerkmal, ohne weitere Erörterung, ein bestimmtes Verhalten einschließt, als danach, in welchem Zusammenhang das entsprechende Wort ggf. Anwendung finden kann. Die Konturierung einer tatbestandlichen Voraussetzung anhand des Wortsinns setzt somit als Erstes voraus, dass der konkrete Wortlaut, mithin also das konkrete Tatbestandsmerkmal isoliert, das fragliche Verhalten überhaupt umfasst. ${ }^{418}$

Im Hinblick auf $\int 212$ StGB ist die Frage folglich dahingehend zu konkretisieren, ob „,tötet“ allein das Unterlassen einschließt, ohne zu erwähnen, dass es sich um ein Unterlassen handelt. Indem Zusatzinformationen hinzugedacht werden,

415 Scbünemann, Grund und Grenzen der unechten Unterlassungsdelikte, 1971, S. 57; dieses Beispiel auch bei Welzel, Strafrecht, 5. Aufl. 1956, S. 167 und bei LK-StGB/Nagler/Schaefer, 6/7. Aufl. 1951, Bd. 2, \212 II. 2; dass in diesem Fall ein „Töten“ vorliegt auch bei MK-StGB/Freund, \ 13 Rn. 300; siehe auch H. Mayer, AT, 1953, S. 153.

416 Scbünemann, Grund und Grenzen der unechten Unterlassungsdelikte, S. 57.

417 Scbünemann, Grund und Grenzen der unechten Unterlassungsdelikte, S. 57.

418 Vgl. hierzu BVerfGE 92, 1, 16 ff. Das Bundesverfassungsgericht hatte sich in dieser Entscheidung im Hinblick auf den Gewaltbegriff mit der spiegelbildlichen Konstellation auseinanderzusetzen. So besitzt der Gewaltbegriff, wie das Bundesverfassungsgericht auf S. 16 zutreffend feststellt, ein breites Bedeutungsspektrum. Der Wortlaut ist somit weiter als dass dies dem Wortsinn noch entspricht. Um den Wortsinn konkret bestimmen zu können, muss der Gewaltbegriff „im Zusammenhang des Normgefüges verstanden werden“, sodass insoweit auch die gesetzgeberischen Intentionen heranzuziehen sind.

Für die Frage nach der originären Tatbestandsmäßigkeit des Unterlassens kann dies jedoch dahinstehen, da zunächst dem Grundsatz nach zu klären ist, ob, anders als bei dem Gewaltbegriff, das Unterlassen im Wortlaut überhaupt aufgeht. 
scheint es so, als ob die Bedeutungsreichweite verfälscht werden könnte. ${ }^{419}$ Denn gerade Zusatzinformationen oder etwa eine konkrete Bestimmung von Ausführungsmodalitäten sind dem $\$ 212 \mathrm{StGB}$ fremd. Lautete der $\$ 212 \mathrm{StGB}$,Wer einen Menschen aktiv oder durch ein Unterlassen tötet [...]", so stellte sich das hiesige Problem freilich gar nicht. Aus diesem Grund muss sich die Ergründung des Wortlautumfangs auf das beschränken, was das Gesetz an Anhaltspunkten bietet. Die Auslegung ist somit allein an dem Begriff „tötet“ vorzunehmen. Hieraus folgt, dass die Beispiele zur Bedeutungsergründung auch nicht mehr Informationen enthalten dürfen, als der eigentliche Straftatbestand.

Im Rahmen des Beispielsfalls der Mutter, die ihr Kind verhungern lässt, dürfte es somit nur heißen „die Mutter hat ihr Kind getötet“. Auf dieser Basis ist nunmehr zu entscheiden, was „getötet" bedeutet. Durch solch eine Reduktion des Sachverhalts ist die Bestimmung der Begriffsreichweite augenscheinlich erschwert, wobei allerdings allein das Erkennen einer möglichen Begehung durch Unterlassen ausreichen würde, um dieses dem Wortlaut zuzuordnen.

Hier wird aufgrund der engen Beziehung zwischen einer Mutter und ihrem Kind ein Abhängigkeitsverhältnis begründet. Diese besondere Beziehung wird auch für einen unbeteiligten Dritten den Schluss zulassen, dass das Kind aufgrund eines Unterlassens der Mutter ,getötet" worden sein könnte. Gleiches muss auch für den Vater gelten, der sich vor dem Unterlassen von Rettungsbemühungen über seine Strafbarkeit informiert. Zumindest aufgrund der Stellung zu seinem eigenen Sohn wird ihm hier eine unterlassene Hilfe als „tötet“ i.S. des \212 Abs. 1 StGB vorkommen.

Fraglich erscheint aber sodann, ob solch eine besondere Beziehung zwischen Täter und Opfer erforderlich ist, um unter einem „tötet" auch eine mögliche Unterlassung zu fassen. Um dies zu ergründen, sind gleichfalls besondere Näheverhältnisse auszublenden. Anstatt der Mutter, die ihr Kind tötet, darf es nunmehr nur noch heißen „A tötet B“. Es ist zu erkennen, dass es in einer solchen Konstellation ohne Sonderwissen nochmals schwieriger wird, unter „tötet“ auch ein Unterlassen zu verstehen.

Ob jedoch auch ein unbeteiligter Dritter i.S. des $\$ 212$ StGB durch Unterlassen „tötet“" erscheint hinsichtlich der Wertung uneindeutig und soll hier dahinstehen. Die Frage danach, ob jedwedes Unterlassen tatbestandlich ist oder erst in Verbindung mit der Erfolgsabwendungspflicht Relevanz entfaltet, wird im Rahmen des „Bestimmtheitsgebots“ Beachtung finden. Denn die Wortlautreichweite besitzt Bedeutung dafür, ob die Garantenstellung strafbegründend wirkt oder einen allein einschränkenden Charakter aufweist. Erfasst das Töten jedwedes Unterlassen, so wirkte die Garantenstellung einschränkend, wohingegen ihr eine konstitutive Wirkung zukommen würde, wenn gerade nur Unterlassungen relevant sind, die durch

419 Vgl. hierzu Androulakis, Studien zur Problematik der unechten Unterlassungsdelikte, S. 169 ff. i.V.m. Fn. 4. und die entsprechenden Verweise auf die Vertreter; siehe gegen die Auffassung Androulakis' im Übrigen Nickel, Die Problematik der unechten Unterlassungsdelikte, S. 77 ff. 
einen Garanten begangen wurden. ${ }^{420} \mathrm{Im}$ zweiten Fall handelte es sich ohne den $\int 13$ StGB bei der Garantenstellung um eine ,versteckte Strafbarkeitsvoraussetzung“, was dem Bestimmtheitsgrundsatz widersprechen würde.

Für die Frage nach einem Verstoß gegen das Analogieverbot ist somit festzustellen, dass der Wortlaut des $\ 212$ Abs. 1 StGB die Erfolgsherbeiführung durch ein Unterlassen zumindest dann erfasst, wenn der Täter Garant ist. ${ }^{421}$

\section{(bb.) § 223 StGB Körperverletzung}

Gem. \223 Abs. 1 StGB ist derjenige strafbar, der „eine andere Person körperlich mißhandelt oder an der Gesundheit schädigt“.422 Dass in diesem Rahmen auch das Unterlassen Relevanz besitzt, fand vor Einführung des $\int 13$ StGB eine breite Akzeptanz. So stellten Petters/Preisendanz ohne weitere Begründung fest, dass „beide Formen der Körperverletzung [...] auch durch Unterlassen verwirklicht werden [können]“.423 Auch Lackner/Maassen erkannten darauf, dass „die Tat [...] durch positives Tun und durch Unterlassen in Garantenstellung [...] begangen werden [kann]“..424 Gleiches gilt auch für Schönke/Schröder, die sich dafür aussprachen, dass „eine Körperverletzung [...] auch durch Unterlassen begangen werden [kann]". 425

$\mathrm{Ob}$ dies in Anbetracht des Analogieverbots so einfach anzunehmen ist, gilt es nunmehr zu prüfen.

\section{(i.) körperliche Misshandlung}

Zunächst gilt es zu entscheiden, ob eine „körperliche Misshandlung“ auch durch ein Unterlassen begangenen werden kann. Nach der strafrechtlichen Definition ist eine körperliche Misshandlung ,ein übles, unangemessenes Behandeln, welches das körperliche Wohlbefinden oder die körperliche Unversehrtheit nicht nur unerheblich beeinträchtigt." ${ }^{426}$ Diese allgemeine Definition besagt allerdings nichts über die konkrete Bedeutung des Wortlauts. Freilich wurde diese Definition aus

420 Siehe zu dieser Überlegung an dieser Stelle nur Armin Kaufmann, JuS 1961, 173, 176.

421 Auch Welzel, Strafrecht, 5. Aufl. 1956, S. 167 geht davon aus, dass „töten“ i.S. des \ 212 StGB ein Unterlassen umfasst, was er aus dem Mutter/Kind-Beispiel folgert. Hierbei geht Welzel aber nicht darauf ein, dass das Unterlassen der Mutter ggf. allein aufgrund deren Handlungspflicht als ein „Töten“ aufgefasst wird. Jedoch wird dieser Gedanken auch von Welzel impliziert, indem er gerade dieses Beispiel zur Veranschaulichung wählte; ablehnend Jakobs, AT, 28/12.

422 Fassung vor 1975: ,Wer vorsätzlich einen anderen körperlich mißhandelt oder an der Gesundheit beschädigt [...].“

423 Petters/Preisendanz, StGB, 28. Aufl. 1974, \ 223 I 3.

424 Lackner/Maassen, StGB, 8. Aufl. 1974, J 223 Nr. 1.

425 Schönke/Schröder, 17. Aufl. 1974, J 223 Rn. 7.

426 MK-StGB/Joecks, \223 Rn. 4. 
dem Gesetz abgeleitete, jedoch darf zur Bestimmung der Reichweite des Wortlauts auch nur der originäre Wortlaut herangezogen werden. Eine gefestigte Definition könnte dem Tatbestandsmerkmal bereits einen Sinngehalt beimessen, der die eigentlichen Grenzen der Norm übersteigt.

Folglich ist originär an den Wortlaut „misshandeln“ anzuknüpfen. Augenfällig ist, dass der Bestandteil „handeln“ das Wort dominiert. Die Auslegung kann somit dahingehend konkretisiert werden, ob unter ,handeln“ auch ein Unterlassen gefasst werden kann.

Wird etwas unterlassen, so wird es nicht ausgeführt. Eine Handlung liegt somit gerade nicht vor. Versucht man des Weiteren ein Unterlassen mit „handeln“ zu umschreiben, so gelingt dies nur, indem man feststellt: „Es wurde nicht gehandelt“. Entweder schreitet der Täter ein, handelt also, oder er schreitet nicht ein, handelt also nicht. Handeln und Unterlassen stellen also bereits vom Wortlaut her ein Antonym dar und können nicht unter „handeln“ zusammengefasst werden. ${ }^{427}$ Eine Misshandlung ist folglich allein durch ein aktives Tun möglich. ${ }^{428}$

\section{(ii.) Gesundheitsschädigung}

Das Unterlassen könnte jedoch tatbestandlich i.S. der Gesundheitsschädigung sein. Anknüpfungspunkt hierfür ist, ob „schädigt“ auch bei einem Unterlassen vorliegt. Sagt A zu B „Ich werde dich schädigen“, so ist die Wortlautreichweite nicht eindeutig. Aus solch einer Aussage wird die Einschätzung resultieren, dass der A sich zukünftig so verhalten wird, dass sich für B negative Folgen ergeben. Aktiv bedeutete dies, dass der A so auf den B bzw. anderweitige Umstände einwirken wird, dass seine momentane Situation eine negative Abweichung erfährt. Schwieriger stellt sich dies jedoch bei einem Unterlassen dar. Insoweit erscheint es uneindeutig, ob allein ein Nichtstun ohne weitere Voraussetzungen tatbestandlich im Sinne der Vorschrift ist. Allein wenn der Sachverhalt um die Information ergänzt wird, dass ein besonderes Näheverhältnis zwischen Täter und Opfer besteht, erscheint die Frage danach, ob auch ein Unterlassen von „,schädigt“ umfasst ist, nicht mehr problematisch. „Die Mutter schädigt die Tochter an deren Gesundheit. " Hier liegt wegen des bestehenden Abhängigkeitsverhältnisses zwischen Kind und Mutter auch eine Gesundheitsschädigung durch Unterlassen nahe.

Wie bereits im Rahmen der Erörterung des Totschlags soll es hier aufgrund der Relevanz für das Bestimmtheitsgebot dahinstehen, ob unter dem Tatbe-

\footnotetext{
427 Anders in Bezug auf „Handlung“ an sich Moser, AT, 2. Aufl. 1953, \$21 II: „Das Wort Handlung umfasst nach dem Sprachgebrauch des StGB auch Unterlassungen."

428 Anders, ohne nähere Reflexion, Welzel, Strafrecht, 5. Aufl. 1956, S. 167; anders H. Mayer, AT, 1953, S. 114.
} 
standsmerkmal „schädigt“ auch ohne eine Garantenstellung ein Unterlassen verstanden werden kann. ${ }^{429}$

Folglich umfasst „schädigt“ zumindest im Fall einer bestehenden Garantenstellung ein Unterlassen. ${ }^{430}$

(iii.) Zwischenergebnis

Eine pauschale Aussage über die Tatbestandsrelevanz des Unterlassens im Rahmen des \223 Abs. 1 StGB verbietet sich. So ist eine körperliche Misshandlung durch ein Unterlassen nicht möglich, wohingegen eine Gesundheitsschädigung auch auf einem Unterlassen beruhen kann, wenn eine Garantenstellung gegeben ist.

\section{(cc.) $§ 239$ StGB Freiheitsberaubung}

Gem. \ 239 Abs. 1 StGB macht sich strafbar, ,wer einen Menschen einsperrt oder auf andere Weise der Freiheit beraubt"..431

Hier ist somit entscheidend, ob der Wortlaut der Verhaltensvarianten „einsperren“/,berauben“ gleichfalls auch ein Unterlassen einschließt. Dass dies der Fall sei, bereitete der Rechtswissenschaft vor Einführung des \13 StGB keine großen Schwierigkeiten. Dreher stellte diesbezüglich fest, dass ,[a]uch durch Unterlassung [...] eine Freiheitsberaubung begangen werden [kann], falls der Unterlassende Garantenstellung hat. “432

\section{(i.) Erste Verhaltensvariante: „,einsperren“}

Wie bei den beiden vorangegangenen Delikten soll auch hier ein Beispielsfall dabei helfen, den Wortsinn zu bestimmen: „A sperrt B ein“. In Bezug auf die Frage, wie $A$ den $B$ eingesperrt haben könnte, werden die ersten Überlegungen wohl dahingehen, dass A durch sein Verhalten den B daran gehindert hat, einen umgrenzten Bereich zu verlassen, was durch Abschließen einer Tür oder durch ver-

429 Siehe hierzu S. 99 f.

430 Anders Jakobs, AT, 28/12, der pauschal die Möglichkeit der Tatbestandsrealisierung durch ein Unterlassen ablehnt, da dies vom Wortlaut nicht umfasst werde.

431 Fassung vor 1975: „Wer vorsätzlich und widerrechtlich einen Menschen einsperrt oder auf andere Weise des Gebrauchs der persönlichen Freiheit beraubt [...].“ Auch wenn der Gesetzeswortlaut der heutigen Fassung von der vor 1975 abweicht, kann dieser Umstand hier dahinstehen, da das erforderliche Täterverhalten nicht modifiziert wurde.

432 Dreher, StGB, 34. Aufl. 1974, \ 239 2) C; siehe zur Freiheitsberaubung durch Unterlassen: RGSt 24, 339 f. (Nichtöffnen einer Tür); BGH, GA 1963, 16; Lackner/Maassen, StGB, 8. Aufl. 1974, $\int 239$ Nr. 2; Pfeiffer/Maul/Schulte, StGB, 1969, \ 239 Nr. 2; Petters/Preisendanz, StGB, 28. Aufl. 1974, \ 239 Nr. 2. c); Schönke/Schröder, 17. Aufl. 1974, 』 239 Rn. 7; Dalcke/Fuhrmann/Schäfer, StGB, 37. Aufl. 1961, \239 Nr. 2); Maurach, BT, 5. Aufl. 1969, \ 15 II B 3. 
barrikadieren der Ausgänge erreicht worden sein könnte. Einsperren wäre hiernach also jedes Verhalten, das dazu führt, dass das Opfer einen umschlossenen Ort nicht mehr verlassen kann. Fraglich erscheint somit, ob ein Täter dem Opfer auch durch ein Unterlassen die Möglichkeit nehmen kann, sich aus einem bestimmten Bereich zu entfernen.

\begin{abstract}
Bsp. 1: O betritt einen Schuppen und schmeißt die Tür ins Schloss. Durch die Wucht löst sich der auf der anderen Seite befindliche Türriegel und versperrt die Tür. O kann den Schuppen nicht mehr verlassen. Kurze Zeit später erblick.t der zufällig vorbeikommende $T$ den $O$ in der Hütte. Obwobl er erkennt, dass $O$ sich nicht selbstständig befreien kann, bilft er ihm nicht und flüchtet.
\end{abstract}

\begin{abstract}
Bsp. 2: T sieht wie $O$ den Schuppen betritt und die Tür schließt. In dem Moment bemerkt $T$, wie der Wind allmählich den Türriegel vor die Tür schiebt und diese zu versperren droht. T kommt dies sehr gelegen, da er dem verhassten $O$ eins auswischen will, und schreitet nicht ein. O kann daraufhin, aufgrund des durch den Wind vorgeschobenen Türriegels, die Tür nicht mehr öffnen.
\end{abstract}

Beide Fälle unterscheiden sich dahingehend, dass im ersten Beispiel durch das Unterlassen die Freiheitsbeschränkung aufrechterhalten wird, wohingegen in der zweiten Konstellation das Nichteinschreiten bereits zu der Freiheitsbeschränkung führt.

Im Rahmen des ersten Falls wird die Bewegungseinschränkung nicht durch den $\mathrm{T}$ begründet, sondern $\mathrm{T}$ nutzt einen „Unglücksfall“ für seine Zwecke aus. Schon vor dem Nichteinschreiten lag eine Einschränkung der Bewegungsfreiheit, begrenzt auf den Schuppen, vor, sodass das Opfer bereits eingesperrt war. Konkret wird man davon sprechen müssen, dass das Opfer sich selbst eingesperrt hat. Dadurch, dass $\mathrm{T}$ nichts unternimmt, hat er $\mathrm{O}$ folglich nicht i.S. des $₫ 239$ Abs. 1 StGB eingesperrt. Zwar ist nicht zu leugnen, dass der T sich inadäquat verhält und die Situation ähnlich dem Einsperren ist, jedoch darf dies nicht dazu führen, dass die Grenzen des Art. 103 Abs. 2 GG missachtet werden.

Anders könnte es sich ggf. im zweiten Fallbeispiel darstellen. Hier führt das Nichthandeln zu der Bewegungseinschränkung in der Form, dass der freiheitsbeschränkende Zustand nicht eingetreten wäre, wenn T den Riegel festgehalten hätte. Anders als im ersten Beispiel nutzt T es hier nicht nur aus, dass O den Schuppen nicht verlassen kann, sondern ein Einschreiten hätte den Freiheitsentzug verhindert. Obschon diese Verknüpfung vorliegt, erscheint es trotzdem nicht eindeutig, ob der $\mathrm{T}$ durch das Unterlassen den $\mathrm{O}$ eingesperrt hat. Nur weil ein Verhalten im benannten Sinne ursächlich für den Erfolgseintritt ist, bedeutet dies nicht, dass 
der Wortlaut dieses Verhalten tatsächlich auch umfasst. Wird allerdings gerade der Wortlaut als Maßstab angelegt, so wird man hier davon sprechen müssen, dass der Wind den $\mathrm{O}$ eingesperrt hat und nicht der T. Die subjektive Komponente des Täters darf hier, im Rahmen des objektiven Tatbestands, keine Berücksichtigung finden. Dieses Ergebnis wird deutlicher, wenn die Willensrichtung des T ausgeblendet wird. Bemerkt der T den Wind und die Möglichkeit des Verschließens der Tür nicht, so erscheint das objektive Tatbestandsmerkmal „einsperren“ gänzlich fern.

Aus dieser Erkenntnis folgt, dass der Wortlaut „einsperren“ allein ein aktives Verhalten erfasst und ein Unterlassen nicht einschließt. ${ }^{433}$

\section{(ii.) Zweite Verhaltensvariante: ,, auf andere Weise der Freiheit berauben "}

Auch wenn das Unterlassen im Rahmen des Einsperrens keine Bedeutung entfaltet, besteht weiterhin die Möglichkeit, dass das Nichteinschreiten tatbestandsmäBig im Sinne der zweiten Variante ist.

Zu klären ist, ob „Wer einen Menschen auf andere Weise der Freiheit beraubt“ auch durch ein Unterlassen verwirklicht werden kann. Den konkreten Anknüpfungspunkt bildet hier „berauben“. Wiederum losgelöst von jedweder Sachverhaltsmodifikation oder wissenschaftlich akzeptierten Definitionen, muss allein „berauben“ für die Bestimmung der Wortgrenzen genügen.

Wird diesbezüglich wieder ein auf das Wesentliche reduzierter Beispielsfall gebildet, so lautete dieser „A beraubt B“. Ohne jedoch die freiheitsentziehende Komponente zu benennen, kommt hier allenfalls eine Eigentumsverletzung in Betracht, weswegen auch im Beispiel darauf hinzuweisen ist, dass es sich um die Freiheitsberaubung handelt. Gleichfalls ist der Sachverhalt bzgl. der Begehung unvollständig, denn die Freiheitsentziehung darf im Rahmen dieser Variante gerade nicht auf einem Einsperren beruhen. Unter Berücksichtigung dieser beiden Umstände muss der Fall somit lauten: „A beraubt B der Freiheit, ohne ihn einzusperren." Die beiden in $\int 239$ Abs. 1 Var. 2 StGB enthaltenen konkretisierenden Elemente liegen nunmehr vor, weswegen sich der Wortlaut an diesem Fall messen lassen muss. Es gilt somit zu ermitteln, wie der A den Freiheitsentzug herbeigeführt hat. Unter den gegebenen Voraussetzungen erscheint es möglich, dass der A den B festhält oder fesselt. Dass der Entzug der Freiheit durch ein Unterlassen erreicht wurde, erschließt sich so zunächst nicht.

Versuchte man nunmehr das „Berauben“ weiter zu konkretisieren und umschreibt es zu diesem Zweck, so stellt das „Berauben der Freiheit“ allein eine „Wegnahme“ oder auch einen „Entzug“ der Freiheit dar. Bereits hier muss er-

433 Ebenso Jakobs, AT, 28/12; anders Welzel, Strafrecht, 5. Aufl. 1956, S. 167. 
kannt werden, dass die Grenze des Wortlauts erreicht ist. Ein Mensch „nimmt“, „entzieht“ bzw. beraubt einen anderen Menschen, wenn er aktiv, folglich also durch ein Tun, auf diesen einwirkt. Wird hingegen eine Handlung unterlassen, so wird gerade nichts genommen oder gar entzogen, sodass die Tatbestandlichkeit des Unterlassens die Wortlautgrenze überschreiten würde. \239 Abs. 1 Var. 2 StGB kann folglich nicht durch ein Unterlassen erfüllt werden. ${ }^{434}$

\section{(iii.) Zwischenergebnis}

Wie zu Beginn dargelegt, war es in der Wissenschaft akzeptiert, dass ein Unterlassen auch ohne besondere gesetzliche Normierung taugliches Tatverhalten im Rahmen des $\ 239$ Abs. 1 StGB ist. ${ }^{435}$ Verkannt wurde hierbei allerdings, dass der Wortlaut des $\ 239$ Abs. 1 StGB allein auf eine aktive Begehung begrenzt ist. Obschon dieser alten Auffassung zuzugestehen ist, dass es sich in beiden Fällen um ein vergleichbares inadäquates Verhalten handelt, darf Art. 103 Abs. 2 GG nicht unbeachtet bleiben.

Im Ergebnis gilt somit, dass \239 Abs. 1 StGB vor Einführung des $\int 13$ StGB nicht durch ein Unterlassen verwirklicht werden konnte und es somit einer besonderen gesetzlichen Ausgestaltung bedarf, um auch diesem Verhalten deliktische Qualität beizumessen.

\section{(dd.) Verstoß gegen das Analogieverbot: Ergebnis}

Nachdem der Totschlag, die Körperverletzung und die Freiheitsberaubung einer exemplarischen Prüfung unterzogen wurden, zeigt sich kein eindeutiges Bild. So resultiert aus der Untersuchung des Totschlags, dass der Wortlaut „tötet“ ein Unterlassen zumindest dann erfasst, wenn der Täter eine Handlungspflicht besitzt, wohingegen sich im Rahmen der Körperverletzung ein differenziertes Bild bot. So ergab sich, dass eine körperliche Misshandlung nicht durch ein Unterlassen begangen werden kann, die Gesundheitsschädigung allerdings ein Nichteinschreiten zumindest dann einschließt, wenn zwischen dem Betroffenen und dem Täter ein besonderes Näheverhältnis besteht. \239 StGB ist hingegen einer Begehung durch Unterlassen gänzlich verschlossen.

Diese Untersuchung verdeutlicht, dass der Wortlaut der Begehungsdelikte bei bestehender Garantenstellung mitunter auch ein Unterlassen erfasst, teilweise das Unterlassen, zumindest partiell, beschränkt auf einzelne Verhaltensvarianten, in den Begehungsdelikten aufgeht und Tatbestände existieren, die allein die aktive Begehung mit Strafe bedrohen.

434 Siehe auch Jakobs, AT, 28/12, der die Möglichkeit der Realisierung des $₫ 239$ StGB ablehnt.

435 Siehe Fn. 432. 
Dies hat zur Folge, dass die Subsumtion des Unterlassens unter bestimmte Begehungsdelikte gegen das Analogieverbot verstößt, ${ }^{436}$ sodass $\ 13$ StGB in diesen Fällen konstitutive Wirkung zukommt. Denn ohne diese spezielle Normierung existierte keine verfassungskonforme Strafbarkeit.

Im Umkehrschluss heißt dies jedoch nicht, dass $₫ 13$ StGB rein deklaratorisch ist, wenn kein diesbezüglicher Verstoß vorliegt. Es darf nicht außer Acht gelassen werden, dass Maßstab hier allein das Analogieverbot war. Fraglich bleibt deswegen weiterhin, ob durch eine im Rahmen der Begehungsdelikte angenommene Tatbestandsmäßigkeit des Unterlassens nicht ein anderweitiger Verstoß gegen das Gesetzlichkeitsprinzip vorliegt.

\section{(b.) Bestimmtheitsgrundsatz}

Wie zu erkennen war, lässt das Analogieverbot keinen allgemeingültigen Schluss darauf zu, ob das Berücksichtigen eines Unterlassens im Rahmen der Begehungsdelikte tatsächlich einen Verstoß gegen Art. 103 Abs. 2 StGB darstellt. Fraglich bleibt aber, ob durch solch ein Vorgehen gegebenenfalls eine weitere Ausprägung des Gesetzlichkeitsprinzips verletzt sein könnte. In Betracht kommt insoweit eine Missachtung des Bestimmtheitsgebots. ${ }^{437}$ „Art. 103 Abs. 2 GG verpflichtet den

436 Grünwalds Feststellung (Grünwald, ZStW 1958, 412, 413) „wenn man [...] die Unterlassung der Abwendung eines Erfolges, dessen Herbeiführung vom Gesetz mit Strafe bedroht ist, bestraft, so wendet man in Wahrheit nicht die Tatbestände an, so wie sie das StGB enthält. Man wendet vielmehr ungeschriebene Tatbestände an[...].“ und der Schluss, dass „die Tat desjenigen, der wegen »Tötung durch Unterlassen« bestraft wird, nur unter einen Tatbestand subsumiert werden [kann], der an Stelle der Merkmale des \212 »Tötung eines Menschen« die Merkmale »Nichtabwendung des Todes eines Menschen« enthält." treffen somit in dieser pauschalierten Form nicht zu. Wie zu erkennen war, kann ,tötet“ i.S. des \212 StGB zumindest dann ein Unterlassen umfassen, wenn eine Garantenstellung seitens des Täters besteht. Ob jedoch aufgrund des Erfordernisses einer Garantenstellung eine Eigenständigkeit der Unterlassungsdelikte folgt, gilt es im Folgenden zu prüfen; neben dem Verstoß gegen das Analogieverbot weist H. Mayer, AT, 1967, S. 80 zudem darauf hin, dass ,[d]ie Analogie [...] aber auch inhaltliche Bedenken [erregt]." So handele es sich bei einem aktiven Verhalten um Willensaktivität, wohingegen das Unterlassen regelmäßig Willensschwäche sei.

437 Grünwald, ZStW 1958, 412, 418 Fn. 18 (bzw. ders., Das unechte Unterlassungsdelikt, S. 68) erkennt wohl auch eine Spannung zu dem Bestimmtheitsgebot. Überraschend ist jedoch dessen diesbezügliche Haltung, dass die Frage der Verfassungskonformität des Unterlassens im Rahmen der Begehungsdelikte solange „müßig“ sei, ,als keine Aussicht besteht, daß die Rechtsprechung bereit wäre, eine solche radikale Folgerung zu akzeptieren." (Grünwald, ZStW 1958, 412, 418 Fn. 18; bzw. siehe hierzu ders., Das unechte Unterlassungsdelikt, S. 70). Solch eine Einstellung bedeutete ja, dass es stets „müßig“ ist, auf Verfassungswidrigkeiten aufmerksam zu machen, solange diese von der ständigen Rechtsprechung in Kauf genommen werden. Aufgabe der Rechtswissenschaft ist es doch gerade, sich solcher Rechtspraktiken zuzuwenden und auf eventuelle Fehlentscheidungen aufmerksam zu machen. Ein eventuell verfassungswidriges Verständnis allein aufgrund einer stetigen Praxis nicht näher beleuchten zu wollen, ist nur schwerlich überzeugend. 
Gesetzgeber [...], die Voraussetzungen der Strafbarkeit so konkret zu umschreiben, daß Tragweite und Anwendungsbereich der Straftatbestände zu erkennen sind und sich durch Auslegung ermitteln lassen. Diese Verpflichtung dient einem doppelten Zweck. Es geht einerseits um den rechtsstaatlichen Schutz des Normadressaten: Jedermann soll vorhersehen können, welches Verhalten verboten und mit Strafe bedroht ist. Im Zusammenhang damit soll andererseits sichergestellt werden, daß der Gesetzgeber über die Strafbarkeit entscheidet. Insoweit enthält Art. 103 Abs. 2 GG einen strengen Gesetzesvorbehalt, der es der vollziehenden und der rechtsprechenden Gewalt verwehrt, über die Voraussetzungen einer Bestrafung selbst zu entscheiden. “438

Zusammenfassend soll der Bestimmtheitsgrundsatz somit sicherstellen, dass der Bürger aus der Gesetzeslektüre erkennen kann, wann und unter welchen Voraussetzungen ein Verhalten strafbar ist, wobei zudem durch eine konkrete und hinreichend bestimmte Gesetzesausgestaltung einer möglichen Willkür der Gerichte vorgebeugt werden soll.

Bezogen auf die Unterlassungsstrafbarkeit ist zu entscheiden, ob der Bürger allein aus den Begehungsdelikten die Strafbarkeitsvoraussetzungen des Nichteinschreitens erschließen kann. Anknüpfungspunkt ist, wie bereits im Rahmen des Analogieverbots kurz dargestellt, das Erfordernis der Garantenstellung. Dass im Rahmen der Begehung durch ein Unterlassen eine Garantenstellung Teil des Delikts ist, erschließt sich auf den ersten Blick aus dem Gesetzestext nicht. ${ }^{439}$

\section{(aa.) Charakter der Garantenstellung}

Das Erfordernis einer Garantenstellung ist in diesem Zusammenhang dann problematisch, wenn die Garantenstellung bzw. -pflicht eine strafkonstituierende Wirkung besitzen würde. Hebt diese besondere Stellung des Täters ein an sich strafrechtlich nicht relevantes Verhalten auf eine deliktische Ebene, so würde dieses Merkmal strafbegründend wirken. ${ }^{40}$ Da dieses Tatbestandsmerkmal jedoch positiv nicht in den Begehungsdelikten enthalten ist, erscheint ein Spannungsverhältnis

438 BVerfGE 73, 206, $234 \mathrm{f}$.

439 Siehe zu dem damaligen Streitstand Nickel, Die Problematik der unechten Unterlassungsdelikte im Hinblick auf den Grundsatz ,nullum crimen sine lege‘ (Art. 103 Abs. 2 GG), auf dessen Darstellung im Folgenden Bezug genommen wird.

440 Vgl. hierzu Welp, Vorangegangenes Tun, S. 143 f.; für eine strafbegründende Wirkung Armin Kaufmann, JuS 1961, 173, 176; Grünwald, ZStW 1958, 412, 413, 418; ders., Das unechte Unterlassungsdelikt, S. 69; wohl auch Engisch, JZ 1962, 189, 192; siehe auch Welzel, Strafrecht, 11. Aufl. 1969, S. 208, nach dem die unechten Unterlassungsdelikte fast gänzlich überflüssig wären, wenn Jedermann die Begehungsdelikte durch ein Unterlassen verwirklichen könnte; Busch, FS v. Weber, 1963, S. 192, 199 stellt fest, dass „die Strafbarkeit der unechten Unterlassungsdelikte [...] der verfassungsmäßig geforderten gesetzlichen Bestimmtheit [entbehrt]." Ein Spannungsverhältnis zum Bestimmtheitsgebot liegt jedoch nur dann vor, wenn es sich um ein ungeschriebenes strafbegründendes Tatbestandsmerkmal handelt. 
zum Bestimmtheitsgebot in diesem Fall als sehr wahrscheinlich. Anders könnte es sich aber dann verhalten, wenn jedwedes Unterlassen tatbestandlich wäre und sodann eine Einschränkung vorgenommen wird, dass allein Täter mit einer Handlungspflicht zu bestrafen sind. ${ }^{441}$ In diesem Fall resultierte aus der Garantenstellung, mangels konstituierender Wirkung, kein Verstoß gegen das Bestimmtheitsgebot. Denn kann der Täter alle Tatbestandsmerkmale dem Gesetzestext entnehmen, so schadet es freilich nicht, wenn ihn begünstigende Einschränkungen vorgenommen werden, selbst wenn sich diese so aus dem Gesetzestext nicht ergeben. ${ }^{442}$ Fraglich ist somit, ob der Garantenstellung eine strafbegründende oder eine allein einschränkende Wirkung zukommt.

\section{(i.) Maurach/Unterlassung als Handlung}

Maurach führt an, dass ein Unterlassen gleichfalls eine Handlung sei, weswegen das Täterverhalten „bei den unechten Unterlassungsverbrechen ebenso gesetzlich bestimmt [ist] wie bei den Begehungsdelikten, wenngleich in einer die Haftung überdehnenden Weise.“443

In diesem Fall würde das Garantenerfordernis somit allein einschränkend wirken. Nickel wendet hiergegen ein, dass der $₫ 300$ StGB a.F wie folgt gefasst werden könnte: „, Wer unbefugt ein fremdes Geheimnis offenbart, das ihm bei Ausübung seines Berufes anvertraut oder bekannt geworden ist, wird ... bestraft.' Die gebotene Tatbestandsbegrenzung auf Angehörige bestimmter Berufe müßte und

441 Vgl. hierzu ebenfalls Welp, Vorangegangenes Tun, S. 143 f.; siehe zu dieser Überlegung auch Armin Kaufmann, JuS 1961, 173, 176; für eine einschränkende Wirkung Böbm, JuS 1961, 177, 179 f.; so auch Fubrmann, GA 1962, 161, 172: „Sie [(die Garantenstellungen)] beschränken die ursprünglich vom Gesetzgeber sanktionierte Gleichstellung von Handeln und Unterlassen auf den Personenkreis der Garanten.“; ebenso Maurach, AT, 3. Aufl. 1965, \46 III. A. 4.: „Das gewohnheitsrechtlich begründete Verbrechensmerkmal der, Garantiepflicht' [...] dient also nicht zur verbotenen Erweiterung, sondern zur gebotenen, gewohnheitsrechtlich statthaften Einschränkung der Täterhaftung.“; siehe hierzu auch Schaffstein, FS Gleispach, 1936, S. 70, 90 (auf den Welp, Vorangegangenes Tun, S. 144 in Fn. 18 verweist), der auch auf einen einschränkenden Charakter erkennt, jedoch im Hinblick auf den „,nullum crimen sine lege“ Grundsatz feststellt, dass ,[d]iese rechtstaatlichen Bedenken [...] erst durch die neueste rechtspolitische Entwicklung, die in der Neufassung des $\$ 2$ StGB. ihren Ausdruck findet, behoben [sind].“

442 Vgl. Welp, Vorangegangenes Tun, S. 143.

443 Maurach, AT, 3. Aufl. 1965, \$46 III. A. 4. Die von Maurach in diesem Rahmen in Übereinstimmung mit BGHSt 16, 155, 158 vorgenommene Differenzierung zwischen Garantenstellung und Garantenpflicht soll hier dahinstehen, vgl. hierzu Nickel, Die Problematik der unechten Unterlassungsdelikte, S. 61; siehe zu den Begrifflichkeiten Murmann, Grundkurs, \29 Rn. 28; entscheidend für das Bestimmtheitsgebot ist allein, ob ein zusätzliches Kriterium hinzugedacht wird, das strafbegründend wirkt und sich aus den Begehungsdelikten originär nicht ergibt. 
dürfte selbständig durch die Gerichte vorgenommen werden. “"444 Akzeptierte man diesen Umstand, so gelte dies auch für „,verhaltensbeschreibende Tatbestandselemente“. „Es wäre also sogar die Aussonderung bestimmter das Täterverhalten qualifizierender Merkmale aus dem Garantietatbestand kaum zu vermeiden. " 445 So könne auch nicht verhindert werden, dass bspw. die Unwabrheit aus dem Tatbestand der Verleumdung ausscheiden müsse. Dieser Umstand wirke sodann allein strafbarkeitseinschränkend und sei „,der richterlichen Rechtsfindung zugewiesen $[\ldots]$. " ${ }^{446}$

Nickel denkt die Überlegung Maurachs folglich einen Schritt weiter und zeigt mögliche Konsequenzen auf. Angelehnt an die Überlegung Maurachs, dass ein Unterlassen gleichsam eine Handlung sei und die Begehungsdelikte somit auch durch ein Unterlassen realisiert werden können, geht Nickel davon aus, dass die benannten Tatbestände grundsätzlich jede Handlung umfassen und weitere Tatbestandsmerkmale allein deswegen hinzugefügt wurden, um die Reichweite einzuschränken.

Nickels Ausführungen und Einwände wären allerdings nur dann richtig, wenn aus dem Verständnis Maurachs folgen würde, dass jedwede zusätzliche Tatbestandsvoraussetzung einschränkend wirkt. Maurach stellt aber allein fest, dass eine Unterlassung gleichsam auch eine Handlung sei, sodass nunmehr die Begehungsdelikte auch durch ein Nichteinschreiten realisiert werden könnten. Dies zieht jedoch nicht den Schluss nach sich, dass Entsprechendes auch im Übrigen gelten muss, mithin also zusätzliche Merkmale stets den Tatbestand einschränken. Nickel verkennt somit die Reichweite der Auffassung Maurachs.

In diesem Kontext wendet Armin Kaufmann ein, dass es widersprüchlich sei, nach einer extensiven Auslegung nach dem Sprachgebrauch, was zu einer Inklusion des Unterlassens führte, nunmehr einschränkende Momente heranzuziehen. „Denn jede Einschränkung wegen fehlender Garantenstellung würde den zur Richtschnur erhobenen Sprachgebrauch wieder desavouieren, weil sie diesen Sprachgebrauch für strafrechtlich irrelevant erklären, indem sie ihm gerade nicht in allen Fällen folgt.“"447 Dieses Argument überzeugt jedoch nur bedingt, stellt es doch z.B. den Gedanken der teleologischen Reduktion gänzlich in Frage.

Unabhängig von der Überzeugungskraft dieser Einwände kann ggf. die Systematik des Gesetzes für die Auslegung dienlich sein. Diesbezüglich stellt Welzel fest, dass die unechten Unterlassungsdelikte fast insgesamt entbehrlich wären, wenn jedwede Unterlassung im Rahmen der Begehungsdelikte erfasst werden würde. ${ }^{448}$ „[D]as Vorhandensein des $\int 330$ c [zeigt], daß z. B. derjenige, der bei

444 Nickel, Die Problematik der unechten Unterlassungsdelikte, S. 61 f.; siehe hierzu auch Welzel, Strafrecht, 11. Aufl. 1969, S. 208, der gleichfalls einen Bezug zu $\ 300$ StGB a.F. bildet und das unechte Unterlassungsdelikt als „echtes Sonderdelikt" versteht.

445 Nickel, Die Problematik der unechten Unterlassungsdelikte, S. 62.

446 Nickel, Die Problematik der unechten Unterlassungsdelikte, S. 62.

447 Armin Kaufmann, Dogmatik, S. 281; ders., JuS 1961, 173, 175.

448 Welzel, Strafrecht, 11. Aufl. 1969, S. 208; dem folgend Welp, Vorangegangenes Tun, S. 144. 
einem Unglücksfall den drohenden Schaden nicht abwendet, obwohl er es könnte, sich grundsätzlich nur nach $\$ 330 \mathrm{c}$, nicht aber nach $\int \mathbb{S} 211$, 223f. strafbar macht.“"449 Nach Welzel reicht allein die Nichtabwendung des begehungsdeliktischen Erfolgs nicht aus, um eine dahingehende Strafbarkeit zu bejahen. „Vielmehr muß hier die Täterschaft selbständig $\mathrm{n}$ e b e $\mathrm{n}$ dem tatbestandlichen Verhalten durch spezielle täterschaftliche Merkmale begründet werden.“450

Diese Überlegung lässt sich gut hören. Denn warum bedarf es einer spezialgesetzlichen Ausgestaltung, wenn das zu missbilligende Verhalten schon durch die Begehungsdelikte erfasst wäre. Vielmehr wird durch die besondere Normierung des $₫ 330$ c StGB a.F. deutlich, dass das dortige Verhalten ohne eine gesetzliche Fixierung gerade keine strafrechtliche Relevanz besitzen würde. Hieraus ist zu Recht zu schließen, dass die Begehungsdelikte das Unterlassen im Allgemeinen, ohne eine besondere Handlungspflicht, nicht umfassen und somit durch das Erfordernis einer Garantenstellung der Tatbestand gerade nicht eingeschränkt wird.

Abschließend und auf den nächsten Prüfungspunkt überleitend kann aus der Feststellung, dass das Unterlassen eine Handlung sei, nicht pauschal und undifferenziert abgeleitet werden, dass nunmehr jeder Tatbestand neben dem aktiven Tun gleichfalls auch ein Unterlassen umfasst. Maßstab muss stets der Wortlaut des fraglichen Delikts bleiben. ${ }^{451}$ Ähnlich argumentiert auch Armin Kaufmann. Dieser stellt fest, dass schon gar kein einheitlicher Sprachgebrauch dahingehend existiere, dass z.B. „töten" stets auch ein Unterlassen umfasse. So töte die Mutter ihr Kind, wenn sie die Ernährung einstellt, anders sei dies jedoch dann, „[w]enn der Chirurg $\mathrm{X}$ zum Urlaub nach den Balearen fliegt, statt die Maschine nach Karthum zu besteigen und dort den Y zu operieren, von dessen Leiden er durch den Rundfunk erfahren hat[...].“ In diesem Fall würde niemand von einem „töten“ sprechen. ${ }^{452}$ Dieser Einwand überschneidet sich mit der im Rahmen des Analogieverbots aufgeworfenen Frage, ob das im aktiven Delikt determinierte strafrechtliche Verhalten das Unterlassen nur dann erfasst, wenn der Täter eine Garantenstellung be-

449 Welžel, Strafrecht, 11. Aufl. 1969, S. 208. Hiermit greift Welzel die Überlegung des BGH auf, der feststellt, dass ,beide Bestimmungen [(\$\$ 330c, \$139 StGB)] [...] nicht von dem Gedanken einer allgemein bestehenden Rechtspflicht zur Abwehr jeder, einem anderen oder der Allgemeinheit drohenden Gefahr aus[gehen] [...].“ Es bestehe vielmehr nur eine „,beschränkte Pflicht zum Eingreifen“. „Sie bedrohen allein das Unterlassen dieser besonders gebotenen Handlung als solches mit Strafe. Diese Beschränkung des Gesetzgebers läßt folgern, daß er eine darüber hinausgehende allgemeine Pflicht des Täters zur Abwendung eines Verbrechenserfolges nicht begründen wollte." (BGHSt 3, 65, 67); so auch Welp, Vorangegangenes Tun, S. 144, der aus der Existenz der echten Unterlassungsdelikte schließt, „daß das Gesetz die Unterlassung des tatmächtigen quivis ex populo der entsprechenden Handlung nicht gleichgestellt wissen wollte."

450 Welzel, Strafrecht, 11. Aufl. 1969, S. 208.

451 Siehe hierzu schon oben im Rahmen des Analogieverbots S. 95 ff.

452 Armin Kaufmann, Dogmatik, S. 281; detailliert zum Wortlaut S. 111 f. 
sitzt. ${ }^{453}$ Es gilt nunmehr anhand des Wortlauts zu bestimmen, inwieweit das Unterlassen originär und eigenständig im Rahmen des Begehungstatbestands Relevanz besitzt.

\section{(ii.) Bestimmung anhand des Wortlauts}

Wie schon im Rahmen des Analogieverbots erwähnt, könnte der Charakter der Garantenstellung davon abhängen, ob der Täter das strafrechtlich relevante Verhalten durch ein Unterlassen auch dann verwirklichen kann, wenn er kein Garant ist.

So erschien es eindeutig, dass z.B. „tötet“ i.S. des \ 212 StGB bei einem Nichthandeln dann vorliegt, wenn zwischen Täter und Opfer eine besondere Nähebeziehung besteht. Ob jedoch auch ein „,tötet“ gegeben ist, wenn anstatt des Vaters der Passant P das Kind nicht vor dem Ertrinken rettet, blieb hierbei ungeklärt. ${ }^{454}$ Wird hierzu wiederum ein auf das Wesentliche reduziertes Beispiel gebildet, hier „A tötet B“, so tritt das Problem sofort klar hervor. Aufgrund des Fehlens besonderer Angaben zu der Beziehung zwischen A und B liegt die Annahme, dass der Tod durch ein Nichthandeln hervorgerufen wurde, fern. Erst dann, wenn besondere Überlegungen hinzutreten, die das Geschehen näher ausgestalten, kommt ein Unterlassen in Betracht. Wird der Fall dahingehend modifiziert, dass die Mutter das Kind tötet, so erlangt das Unterlassen, wie schon im Rahmen des Analogieverbots festgestellt, eine gewisse Präsenz. Das gleiche Phänomen zeigt sich in gegenläufiger Form auch im Passantenbeispiel. Der Vorwurf gegenüber P wird hier nicht lauten, das Kind „getötet“ zu haben, sondern vielmehr nicht eingeschritten zu sein. ${ }^{455}$

Wird diese Erkenntnis zugrunde gelegt, so wird der tatsächliche Unterschied deutlich. Indem der Fall dahingehend abgewandelt wird, dass die Mutter ihr Kind tötet, wird impliziert, dass zwischen Täter und Opfer ein besonderes Verhältnis besteht. Gerade diese Zusatzinformation enthält der Beispielsfall des Passanten nicht. Da es sich nur um einen unbeteiligten Dritten handelt, liegt eine besondere Verbindung gerade nicht vor.

Wird dieses Ergebnis in ein abstraktes Beispiel übertragen, so müsste es, um ein mögliches Unterlassen einzuschließen, lauten: „Der gegenüber dem B handlungspflichtige A tötet diesen." Aufgrund der zusätzlichen Information wird der

453 Siehe hierzu im Rahmen des $₫ 212$ StGB S. 99 f., im Rahmen der Gesundheitsschädigung S. 101.

454 Die Darstellung erfolgt exemplarisch anhand des $₫ 212$ StGB.

455 Vgl. Armin Kaufmann, Dogmatik, S. 281 bzw. S. 110 f., der darauf hinweist, dass kein einheitlicher Sprachgebrauch in Bezug auf ,töten“ existiert. So töte die Mutter zwar ihr Kind, wenn sie dies verhungern lässt, jedoch tötet der Chirurg nicht den Kranken im Ausland, wenn er nicht zu diesem reist, sondern seinen geplanten Urlaub antritt. 
Schluss des Betrachters nicht fernliegen, dass der Erfolg auch aufgrund einer Unterlassung eingetreten sein könnte.

Es ist somit zu erkennen, dass der Wortlaut der Begehungsdelikte allein dann ein Unterlassen umfasst, wenn der Delinquent Garant des Opfers ist. Erst wenn also eine Pflicht zum Einschreiten besteht, kann dem Unterlassen Tatbestandscharakter beigemessen werden. Dies lässt den Schluss zu, dass das in den Begehungsdelikten definierte Verhalten, sofern der Wortlaut ein Unterlassen überhaupt umfasst, nur dann durch ein Nichteinschreiten realisiert werden kann, wenn eine Handlungspflicht besteht. Diese Überlegungen werden durch den Sinn und Zweck der Garantenstellung bestätigt. Denn „die Gleichstellung des Unterlassens mit dem Tun setzt voraus, daß der Täter auf Grund seiner besonderen Stellung rechtlich verpflichtet ist, tatbestandliche Erfolge zu verhindern, er muß ,Garant ${ }^{\text {f }}$ ür den Nichteintritt eines Erfolges oder die Nichterfüllung eines Tatbestandes sein. "“56

Originär schließt der Wortlaut des Begehungsdelikts das Unterlassen somit nicht ein, weswegen es sich bei der Inklusion der Unterlassung um eine Erweiterung handelt. Folglich wirkt die Garantenstellung, die eine Pönalisierung der Unterlassung im Rahmen der Begehungsdelikte erst ermöglicht, nicht einschränkend sondern strafbarkeitsbegründend.

\section{(iii.) Zwischenergebnis}

„Tötet“ i.S. des $\ 212$ StGB erfasst ein Unterlassen nur dann, wenn der Täter als Garant dazu verpflichtet gewesen ist, den Erfolgseintritt zu verhindern. Das Unterlassen besitzt somit erst dann deliktische Qualität, wenn kumulativ zu dem Nichthandeln eine Garantenstellung hinzutritt. Besteht solch eine besondere Beziehung zu dem Opfer nicht, so liegt durch das Unterlassen schon kein strafrechtlich relevantes Verhalten vor.

Die Garantenstellung des Täters besitzt mithin einen konstitutiven Charakter und wirkt folglich strafbegründend. ${ }^{457}$

456 Schönke/Schröder, 17. Aufl. 1974, Vorbem. Rn. 100 (meine Unterstreichung); siehe auch Dreher, StGB, 34. Aufl. 1974, Vor 1 D/D.I., der feststellt, dass die Herbeiführung des Erfolgs durch ein Unterlassen dem aktiven Tun nur dann gleichgestellt werden kann, wenn der Täter eine „Garantenstellung gegenüber dem bedrohten Rechtsgut einnimmt.“; Grünwald, ZStW 1958, 412, $413 \mathrm{f}$.

457 So auch Armin Kaufmann, JuS 1961, 173, 176, der es für überzeugender hält, dass die Garantenstellung gerade eine strafbegründende Position einnimmt. ,[U]nter den zahllosen Fällen der Unterlassung der Erfolgsabwendung werden einige wenige Garantenunterlassungen für strafbar erklärt." 


\title{
(bb.) Verletzung des Bestimmtheitsgebots
}

Aufgrund des strafbegründenden Charakters der Garantenposition könnte die tatbestandliche Relevanz des Unterlassens im Rahmen der Begehungsdelikte ohne besondere gesetzliche Normierung gegen den Bestimmtheitsgrundsatz verstoßen.

\section{(i.) Die Garantenstellung und der Wortlaut des konkreten Begehungsdelikts}

Klärungsbedürftig ist somit, ob allein durch die Lektüre des Gesetzestexts zu erkennen ist, dass das im Begehungsdelikt definierte Verhalten im Fall einer bestehenden Garantenstellung auch ein Unterlassen umfasst.

\begin{abstract}
Bsp. 1: $M$ ist das Geschrei ibres Neugeborenen Leid, weswegen sie das Kind für immer zum Schweigen bringen möchte. Da sie es nicht fertigbringt, $K$ aktiv qu töten, beabsichtigt sie das Kind verhungern zu lassen. Bevor sie dieses Vorhaben jedoch in die Tat umsetzt, möchte sie um die strafrechtlichen Konsequenzen ihres Verhaltens wissen.
\end{abstract}

Wie bereits festgestellt, muss zumindest dann von einem Töten durch Unterlassen ausgegangen werden, wenn zwischen Täter und Opfer ein besonderes Näheverhältnis besteht.

Vorliegend erkennt die M, dass es sich bei $\mathrm{K}$ um ibr Kind handelt, sodass sie um die die Garantenstellung begründenden Umstände und somit die Garantenstellung weiß, weswegen sie folglich das geplante Verhalten als „tötet“ i.S. des \212 StGB begreifen wird. ${ }^{458}$ Die Mutter würde aufgrund der äußeren Umstände die richtige Subsumtion vornehmen, obwohl der besondere Umstand der Garantenstellung im Tatbestand des $\int 212$ StGB nicht benannt ist. Dass die Mutter in der konkreten Situation ihr Verhalten unter den Tatbestand des \212 StGB fasst, ändert allerdings nichts daran, dass das Tatbestandsmerkmal der Garantenstellung gesetzlich nicht fixiert ist. Das Gesetz spricht allein von „tötet“. Warum das Unterlassen hier tatbestandsmäßig ist und vor allem wann es diese strafrechtliche Relevanz besitzt, erschließt sich dem Bürger aus $\int 212$ StGB nicht. ${ }^{459}$

Dies wird vor allem in einem weiteren Beispiel deutlich:

458 Siehe hierzu im Rahmen des Analogieverbots S. $97 \mathrm{ff}$.

459 Vgl. Nickel, Die Problematik der unechten Unterlassungsdelikte, S. 53. 
Bsp. 2: X sieht sich aus Interesse den $\int 212$ StGB an, weil er wissen möchte, welches die Strafbarkeitsvoraussetzungen dieses Tatbestands sind.

Der potentielle Täter wird nunmehr überlegen, was von „,tötet“ i.S. des $\int 212$ StGB umfasst sein könnte. Diese Überlegungen müssten ihn dazu führen, dass im Fall einer Nähebeziehung zwischen Opfer und Täter ein Unterlassen im Rahmen des $\int 212$ StGB tatbestandlich ist. Mangels näherer Angaben wird es dem Betrachter aber nicht möglich sein, den Straftatbestand dahingehend zu ergründen. Aber selbst wenn es wie im ersten Beispiel gelingt und dies für die Frage eines VerstoBes in diesem konkreten Rahmen Beachtung finden könnte ${ }^{460}$, bleibt im Übrigen die Problematik bestehen. So ist der Fall der Mutter besonders plakativ, bei dem vor allem aufgrund persönlicher Gefühlsregungen von einem „Töten“ gesprochen wird. Anders könnte es sich allerdings dann darstellen, wenn z.B. ein Bademeister ein Kind nicht vor dem Ertrinken rettet. ${ }^{461}$ Dass der Bademeister das Kind i.S. des \212 StGB ,tötet“, ist allein durch Lektüre des \ 212 StGB alles andere als selbstverständlich.

Aus den konkreten Begehungsdelikten ergibt sich die Relevanz einer Garantenunterlassung somit nicht. Fraglich erscheint jedoch, ob die Garantenstellung ggf. auf anderem Wege hergeleitet werden könnte. ${ }^{462}$

460 Vgl. S. 96 und vgl. insoweit Grünwald, ZStW 1958, 412, 417 f., wonach ein Verstoß ausscheiden muss, wenn sowohl Gesetzgeber und Bürger kongruent darüber befinden, dass der Tatbestand ein Unterlassen einschließt.

461 Siehe zur Garantenstellung des Bademeisters Schönke/Schröder, 17. Aufl. 1974, Vorbem. Rn. 104 („Badewärter“); Welzel, Strafrecht, 11. Aufl. 1969, S. 210: „Demgemäß macht sich der Bademeister, der einen Ertrinkenden in seiner Anstalt vorsätzlich oder fahrlässig nicht rettet, wegen Verletzung einer Garantenpflicht zur Lebensrettung [...] gemäß $\int \ 211 / 2$ oder $\ 222$ strafbar [...].“

462 Siehe zum Verhältnis von Garantenstellung und Art. 103 Abs. 2 StGB ausführlich Nickel, Die Problematik der unechten Unterlassungsdelikte im Hinblick auf den Grundsatz ,nullum crimen sine lege' (Art. 103 Abs. 2 GG). 


\section{(ii.) Herleitung der Handlungspflicht nach Böhm}

Böhm leitet die Voraussetzung der Handlungspflicht aus den $\iint 223$ b a.F. ${ }^{463}, 221$, 315 a.F.464 StGB ab. „Aus diesen und anderen gesetzlichen Bestimmungen kann m. E. ein allgemein geltender, Gleichstellungsobersatz" abgeleitet werden. " 465 Böhm versucht sodann darzulegen, dass es sich hierbei um keine Ausnahmetatbestände handelt.

In Bezug auf $\int 223 \mathrm{~b}$ StGB a.F. stellt er fest, dass der Gesetzgeber hier eine Gesundheitsschädigung durch ein Unterlassen annehme und diese aufgrund der Sorgepflichtverletzung wie eine Misshandlung bewerte. Böhm wirft die Frage auf, $\mathrm{ob}$ es beim Eintritt einer schweren Folge „durch böswillige Vernachlässigung seiner Sorgepflicht [(die des Täters)]“ sinnvoll sei, den Unterlassenden nur nach \223b StGB a.F. zu bestrafen, „wenn schon die Herbeiführung einer einfachen Gesundheitsbeschädigung ebenso bestraft wird wie die Mißhandlung. " "466

Sodann trägt Böhm bzgl. des \221 StGB vor, dass der Aussetzende sich wegen Mords bzw. Totschlags strafbar macht, wenn durch diese Aussetzung der Tod des Opfers vorsätzlich herbeigeführt wird. Wird das Opfer hingegen in einer hilflosen Lage belassen, obschon der Täter für dieses verantwortlich war, und stirbt es daraufhin, so sei fraglich, warum der Täter nicht wegen \211 bzw. \212 StGB

$463 \int 223$ b Abs. 1 StGB a.F.: „Wer Kinder, Jugendliche oder wegen Gebrechlichkeit oder Krankheit Wehrlose, die seiner Fürsorge oder Obhut unterstehen oder seinem Hausstand angehören oder die von dem Fürsorgepflichtigen seiner Gewalt überlassen worden oder durch ein Dienstoder Arbeitsverhältnis von ihm abhängig sind, quält oder roh mißhandelt oder wer durch böswillige Vernachlässigung seiner Pflicht, für sie zu sorgen, sie an der Gesundheit schädigt, wird $[\ldots]$ bestraft.

$464 \int 315$ Abs. 1 StGB a.F.: „Wer die Sicherheit des Betriebs einer Schienenbahn auf besonderem Bahnkörper oder Schwebebahn, der Schiffahrt oder der Luftfahrt durch Beschädigen, Zerstören oder Beseitigen von Anlagen oder Beförderungsmitteln, durch Bereiten von Hindernissen, durch falsche Zeichen oder Signale oder durch ähnliche Eingriffe oder durch eine an Gefährlichkeit einem solchen Eingriff gleichkommende pflichtwidrige Unterlassung beeinträchtigt und dadurch eine Gemeingefahr herbeiführt, wird [...] bestraft.“

Böbm, JuS 1961, 177, 179; siehe auch Welzel, Strafrecht, 11. Aufl. 1969, S. 210 wonach sich „sowohl aus Tatbeständen, in denen echte Unterlassungsdelikte gesetzlich normiert sind, wie den oben erwähnten $\iint 121 / 347,223$ b, 354/355, als auch aus den Tatbeständen der echten Sonderdelikte ergibt [...], daß als Unterlassungstäter nur eine solche tatmächtige Person in Frage kommt, die zu dem bedrohten Rechtsgut in einer engen Beziehung steht, aus der heraus sie für das betreffende Rechtsgut zu sorgen hat [...]." Nachdem dies die Problematik mildern solle, „,[folgt] aus dem geschriebenen Recht [...], daß als Unterlassungstäter nur eine solche tatmächtige Person in Betracht kommt, die mit dem bedrohten Rechtsgut durch ein enges und spezielles Lebensverhältnis verbunden ist, aus dem heraus diese Person der ,Garant' für die Unversehrtheit des Rechtsguts ist."; siehe zu dieser Überlegung auch Nagler, GerS 111, 1, 58 ff.; vgl. Jescheck, AT, 2. Aufl. 1972, \58 IV 5. b), wonach ,[...] die Garantenmerkmale der gesetzlich geregelten unechten Unterlassungsdelikte gewisse Anhaltspunkte dafür [geben], wie das Garantenproblem in den nicht geregelten Fällen zu lösen ist". 
strafbar sein soll, „obwohl $\ 221$ StGB bei fahrlässiger Todesverursachung zwischen Tun (Aussetzen) und Unterlassen (Verlassen) keinen Unterschied macht.“467

Zuletzt folgert Böhm, dass es aufgrund der Gleichstellung von Tun und Unterlassen im Rahmen des $₫ 315$ StGB a.F. und der sich hieraus ergebenen Folge, „daß eine pflichtwidrige Unterlassung eine Gemeingefahr herbeiführen kann", schwierig sei, bei anderen gemeingefährlichen Delikten ein Unterlassen auszublenden. ${ }^{468}$

Aus diesen Feststellungen zieht Böhm den Schluss, dass „der Gesetzgeber [...] in den aufgezählten Fällen die Tatbestandsverwirklichung durch Unterlassen deshalb aufgeführt haben [wird], weil sie eine häufige Begehungsmodalität ist, nicht aber deshalb, weil er etwa nur in diesen Fällen das Unterlassen für strafwürdig erachtet. Hat der Gesetzgeber aber in verschiedenen Fällen die Begehung durch Unterlassen geregelt und ist es offenbar, daß eine Beschränkung auf die geregelten Fälle weder beabsichtigt war noch sinnvoll ist, so liegt es nahe, aus den geregelten Fällen allgemeine Kriterien für die Gleichstellung zu gewinnen. “469 Zudem weist er darauf hin, dass es sich bei diesem Vorgehen nicht um eine Erweiterung des Tatbestands handele, weswegen eine Kollision mit dem Analogieverbot nicht vorliege, ,sondern um eine Auslegung des Tatbestandes nach im Gesetz aufgestellten Regeln: Der Gesetzgeber geht erkennbar davon aus, daß die Tatbestände auch durch Unterlassen der Erfolgsabwendung verwirklicht werden können“ “.470

Der Auffassung Böhms ist zunächst zugutezuhalten, dass es schlüssig ist, sich eines systematischen Vorgehens zu bedienen, um den Gesetzeswortlaut zu ergründen. In diesem Rahmen sind daher auch die Überlegungen und der Vergleich mit den von ihm behandelten Strafvorschriften nachvollziehbar. Nickel hält dem Vorgehen Böhms jedoch entgegen, dass der gezogene Schluss zu weitreichend sei. „Böhms Gleichstellungskriterien sind viel allgemeiner als das, was den gesetzlich geregelten Einzelfällen wirklich entnommen werden kann. So knüpft beispielsweise die Unterlassungsalternative des $₫ 123$ eine Handlungspflicht an ein vorangegangenes Verhalten, läßt aber nicht im entferntesten erkennen, welche Anforderungen an ein vorangegangenes Verhalten bei anderen unterlassungsoffenen Tatbeständen zu stellen wären." "471 Nickel wendet zudem ein, dass die $\int \$ 340,341$, 347, 357 StGB für die Begründung einer Garantenstellung nicht fruchtbar gemacht werden könnten. Die benannten Paragraphen stehen im Abschnitt der Verbrechen und Vergehen im Amt, sodass eine Übertragung auf anderweitige Delikte außerhalb dieses Regelungsbereichs zweifelhaft sei.

Jedoch reicht mit Nickel nicht nur der gezogene Schluss zu weit, sondern Böhm lässt zudem einen wichtigen Umstand unberücksichtigt, der die Argumentation

467 Böbm, JuS 1961, 177, 179.

468 Böbm, JuS 1961, 177, 179.

469 Böhm, JuS 1961, 177, 179, der gleichsam auch auf Welzel, Strafrecht, 11. Aufl. 1969, S. 210 verweist.

470 Böhm, JuS 1961, 177, 179.

471 Nickel, Die Problematik der unechten Unterlassungsdelikte, S. 74. 
insgesamt entkräftet. Denn selbst wenn der Gesetzgeber tatsächlich die von Böhm dargestellte Intention besaß, so muss Maßstab trotzdem das Gebot der Bestimmtheit bleiben. Es kommt in diesem Rahmen für die Strafbarkeit eines Verhaltens nicht darauf an, was der Gesetzgeber gewollt hat, sondern einzig, was in den konkreten gesetzlichen Normierungen fixiert wurde. ${ }^{472}$ Dies ist wichtig, denn wird der Sinn und Zweck des Bestimmtheitsgebots in Erinnerung gerufen, so soll es dem Bürger hierdurch doch gerade ermöglicht werden, genau ermitteln zu können, wann er delinquiert. Dies wäre freilich dann nicht mehr zu erreichen, wenn nicht nur der Gesetzestext und dessen Wortlaut, sondern darüber hinaus auch der Wille des Gesetzgebers herangezogen werden müsste. So ist die Überlegung Böhms in Bezug auf den \221 zwar nachvollziehbar, widerspricht jedoch dem Bestimmtheitsgebot. Denn wie soll der potentielle Täter durch den Blick in das Gesetz erkennen, dass in diesem Fall auch ein Totschlag bzw. Mord durch die unterlassene Hilfe möglich erscheint. Er müsste den gleichen Gedankengang wie Böhm vollziehen und feststellen, dass im Fall des Todes durch aktive Aussetzung eine Strafbarkeit gem. \211/212 StGB in Betracht kommt, um hieraus den Rückschluss zu ziehen, dass dies logischerweise, denn nichts anderes behauptet Böhm, auch für das Unterlassen gelten muss. Abstrahiert man die Unterlassungsproblematik von \ 221 StGB, so verschärft sich der Gedankengang des Bürgers dahingehend, dass der Täter aus der möglichen Strafbarkeit des Unterlassens im Rahmen der $\iint 221,223$ b a.F., 315 a.F. StGB zu schließen hätte, dass z.B. auch der Mord durch Nichteinschreiten realisiert werden kann. Hier müsste der Täter folglich mehrere gedankliche Haken schlagen, um das von Böhm benannte Ergebnis zu erzielen, was von einem juristischen Laien nicht geleistet werden kann. Der Bürger würde somit die strafrechtliche Relevanz des eigenen Verhaltens verkennen. ${ }^{473}$

Die Auffassung Böhms kann nicht über den Verstoß gegen das Bestimmtheitsgebot hinweghelfen.

472 Nickel, Die Problematik der unechten Unterlassungsdelikte, S. 74 weiter: „Wenn es lediglich darum ginge, bestimmte im Gesetz geregelte Garantenpositionen auf andere unterlassungsoffene Tatbestände sinngemäß zu übertragen, so könnte man vielleicht die verfassungsrechtliche Zulässigkeit eines solchen begrenzten Analogiegebots, das sich immerhin auf die prinzipielle gesetzliche Anerkennung unterlassungsoffener Tatbestände stützen könnte, in Erwägung ziehen.“

473 Für den Bürger ähnlich schwierig nachzuvollziehen, wenn auch auf einer anderen Begründung beruhend, Bärwinkel, Zur Struktur der Garantieverhältnisse bei den unechten Unterlassungsdelikten. Hierzu kurz zusammenfassend mit entsprechender Würdigung Nickel, Die Problematik der unechten Unterlassungsdelikte, S. 83 ff. 


\section{(iii.) Herleitung der Handlungspflicht nach Schönke/Schröder}

Schönke/Schröder erkennt, „daß die Tatbestandsmerkmale der Garantenpflicht ,ungeschrieben“ sind“ und dies ,,...] unbestreitbar einen Verzicht auf rechtsstaatliche Bestimmtheit [bedeutet]. “474

Diese sogar erkannte Unbestimmtheit soll jedoch ,angesichts der traditionellen Anerkennung unechter Unterlassungsdelikte“ nicht zu einer Unzulässigkeit oder gar Verfassungswidrigkeit führen. ${ }^{475}$

Es mag dahingehend einleuchten, dass durch eine traditionelle Anwendung Kriterien festgelegt wurden, die eine Garantenstellung begründen. Dies besitzt aber keine Auswirkungen darauf, ob die Strafbarkeit des Unterlassens mit dem Bestimmtheitsgrundsatz zu vereinbaren ist, denn das Garantenerfordernis bleibt dem Bürger trotzdem verborgen. Zudem erscheint das Argument der „traditionellen Anerkennung“" so, als ob die Unterlassungsstrafbarkeit aus Gewobnheitsrecht abgeleitet werden soll. ${ }^{476}$ Gewohnheitsrecht als Strafgrund verstößt jedoch freilich gleichfalls gegen Art. 103 Abs. 2 GG. ${ }^{477}$ Denn wie Nickel richtig erkennt, „[verbietet] [d]er nullum-crimen-sine-lege-Satz [...] die außergesetzliche Bildung neuer Tatbestände in toto, aber auch einzelner strafbarkeitskonstituierender Tatbestandsteile, da nur dann die Strafbarkeit allein durch das Gesetz bestimmt und dadurch die staatsbürgerliche Freiheit gegen richterliche Willkür geschützt wird. Da die Garantenstellungen als strafbarkeitskonstitutive Merkmale Bestandteile der Garantietatbestände der verschiedenen unechten Unterlassungsdelikte sind, beruht die These von der zulässigen gewohnheitsrechtlichen Entwicklung der Garantenpositionen auf einer an entscheidender Stelle zu engen und deshalb fehlerhaften Prämisse. [...] [E]ine sich allein auf Gewohnheitsrecht gründende Legitimierung der Garantenstellungen wäre mit dem traditionell verstandenen Grundsatz der notwendigen gesetzlichen Fixierung des Garantietatbestands unvereinbar. “478

474 Schönke/Schröder, 17. Aufl. 1974, Vorbem. Rn. 100a.

475 Schönke/Schröder, 17. Aufl. 1974, Vorbem. Rn. 100a.

476 Siehe zur gewohnheitsrechtlichen Begründung Jescheck, AT, 2. Aufl. 1972, \54 IV 5 m.w.N.; siehe zur gewohnheitsrechtlichen Herleitung im Allgemeinen auch LK-StGB/Jagusch, 8. Aufl. 1957, \2 Anm. I. 2.; siehe auch Sax, in: Die Grundrechte, III/2, 1959, S. 1002 f. inklusive Fn. 296; siehe zur Auffassung Sax' Nickel, Die Problematik der unechten Unterlassungsdelikte, S. $65 \mathrm{f}$.

477 Siehe zum Verbot des Gewohnheitsrechts nur BVerfGE 26, 41, 42; für die Anwendung von Gewohnheitsrecht LK-StGB/Jagusch, 8. Aufl. 1957, \2 Anm. I. 2.; gegen Jagusch Nickel, Die Problematik der unechten Unterlassungsdelikte, S. 65: „Im Hinblick auf die These von Jagusch mag offenbleiben, ob im Bereich des Allgemeinen Teils die gewohnheitsrechtliche Bildung von Rechtsbegriffen und -figuren zulässig ist. Soweit es sich um Teile von Garantietatbeständen handelt wie unzweifelhaft bei den Garantenstellungen, ist deren gewohnheitsrechtliche Entwicklung ohne Bruch mit dem traditionsgebundenen Verständnis des nullum-crimen-sine-lege- Satzes nicht zu rechtfertigen.“; siehe im Übrigen ders. S. 63 ff., der sich mit weiteren gewohnheitsrechtlichen Herleitungen auseinandersetzt. Entsprechende Nachweise siehe dort.

Nickel, Die Problematik der unechten Unterlassungsdelikte, S. 64. 


\section{(iv.) Herleitung der Handlungspflicht nach Meyer-Bahlburg}

Schon zu Beginn seines Beitrags macht Meyer-Bablburg deutlich, dass es sich allein um „Auslegungsfragen“ handele, ob ein Unterlassen auch im Rahmen der Begehungsdelikte strafrechtliche Relevanz entfalten kann. ${ }^{479}$ Insoweit erscheinen ihm Bedenken bzgl. eines Verstoßes gegen nulla-poena-sine-lege unbegründet. ${ }^{480}$ Des Weiteren wird von Meyer-Bablburg auch die „sonderbare“ Herangehensweise der Wissenschaft kritisiert. Anstatt pauschaliert zu beantworten, ob das Unterlassen auch im Rahmen der Begehungsdelikte tatbestandlich ist, sei es zielführend, die Delikte individuell auf ihre Unterlassungstauglichkeit hin zu untersuchen. ${ }^{481} \mathrm{Zu}$ dem besitze die Garantenstellung nicht allein im Rahmen der unechten Unterlassungsdelikte Relevanz, sodass eine isolierte Betrachtung der unechten und echten Unterlassungsdelikte inadäquat sei. Übertrete der Täter z.B. eine der in den

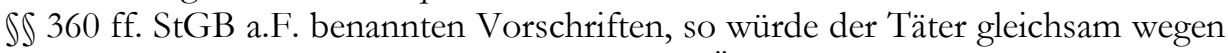
z.B. einer Tötung bestraft, wenn durch diese Übertretung ein Mensch den Tod finde. ${ }^{482}$ Hieraus folge, dass sowohl bei den Verletzungsdelikten als auch bei den Gefährdungsdelikten von einer Garantenstellung gesprochen werden könne. ${ }^{483}$ „Die Garantenstellungen stellen nichts dar, wodurch sich die unechten Unterlassungsdelikte von den echten schlechthin unterscheiden. Daher sind bei der Behandlung der Auslegungsprobleme mancher unechter Unterlassungsdelikte auch verwandte echte Unterlassungsdelikte zu berücksichtigen. Wenn z.B. der den \367 Nr. 5 ausfüllende \11 der Preuß. Sprengstoffverkehrsverordnung vom 4. 9. 1935 sagt: »Fahrzeuge, welche Sprengstoff führen, dürfen niemals ohne Bewachung bleiben. Der Transportführer ist für die ordnungsgemäße Bewachung verantwortlich«, so lassen sich daraus auch für die Beantwortung der Frage Schlüsse ziehen, wer wegen fahrlässiger Tötung zu bestrafen ist, wenn bei einer auf mangelnde Bewachung zurückzuführende Explosion des Sprengstoffs ein Mensch getötet wird. Dementsprechend ist die Frage, wer wegen des Unverdecktlassens von Gruben und dgl. nach \367 Nr. 12 oder wegen mangelhafter Unterhaltung der Feuerstätten in seinem Haus nach \368 Nr. 4 zu bestrafen ist, ebenso zu beantworten wie die Frage, wer für eine auf solcher Unterlassung beruhende Tötung oder Verletzung eines Menschen oder einen dadurch verursachten Brand wegen fahrlässiger oder auch vorsätzlicher Tötung, Körperverletzung oder Brandstiftung zu bestrafen ist. Es ist also möglich, von der Garantenstellung bei dem einen Delikt auf die Garantenstellung bei einem verwandten Delikt der anderen Deliktsgruppe zu schließen. Daher ist der Satz, die Garanten-

\footnotetext{
479 Meyer-Bablburg, GA 1966, 203.

480 Meyer-Bablburg, GA 1966, 203 Fn. 1.

481 Meyer-Bablburg, GA 1966, 203.

482 Meyer-Bablburg, GA 1966, 203, 204; siehe hierzu auch ders., Beitrag zur Erörterung der Unterlassungsdelikte, S. 32 f., 55 f.

483 Meyer-Bablburg, GA 1966, 203, 204.
} 
pflicht bei einem unechten Unterlassungsdelikt dürfe nicht aus einem echten Unterlassungsdelikt genommen werden, in dieser Allgemeinheit unrichtig. “484

Unterstellt, die abstrakte Möglichkeit der Bezugnahme besteht, so bleibt trotzdem ungeklärt, ob durch solch ein Vorgehen dem Bestimmtheitsgebot entsprochen werden kann. Verletzt der Täter ein von Meyer-Bablburg benanntes Gefährdungsdelikt durch Nichthandeln, so müsste aus der Lektüre dieses Tatbestands gleichsam folgen, dass im Fall des Todes eines Menschen zudem eine weitergehende Strafbarkeit wegen der Unterlassung resultiert. Ob also \212 StGB auch durch ein Nichteinschreiten realisiert werden kann, würde sich somit aus einem Zusammenspiel dieser beiden Tatbestände ergeben. Dieser Umstand findet aber in keinster Weise eine Verankerung im Gesetz. Freilich müsste man Meyer-Bablburg dahingehend zustimmen, dass es sich hierbei um eine Konstellation handelt, die zu einer Strafbarkeit wegen eines unechten Unterlassungsdelikts führt. Dass dies jedoch so ist, lässt sich ohne $\int 13 \mathrm{StGB}$ aus der gesetzlichen Normierung nicht ableiten. Zudem fällt auf, dass es an einer stetigen Entsprechung auf Seiten der echten Unterlassungsdelikte mangelt. So existieren nur wenige Normierungen, die ein Unterlassen in Form eines echten Unterlassungsdelikts erfassen, sodass das Abstellen im Übrigen schon gar nicht möglich ist und somit über die Problematik der mangelnden Bestimmtheit im Allgemeinen nicht hinweghelfen kann. Ähnlich wendet auch Nickel ein, dass die Herleitung aus den konkreten Tatbeständen Meyer-Bablburg nicht stets gelingt, weswegen ,[...] er Merkmale aus bestimmten im Gesetz geregelten Fällen auf andere Tatbestände, die eine solche Regelung nicht aufweisen, ohne Zulässigkeit und Grenzen einer derartigen Übertragung zu erörtern[, überträgt].“ Nickel kritisiert weiter, dass ,[...] Meyer-Bahlburg [hierbei] nicht etwa [versucht], die Auslegung der das Täterverhalten beschreibenden Tatbestandsmerkmale [...] durch systematische Überlegungen, z.B. über die Bedeutung gesetzlich geregelter Garantenfälle für andere Straftatbestände, zu stützen, sondern er systematisiert eine umfangreiche Kasuistik nach Garantenkriterien, über deren Gewinnung ex lege er keinen oder nur unzureichenden Aufschluß gibt." “485

Der Versuch, die stringente Trennung von echten und unechten Unterlassungsdelikten aufzubrechen, kann für die vorliegende Problematik somit nicht fruchtbar gemacht werden.

\section{(v.) Ergebnis}

Die Garantenstellung als strafbegründendes Merkmal kann abseits des $₫ 13 \mathrm{StGB}$ nicht aus den gesetzlichen Normierungen hergeleitet werden. Darüber können auch nicht die Überlegungen von Böbm, Schönke/Scbröder und Meyer-Bablburg hin-

484 Meyer-Bablburg, GA 1966, 203, 205.

485 Nickel, Die Problematik der unechten Unterlassungsdelikte, S. 72. 
weghelfen. ${ }^{486} \mathrm{Ob}$ und wann ein Unterlassen im Rahmen der Begehungsdelikte deliktische Qualität aufweist bzw. dass es überhaupt diese Qualität erreichen kann, ist für den Bürger nicht ersichtlich. Zwar wird es möglich sein, in manchen Fällen eine Gleichwertigkeit zu erkennen (Mutter/Kind-Beispiel), jedoch gilt dies allein für einen äußerst begrenzten Kreis. ${ }^{487}$ Wie der Fall des Bademeisters zeigt, ist es bei Verhaltensweisen, die keine erhöhte soziale Abträglichkeit aufweisen, erschwert bzw. unmöglich, auf eine Äquivalenz von Unterlassen und Handeln zu schließen. Es bedürfte folglich auf Seiten des Täters nicht nur Gesetzeskenntnis, wobei schon dieses Wissen wohl in den seltensten Fällen vorliegt, sondern zudem auch Kenntnis einschlägiger Literatur und Kasuistik der Rechtsprechung. Dies kann von einem juristischen Laien freilich nicht verlangt werden und würde zudem Art. 103 Abs. 2 GG nicht genügen. So kann Armin Kaufmann zugestimmt werden, dass „,[d]as Problem der mangelnden Tatbestandsbestimmtheit des unechten Unterlassungsdeliktes [...] durch keine wie auch immer geartete dogmatische Konstruktion zu bewältigen [ist]. “488

\section{(c.) Verfassungsmäßigkeit des unechten Unterlassungsdelikts ohne besondere gesetzliche Ausgestaltung aufgrund von faktischen Limitierungen}

Die vorangegangenen Ausführungen haben ein Spannungsverhältnis zum Bestimmtheitsgrundsatz offengelegt, sofern ein Unterlassen ohne besondere gesetzliche Ausgestaltung unter die Begehungsdelikte subsumiert wird. Folglich scheint es so, als ob dieses Vorgehen mit Art. 103 Abs. 2 GG kollidiert. Gegen solch eine Unzulässigkeit könnten jedoch faktische Momente sprechen: „Eine einwandfreie Lösung wäre aber nur darin zu sehen, daß wir im einzelnen sagen, welche Formen des Untätigbleibens dem Herbeiführen des Erfolgs durch aktives Tun gleichstehen sollen. Das ist schon begrifflich, vor allem aber praktisch-technisch ausgeschlossen. Andererseits geht es nicht an, auf die Erfassung unechter Unterlassungsdelikte völlig zu verzichten. Im Übrigen ist die ge s e t z li c h e B e s ti m m th e it

486 Siehe hierzu Armin Kaufmann, JuS 1961, 173, 175 bzw. ders., Dogmatik, S. 282 im Allgemeinen: „Die rechtsstaatliche Problematik der mangelnden Tatbestandsbestimmtheit des unechten Unterlassungsdelikts ist durch keine wie auch immer geartete dogmatische Konstruktion zu bewältigen."; vgl. zu weiteren Herleitungsversuchen Nickel, Die Problematik der unechten Unterlassungsdelikte, S. 55 ff. mit entsprechenden Nachweisen und Stellungnahmen Nickels.

487 Siehe hierzu Armin Kaufmann, JuS 1961, 173, 175 f. bzw. ders., Dogmatik, S. 281 f., wonach eine Gleichstellung von Unterlassen und Tun nach allgemeinem Sprachgebrauch möglich sei, wie in dem Fall, in dem ein Kind durch mangelnde Ernährung durch die Mutter getötet wird. Jedoch handele es sich hierbei allein um wenige Konstellationen, die solch eine Deckungsgleichheit im Rahmen des Sprachgebrauchs aufweisen. „Wer will ernsthaft daran die Garantenstellung erkennen und sie auf diese Fälle begrenzen?"(Armin Kaufmann, JuS 1961, 173, 175 f.). 
der Strafbarkeit auch an anderen Stellen nicht vollständig durchgeführt, so etwa auf dem Gebiet der nicht ausrottbaren normativen Tatbestandsmerkmale. Diese Beispiele machen uns die Unmöglichkeitsgrenze deutlich, der wir auch an vielen anderen Stellen begegnen. Wir müssen also erkennen, daß eine Formel, die wir in das Gesetz aufnehmen könnten, auch nur beschränkten Wert hätte. Sie räumt jenes verfassungsrechtliche Bedenken nicht aus und nützt andererseits nicht sehr viel.“489 Ebenso stellt auch Freiherr von Stackelberg darauf ab, dass „[d]ie nötige Konkretisierung des Tatbestandes [...] einfach unmöglich [erscheint]." ${ }^{490}$ Zudem wird u.a. von Schmidt darauf hingewiesen, dass die Legitimation der unechten Unterlassungsdelikte in Bezug auf die „verfassungsrechtlichen Bedenken“ nur dann gelinge, „wenn wir sagen können, daß die Verfassung selbst die Existenz und die Notwendigkeit der unechten Unterlassungsdelikte anerkannt hat."“491

Diese Einwände erscheinen jedoch wenig überzeugend. In Bezug auf die mangelnde Umsetzbarkeit zeigt sich, dass mit dem aktuellen \13 StGB eine Vorschrift verabschiedet wurde, die dem verfassungsrechtlichen Bestimmtheitsgebot genügt. ${ }^{492}$ Selbst wenn eine faktische Umsetzung aufgrund einer erforderlichen feingliedrigen Ausgestaltung nicht möglich wäre, so kann dies einen Verstoß gegen verfassungsrechtliche Grundsätze nicht rechtfertigen. Auch in diesen Fällen ist der vermeintliche Täter in dem Sinne schutzbedürftig, dass er sich vor Tatbegehung Kenntnis über die strafrechtlichen Folgen seines Verhaltens durch Gesetzeslektüre verschaffen können muss und dass er nicht der Willkür einzelner Strafrichter ausgesetzt ist.

Es erscheint widersprüchlich, abstrakte Gesetzesregularien aufzustellen, die dann nicht gelten sollen, wenn die Umsetzung dieser Vorgaben Schwierigkeiten bereitet. Vielmehr müsste dann auf Verfassungsebene angeknüpft werden, um die dortigen Vorgaben dem entsprechenden Bedürfnis anzupassen. ${ }^{493}$

Gleiches gilt auch für den Einwand Schmidts. Dessen Behauptung, dass der Verfassungsgeber und somit die Verfassung selbst die Strafbarkeit der unechten Unterlassungsdelikte anerkennt, führte zu einer faktischen Beschränkung des Art. 103 Abs. 2 GG. Es erscheint auch hier wenig überzeugend, dass Grenzen der Strafbarkeit auf Verfassungsebene determiniert werden, diese jedoch in demselben Schritt wieder eingeschränkt werden, wobei diese Geltungsreduktion in keinster Weise Berücksichtigung in der grundgesetzlichen Ausgestaltung gefunden hat.

489 Bockelmann, Niederschriften über die Sitzungen der Großen Strafrechtskommission, Bd. 2, S. 277; vgl. hierzu auch H. Mayer, AT, 1967, S. 81; siehe auch Jescheck, AT, 1969, \58 IV 5. b); Baumann, AT, 5. Aufl. 1968, \18 II 2. b).

490 Freiherr von Stackelberg, Niederschriften über die Sitzungen der Großen Strafrechtskommission, Bd. 2, S. 278.

491 Schmidt, Niederschriften über die Sitzungen der Großen Strafrechtskommission, Bd. 2, S. 281.

492 Zur Verfassungsmäßigkeit des $₫ 13$ StGB siehe nur BVerfGE 96, 68, 97; diesbezüglich kritisch u.a. MK-StGB/Freund, \13 Rn. 26 m.w.N.

493 Vgl. Schmidt, Niederschriften über die Sitzungen der Großen Strafrechtskommission, Bd.2, S. 267. 
Verstärkend käme hinzu, dass solch ein Verständnis den Verfassungsgeber dazu zwingen würde, bei Normierungen stets darauf hinzuweisen, dass die aus der neuen Regelung resultierenden Konsequenzen so tatsächlich auch beabsichtigt waren, da anderenfalls ein diesbezüglicher Interpretationsspielraum verbliebe. ${ }^{494}$

Eine Rechtfertigung des Verstoßes gegen Art. 103 Abs. 2 GG bzw. eine Ausnahme von dieser verfassungsrechtlichen Normierung ist folglich nicht zu erkennen. Ohne eine besondere gesetzliche Ausgestaltung verstoßen die unechten Unterlassungsdelikte gegen Art. 103 Abs. 2 GG. ${ }^{495}$

\section{(2.) Konsequenzen für den Charakter des $₫ 13 \mathrm{StGB}$}

Die Strafbarkeit des Unterlassens i.S. des geltenden $₫ 13$ StGB kann aufgrund eines Verstoßes gegen Art. 103 Abs. 2 GG nicht allein aus den Begehungsdelikten abgeleitet werden. Offen ist nunmehr, welche Konsequenzen hieraus für die Einordnung des $₫ 13 \mathrm{StGB}$ als deklaratorische bzw. konstitutive Vorschrift folgen.

$\int 13$ StGB ist für die Strafbarkeit der unechten Unterlassung zwingend erforderlich, sodass ein strafbegründender Charakter nahe liegt. Dies wäre aber nur dann der Fall, wenn die Strafbarkeit der unechten Unterlassungsdelikte tatsächlich allein aus dieser Vorschrift resultiert. Die vorangegangenen Ausführungen haben bisher allerdings nur gezeigt, dass die Strafbarkeit des Unterlassens im Rahmen der Begehungsdelikte zu einem Verstoß gegen Art. 103 Abs. 2 GG führt, da sich der Umstand der Garantenstellung so aus den aktiven Delikten nicht ergibt. Fraglich erscheint jedoch, ob diesen Delikten nicht trotzdem das Unterlassen einverleibt werden kann. So könnte auch eine dahingehende Auslegung in Betracht kommen, dass die Begehungsdelikte die Unterlassungsstrafbarkeit enthalten, wenn auch verfassungswidrig, und es daher eines „Schlüssels“ bedarf, der diese Strafbarkeit erst relevant werden lässt. Durch eine Norm, die gerade nur verdeutlicht, dass neben aktivem Tun auch Unterlassen im Rahmen der Begehungsdelikte Bedeutung besitzt, könnte den Anforderungen des Art. 103 Abs. 2 GG gegebenenfalls ebenso entsprochen werden. \13 StGB würde bei solch einem Verständnis

494 Dies greift bereits im vorliegenden Fall, denn es lässt sich freilich auch vertreten, dass Art. 103 GG gerade eingeführt wurde, um die bisherige Praxis zu unterbinden.

495 Gleichfalls für eine Verfassungswidrigkeit u.a. Armin Kaufmann, JuS 1961, 173, 176 bzw. ders., Dogmatik, S. 282: „Das Problem der mangelnden Tatbestandsbestimmtheit des unechten Unterlassungsdeliktes ist durch keine wie auch immer geartete dogmatische Konstruktion zu bewältigen.“; Busch, FS v. Weber, 1963, S. 192, 199 „Die Strafbarkeit der unechten Unterlassungsdelikte entbehrt, darüber besteht kein Zweifel, der verfassungsmäßig geforderten gesetzlichen Bestimmtheit." Trotz dieser Erkenntnis spricht sich Busch für eine Fortsetzung dieser Praxis bis zu einer Gesetzesänderung aus: „Inzwischen wäre es Aufgabe der Rechtsprechung [...] zu der zu Unrecht als positivistisch verschrieenen älteren Rechtsprechung und ihrer wahrlich bescheidenen rechtlichen Verfestigung der Strafbarkeit unechten Unterlassens zurückzufinden.“ (Busch, FS v. Weber, 1963, S. 192, 206).

Dieses Ergebnis bedeutet freilich auch, dass vor Einführung des $₫ 13$ StGB neben positiv normierten Unterlassungsdelikten keine verfassungskonforme Unterlassungsstrafbarkeit existierte. Insoweit sind dahingehende Urteile verfassungswidrig! 
mithin nur das Aussagen, was innerhalb der Begehungsdelikt „versteckt“ geschrieben steht, sodass ein deklaratorischen Charakter und mithin eine Unselbstständigkeit vorliegen könnte.

Gegen solch eine Interpretation spricht, dass ohne $₫ 13$ StGB eine Unterlassungsstrafbarkeit wegen eines Verstoßes gegen Art. 103 Abs. 2 GG gerade nicht möglich wäre. $₫ 13$ StGB begründet erst die Möglichkeit, Unterlassungen strafrechtlich zu verfolgen. Zwar stellt $\ 13$ StGB nach dieser Auslegung nur das fest, was die Begehungsdelikte schon aussagen, jedoch können die Begehungsdelikte diese „Aussage“ nicht eigenständig entfalten. $\int 13$ StGB besäße bei diesem Verständnis somit nur eine hinweisende Funktion, aufgrund des zwingenden Erfordernisses dieser Vorschrift käme ihr aber trotzdem eine strafbegründende und somit konstitutive Wirkung zu.

Allerdings ist nicht aufgrund dieser Überlegung ein konstitutiver Charakter gegeben, sondern bereits der Umstand, dass die Begehungsdelikte trotz des VerstoBes gegen Art. 103 Abs. 2 GG die Unterlassung gleichfalls erfassen sollen, ist wenig überzeugend. Denn gerade das Spannungsverhältnis zu Art. 103 Abs. 2 GG zeigt auf, dass ein Unterlassen im Rahmen der Begehungsdelikt ohne eine weitere gesetzliche Normierung gerade keine Relevanz entfaltet. Die Annahme, dass die Begehungsdelikte gleichfalls auch ein Unterlassen enthalten, wäre bloße Fiktion und entspricht nicht der Wirklichkeit der Gesetzesmaterie.

Im Ergebnis schließen die aktiven Delikte das Unterlassen nicht ein. $\ 13$ StGB wirkt strafbegründend. ${ }^{496}$

cc. Wortlaut des $₫ 13$ Abs. 1 StGB/Betrachtung der Tatbestandsvoraussetzungen Abseits der vorangegangenen Diskussion könnte bereits der Wortlaut des $₫ 13$ StGB für eine konstitutive Wirkung streiten.

\section{(1.) Allgemeine Erwägungen}

\13 Abs. 1 StGB hebt für die Strafbarkeit des Unterlassens auf das Begehungsdelikt ab. ${ }^{497}$ Zudem ist gem. $\int 13$ Abs. 1 StGB das Unterlassen „nach diesem Gesetz nur dann strafbar", wenn die beiden weiteren benannten Voraussetzungen gegeben sind, wobei mit „nach diesem Geseť̌" gerade das Begehungsstrafgesetz gemeint

496 So auch Murmann, GA 2012, 711, 714.

Etwas anderes gilt freilich für die Tatbestände, die das Unterlassen vom Wortlaut her umfassen. So umfasst „mißbraucht“ i.S. des $₫ 266$ StGB gleichfalls auch ein Unterlassen (siehe hierzu an dieser Stelle allein MK-StGB/Dierlamm, \266 Rn. 139). Weitere echte Unterlassungsdelikte z.B. $\iint 123$ Abs. 1 Alt. 2, 138, 170, 171, 221, 225, 339, 323 c (aus NK-StGB/Woblers, $\ 13$ Rn. 2. Siehe hierzu näher S. 136 ff., wo versucht wird, aus diesen Normierungen Rückschlüsse auf die deliktische Natur des $₫ 13$ StGB zu ziehen.)

$497 \int 13$ Abs. 1 StGB: „Wer es unterlässt, einen Erfolg abzuwenden, der zum Tatbestand eines Strafgesetzes gehört, $[\ldots] . “$ 
sein könnte. Der Täter würde sich dann wegen des Begehungsdelikts strafbar machen und \13 StGB käme wohl eine allein deklaratorische Wirkung zu.

Zutreffend ist, dass $\int 13$ StGB auf das Begehungsdelikt abstellt. Bei genauerer Betrachtung wird jedoch deutlich, dass gerade nicht auf das Begehungsdelikt insgesamt Bezug genommen wird, sondern nur auf den darin enthaltenen Erfolg. 498 Es findet bei der Rekurrierung auf das aktive Delikt mithin eine klare Aufspaltung zwischen Erfolg und Tatbestandsvoraussetzungen statt. ${ }^{499}$ Der Sinn und Zweck dieses Verweises ist viel weniger eine Bezugnahme auf die Handlungsdelikte als ein Resultat ökonomischer Überlegungen. Denn die zu missbilligenden Erfolge sind bereits umfassend im Strafgesetzbuch enthalten, sodass es dienlich ist, auf diese zu verweisen, anstatt die Unterlassungsdelikte selbst insgesamt positiv zu normieren. Nicht nur, dass dies eine unnötige Gesetzeserweiterung zur Folge hätte, sondern es würde in gleichem Maße auch die Übersichtlichkeit beeinträchtigen. Die Bezugnahme auf das Begehungsdelikt kann folglich nicht für eine Unselbstständigkeit des $\int 13 \mathrm{StGB}$ angeführt werden.

Zudem spricht auch der Auszug ,ist nach diesem Gesetz nur dann strafbar“ nicht für eine rein deklaratorische Wirkung. Zwar heißt es im zweiten schriftlichen Bericht des Sonderausschusses für die Strafrechtsreform diesbezüglich: „Mit der neu aufgenommenen Formulierung, ist nach diesem Gesetz nur dann (strafbar) wird auf den Tatbestand abgestellt, den der Täter durch sein Unterlassen verwirklicht ${ }^{\star 500}$, was nunmehr für einen allein hinweisenden Charakter streiten könnte. Allerdings ist bei dieser Bewertung auch der weitere Halbsatz des Gesetzes miteinzubeziehen. Zu beachten ist, dass \13 StGB das entsprechende Begehungsdelikt modifiziert. Gem. $\int 13$ Abs. 1 StGB macht sich der Täter nach dem eigentlichen Begehungsdelikt nur dann strafbar, „wenn er rechtlich dafür einzustehen hat, daß der Erfolg nicht eintritt, und wenn das Unterlassen der Verwirklichung des gesetzlichen Tatbestandes durch ein Tun entspricht." \13 StGB legt somit eigenständige Voraussetzungen fest, die für die Strafbarkeit eines Unterlassens erforderlich sind. Definierte man den Tatbestand als Summe alle Tatbestandsmerkmale 501 , so könnten die abweichenden Strafbarkeitsvoraussetzungen zu einer deliktischen Eigenständigkeit der unechten Unterlassungsdelikte führen. ${ }^{502}$

\footnotetext{
498 Siehe hierzu auch $\int 13$ Abs. 1 StGB: „Wer es unterläßt, einen Erfolg abzuwenden, der zum Tatbestand eines Strafgesetzes gehört[...].“; eine Auffassung will neben den Erfolgsdelikten gleichsam auch Tätigkeitsdelikte erfassen (siehe hierzu nur Rengier, AT, $₫ 49$ Rn. 7 m.w.N.), was hier jedoch dahinstehen soll.

499 Vgl. Baumann/Weber/Mitsch, AT, \$ 15 Rn. 34.

500 BT-Drs. V/4095, S. 8.

501 SSW-StGB/Kudlich, vor $\$ 13$ Rn. 7.

502 Dazu im Folgenden.
} 
(2.) Eigenständigkeit aufgrund des Garantenerfordernisses

Bzgl. des Erfordernisses einer Garantenstellung wirft Armin Kaufmann im Zusammenhang mit der Auffassung Naglers die Frage auf: „Erfüllt [...] das Verhalten des Garanten wirklich d e $\mathrm{n}$ Tatbestand des B e g e h u n g s delikts?" Armin Kanfmann legt sodann einen Tatbestand zugrunde, der die Merkmale $a+b+c$ aufweist, wobei die Kausalität (c) aufgrund der Auffassung Naglers in „[...] $\mathrm{c}_{1}$ (= Begehungskausalität) und $\mathrm{c}_{2}$ (= Unterlassungskausalität) [zu unterteilen ist].“" ${ }^{\circ 03}$ Diese Aufteilung sei zwar unschädlich, jedoch zeige sich sodann folgendes Bild. Aufgrund des Umstands, dass im Rahmen der unechten Unterlassung die Garantenstellung $(\mathrm{g})$ als weiteres Merkmal hinzutrete, liege eine Strafbarkeit erst dann vor, wenn der Täter $\mathrm{a}+\mathrm{b}+\mathrm{c}_{2}+\mathrm{g}$ verwirkliche, wohingegen im Rahmen der aktiven Begehung $\mathrm{a}+\mathrm{b}+\mathrm{c}_{1}$ für eine Strafbarkeit ausreiche. „Das Zufügen der weiteren Voraussetzung g (Garantenstellung) im Falle $c_{2}$ (kausale Unterlassung) beweist, daß es sich um verschiedene Tatbestände handeln muß.“"504 „Die Garantenstellung ist ke e in ungeschriebenes Tatbestandsmerkmal des B e ge b ung s delikts (sondern ein Erfordernis des Tatbestandes des [unechten] Un te $r$ la s s u $n g$ s delikts). Dann aber erfiullt eben die unechte Unterlassung nicht den Tatbestand des Begebungsverbrechens, sondern einen a n d e r e $n$ Tatbestand, eben den des unechten Unterlassungsdelikts." "505

Bärwinkel wendet gegen die Argumentation von Armin Kaufmann zunächst ein, „daß schon mathematisch $c_{1}$ nicht gleich $c_{2}$ sein kann, wohl aber $c_{2}$ plus g gleich $c_{1}$. " ${ }^{\text {"506 }}$ Würden die Begrifflichkeiten zudem dahingehen substituiert, dass $c$ die Verbaltensweise darstelle, $c_{1}$ als Begehung charakterisiert werde und die Unterlassung ihre Entsprechung in $c_{2}$ finde, so folge hieraus, dass die Garantenstellung $g$ keine zwingende Tatbestandserweiterung sei, die die benannte Formel $\mathrm{a}+\mathrm{b}+c_{1}$ ergänze. Der Charakter des aktiven Delikts werde durch das Hinzutreten der Garantenstellung nicht berührt. ${ }^{507}$ Auch weichten die Unterlassungstatbestände nicht allein im Punkt der Garantenstellung ab, weswegen es sich verbiete, die Eigenständigkeit allein „auf die Zusätzlichkeit dieses Merkmals“ zu stützen.508 Des Weiteren sei der Schluss der Argumentation, dass es sich bei den unechten Unterlassungsdelikten um ungeschriebene Tatbestände handele, unzutreffend, da „hier [...] wieder nicht zwischen dem Auslegungstatbestand und dem Kodifikationstatbestand unter-

503 Armin Kaufmann, Dogmatik, S. 253.

504 Armin Kaufmann, Dogmatik, S. 253; siehe auch Welzel, Strafrecht, 11. Aufl. 1969, S. 210 f.: „Wenn aber die unechte Unterlassung ein z u s ät z li c h e s Merkmal aufweisen muß, um tatbestandsmäßig zu sein, dann ist der in Bezug genommene Tatbestand eben ein anderer, nicht der des Begehungsdelikts: ein Garantengebotstatbestand.“; siehe hierzu auch Fubrmann, GA 1962, 161, 172: „Durch das Hinzutreten dieser ungeschriebenen Merkmale wird ein neuer Tatbestand geschaffen, der als echter Gebotstatbestand sich gegenüber dem Begehungsdelikt als Sonderdelikt erweist.“

505 Armin Kaufmann, Dogmatik, S. 255; vgl. Grünwald, Das unechte Unterlassungsdelikt, S. 44.

506 Bärwinkel, Garantieverhältnisse, S. 25.

507 Bärwinkel, Garantieverhältnisse, S. 25.

508 Bärwinkel, Garantieverhältnisse, S. 25. 
schieden [wird]. Die Auslegungstatbestände von Handlung und Unterlassung müssen verschieden sein wegen der Verschiedenheit der ihnen zugrunde liegenden sozialen und rechtlichen Phänomene. Im Gesetz, im kodifizierten Tatbestand, können jedoch beide Auslegungstatbestände zusammengefaßt und einer einheitlichen Rechtsfolge unterworfen sein, weil die beiden verschiedenartigen menschlichen Verhaltensweisen als Unrecht angesehen werden. Weil diese Gleichstellung innerhalb der gesetzlichen Regelung möglich ist, ist der Schluß auf das Ungeschriebensein bei der unechten Unterlassung solange voreilig, als nicht die gesetzlichen Tatbestände eingehend daraufhin untersucht sind.“509

Bei der Kritik Bärwinkels erscheint schon fraglich, warum $c_{1}$ und $c_{2}$ mathematisch nicht gleich sein können. Freilich ist es, in Entsprechung zu $x$ und $y$, die gleichsam für z.B. fünf stehen können, möglich, dass $c_{1}$ und $c_{2}$ Platzhalter für denselben Wert sind. Auch die von Bärwinkel vorgenommene Abstrahierung auf die Verhaltensweise an sich kann nicht darüber hinweghelfen, dass der Unterlassung andere Voraussetzungen immanent sind als der aktiven Begehung. Nur weil die einzelnen Voraussetzungen nicht mehr separiert benannt, sondern unter einem Oberbegriff zusammengefasst werden, ändert dies nichts an ihrer Existenz. Bänwinkel will jedoch durch diese Abstraktion wohl die Gegenüberstellung von Begehung und Unterlassung bewirken. Wie bereits angedeutet, differenziert Bärwinkel zwischen dem Kodifikationstatbestand und den Auslegungstatbeständen, wobei sowohl das Begehungs- als auch das Unterlassungsdelikt eigenständige Auslegungstatbestände darstellen sollen. Insoweit muss Bärwinkel dahingehend zugestimmt werden, dass bei solch einem Verständnis die Ergänzung des aktiven Begehungstatbestands um die Garantenstellung diesen nicht zu einem Unterlassungsdelikt werden ließe. ${ }^{510}$ Man erreichte allein die Limitierung der aktiven Begehung. Täter wäre hiernach, in Entsprechung zu der Unterlassung, allein derjenige, der eine besondere Pflichtenstellung gegenüber dem Opfer besäße. Allerdings ist schon fraglich, ob ein Tatbestand tatsächlich zwei Auslegungstatbestände umfassen kann. Hierzu wurde bereits festgestellt, dass das Erfordernis einer Garantenposition aus der originären gesetzlichen Normierung nicht resultiert. ${ }^{511}$ Insoweit kann schon kein Unterlassungsauslegungstatbestand neben der Begehung existieren. Des Weiteren bleiben die tatbestandlichen Voraussetzungen der beiden Ausführungsarten trotz der Aufgliederung in zwei Auslegungstatbestände divergent. Selbst wenn das Unterlassen neben der aktiven Begehung stünde und somit keine Abänderung des Begehungsteils vorläge, existierten doch diese tatbestandlichen Unterschiede. Auch wenn somit beide Begehungsformen Teil derselben gesetzlichen Normierung wären, so verhielten sie sich doch wie zwei Delikte, mit der jeweils eigenständigen Ausgestaltung, sodass insoweit die Feststellung Bärwinkels zutrifft,

509 Bärwinkel, Garantieverhältnisse, S. 26; siehe zu der Unterscheidung von Kodifikationstatbestand und Auslegungstatbestand auch ebenda S. 22 f.

510 Siehe hierzu Bärwinkel, Garantieverhältnisse, S. 22 f., 25.

511 Siehe S. $113 \mathrm{ff}$. 
dass „,[sich] die Unterlassungstatbestände [...] von den Begehungstatbeständen eben nicht nur durch die Zusätzlichkeit des Merkmals ,Garantenstellung' unterscheiden $\left[\ldots .\right.$. . $512^{\circ}$ Diese abweichenden Tatbestandsvoraussetzungen weisen bereits den Weg für die deliktische Selbstständigkeit der Unterlassung, sind es doch gerade eigene Voraussetzungen, die einen eigenständigen Tatbestand ausmachen. Insoweit erscheint fraglich, warum es nach Bämwinkel für die deliktische Selbstständigkeit nicht ausreichen soll, dass ein zusätzliches Kriterium neben den anderweitigen Abweichungen hinzutritt. ${ }^{513}$ Auch nach Bärwinkel besteht zwischen den beiden Auslegungstatbeständen keine Kongruenz, sodass, selbst beim Zugrundelegen dieser Auffassung, für eine Eigenständigkeit der Unterlassung votiert werden muss. Denn ungeachtet der übrigen Modifikation tritt eine Tatbestandsvoraussetzung hinzu, die kein Äquivalent auf der aktiven Seite besitzt.

Deutlicher wird dies, wenn sich die Betrachtungsperspektive ändert. Losgelöst von den herausgearbeiteten konkreten Tatbestandsvoraussetzungen und somit abstrakter beleuchtet, bleibt allein das Delikt bestehen. Die Tatbestandsvoraussetzungen resultieren sodann aus der Auslegung der Normierung. Wie jedoch bereits dargestellt, ist die Garantenstellung eine Tatbestandsvoraussetzung, die sich so aus dem Tatbestand nicht ergibt. Es tritt also etwas Zusätzliches abseits des Tatbestands hinzu, das gerade nur dort Relevanz entfalten soll. Versuchte man nunmehr die abstrakten Tatbestandsvoraussetzungen in eine mathematische Form zu bringen, die da lautet $\mathrm{a}+\mathrm{b}+\mathrm{c}^{514}$, wobei diese Formel im Sinne des Kodifikationstatbestands sowohl aktives Verhalten als auch das Unterlassen erfassen soll, so ist zu erkennen, dass der Unterlassungsstrafbarkeit durch diese drei Platzhalter nicht entsprochen werden kann. Es fehlt an der Garantenstellung und somit an einem weiteren Tatbestandsmerkmal, dessen Vorliegen die Strafbarkeit erst begründet. $\mathrm{a}+\mathrm{b}+\mathrm{c}$ kann somit nicht gleich $\mathrm{a}+\mathrm{b}+\mathrm{c}+\mathrm{g}$ sein. ${ }^{515}$ Bei dem Unterlassungsdelikt muss es sich folglich um einen eigenständigen Tatbestand handeln. Die Kritik trägt somit nicht.

Wenn der Tatbestand der Oberbegriff für die enthaltenen Voraussetzungen ist, so muss schon hieraus folgen, dass das unechte Unterlassungsdelikt ein eigenständiger Tatbestand ist. ${ }^{516}$

512 Bärwinkel, Garantieverhältnisse, S. 25.

513 Vgl. Bärwinkel, Garantieverhältnisse, S. 25.

514 a = Erfolg; b = Verursachungsart (Tun/Unterlassen); c = Kausalität.

515 Siehe auch Armin Kaufmann, Dogmatik, S. 254.

516 Auch trifft somit der Vortrag Naglers, dass „[a]us der vollen Gleichschaltung der Unterlassung des Garanten mit der tatbestandsmäßigen Handlung [...] die wichtige Folgerung abzuleiten [ist], daß sich die S t r u k t u r der Kommission durch Unterlassung grundsätzlich i n n i c h t s von dem normalen Begehungsverbrechen u n t e r s c h e i d e t" (Nagler, GerS 111, 1, 69), nicht zu. Siehe zu Naglers Aussage Armin Kaufmann, Dogmatik, S. 252, der auf Nagler, GerS 111, 1, 54 und der daraus folgenden immanenten Widersprüchlichkeit aufmerksam macht. Dort nämlich stellt Nagler selbst fest, dass „der Aufbau der unechten Unterlassungsverbrechen [...] nur an dieser Stelle von den normalen Begehungsverbrechen ab[weicht]“. 
(3.) Eigenständigkeit aufgrund der Kausalitätsanforderungen

Nicht nur durch das zusätzliche Erfordernis der Garantenstellung, sondern bereits aufgrund der unterschiedlichen Kausalitätsanforderungen könnte sich eine Eigenständigkeit der unechten Unterlassungsdelikte ergeben. „Ursächlichkeit liegt bei den (unechten) Unterlassungsdelikten vor, wenn bei Vornahme der pflichtgemäßen Handlung der tatbestandsmäßige Schadenserfolg ausgeblieben wäre, dieser also entfiele, wenn jene hinzugedacht würde. " ${ }^{\text {"517 }}$ Nach der Äquivalenztheorie im Rahmen der aktiven Handlung ,ist Ursache eines strafrechtlich bedeutsamen Erfolges jede Bedingung, die nicht hinweggedacht werden kann, ohne daß der Erfolg entfiele. " 518

Die Ursächlichkeit ist folglich auf die Verhaltensform zugeschnitten. Im Rahmen der aktiven Begehung ist die Handlung somit hinwegzudenken, wohingegen die Frage nach der Kausalität der Unterlassung mit der Überlegung zu beantworten ist, ob im Fall des Hinzudenkens der gebotenen Handlung der Erfolg entfiele.

Armin Kaufmann misst im Rahmen der Diskussion der Auffassung Naglers dem Umstand der verhaltensabhängigen Kausalitätsvoraussetzung wohl keine Bedeutung bei, „da nach der Prämisse $\mathrm{N}$ a g l e r s $\mathrm{c}_{1}$ und $\mathrm{c}_{2}$ den gemeinsamen Oberbegriff - Ursächlichkeit überhaupt - ausfüllen. "519

Da die voneinander abweichenden Kausalitätsanforderungen gleichsam der Bestimmung der Ursächlichkeit eines Verhaltens für einen bestimmten Erfolg dienen, erscheint es zunächst schlüssig, beide Kausalitätsformen unter dem Oberbegriff „Ursächlichkeit“ zusammenzufassen. Dies kann aber nicht darüber hinwegtäuschen, dass tatsächlich eine Voraussetzungsdivergenz besteht. So bleibt die Schublade zwar dieselbe, jedoch ändert sich der Inhalt mit dem Wechsel der Begehungsform. Der Oberbegriff wird insoweit ausgehöhlt und mit neuen/anderen Voraussetzungen bestückt. Was zurückbleibt ist allenfalls eine gemeinsame Hülle, die versucht, die Ursächlichkeit zu ergründen.

Nicht nur wenn sich die Oberbegriffe ändern, sondern auch dann, wenn deren Inhalt modifiziert wird, ändern sich die Voraussetzungen, die für eine Strafbarkeit gegeben sein müssen. Dass nicht der Oberbegriff sondern dessen inhaltliche Anforderungen Maßstab für die tatbestandliche Eigenständigkeit sind, wird auch dann deutlich, wenn eine allgemeine Parallele zu den Erfolgsdelikten gezogen wird. Werden die diesbezüglichen einzelnen Voraussetzungen abstrahiert, so ist allen Erfolgsdelikten gemein, dass der Täter gehandelt hat und hierdurch ein zurechenbarer Erfolg eingetreten ist. Unter der Prämisse, dass allein die Oberbegriffe für die Bewertung der Eigenständigkeit heranzuziehen sind, hätte dies nunmehr zur Folge, dass, trotz der inhaltlich gänzlich abweichenden Deliktsanforderungen, im Strafgesetzbuch allein ein Erfolgstatbestand existierte und somit z.B. \212 und \223 StGB Teil desselben Tatbestands wären.

517 BGHSt 37, 106, 126.

518 BGHSt 1, 332, 333.

519 Armin Kaufmann, Dogmatik, S. 254. 
Folglich lässt auch die Anforderungsdivergenz im Rahmen des Kausalitätserfordernisses den Rückschluss auf eine Eigenständigkeit der unechten Unterlassungsdelikte zu.

(4.) Eigenständigkeit aufgrund der Entsprechungsklausel

Gem. $\int 13$ Abs. 1 StGB ist es neben der Einstandspflicht erforderlich, dass „das Unterlassen der Verwirklichung des gesetzlichen Tatbestandes durch ein Tun entspricht.“

Der Gesetzgeber sah somit die Möglichkeit, dass ein Unterlassen dem Tun nicht gleichsteht. Im Gesetzesentwurf wird festgestellt, „daß das Unrecht der besonderen Tatbestände nicht nur durch die der Tat innewohnenden Rechtsgutverletzung und den hierdurch herbeigeführten Erfolg geprägt ist, sondern auch durch die Eigenart der nach dem Tatbestand vorausgesetzten Tathandlung.“" ${ }^{\circ 20}$ Der letzte Anknüpfungspunkt könne bei der Unterlassung jedoch verloren gehen. „Denn eine etwa in einer Tathandlung liegende besondere Ausprägung des Unrechts tritt im Unterlassen nicht stets in Erscheinung. Da im Besonderen Teil die Unrechtsbewertung auch von etwaigen besonderen Handlungsmerkmalen des jeweiligen Tatbestandes beeinflußt ist, erhebt sich die Frage, wie dem im Falle des Begehens durch Unterlassen Rechnung zu tragen ist.“" 521 Entscheidend hierfür sei die Gleichwertigkeit. Als Beispiel für solch einen abgestuften Unrechtsgehalt soll die Kuppelei dienen. Gem. $\$ 180$ Abs. 1 StGB a.F. wird bestraft, „[w]er gewohnheitsmäßig oder aus Eigennutz durch seine Vermittelung oder durch Gewährung oder Verschaffung von Gelegenheit der Unzucht Vorschub leistet [...].“ Unabhängig von der Begehungsart sei der Erfolg derselbe, was für das verkörperte Unrecht aber nicht zwingend gelte, sondern für das Unterlassen gegenüber dem aktiven Tun nur dann der Fall sei, wenn die Erfolgsabwendung zumutbar ist. ${ }^{522}$

Definiert der Tatbestand ein Verhalten, welches auf die aktive Begehung ausgerichtet ist, so besitze die Art und Weise der Erfolgsrealisierung für die Unrechtsbewertung Bedeutung. So mache es bezogen auf den Unrechtsgehalt einen Unterschied, ob der Täter, um die Versicherungsansprüche auszuweiten, seinen pathologischen Zustand allein durch das Nichtaufsuchen eines Arztes verschlechtert oder ob dieser die Heilung „durch listige Machenschaften“ beeinträchtigt. ${ }^{523}$ Für die Frage nach der Gleichwertigkeit von aktivem Tun und einem Unterlassen sei der Unrechtsgehalt des originär aktiven Delikts Maßstab, woran „das Verhalten des Garanten unter Berücksichtigung der Umstände des einzelnen Falles zu messen [ist]. Es kommt hierbei darauf an, ob dessen Unterlassung nach ihrem sozialethischen Unwert bei sinngemäßer Auslegung des Gesetzes in den Unrechtsbereich der betreffenden Strafnorm fällt.“ Entscheidend hierfür sei eine „Gesamt-

520 BT-Drs. IV/650, S. 125.

521 BT-Drs. IV/650, S. 125.

522 BT-Drs. IV/650, S. 125.

523 BT-Drs. IV/650, S. 125. 
bewertung“, wobei Umstände wie z.B. „die größere Pflichtenbindung des Garanten" das Fehlen von aktiven Merkmalen kompensieren können. ${ }^{524}$

$\mathrm{Zu}$ erkennen ist somit, dass das Unterlassen der aktiven Begehung nicht stets gleichgesetzt werden kann. Erst wenn durch das Nichteinschreiten die gleiche Unrechtsdimension erreicht wird, ist die Realisierung der aktiven Delikte durch ein Unterlassen möglich. Diese grundsätzliche Frage nach dem durch das Unterlassen begründeten Unrecht zeigt auf, dass das Unterlassen keine besondere Ausprägung der Begehung ist, sondern isoliert neben den aktiven Delikten steht. Anderenfalls bedeutete dies, dass das Unterlassen vollwertiger Teil der Begehungsdelikte wäre, jedoch die strafrechtliche Relevanz, in Abgrenzung zu der aktiven Erfolgsrealisierung, eigenständig begründet werden müsste. Hierdurch würde die vollständige Gleichschaltung fakultativ übergangen, sodass die Zuordnung der Unterlassung zu den Begehungsdelikten systemwidrig wäre.

Aber nicht nur der Umstand der isolierten Unrechtsgehaltsprüfung, sondern auch die Divergenzen bei einer dahingehenden Entsprechung streiten für die deliktische Eigenständigkeit. So ist es nicht zwingend, dass das Unterlassen im Fall der Unrechtsentsprechung das gleiche Unrecht verkörpert wie die aktive Begehung. Ein Unrechtsmangel kann, wie gesehen, durch unterlassungsspezifische Momente ausgeglichen werden, sodass die Unrechtsschwelle zwar überwunden wäre, im konkreten Vergleich jedoch das Unrecht ein anderes ist als bei einem Tun.

Im Übrigen ist gleichlaufend zur Garantenstellung festzustellen, dass die Entsprechungsklausel ein zusätzliches unterlassungsspezifisches Tatbestandsmerkmal darstellt, das im Rahmen der aktiven Begehung keine Relevanz besitzt. Die Strafbarkeit des Unterlassens hat folglich gegenüber dem aktiven Tun ein erweitertes Anforderungsprofil, was gleichfalls für die Eigenständigkeit der unechten Unterlassungsdelikte spricht.

\section{(5.) Ergebnis der Wortlautanalyse}

Die Verknüpfung des Unterlassens mit den Begehungsdelikten ist auf den Erfolg beschränkt und allein Konsequenz von ökonomischer Erwägungen. Das ursprüngliche Begehungsdelikt bleibt im Rahmen der Unterlassung somit nur dergestalt erhalten, dass es den tatbestandlichen Erfolg charakterisiert, wohingegen sich gerade die besonderen Voraussetzungen der Unterlassungsstrafbarkeit aus \ 13 StGB ergeben. Diese Voraussetzungsabweichung wird auch von Armin Kaufmann anhand des Garantenerfordernisses nachgewiesen.

Unabhängig hiervon trifft es für beide Begehungsweisen zu, dass das Verhalten zu einer ursächlichen Erfolgsrealisierung geführt haben muss. Dies kann aller-

524 BT-Drs. IV/650, S. 125; siehe hierzu auch Metzen, Strafmilderung, S. 131, der mit Hinweis auf Dreher, Niederschriften über die Sitzungen der Großen Strafrechtskommission, Bd. 12, S. 98 aufzeigt, dass im Fall von besonderen Tatmodalitäten das Unterlassen dem Handeln nie gleichstehe. 
dings nicht darüber hinweghelfen, dass die Anforderungen, die an den Ursachenzusammenhang gestellt werden, voneinander abweichen.

Abschließend verdeutlicht die Entsprechungsklausel, dass dem Unterlassen eine deliktische Eigenständigkeit zukommen muss. Denn würde die Tatbestandsidentität beider Verhaltensweisen bejaht, so hätte dies zur Folge, dass das Unterlassen zwar Teil der aktiven Begehung wäre, jedoch trotzdem geprüft werden müsste, ob das Nichteinschreiten im konkreten Fall überhaupt dem Unrechtsgehalt der aktiven Begehung gleichkommt. Selbst wenn sodann die gleiche Unrechtsintensität vorliegen würde, handelte es sich um ein eigenständig begründetes Unrecht, welches sich an den Unterlassungsmomenten bemisst. Aber auch abstrakt betrachtet wird durch das Entsprechungskriterium und dem dadurch vom aktiven Delikt abweichenden Unterlassungstatbestand aufgezeigt, dass das Unterlassen nicht Teil des Begehungsdelikts ist.

\section{dd. Die fakultative Strafmilderung ( $(13$ Abs. 2 StGB)}

Neben dem Wortlaut des $₫ 13$ Abs. 1 StGB könnte zudem $₫ 13$ Abs. 2 StGB für die Einordnung des $₫ 13$ StGB Relevanz besitzen. ${ }^{525}$

(1.) Rückschluss von der Milderungsmöglichkeit bzw. deren Rechtsgrund auf die deliktische Eigenständigkeit

Festzustellen ist, dass dem Unterlassen in $\int 13$ Abs. 2 StGB eine begehungsformspezifische fakultative Milderungsmöglichkeit eingeräumt wird, wohingegen im Rahmen der aktiven Begehung eine Strafrahmenverschiebung allein aufgrund der Begehungsform nicht vorgesehen ist. Dies bedeutet, dass es bei aktiven Tatbeständen für den Strafrahmen grundsätzlich gleich ist, wie der Erfolg herbeigeführt wurde und ob der Täter ggf. besonders schonend vorgegangen ist. Es wird somit vorausgesetzt, dass jedweder aktiven Ausführungsmöglichkeit durch den tatbestandlichen Strafrahmen entsprochen werden kann.

Im Rahmen des Nichteinschreitens geht der Gesetzgeber hingegen davon aus, „daß unter sonst gleichen Umständen das Unterlassen der Abwendung des tatbestandsmäßigen Erfolges regelmäßig weniger schwer wiege als die Herbeiführung dieses Erfolges durch ein positives Tun [...].“"526 Die Wertigkeit des Unterlassens könne somit geringer sein, als dass dies allein durch den vorhandenen Strafrahmen hätte aufgefangen werden können, sodass eine Milderungsmöglichkeit für erforderlich gehalten wurde. ${ }^{527}$

Durch $\ 13$ Abs. 2 StGB besteht auf Rechtsfolgenseite somit eine fakultative Ungleichwertigkeit zwischen den Begehungsformen. Dies bedeutet, dass das Unterlassen durch die Erfordernisse der Garantenstellung und der Gleichstellungs-

525 So auch Murmann, GA 2012, 711, 714.

526 BT-Drs. V/4095, S. 8.

527 BT-Drs. V/4095, S. 8; noch gegen eine Milderungsmöglichkeit BT-Drs. IV/650, S. 126; zu einer möglichen Zäsur aufgrund einer Unrechtsabweichung siehe S. 39 ff. 
klausel dem Tun zwar tatbestandlich gleichsteht, diese Gleichstellung auf Rechtsfolgenseite jedoch relativiert wird.

Im Fall einer deliktischen Unselbstständigkeit der unechten Unterlassungsdelikte hätte dies zur Folge, dass trotz der Deliktsidentität das Unterlassen fakultativ privilegiert werden würde. Obschon das Unterlassen hiernach Teil des Begehungsdelikts wäre, käme es auf Rechtsfolgenseite durch den $\int 13$ Abs. 2 StGB zu einer Ungleichbehandlung. Neben der hieraus resultierenden Frage, warum eine Verhaltensweise, die originärer Teil eines Tatbestands ist, solch einer Milderungsmöglichkeit überhaupt bedarf, hätte dies zur Konsequenz, dass an denselben Tatbestand unterschiedliche Rechtsfolgen geknüpft würden. ${ }^{528}$ Reduzierte man dies im Fall einer Milderung nach dem Vorbild Armin Kaufmanns auf eine Formel, so wäre $\mathrm{a}+\mathrm{b}+\mathrm{c}=\mathrm{x}^{529}$ bzw. $=\mathrm{y}^{530}$. Verkürzt bedeutete dies, dass $\mathrm{x}=\mathrm{a}+\mathrm{b}+\mathrm{c}=\mathrm{y}$ ist, was aufgrund der divergierenden Rechtsfolgen aber nicht zutrifft.

Die abweichenden Rechtsfolgen sprächen folglich ebenfalls dafür, dass es sich bei den unechten Unterlassungsdelikten nicht um einen Teil des Begehungsdelikts handeln kann, sondern ein eigenständiger Tatbestand vorliegt. Dies gilt so jedoch nur dann, wenn $\int 13$ Abs. 2 zur Anwendung kommt. Es darf nicht vergessen werden, dass es sich bei dieser Vorschrift allein um eine fakultative Milderungsmöglichkeit handelt. Auch wenn es wohl den Regelfall darstellt, dass es im Fall der Unterlassung zu einer Strafrahmenverschiebung gem. \13 Abs. 2 i.V.m. \ 49 Abs. 1 StGB kommt ${ }^{531}$, so ist es doch nicht zwingend, dass das Unterlassen weniger schwer wiegt als die entsprechende Erfolgsherbeiführung durch aktive Begehung. ${ }^{532}$ Allerdings steht unabhängig von der konkreten Anwendbarkeit fest, dass abweichend von den Begehungsdelikten im Rahmen des Nichteinschreitens zumindest abstrakt eine Milderungsmöglichkeit besteht. Bereits dies zeigt einen wesentlichen Unterschied zwischen der strafrechtlichen Bewertung der Begehungsformen, der für die tatbestandliche Individualität des Unterlassungsdelikts streitet. 533

528 Den Umstand des geänderten Strafrahmens erkennt auch Murmann, GA 2012, 711, 714.

$529 \mathrm{x}=$ Strafrahmen aktives Tun.

$530 \mathrm{y}=$ Strafrahmen Unterlassen.

531 Vgl. LK-StGB/Weigend, \13 Rn. 98, der feststellt, dass der Unrechtsgehalt „,typischerweise [...] geringer ist als bei der aktiven Herbeiführung des ,Erfolges ${ }^{6}[. .$.$] ."; siehe auch BT-Drs.$ V/4095, S. 8, wonach die Ausschussmehrheit davon ausgeht, dass „das Unterlassen der Abwendung des tatbestandsmäßigen Erfolges regelmäßig weniger schwer wiege als die Herbeiführung dieses Erfolges durch ein positives Tun [...].“

532 Für einen sogar gesteigerten Unrechtsgehalt des Unterlassens gegenüber der aktiven Begehung wird in BT-Drs. IV/650,126 angeführt, dass ,,[e]ine Mutter, die ihr Kind verhungern läßt, [...] oft schwereres Unrecht [begeht] als die, welche es schmerzlos umbringt."

533 Murmann, GA 2012, 711, 714 stellt für die konstitutive Wirkung des \13 StGB gleichfalls auf \13 Abs. 2 StGB ab, lässt hierbei jedoch den fakultativen Charakter unberücksichtigt, indem er feststellt, „dass $\$ 13$ II StGB einen gegenüber den Tatbeständen des Besonderen Teils geänderten Strafrahmen eröffnet“. 
(2.) Anwendungsumfang des $₫ 13$ Abs. 2 StGB im Fall eines

Begehungsformwechsels bei Fortbestehen derselben Tat

Würde die deliktische Eigenständigkeit der unechten Unterlassungsdelikte verneint und auch im Übrigen eine Zäsur bei einem Begehungsformwechsel abgelehnt, so stellte sich die Frage nach der Anwendbarkeit des $\int 13$ Abs. 2 StGB:

\section{Bsp.: Der versuchte Totschlag durch Unterlassen scheitert. Der Täter ersticht das Opfer sodann mit einem Messer.}

Mangels Zäsur existierte keine eigenständige Strafbarkeit des Unterlassungsversuchs. Die Tat wurde durch die aktive Begehung vollendet, sodass allein eine Strafbarkeit gem. \212 Abs. 1 StGB vorliegt. ${ }^{534}$ Aufgrund des Umstands, dass die erste Passage der Tat ein Unterlassen umfasst, erscheint eine Strafrahmenverschiebung gem. \13 Abs. 2 StGB i.V.m. \4 49 Abs. 1 StGB möglich. Diesbezüglich ist fraglich, ob $\int 13$ Abs. 2 StGB in solch einer Fallkonstellation überhaupt Relevanz entfalten kann, denn neben dem Nichteinschreiten kam es durch ein aktives Handeln zum Erfolgseintritt.

Wird in diesem Beispiel das Unterlassen hinweggedacht, so zeigt sich, dass allein das verbleibende aktive Handeln \212 StGB erfüllt. Das Hinzutreten des Unterlassens stellt nur eine Steigerung des Unrechts dar, wenn auch die Unrechtserhöhung geringer ausfällt, als wenn zwei aktive Ausführungen vorliegen würden. Dadurch, dass das aktive Tun jedoch bereits für sich genommen dem Unrechtsgehalt des \212 StGB entspricht, wäre eine Strafrahmenverschiebung deplatziert.

Dass für eine Milderung in einer begehungsformübergreifenden Mehraktigkeit kein Raum ist, wird vor allem dann noch deutlicher, wenn die sich an das fehlgegangene Unterlassen anschließende erfolgsursächliche aktive Handlung eine hohe Strafe erforderte. Erschiene diesbezüglich eine Freiheitsstrafe von 14 Jahren angemessen und käme es aufgrund des vorangegangenen Unterlassens zu einer Milderung gem. \13 Abs. 2 StGB i.V.m. \ 49 Abs. 1 StGB, so bedeutete dies gem. $\int 49$ Abs. 1 Nr. 2 StGB, dass nunmehr höchstens auf drei Viertel des angedrohten Höchstmaßes erkannt werden dürfte. Für das Strafmaß des \ 212 StGB hätte dies eine Begrenzung der Freiheitsstrafe auf elf Jahre und drei Monate zur Konsequenz, sodass sich durch das zusätzliche Unterlassen die Strafe um zwei Jahre und neun Monate gegenüber einer allein aktiven Begehung verringerte.

Folglich wäre $\int 13$ Abs. 2 StGB immer dann unanwendbar, wenn bei Tatidentität auf ein Unterlassen eine aktive Handlung folgt, die den tatbestandlichen Erfolg herbeiführt. Gerade diese absolute Unanwendbarkeit scheint allerdings der gesetzlichen Ausgestaltung zu widersprechen, wonach die Milderung der Bewer-

534 Siehe hierzu S. 139 ff. 
tung des Gerichts obliegt, was für die deliktische Eigenständigkeit des Unterlassens sprechen könnte. Jedoch muss das Gericht auch in diesen Fällen die gegebene Konstellation individuell auf eine Milderungsmöglichkeit hin untersuchen. Wird sodann die Strafrahmenverschiebung versagt, so ist dies allein dahingehend obligatorisch, als dass bei gleichem Unwertgehalt $\int 13$ Abs. 2 StGB stets keine Anwendung findet.

Der Ausschluss einer Strafrahmenverschiebung bei einer begehungsformübergreifenden Mehraktigkeit zwingt somit nicht dazu, \ 13 StGB als konstitutive Vorschrift zu begreifen.

\section{(3.) Vergleich der Verweise auf \49 Abs. 1 StGB}

Es ist zu erkennen, dass die Verweise auf den $\int 49$ Abs. 1 StGB535 innerhalb des Strafgesetzbuchs keiner Stringenz unterliegen. Das Ziel ist zwar in allen Fällen eine Strafrahmenverschiebung, jedoch ist der Grund hierfür stets ein anderer.

So berücksichtigt z.B. \17 S. 2 StGB, dass der Täter keine Unrechtseinsicht besaß. \ 23 Abs. 2 StGB trägt hingegen dem Umstand Rechnung, dass ein Versuch zumeist weniger schwer wiegt als die Vollendung, wobei \ 27 Abs. 2 S. 2 StGB verhindern soll, dass ein helfender Teilnehmer auf Rechtsfolgenseite dem Täter gleichsteht.

Andererseits wird dem Täter aber auch im Rahmen des Täter-OpferAusgleichs nach \46a StGB bzw. wenn er gem. \46b StGB durch Mitteilung seines vorhandenen Wissens eine Tat hilft aufzuklären oder zu verhindern eine Strafrahmenverschiebung gem. \ 49 Abs. 1 StGB gewährt.

Mithin ist festzustellen, dass die Motivation des Gesetzgebers, eine Strafmilderung zu gewähren, auf vielschichtigen Überlegungen beruht, weswegen es innerhalb der Verweise auf $\int 49$ Abs. 1 StGB keine allgemeinen Voraussetzungen gibt, die Rückschlüsse auf die Eigenständigkeit des $\int 13$ StGB zulassen.

(4.) Ergebnis

Die fakultative Milderungsmöglichkeit des $\int 13$ Abs. 2 StGB kann allein dahingehend für eine deliktische Eigenständigkeit der unechten Unterlassungsdelikte fruchtbar gemacht werden, dass durch sie selbst eine Sondervorschrift existiert, die isoliert im Rahmen der Unterlassung Relevanz besitzt.

535 U.a. im StGB: \13 Abs. 2 (fakultativ), \17 S. 2 (fakultativ), \ 21 (fakultativ), \ 23 Abs. 2 (fakultativ), \27 Abs. 2 S. 2 (obligatorisch), \ 28 Abs. 1 (obligatorisch), \ 30 Abs. 1 S. 2 (obligatorisch), \35 Abs. 1 S. 2 (fakultativ), \ 46 a (fakultativ), \ 35 Abs. 2 S. 2 (obligatorisch), \ 142 Abs. 4 (obligatorisch), \239 a Abs. 4 S. 1 (fakultativ) StGB (entnommen aus SSWStGB/Eschelbach, \ 49 Rn. 4 u. 6). 
ee. Gesetzessystematik

Neben $\int 13$ StGB wird ein Unterlassen im Strafgesetzbuch noch auf zwei weitere Arten erfasst. Es existieren explizit normierte Unterlassungstatbestände, wie z.B.

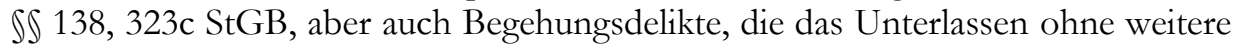
gesetzliche Ausgestaltung einschließen. So formuliert \225 Abs. 1 Var. 3 StGB positiv, dass sich derjenige strafbar macht, der seine Pflicht böswillig vernachlässigt.

\section{(1.) Vergleich mit den echten Unterlassungsdelikten}

Werden die ausdrücklich normierten echten Unterlassungsdelikte mit $\int 13$ StGB verglichen, so zeigt sich sogleich ein wesentlicher Unterschied. Die in diesen Tatbeständen geregelten Fälle besitzen keine aktive Entsprechung, sondern bestrafen das Unterlassen an sich. So bestraft z.B. \323c StGB das „Nicht-Hilfe-Leisten“, was freilich nur durch ein Nichthandeln zu realisieren ist. \13 StGB könnte einen unter diesen Tatbestand fallenden Sachverhalt allenfalls dann erfassen, wenn der Täter Garant wäre und der Erfolg eines aktiven Begehungsdelikts eintritt. Da aber auch ohne diese weiteren Voraussetzungen ein „Nicht-Hilfe-Leisten“ als sozialethisch missbilligenswert erachtet wurde, also gerade das Nichteinschreiten an sich pönalisiert werden sollte, bedurfte es der besonderen Regelung des $\int 323 \mathrm{c}$ StGB.

Antwort auf die Frage, ob $\int 13$ StGB nunmehr deklaratorisch oder konstitutiv ist, kann durch einen Vergleich jedoch nicht gegeben werden. Vor allem die mangelnde Kongruenz zwischen $\int 13$ StGB und dieser Unterlassungsstrafbarkeit lässt Rückschlüsse nicht zu.

\section{(2.) Vergleich mit \ 225 Abs. 1 Var. 3 StGB}

Anders könnte sich dies allerdings im Fall eines Vergleichs mit \ 225 Abs. 1 Var. 3 StGB darstellen. \225 Abs. 1 Var. 3 StGB erfasst explizit und originär das Unterlassen, wobei vorausgesetzt wird, dass aus dem Nichthandeln ein Erfolg resultiert. Schließt jedoch \225 StGB als grundsätzlich aktives Delikt das Unterlassen aufgrund seiner besonderen Ausgestaltung auch ohne einen Bezug auf $\int 13$ StGB ein, so muss dies für die übrigen Tatbestände, die ihrer Form nach dem \225 StGB gerade nicht entsprechen, bedeuten, dass das Unterlassen diesbezüglich nur über $\int 13 \mathrm{StGB}$ tatbestandlich sein kann. In diesem Falle käme $\int 13$ StGB konstituierende Wirkung zu.

Klärungsbedürftig ist folglich, ob $\int 13 \mathrm{StGB}$ auch dann zu berücksichtigen ist, wenn sich die originäre strafrechtliche Relevanz des Unterlassens bereits aus dem Delikt an sich ergibt. Wie Güntge zu Recht erkennt, normiert der $\int 225$ Abs. 1 alle Unterlassungsvoraussetzungen, weswegen aufgrund dieser Deckungsgleichheit der $\int 13 \mathrm{StGB}$ auch in diesem Rahmen Anwendung finden könnte. 536 Die Konsequenz hiervon sei, dass ,[...] beispielsweise über die mit $\int 13 \mathrm{StGB}$ verknüpfte 
Garantendogmatik im Einzelfall bestimmt werden [könnte], unter welchen Voraussetzungen der Täter Sonderpflichtiger i.S.d. speziell geregelten Unterlassungsdelikts ist. “537 Zudem könne auch das Entsprechungskriterium Wirkung entfalten. „Mit seiner Hilfe könnte jeweils konkret geprüft werden, ob das dem geschriebenen Tatbestand unterfallende Unterlassen tatsächlich dem Unrechtsgehalt der ebenfalls gesetzlich erfaßten Begehungsalternativen entspricht." "538 Bezüglich $₫ 225$ StGB hieße dies zu prüfen, „ob eine Vernachlässigung der Fürsorgepflicht im speziellen Fall den Unrechtsgehalt der Tatbestandsvarianten des ,Quälens' und ,Roh Mißhandelns' der ersten beiden Begehungsalternativen des $\int 223 \mathrm{~b}$ StGB erreicht. “539 Konsequenz der Anwendung des $₫ 13$ StGB sei somit zum einen eine Strafbarkeitseinschränkung durch die Entsprechungsklausel als auch eine Strafbarkeitserweiterung, da sich eine Pflichtigkeit z.B. auch aus vorangegangenem pflichtwidrigen Verhalten ergeben könne. ${ }^{540}$

Fraglich sei jedoch, ob Normierungen, die eigenständig ein Unterlassen pönalisieren, durch die Anwendung des $₫ 13$ StGB tatsächlich modifiziert werden dürfen. ${ }^{541}$ Die Vorschriften des Allgemeinen Teils dienten der Ergänzung der Tatbestände des Besonderen Teils, sodass $₫ 13$ StGB gleichfalls diese Funktion zukomme. ${ }^{542}$ „Welcher Art diese Ergänzungsfunktion ist, ergibt sich nun bei einer Sichtung der für $\ 13$ StGB einschlägigen Gesetzesmaterialien." Die Einführung des $₫ 13$ StGB habe dazu gedient, die Strafbarkeit des Unterlassens im Rahmen der aktiven Begehungsdelikte zu ermöglichen. ${ }^{543}$ Hingegen lasse sich nicht erkennen, dass $₫ 13$ StGB auch Auswirkungen auf Tatbestände haben sollte, die bereits vor Einführung des $₫ 13$ StGB das Unterlassen erfassten. ${ }^{544}$ Dies bedeute, dass im Rahmen von Delikten, die das Unterlassen originär berücksichtigen, $\ 13 \mathrm{StGB}$ keine Relevanz entfalte. Auch teleologisch mache dies Sinn. „Die Ergänzung eines Tatbestandes um ein strafbares handlungsentsprechendes Unterlassen eines Garanten macht nur dort Sinn, wo es an einem derartigen strukturierten Unterlassungsdelikt fehlt.، “545

Vollkommen zutreffend weist Güntge darauf hin, dass Sinn und Zweck der Einführung des $₫ 13$ StGB die Bestrafung des Unterlassens im Rahmen der Begehungsdelikte war. Bedenken bzgl. einer möglichen Verfassungswidrigkeit der Strafbarkeit eines Nichteinschreitens im Rahmen der aktiven Delikte sollten durch diese Normierung beseitigt werden.546 Der Rechtsgrund spart mithin die Vor-

\footnotetext{
537 Güntge, wistra 1996, 84, 87.

538 Güntge, wistra 1996, 84, 87.

539 Güntge, wistra 1996, 84, 88.

540 Güntge, wistra 1996, 84, 88.

541 Güntge, wistra 1996, 84, 87.

542 Güntge, wistra 1996, 84, 88.

543 Güntge, wistra 1996, 84, 88, der auf BT-Drs. V/4095, S. 8 verweist.

544 Güntge, wistra 1996, 84, 88.

545 Güntge, wistra 1996, 84, 88.

546 Siehe hierzu S. $91 \mathrm{ff}$.
} 
schriften aus, die das Unterlassen bereits ohne anderweitige Ausgestaltungen erfassen. Folglich muss der Regelungsgehalt des $₫ 13$ StGB auch allein auf die Tatbestände begrenzt werden, aus denen sich die Unterlassungsstrafbarkeit nicht originär ergibt.

Festzustellen ist somit, dass Tatbestände existieren, die das Unterlassen originär enthalten und ohne $₫ 13$ StGB bestrafen. Zugleich folgt hieraus aber auch, dass die übrigen Delikte das Unterlassen gerade nicht erfassen. Denn erkennt man im Rahmen des $\$ 225 \mathrm{StGB}$ an, dass neben dem aktiven Tun gleichfalls das Unterlassen pönalisiert ist, so muss im Umkehrschluss zugegeben werden, dass die übrigen Begehungsdelikte, die diese Voraussetzungen originär nicht erfüllen, das Unterlassen gerade nicht einschließen. Ohne $₫ 13$ StGB wäre in diesen Fällen das Unterlassen nicht tatbestandsmäßig, sodass $\ 13$ StGB hiernach konstitutive Wirkung zukommen muss.

\section{ff. Strafrechtlicher Vorwurf}

Losgelöst von der gesetzlichen Ausgestaltung scheint auch der begehungsformspezifische strafrechtliche Vorwurf für die deliktische Eigenständigkeit des Unterlassens zu sprechen. Wird dem aktiven Täter vorgeworfen, durch sein Tun ein Rechtsgut verletzt zu haben, so ist im Rahmen des Unterlassens das Nicbtabwenden einer Rechtsgutsverletzung pönalisiert. Der strafrechtliche Vorwurf ist mithin ein gänzlich anderer und lässt den grundsätzlichen Unterschied dieser beiden Begehungsformen erkennen.

Werden in diesen Vergleich die übrigen gesetzlichen Tatbestände einbezogen, so ist festzustellen, dass der enthaltene Vorwurf stets ein anderer ist. Hierbei bezieht sich jeder Straftatbestand auf ein bestimmtes unerwünschtes Verhalten und ist in sich abgeschlossen.

Einem eigenständigen Tatbestand ist folglich ein individueller Vorwurf immanent. In Kombination mit der Feststellung, dass das Unterlassen einen eigenständigen Vorwurf gegenüber der aktiven Begehung verkörpert, spricht dies auch dafür, dass es sich bei den unechten Unterlassungsdelikten um eigenständige Tatbestände handeln muss.

gg. Charakter des $₫ 13$ StGB: Ergebnis

Die vorangegangenen Ausführungen haben gezeigt, dass $₫ 13$ StGB eine konstitutive Wirkung entfaltet. So war zu erkennen, dass die Eingliederung des Unterlassens in die Begehungsdelikte ohne eine besondere gesetzliche Ausgestaltung vereinzelt schon an der Wortlautgrenze scheitert. Bereits durch diese Limitierung kommt $\int 13 \mathrm{StGB}$ in diesen Fällen eine konstitutive Wirkung zu. Eine hingegen allgemeingültige Aussage konnte aus der Garantenstellung gewonnen werden. Ihre strafbegründende Wirkung in Verbindung mit der mangelnden originären Ableitbarkeit aus dem Gesetz führt dazu, dass im Fall einer Bestrafung des Unter- 
lassens im Rahmen des aktiven Begehungsdelikts ohne besondere gesetzliche Normierung ein Verstoß gegen den Bestimmtheitsgrundsatz und somit gegen Art. 103 Abs. 2 GG vorliegt. Neben der Verfassungswidrigkeit ergeben sich zudem aus $\int 13$ StGB Argumente für eine strafbegründende Wirkung. So definiert $\int 13$ StGB eigenständige Voraussetzungen, was dazu führt, dass das aktive Delikt auf den verkörperten Erfolg reduziert wird und zudem gegenüber der aktiven Begehung gänzlich abweichende Tatbestandsvoraussetzungen erfüllt sein müssen. So unterscheiden sich der aktive Tatbestand und das unechte Unterlassungsdelikt durch das Garantenerfordernis und den konkreten Ursachenzusammenhang. Gleichsam konnte durch die Entsprechungsklausel und die Existenz des \ 13 Abs. 2 StGB die deliktische Eigenständigkeit der unechten Unterlassungsdelikte nachgewiesen werden. Auch belegt der Vergleich mit \225 Abs. 1 Var. 3 StGB und der dort explizit vorgesehenen Unterlassungsstrafbarkeit, dass aktive Delikte, ohne solch eine originäre Berücksichtigung des Unterlassens, das Unterlassen nicht einschließen und $\int 13$ StGB in diesen Fällen konstitutive Wirkung zukommt. Nicht zuletzt wird dies durch den Umstand ergänzt, dass dem Täter im Rahmen des Unterlassens etwas gänzlich anderes vorgeworfen wird, als bei der aktiven Begehung.

\section{c. Folgen für die Einheitlichkeit des Geschehens bei einem Begehungsformwechsel}

$\int 13$ StGB ist eine konstitutive Vorschrift, die die Strafbarkeit des Unterlassens im Rahmen der Begehungsdelikte begründet. Dieses Ergebnis bedingt, dass es sich bei den unechten Unterlassungsdelikten um eigenständige Tatbestände handelt, sodass aus einem Begehungsformwechsel zugleich ein Tatbestandswechsel folgt. Wird diese Erkenntnis nunmehr mit der Feststellung zusammengeführt, dass aus einem Tatbestandswechsel eine Zäsur resultiert, so bedeutet dies, dass der Begehungsformwechsel die Einheitlichkeit des Geschehens trennt. Ein Unterlassen und ein Tun können somit nicht Teil derselben Tat i.S. des $\int 24$ Abs. 1 StGB sein.

\section{Begehungsformübergreifende sukzessive/iterative Tatbestandserfüllung}

Abseits der Fehlschlagsproblematik besitzt der Begehungsformwechsel für die Einheitlichkeit auch dann Relevanz, wenn der Täter nach dem Scheitern des Unterlassungsversuchs nicht nur erkennt, dass er den Erfolg noch aktiv herbeiführen kann, sondern diese Möglichkeit tatsächlich auch ergreift.

Bsp.: Vater $V$ sieht, dass seine Tochter zu ertrinken droht und schreitet mit Tötungsvorsatz nicht ein. Als sich die Tochter wider Erwarten ans Ufer retten kann, eilt er zu ibr und drückt ihren Kopf unter Wasser, bis sie verstirbt. 
Fraglich ist hier, ob insoweit ein versuchter Totschlag durch Unterlassen und ein vollendeter aktiver Totschlag in Betracht kommen bzw. allein eine Verwirklichung des $\int 212$ Abs. 1 StGB vorliegt. Denn sind beide Begehungsformen Teil derselben Tat, so wurde die durch das Unterlassen versuchte Tat durch die aktive Begehung vollendet. Auch in diesem Fall ist somit entscheidend, ob die verschiedenen Begehungsformen zu einer Tat zusammengefasst werden können. ${ }^{547}$

Bedeutung besitzt in diesem Kontext vor allem die inverse Form, bei der nach der aktiven Passage ein Unterlassen hinzutritt. Führt eine Sorgfaltspflichtverletzung des Delinquenten zum Tod des Opfers und schreitet der Täter vor Erfolgsrealisierung mit Vorsatz bzgl. aller objektiven Tatbestandsmerkmale nicht helfend ein, so ergibt sich neben einer Strafbarkeit gem. \222 StGB wegen fahrlässiger Tötung zudem eine strafrechtliche Verantwortlichkeit nach $\iint 212$ Abs. 1, 13 Abs. 1 StGB. Die neben der aktiven Passage stehende Unterlassungsstrafbarkeit erscheint aufgrund des Vorsatzdefizits der fahrlässigen Tötung unproblematisch. ${ }^{548}$

Stets gänzlich unbeachtet bleibt die Strafbarkeit wegen eines Unterlassens hingegen im Fall der volldeliktischen aktiven Erfolgsherbeiführung. ${ }^{549}$ Schießt der Täter auf das Opfer und verlässt daraufhin den Tatort, obschon er das Opfer noch retten könnte, so würde eine gutachterliche Erörterung sich auf eine Strafbarkeit gem. \212 Abs. 1 StGB beschränken. ${ }^{550}$ Insoweit hieße es bereits im Obersatz allein, dass der Täter sich durch den Schuss wegen eines Totschlags gem. \ 212 Abs. 1 StGB strafbar gemacht haben könnte. Warum dem Unterlassen in diesem Rahmen keine Bedeutung beigemessen wird, lasse sich nach einer Auffassung auf ein Zurücktreten im Rahmen der Konkurrenzen zurückführen bzw. scheitere nach anderer Meinung bereits am Vorliegen einer Garantenstellung. 551

547 Vgl. S. 134.

548 SSW-StGB/Kudlich, \13 Rn. 51, wobei zudem auch die Fahrlässigkeitspassage aufgrund der aktiven Begehung Ausdruck im Schuldspruch finden müsse; siehe MK-StGB/Freund, \13 Rn. 291, der ,die fahrlässige Tötung durch aktives Tun hinter die vorsätzliche Tötung durch begehungsgleiches Unterlassen zurück[treten]“ lässt; siehe hierzu auch Stein, JR 1999, 265, 266 f.

549 Zu der Existenz Freund, NStZ 2004, 326, 327: „Dabei dürfte gar nicht selten eine Überschneidung dahingehend zu verzeichnen sein, dass sich der Versuchstäter des beendeten Begehungsversuchs zugleich in der Situation des kraft Ingerenz für die Gefahrabwendung Sonderverantwortlichen und damit in der Situation des Unterlassungsversuchs befinden: Wer sein Opfer mit Tötungsvorsatz lebensgefährlich verletzt hat, muss im Rahmen des ihm Möglichen und Zumutbaren die von ihm geschaffene Lebensgefahr kraft einer qualifizierten (Garanten-)Rechtspflicht abwenden [...].“; zudem ders., NStZ 2004, 326, 328: „Er tritt durch die reichlich späte Verständigung des Notarztes nicht nur von dem am Nachmittag des 15. 3. 2001 begonnenen und am Abend dieses Tages in der Verhaltensform des aktiven Tuns erneuerten Tötungsversuch zurück. Sein Rücktritt bezieht sich auch auf die durch vorsätzliche Ingerenz begründete nachfolgende versuchte Tötung durch begehungsgleiches Unterlassen.“

550 Siehe hierzu nur Stein, JR 1999, 265, 267.

551 Siehe zu den Vertretern Stein, JR 1999, 265, 267 Fn. 25; Busch, FS v. Weber, 1963, S. 192, 197 will mit Sauer, GerS 114, 279, 292 das Unterlassen als straflose Nachtat behandeln: „Dieses Unterlassen wird als sog. straflose Nachtat von dem vorangegangenen Tun konsumiert."; ebenfalls 
Unabhängig von der konkreten Lösung des Verhältnisses von Tun und Unterlassen in dieser Konstellation fällt auf, dass sich die Bewertung der Strafbarkeit gem. \212 StGB auf die aktive Begehung beschränkt. Das Unterlassen besitzt in dem dortigen Rahmen keine Relevanz in Form einer iterativen bzw. sukzessiven Tatbestandsverwirklichung. Es steht mithin separiert neben dem aktiven Handlungsabschnitt und bildet augenscheinlich einen neuen Anknüpfungspunkt für eine strafrechtliche Bewertung. 552

Wird dies nunmehr mit dem Umstand zusammengeführt, dass die Zusammengehörigkeit einzelner Verhalten im Rahmen der sukzessiven Tatbestandsverwirklichung nach dem BGH gleichsam anhand der Gesamtbetrachtungslehre und deren etablierter Maßstab i.S. eines einheitlichen Lebensvorgangs bestimmt wird ${ }^{553}$, so ergeben sich hieraus direkte Konsequenzen für die Tatreichweite bei $\$ 24$ Abs. 1 StGB. Können Unterlassen und Tun mithin nicht Teil einer sukzessiven bzw. iterativen Tatbegehung sein, so muss aufgrund des identischen Bewertungsmaßstabs Entsprechendes auch für die Problematik im Rahmen des Rücktritts gelten.

für eine konkurrenzrechtliche Lösung Stein, JR 1999, 265, 268 und MK-StGB/Freund, \ 13 Rn. 292. Zur Frage, ob auch ein vorsätzliches Vorverhalten eine Garantenstellung begründet siehe S. 154 f.; zur konkreten rechtlichen Bedeutung eines sich an eine aktive Begehung anschließenden Unterlassens S. $154 \mathrm{ff}$.

552 Engländer, JZ 2012, 130, 133 verweist hingegen darauf, dass aufgrund eines Schlechterstellungsverbots auch bei einem Begehungsformwechsel eine sukzessive Tatbestandsverwirklichung möglich sein müsse. Zu dem Argument des Schlechterstellungsverbots siehe S. 144 ff.; keine Relevanz kann das Unterlassen hingegen besitzen, wenn der Täter nach der aktiven Handlung davon ausgeht, sich in einem unbeendeten Versuch zu befinden. Tritt der Erfolg sodann ein, so mangelt es in Bezug auf das Unterlassen an der subjektiven Komponente.

553 BGHSt 41, 368 f.: „Die Frage, wann in Fällen, in denen der Täter mehrfach zur Tatvollendung ansetzt, eine Tat im Rechtssinne vorliegt, ist im Zusammenhang mit der Prüfung der Konkurrenzen wenig erörtert. Die Frage nach der Reichweite der Tat im materiellen Sinne in Fällen der vorliegenden Art ist jedoch weitgehend geklärt, soweit es darum geht, wie weit ein möglicher Rücktritt des Täters sich auf vorangegangene Einzelakte erstreckt. Es bestehen keine Bedenken, die Ergebnisse dieser Rechtssprechung auch auf die Beurteilung der Konkurrenzen anzuwenden, denn Tat i.S. des $\ 24$ Abs. 1 StGB, auf die sich der Rücktritt erstreckt, ist die für die Beurteilung der Konkurrenzen maßgebliche Tat im materiellrechtlichen Sinne. Danach gilt folgendes: Eine Tat im Rechtssinne liegt vor, wenn die der Tatbestandsvollendung dienenden Teilakte einen einheitlichen Lebensvorgang bilden, wobei der Wechsel des Angriffsmittels nicht von entscheidender Bedeutung ist. Ein einheitlicher Lebensvorgang in diesem Sinne ist gegeben, wenn die einzelnen Handlungen in engem räumlichen und zeitlichen Zusammenhang stehen. [...] Die tatbestandliche Einheit [...] endet dort, wo der Täter nach den Regelungen über den Rücktritt nicht mehr strafbefreiend zurücktreten kann, d.h. entweder bei der vollständigen Zielerreichung oder beim fehlgeschlagenen Versuch.“; siehe hierzu auch Murmann, Grundkurs, $\ 31$ Rn. 21, der auf den Dagobert-Fall (BGHSt 41, 368 ff.) verweist; siehe auch ders., GA 2012, 711, 716. 
5. Vereinbarkeit einer Rücktrittserweiterung mit den Grundsätzen des Rücktritts

Durch das Zusammenfassen von Unterlassen und Tun würden die Rücktrittsmöglichkeiten des Täters ausgeweitet. Trotz des Fehlgehens des Unterlassungsabschnitts könnte der Täter strafbefreiend zurücktreten, indem er eine weitere aktive Handlung unterlässt bzw. nach begonnener Ausführung sich von dieser abwendet. Ist das Unterlassen hingegen nicht fehlgeschlagen und somit eigentlich rücktrittsfähig, so wäre dem Täter allerdings gleichfalls, aufgrund des Fortbestehens derselben Tat, erst mit der Aufgabe der aktiven Passage und nicht schon im Zeitpunkt des Begehungsformwechsels ein Rücktritt möglich. Hierbei betrifft diese Fallgestaltung jedoch im Gegensatz zu den ersten beiden Konstellationen allein die Strafzumessungsebene und nicht die grundsätzliche Strafbarkeit des Delinquenten. ${ }^{554}$

Wie zu erkennen ist, führt das Zusammenfassen von Tun und Unterlassen zumeist zu einer Rücktrittserweiterung, sodass sich die Frage nach der Vereinbarkeit mit den Grundsätzen des Rücktritts stellt.

\section{a. Mangelnde Distanzierung von der Unterlassungspassage}

Sieht der Unterlassungstäter von einer weiteren möglichen aktiven Handlung ab und tritt hierdurch zurück, so bedeutete dies, dass der Täter Strafaufhebung bzgl. des gescheiterten versuchten Unterlassens nur deshalb erlangt, weil das weitere mögliche aktive Handeln als Teil derselben Tat nicht umgesetzt wurde. Folglich orientierte sich nicht nur die Frage nach dem Fehlschlag an dem unterlassenen aktiven Akt, sondern zugleich auch das für eine Strafbefreiung erforderliche Rücktrittsverhalten. Da das Unterlassen nicht erfolgreich war und der Fehlschlag nur deswegen negiert wird, weil der Täter erkennt, dass neben seinem gescheiterten Unterlassen die Möglichkeit einer aktiven Begehung besteht, muss der Täter auch davon ausgegangen sein, durch das Unterlassen noch nicht alles Erforderliche getan zu haben, um den deliktischen Erfolg herbeizuführen. Der Delinquent befände sich somit nach dem Scheitern des Unterlassens in einem unbeendeten Versuch, sodass gem. \24 Abs. 1 S. 1 Var. 1 StGB die Aufgabe der weiteren Tatausführung für die Strafbefreiung ausreichte. Indem der Täter nunmehr von der Vornahme der Handlung absieht, hätte er von der Tatausführung abgelassen und wäre strafbefreiend zurückgetreten.

$\mathrm{Zu}$ erkennen ist, dass die beiden Begehungsformen zwar in derselben Tat verschmelzen, durch das Ablassen von der aktiven Handlung allerdings keine konkrete Distanzierung von dem fehlgegangenen Unterlassen gegeben ist. Hierbei darf aber nicht unberücksichtigt bleiben, dass diese Distanzierungsproblematik im Rahmen der Gesamtbetrachtungslehre stets dann besteht, wenn ein Handlungsabschnitt fehlgegangen ist. Verfehlt der einzig zur Verfügung stehende Schuss das

554 Siehe zu den Folgen bereits S. 31. 
Opfer und erkennt der Täter die Möglichkeit eines Messereinsatzes ${ }^{555}$, führt dies jedoch nicht aus, so stellte sich ebenso die Frage nach der Distanzierung. ${ }^{556}$ Viel entscheidender ist aber, dass bei diesem Einwand der konkrete gesetzliche Bezugspunkt unbeachtet bleibt. Wie $\$ 24$ Abs. 1 S. 1 Var. 1 StGB erkennen lässt, ist es für den Rücktritt allein entscheidend, ob der Täter die weitere Ausführung der Tat aufgegeben hat. Ist mit der Gesamtbetrachtungslehre somit eine weitere mögliche Handlung noch Teil derselben Tat und führt der Täter diese nicht aus, so hat der Täter sich nicht nur von der weiteren möglichen Handlung distanziert, sondern insoweit auch von der ganzen Tat Abstand genommen. ${ }^{557}$ Dies trifft so aber nur dann zu, wenn das weite Verständnis der Gesamtbetrachtungslehre für sich genommen nicht schon gegen die Grundsätze des strafbefreienden Rücktritts verstoßen würde. $\mathrm{Ob}$ dies der Fall ist, kann für die konkrete Frage nach einer Zäsur im Rahmen eines Begehungsformwechsels nur bedingt weiterhelfen. Hierdurch würde die konkrete Ebene des Begehungsformwechsels verlassen und die Gesamtbetrachtungslehre insgesamt in Frage gestellt, was an dieser Stelle außen vor bleiben soll..$^{558}$

\section{b. Opferschutz.}

Für eine einheitliche Bewertung beider Begehungsformen könnte der Opferschutz sprechen. Eine in diesem Rahmen vorliegende Zäsur hätte ggf. zur Folge, dass der Täter nach dem Scheitern des Unterlassens motiviert wird, den tatbestandlichen Erfolg doch noch herbeizuführen. ${ }^{559}$ Erkennt der Vater das Fehlgehen seines Unterlassungsversuchs, so könnte die aus der Zäsur resultierende zwingende Versuchsstrafbarkeit diesen veranlassen, die Tochter zu töten, um den einzig möglichen Zeugen zu beseitigen.

Festzustellen ist, dass das Unterlassen gegenüber der aktiven Begehung ein meist heimliches Delikt ist, bei dem der Täter unerkannt bleibt. ${ }^{500}$ So wird es der in einer Notsituation befindlichen Tochter schwerlich auffallen, dass ihr Vater das gesamte Geschehen beobachtet und dem Erfolgseintritt freudig entgegenblickt. Die Verneinung des Rücktritts begründet in diesem Rahmen folglich nicht in gleichem Maße wie bei einem fehlgegangenen aktiven Akt die Gefahr der Tatbestandsvollendung. Allein dann, wenn der Täter davon ausgeht, entdeckt worden

\footnotetext{
555 Beispiel so bei Engländer, JZ 2012, 130, 132.

556 Zur allgemeinen Problematik der mangelnden Distanzierung im Rahmen der Gesamtbetrachtungslehre S. 20 ff.; siehe auch Murmann, GA 2012, 711, 718 ff., der versucht die Distanzierung nach einem eigenen Verständnis zu determinieren; siehe auch ders., Versuchsunrecht und Rücktritt, 1999, S. 44 ff.

557 Aufgrund des Tatbezugs stimmen auch die Ergebnisse der anderen beiden Fallkonstellationen (S. 142) mit dem $\$ 24$ Abs. 1 StGB überein.

558 Zur Gesamtbetrachtungslehre S. 153 ff.

559 Allgemein zum Opferschutz S. 24 ff.

560 Vgl. hierzu S. 36 ff.
} 
zu sein, könnte er aufgrund der bestehenden Unterlassungsstrafbarkeit die Motivation entwickeln, das Opfer zu beseitigen. Die Bewertung des Opferschutzes ist insoweit nicht eindeutig und hängt in diesem Rahmen vom Einzelfall ab.

Abweichend hiervon könnte der Opferschutzgesichtspunkt aber dann uneingeschränkt für eine weite Tat sprechen, wenn der Täter durch die Rücktrittserweiterung ggf. motiviert werden könnte, die Rechtsgutsgefährdung durch das Unterlassen zu beenden. Hiergegen spricht bereits, dass, solange der Unterlassungsversuch nicht fehlgeschlagen ist, eine Rücktrittsmöglichkeit gem. \24 Abs. 1 StGB besteht, wodurch dem Täter in diesem Kontext ein Anreiz gesetzt wird, den Erfolgseintritt zu verhindern. Schlägt der Unterlassungsversuch hingegen fehl, so ist die Rechtsgutsgefährdung abgescblossen und das Opfer außer Gefahr, weswegen es keiner Auslobung strafrechtlicher Vorteile mehr bedarf, um den Täter zur Erfolgsabwendung und mithin zum Opferschutz zu veranlassen. Vielmehr ist es für das Opfer sogar von Vorteil, wenn die Rücktrittsmöglichkeit auf das Unterlassen beschränkt wird. Um in den Genuss der Straffreiheit gem. \24 Abs. 1 StGB zu kommen, sähe sich der Täter gezwungen, den gefassten Unterlassungsentschluss schnellstmöglich aufzugeben und Rettungsmaßnahmen einzuleiten, bevor das Opfer sich selbst rettet bzw. der Erfolgseintritt durch Dritte verhindert wird. Ein enger Tatbegriff erhöhte folglich sogar den Druck auf den Täter die Rechtsgutsverletzung abzuwenden und förderte hierdurch den Schutz des Betroffenen.

Festzustellen ist somit, dass die Opferschutzperspektive im hiesigen Rahmen zu keinem eindeutigen Ergebnis führt. Ein Argument für oder gegen einen weiten Tatbegriff ergibt sich hieraus mithin nicht.

\section{Schlechterstellungsverbot nach Engländer}

\section{a. Auffassung Engländers}

Für die Einordnung des Begehungsformwechsels stellt Engländer auf die Gleichstellung von Tun und Unterlassen durch den $₫ 13$ StGB an sich ab. „Axiologisch folgt aus dieser Gleichstellungsfunktion des $₫ 13$ StGB allerdings zugleich ein Schlecbterstellungsverbot. Man darf den Unterlassenden unter bestimmten Bedingungen zwar ebenso behandeln wie den aktiv Handelnden. Es ist aber nicht zulässig, ihn gegenüber diesem schlechter zu stellen. “561 Könne der aktive Täter nach dem Fehlgehen des ersten Akts durch das Ablassen von einer weiteren möglichen Handlung zurücktreten, so dürfe für den gescheiterten Unterlassungstäter nichts anderes gelten..$^{562}$

561 Engländer, JZ 2012, 130, $132 \mathrm{f}$.

562 Engländer, JZ 2012, 130, 133. 


\section{b. Allgemeine Bewertung}

Engländer stellt zu Recht fest, dass die Annahme einer Zäsur bei einem Begehungsformwechsel dazu führte, dass mit der Gesamtbetrachtungslehre der Rücktritt im Rahmen einer allein aktiven Begehung weiter reichen würde, als im Fall der versuchten Erfolgsherbeiführung durch ein Unterlassen. Obschon die weiteren äußeren Umstände identisch wären, könnte der Täter nur im ersten Fall Straflosigkeit durch Ablassen von einer weiteren Ausführung erreichen. Diese Divergenz ist evident.

Murmann folgt der Auffassung Engländers obschon dieser Augenfälligkeit nicht, „denn die Gleichstellungsfunktion betrifft die Erfolgszurechnung, besagt aber, wie die fakultative Strafmilderungsmöglichkeit nach \ 13 II StGB zeigt, nicht, dass der Verhaltensunwert beim Unterlassen dem des positiven Tuns entsprechen muss. [...] Die mit einem Wechsel vom Unterlassen zu einem positiven Tun zumindest regelmäßig verbundene Unrechtssteigerung spricht also gegen einen einheitlichen Lebensvorgang." ${ }^{653} \mathrm{Zu}$ Recht verweist Murmann auf $\int 13$ Abs. 2 StGB und den hieraus fakultativ resultierenden Unrechtswechsel im Fall einer Änderung der Begehungsform. Wie aber bereits gesehen, kann allein aus dem Umstand einer Unrechtsdivergenz eine Zäsur im Rahmen der Gesamtbetrachtungslehre nicht begründet werden ${ }^{564}$, sodass dieser Einwand das Verständnis Engländers nicht zu widerlegen vermag.

Gegen Engländer lässt sich jedoch einwenden, dass \13 StGB ausschließlich eingeführt wurde, um mögliche Zweifel über die Verfassungskonformität der unechten Unterlassungsdelikte auszuräumen ${ }^{565}$, was eine vollständige Gleichschaltung der Begehungsformen per se nicht einschließt. Dies zeigt auch die konkrete Wirkungsweise des $\int 13$ StGB. So bezieht sich $\int 13$ StGB aufgrund von ökonomischen Überlegungen auf den Erfolg der aktiven Begehungsdelikte und füllt den Tatbestand im Übrigen durch unterlassungsspezifische Voraussetzungen auf.566 Die so zwischen dem Tun und Unterlassen bestehende Äquivalenz beschränkt sich auf die Möglichkeit, denselben tatbestandlichen Erfolg herbeiführen zu können.

Dass sich aus $\int 13$ StGB kein Schlechterstellungsverbot ergibt, zeigt auch die deliktische Eigenständigkeit des $\int 13$ StGB. ${ }^{567}$ Denn bereits hieraus folgt eine Ungleichheit beider Begehungsformen, die eine differenzierte Betrachtung rechtfertigt.

\footnotetext{
563 Murmann, GA 2012, 711, $714 \mathrm{f}$.

564 Siehe S. $39 \mathrm{ff}$.

565 Siehe S. 91 ff. bzw. BT-Drs. V/4095, S. 8 und BT-Drs. IV/650, S. 124.

566 Siehe hierzu S. $124 \mathrm{ff}$.

567 Siehe S. $91 \mathrm{ff}$.
} 


\section{c. Weitere Konsequenzen des Schlechterstellungsverbots}

Unabhängig von der von Engländer vorgenommenen Überinterpretation des $\ 13$ StGB, könnten zudem die sich aus einem Schlechterstellungsverbot ergebenen Konsequenzen gegen eine solche vollständige Gleichschaltung von Tun und Unterlassen sprechen. Wird das Schlechterstellungsverbot auf das Unterlassen im Allgemeinen übertragen, so folgte hieraus, dass auch bei einem fortgesetzten Unterlassen die Einheitlichkeit aus Gleichstellungserwägungen fortbestehen müsste.

Bsp. 1: Der Sohn S droht zu ertrinken. Vater V schreitet mit Tötungsvorsatz. nicht ein. S kann sich wider Erwarten selbst retten, fällt jedoch, nachdem er am Steg sicheren Stand erlang hat, wieder zurück ins Wasser. Der Vater eilt sodann zu seinem Sohn und rettet ihn.

In dieser Konstellation müsste der Vater aufgrund des Schlechterstellungsverbots vollständig straffrei werden. Denn handelte der Täter aktiv, so könnte der Täter vollständig zurücktreten, wenn er nach einem fehlgegangenen Einzelakt ein anderes Mittel einsetzt und sodann die Vollendung verhindert.

Bsp. 2: Der Säugling S droht in der Waschwanne zu ertrinken. Da die Mutter die Schreie leid ist, schreitet sie mit Tötungsvorsatz, nicht ein. Als es dem Kind sodann gelingt, die Waschwanne umzuwerfen, erkennt die Mutter, dass sie S verdursten lassen könnte, sieht hiervon jedoch ab. ${ }^{568}$

Auch hier bedingte das Schlechterstellungsverbot einen vollständigen Rücktritt. Schlägt nämlich im Rahmen eines aktiven Versuchs die erste Handlung fehl, so wird der Täter straffrei, wenn er von einer weiteren Möglichkeit absieht.

Klärungsbedürftig ist somit, ob ein versuchtes Unterlassen und eine erneute Unterlassung bzw. eine Unterlassungsmöglichkeit Teil derselben Tat sein können.

568 Fall angelehnt an Kudlich, JR 2003, 379, 381. 
aa. Mehrere Unterlassungen als Teil derselben Tat

(1.) Grundsätzliche Möglichkeit einer mehraktigen Unterlassung

\begin{abstract}
F, der Freund der Angeklagten (A), schlug den Sängling der A. Trotz der erkannten Todesgefahr unternahm $A$ nichts. Als $F$ das Kind später erneut misshandelte, binderte $A$ den $F$ in Kenntnis der Lebensgefährlichkeit der Behandlung wiederum nicht. Ärqtliche Hilfe wurde von $F$ und $A$ erst am folgenden Tag in Anspruch genommen. Zwar konnte das Kind gerettet werden, erlitt durch die Misshandlungen jedoch bleibende Schäden. ${ }^{569}$
\end{abstract}

Fraglich ist, ob der Rücktritt durch das Hilfeholen das gesamte Geschehen erfasst oder nur zu einer partiellen Straflosigkeit führt. Der BGH entschied, dass es sich bei dem ersten Unterlassen nicht um einen fehlgeschlagenen Versuch handele, da die A bereits zu diesem Zeitpunkt den Todeseintritt für möglich gehalten und diese Vorstellung zwischenzeitlich auch nicht aufgegeben habe. „Die Verletzungen durch den ersten Teilakt waren demzufolge aus Sicht der Angeklagten nach wie vor geeignet, den Todeserfolg herbeizuführen, wobei die Verletzungen aus dem zweiten Teilakt nur geeignet waren, den Eindruck akuter Lebensgefährlichkeit i.S. des nahen Erfolgseintritts zu verstärken." 570 Zudem sei selbst dann ein Rücktritt anzunehmen, wenn die Angeklagte bzgl. der zweiten Passage „einen erneuten gleichartigen Tatentschluss gefasst hätte [...]. Der Grund der Strafbefreiung wurzelt in der freiwilligen Änderung der Verhaltensrichtung, solange der Täter alle unerlaubten Risiken noch in der Hand hat. Daher erstreckt sich ein Rücktritt auf sämtliche vorangegangene Tatabschnitte, soweit er auf die Abwendung der durch diese geschaffenen, ungehindert fortwirkenden Gefahren zielt. “571

Folglich scheint es möglich, dass der BGH beide Unterlassungen zu einer Tat i.S. des $\int 24$ Abs. 1 StGB zusammenfasst. Zwingend ist diese Auslegung jedoch nicht. Spaltete man beide Abschnitte zu eigenständigen Taten i.S. des \24 Abs. 1 StGB auf, so lägen zwei unabhängige versuchte Unterlassungen vor. Die Besonderheit der vorliegenden Konstellation gestaltete sich sodann dahingehend aus, dass A von der Erfolgstauglichkeit des ersten Unterlassens fortwährend ausgeht. Selbst wenn zwischenzeitlich der Tatentschluss gänzlich aufgegeben wurde, änderte dies an der Rücktrittsfähigkeit dieser Tat nichts. Zwar reicht die alleinige Aufgabe des Tatentschlusses für eine Strafbefreiung im Fall eines beendeten Versuchs

569 BGH, NStZ 2003, 252 f.; siehe zum Fall auch Murmann, Grundkurs, \ 29 Rn. 116; vom BGH in dieser Entscheidung gänzlich unbeachtet blieb die Frage, ob A neben dem aktiv handelnden F tatsächlich Täter ist (siehe zum Streitstand Murmann, Grundkurs, \29 Rn. 93 ff.).

570 BGH, NStZ 2003, 252, 253.

571 BGH, NStZ 2003, 252, 253. 
gem. $\int 24$ Abs. 1 S. 1 Var. 2 StGB nicht aus, allerdings kann dies solange keine negativen Folgen besitzen, wie der Täter von der Erfolgstauglichkeit seines Beitrags ausgeht. ${ }^{572}$ Dies bedeutete, dass A durch das Herbeirufen des Arztes nicht von einer sondern von zwei Taten i.S. des $\$ 24$ Abs. 1 StGB zurückgetreten wäre, sodass die Separierung hier keine negativen Konsequenzen für die A hätte. Es kann vorliegend somit dahinstehen, ob beide Ausführungsakte zu einer Tat zusammenzuführen sind. 573

Unabhängig hiervon spricht für die grundsätzliche Möglichkeit einer einheitlichen Betrachtung zweier Unterlassungen schon die im Beispiel bestehende Verbindung zwischen dem aktiven Handeln des F und dem Unterlassen. Sein Handeln stellt den unmittelbaren Anknüpfungspunkt für das Unterlassen dar. Würde die grundsätzliche Möglichkeit eines Zusammenfassens mehrmaligen Nichteinschreitens abgelehnt, so hätte dies zur Konsequenz, dass der aktiv handelnde Täter nur einen Versuch und damit eine Tat i.S. des $\ 24$ Abs. 1 StGB begangen hätte, wohingegen sich der hierzu parallel Unterlassende mehreren Versuchen und somit mehreren Taten i.S. des $\ 24$ Abs. 1 StGB gegenüber sähe. Obschon der aktiv handelnde Täter Anknüpfungspunkt für die strafrechtliche Verantwortlichkeit des Unterlassungstäters ist, käme es zu einer schon objektiv abweichenden Bewertung der vorliegenden Taten. ${ }^{574} \mathrm{Zu}$ beachten ist hierbei jedoch, dass dies allein nicht für eine vollständige Gleichstellung beider Begehungsformen streitet. Aufgrund der anderen Struktur der Unterlassung könnte es zu individuellen Zäsuren und somit zu begehungsformspezifischen Ergebnissen kommen. Insoweit erscheint fraglich, ob im Rahmen der Mehraktigkeit mehrerer Unterlassungen Trennungsmomente vorliegen, die eine unterschiedliche Bewertung beider Ausführungsformen bedingen.

\section{(2.) Zäsuren im Rahmen der mehraktigen Unterlassung}

Klärungsbedürftig ist, ob die Einheitlichkeit bei einem Nichteinschreiten gleichfalls immer dann besteht, wenn bei einer entsprechenden aktiven Begehung eine Tat i.S. des $\ 24$ Abs. 1 StGB vorliegt oder ob sich aus den Besonderheiten der Unterlassung ggf. eine Aufspaltung ergeben könnte, die eine Ungleichbehandlung rechtfertigt und somit keinen Raum für ein pauschales Schlechterstellungsverbot lässt.

Hierzu sei auf das erste Fallbeispiel ${ }^{575}$ verwiesen. Dieses Beispiel stellt das Unterlassungspendant zu der aktiven Konstellation dar, in der der Täter nach der

572 Vgl. Freund, NStZ 2004, 326, 327 f.; siehe auch Kudlich, JR 2003, 379, 381.

573 Anders wäre es freilich dann, wenn die A den ersten Beitrag als gänzlich erfolgsuntauglich angesehen hätte. Eine vollständige Straflosigkeit wäre in diesem Fall allein dann möglich, wenn beide Unterlassungen Teil derselben Tat wären.

574 Unberücksichtigt müssen bei dieser objektiven Betrachtung freilich subjektive Umstände bleiben. Stellt sich der Unterlassungstäter in Abweichung zu dem aktiven Täter ein Fehlgehen vor, so kann es hierdurch zu unterschiedlichen Taten kommen.

575 Siehe S. 146. 
zweiten Handlung zurücktritt und hierdurch, trotz des Fehlgehens des ersten Aktes, vollständig straffrei wird. Diese Parallele bietet nunmehr die Möglichkeit, beide Verhaltenskonstellationen gegenüberzustellen und in Bezug auf etwaige Zäsurdivergenzen hin zu beleuchten.

\section{(a.) Zäsur aufgrund des zwischenzeitlichen Scheiterns}

Vorliegend konnte sich der Sohn selbst retten und erlangt sicheren Stand auf dem Steg. In diesem Zeitpunkt scheitert das erste Unterlassen, woraus sich eine Zäsur ergeben könnte.

Das Scheitern an sich ist jedoch einem mehraktigen Tatbegriff stets immanent und führt für sich genommen nicht zu einer Zäsur. So scheitert auch der aktive Täter zwischenzeitlich, wenn in einem mehraktigen Versuch eine Handlung fehlgeht. Insoweit ergibt sich hieraus keine Besonderheit der Unterlassung, die zu einer abweichenden Bewertung führt.

\section{(b.) Zäsur aufgrund des Zufallsmoments}

Der Täter kann im ersten Beispiel sein vorangegangenes strafrechtliches Verhalten allein deswegen relativieren, weil der Sohn noch einmal ins Wasser gefallen ist. Da dieser Umstand aber allein auf Zufällen beruht, könnte sich hieraus eine Zäsur ergeben.

$\mathrm{Zu}$ beachten ist allerdings, dass die Möglichkeit der weiteren Tatausführung auch im Rahmen des aktiven Handelns häufig von glücklichen Umständen abhängt und es gleichfalls meist dem Zufall überlassen bleibt, ob dem Täter noch weitere Handlungsmöglichkeiten zur Verfügung stehen, die sodann einen Rücktritt eröffnen. Dass der Vater hier Glück hatte, dass S erneut ins Wasser gefallen ist, kann diesem, ohne etwas anderes für die aktive Begehung anzunehmen, somit nicht entgegengehalten werden.

\section{(c.) Zäsur durch Aufgabe des Tatentschlusses bzw. durch mangelnde potentielle Gefährlichkeit des Täters}

Ein Unterschied zwischen der aktiven und der passiven Fallkonstellation könnte sich jedoch auf subjektiver Ebene ergeben. Erkennt der aktive Täter die Unmöglichkeit der Zielerreichung mit dem verwendeten Tatmittel, so besteht der deliktische Wille fort, wenn er sich auf die Suche nach weiteren Ausführungsmöglichkeiten begibt. Der abstrakte Angriff in Form einer bestehenden Tatmotivation dauerte folglich an, selbst wenn der Täter in diesem Moment das weitere Tatmittel kon- 
kret noch nicht erblickt hat. Allein die Suche nach weiteren Möglichkeiten stellt eine Bedrohung für die Rechtsgüter des Betroffenen und mithin eine potentielle Gefahr dar.

Anders muss dies aber im Rahmen des Unterlassens beurteilt werden. In dem Zeitpunkt, in dem der Sohn einen sicheren Stand auf dem Steg erlangt, muss der Vater einsehen, dass es ihm nunmehr endgültig nicht mehr möglich ist, den Erfolg durch Unterlassen herbeizuführen. Denn abweichend vom aktiven Tun ist der Vater bzgl. des Unterlassens äußeren Begebenheiten unterworfen, die er ohne ein Tun nicht zu beeinflussen im Stande ist. Erkennt der Täter aber diesen Umstand, so muss zwangsläufig sein Unterlassungstatentschluss entfallen und der Versuch schlägt fehl. Hieran ändert sich auch dann nichts, wenn sich dem Täter später eine erneute Unterlassungsmöglichkeit eröffnet. Der Täter besitzt zu diesem Zeitpunkt keinen Tatentschluss mehr und müsste folglich einen neuen fassen, sodass es sich bei der neuen Unterlassungssituation um eine andere Tat handelt. ${ }^{576}$

Mit dieser Trennung geht zudem ein weiteres Zäsurmoment einher. So mangelt es zwischen den Ausführungspassagen an einer Gefährlichkeit des Täters. Mit dem Erreichen des Stegs geht von dem Täter keine (potentielle) Unterlassungsgefahr mehr aus, sodass, anders als bei der entsprechenden aktiven Begehung, zwischen den zwei Unterlassungsakten keine dahingehende Kontinuität besteht.

\section{(d.) Zwischenergebnis}

Feststellen lässt sich somit, dass das Unterlassen trotz entsprechender Fallgestaltung andere Zäsurmomente beinhaltet als das Tun. Aufgrund dieser Abweichung ist trotz einer Schlechterstellung des Unterlassens eine differenzierte Betrachtung geboten.

bb. Fehlschlagsnegation durch eine weitere Unterlassungsmöglichkeit

Wird dem aktiven Täter bei einem Fehlgehen des ersten Aktes ein Rücktritt durch die Nichtvornahme einer anderen Handlung ermöglicht, so müsste mit dem Schlechterstellungsverbot Entsprechendes auch für den Unterlassungstäter gelten, wenn dieser nach dem Scheitern der ersten Unterlassung ein abstrakt mögliches Unterlassen nicht weiterverfolgt. Bereits hier zeigt sich jedoch, dass sich eine der aktiven Begehung entsprechende Sachlage nicht ergeben kann. Bezogen auf das zweite Beispiel ${ }^{577}$ wird deutlich, dass die Mutter, abweichend von einem aktiven Täter, noch keine Herrschaftsgewalt über den Eintritt der konkreten Gefahr, hier die des Verdurstens, besitzt. Vielmehr bleibt es in diesem frühen Stadium dem Zufall überlassen, ob die gefahrbegründenden Umstände eintreten werden. Folg-

576 Vgl. hierzu BGH, NJW 1986, 2325, 2326; siehe zur Trennungswirkung eines neuen Tatentschlusses auch Kudlich, JR 2003, 379, 381 und Fn. 9.

577 Siehe S. 146. 
lich kann die Mutter keine konkreten Mittel erkennen, die ihr den Erfolgseintritt noch ermöglichen, sodass der Versuch fehlschlägt.

Etwas anderes ergibt sich auch dann nicht, wenn die weitere Unterlassung bereits in solch ein Stadium gelangt ist, in dem eine konkrete Herrschaftsgewalt über den Erfolgseintritt besteht und hierdurch eine eigene Unterlassungsstrafbarkeit begründet würde. Gerade der Umstand der eigenständigen strafrechtlichen Relevanz zeigt den Unterschied zu der aktiven Versuchsausgestaltung. Ist das weitere mögliche aktive Handeln abseits des Rücktritts ein Nullum, das keine Strafbarkeit begründet, käme es im Rahmen des Nichteinschreitens auch isoliert zu einer strafrechtlichen Relevanz der weiteren Unterlassungsmöglichkeit. Dies resultiert aus dem Umstand, dass die nun gebildete Unterlassungskonstellation einem mehraktigen aktiven beendeten und nicht einem unbeendeten Versuch entspricht. Vielmehr wäre hier fraglich, ob durch den Rücktritt von dem weiteren, bereits begonnenen Unterlassen auch bzgl. des vorherigen Nichtstuns Straffreiheit erlangt werden kann. ${ }^{578}$

Es zeigt sich, dass der mehraktige aktive Versuch, bei dem sich der Täter zuletzt in einem unbeendeten Versuch befindet, keine Unterlassungsentsprechung besitzt. Mangels einer vollständigen Gleichschaltung verbieten sich aber auch abstrakte Vergleiche der beiden Begehungsformen. Zwar wird derUnterlassungstäter sodann ggf. anders bewertet, dies beruht aber auf den der jeweiligen Begehungsform immanenten Umständen. Eine Schlechterstellung ergibt sich aufgrund der fehlenden Vergleichsmöglichkeit nicht bzw. ist in der Begehungsform originär angelegt, sodass aus $\int 13$ StGB ein Schlechterstellungsverbot nicht resultiert.

\section{d. Ergebnis}

Aus $\int 13$ StGB folgt kein Schlechterstellungsverbot. Bereits die nachgewiesene deliktische Eigenständigkeit der unechten Unterlassungsdelikte verdeutlicht, dass ein eigenständiger Maßstab erforderlich ist, um $\int 13$ StGB gerecht werden zu können. Des Weiteren ergibt sich weder aus dem historischen Kontext noch ausder konkreten Wirkungsweise des $₫ 13$ StGB, dass diese Normierung ein Schlechterstellungsverbot bedingt.

Im Übrigen ist Engländers Lösungsansatz lückenhaft. Engländer beschränkt seine Darstellung auf den Rücktritt vom versuchten Unterlassungsdelikt durch weiteres Unterlassen und lässt anderweitige Konstellationen außer Betracht. Die Bewertung dieser ausgesparten Fälle zeigt jedoch, dass trotz einer entsprechenden Fallgestaltung eine zwingende Differenzierung zwischen den Begehungsformen auch dann erforderlich ist, wenn das Unterlassen gegenüber dem aktiven Tun hierdurch schlechter gestellt wird. Zudem zeigt sich, dass das Tun Fallkonstellationen umfasst, die sich auf das Unterlassen gerade nicht übertragen lassen. Im Rahmen des

578 Es handelte sich mithin um eine Abwandlung des ersten Beispiels. 
Nichteinschreitens kann es nicht dazu kommen, dass der Fehlschlag eines Unterlassungsversuchs allein durch die bloße Existenz einer weiteren Unterlassungsmöglichkeit beseitigt wird. Die Figur des vorläufigen Fehlschlags besitzt im Rahmen des mehraktigen alleinigen Unterlassens keine Relevanz, was eine Vergleichbarkeit der Begehungsformen verhindert und eine faktische Schlechterstellung bedeutet. Eine vollständige Gleichstellung kann mithin nicht erreicht werden.

\section{Einlassungsmöglichkeiten des Täters}

Neben den vorangegangenen Argumenten gegen eine Vereinheitlichung von aktivem Tun und Unterlassen könnten auch tatsächliche Folgen für die Separierung beider Begehungsformen sprechen. Wie bereits festgestellt, würde ein begehungsformübergreifender Tatbegriff es dem Täter ermöglichen, vom Unterlassen allein dadurch zurückzutreten, dass er Abstand von einer weiteren aktiven Handlung nimmt. Es käme insoweit zu einer für den Täter positiven Ausgestaltung des $\ 24$ Abs. 1 StGB.

Um in den Genuss dieser Rücktrittsmöglichkeit zu kommen, muss der Täter jedoch tatsächlich eine weitere Handlungsmöglichkeit erkannt haben. Anderenfalls schlägt der Versuch fehl und ein Rücktritt scheidet aus. Insoweit kommt freilich der Gedanke, dass der Täter stets vortragen wird, abseits des gescheiterten Akts weitere Alternativverhalten erkannt zu haben. Es entstünden durch das Kumulieren von Unterlassen und Tun Beweisschwierigkeiten. ${ }^{579}$ „Es bestehe die Gefahr, so könnte man argumentieren, dass der Täter sich die Strafbefreiung nach $₫ 24$ Abs. 1 Satz 1 Alt. 1 StGB erschleiche, indem er später einfach nur vorgebe, auf ein ihm in unmittelbaren Fortgang noch mögliches aktives Tun verzichtet zu haben, denn irgendwelche weiteren Handlungsoptionen zur Tatbestandsverwirklichung bestünden praktisch immer." ${ }^{\text {"580 }}$ Dieser Einwand ist, wie Engländer freilich richtig erkennt, kein Spezifikum des Begehungsformwechsels. Die Beweisschwierigkeiten ergeben sich gleichsam auch dann, wenn der Täter nach dem Fehlgehen einer aktiven Handlung vorgibt, bestimmte weitere Ausführungsmöglichkeiten für sich reserviert zu haben. ${ }^{581}$

Insoweit handelt es sich hierbei um ein Problem, das sich im Rahmen der Gesamtbetrachtungslehre insgesamt stellt und somit individuell für den Begehungsformwechsel nicht fruchtbar gemacht werden kann.

579 Engländer, JZ 2012, 130, 133.

580 Engländer, JZ 2012, 130, 133.

581 Engländer, JZ 2012, 130, 133. Ebenda: „Es hieße indes das Kind mit dem Bad auszuschütten, bei Mehraktigkeit den Rücktritt durch Nichtweiterhandeln nur wegen der Gefahr einer missbräuchlichen Berufung auf $₫ 24$ Abs. 1 Satz 1 Alt. 1 StGB auszuschließen.“ 


\title{
8. Die Gesamtbetrachtungslehre
}

Bisher wurde der Untersuchung die Gesamtbetrachtungslehre zugrunde gelegt. Allein hierdurch konnte festgestellt werden, wie sich der Begehungsformwechsel im Rahmen eines weiten Tatverständnisses verhält. Da insoweit die Reichweite des einheitlichen Lebensvorgangs und somit der Gesamtbetrachtungslehre festgelegt wurde, gilt es nunmehr, die Gesamtbetrachtungslehre selbst zu bewerten. Hierbei soll der Streit um ein weites bzw. enges Tatverständnis jedoch nicht erneut ausgebreitet werden, sondern die Gesamtbetrachtungslehre soll allein unter einem Aspekt ihre Schlüssigkeit beweisen.

a. Bewertungsgrundlage

Bsp. 1: Der Sohn S droht zu ertrinken. Vater $V$ schreitet mit Tötungsvorsatz. nicht ein. S kann sich wider Erwarten selbst retten, fällt jedoch, nachdem er am Steg sicheren Stand erlangt hat, wieder zurück ins Wasser. Der Vater eilt sodann zu seinem Sohn und rettet ibn. ${ }^{582}$

Durch das Einschreiten kann V, aufgrund des zwischenzeitlich neu gefassten Tatentschlusses und der mangelnden Gefahrenkontinuität, allein von dem zweiten Abschnitt zurücktreten. ${ }^{583}$ Die Strafbarkeit wegen versuchten Totschlags durch Unterlassen in Bezug auf das erste Hineinstürzen bleibt somit bestehen.

\begin{abstract}
Bsp. 2: Der Vater $V$ stößt seinen Sohn $S$ ins Wasser, um diesen ertrinken zu lassen. S gelingt es jedoch, sich aus dem Meer zu retten. $V$ will es hierbei aber nicht bewenden lassen und gibt dem Sohn erneut einen Stoß. Als S sodann im $W$ asser um Hilfe schreit, reut $V$ sein Verhalten und rettet den Jungen.
\end{abstract}

Nach der Gesamtbetrachtungslehre besteht aufgrund des räumlichen und zeitlichen Zusammenhangs die Einheitlichkeit der Tat fort. Durch das Retten des Sohnes im Rahmen der zweiten Ausführungspassage kann der Vater vollständige Straffreiheit erlangen.

Werden beide Beispiele miteinander verglichen, so ist zu erkennen, dass die zweite Konstellation das vorangegangene Unterlassungsbeispiel inkludiert, wobei der Täter sich nach dem aktiven Stoßen in derselben Situation befindet wie der allein unterlassende Delinquent. Auf eine mathematische Formel abstrahiert bedeu-

582 Beispiel bereits auf S. 146.

583 Siehe S. $147 \mathrm{ff}$. 
tet dies, dass der alleinige Unterlassungstäter $\mathrm{u}_{1}+\mathrm{u}_{2}{ }^{584}$ begangen hätte, wobei dem aktiven Täter in Entsprechung $\mathrm{a}_{1}+\mathrm{u}_{1}+\mathrm{a}_{2}+\mathrm{u}_{2}{ }^{585}$ vorgeworfen werden müsste. $\mathrm{Ob}$ dem Unterlassen hierbei aber eine eigenständige strafrechtliche Würdigung zukommt, erscheint fraglich. ${ }^{586}$

aa. Rechtliche Bedeutung eines sich an ein aktive Handlung anschließenden Unterlassens

\section{(1.) Schwerpunkt der Vorwerfbarkeit}

Gegen eine isoliert strafrechtliche Relevanz des Unterlassens könnte angeführt werden, dass der Schwerpunkt der Vorwerfbarkeit im zweiten Beispiel auf der aktiven Begehung liegt und somit kein Unterlassen gegeben ist. ${ }^{587} \mathrm{Zu}$ beachten ist hierbei jedoch, dass z.B. in Abgrenzung zum Ziegenhaarfall588 vorliegend die Einordnung der Verhaltensqualität unproblematisch ist. So steht eindeutig fest, dass das Stoßen eine aktive Handlung darstellt. Vielmehr tritt zu dem aktiven Tun ein weiterer Unterlassungsanknüpfungspunkt durch das darauffolgende Nichteinschreiten hinzu, sodass sich die Frage nach der Verhaltensform insoweit nicht stellt. Der Schwerpunkt der Vorwerfbarkeit kann mithin nicht gegen eine eigenständige Bedeutung des Unterlassens sprechen. 589

\section{(2.) Garantenstellung bei einem vorsätzlichen Vorverhalten}

Auch wenn sich beide Beispiele in Bezug auf das Unterlassen überschneiden, muss dies nicht zwangsläufig dazu führen, dass das sich an die aktive Begehung anschließende Unterlassen tatbestandlich ist. So muss der Täter auch in diesem Fall Garant sein. Fraglich ist daher, ob aus einem vorsätalichen Vorverhalten eine Garantenstellung resultieren kann. 590

Hierfür spricht, dass im Rahmen eines fahrlässigen Vorverhaltens eine Garantenstellung stets zu bejahen ist. ${ }^{591} \mathrm{Da}$ ein vorsätzliches strafbares Verhalten eine objektive Sorgfaltspflichtverletzung inkludiert und somit dem vorsätzlichen Handeln gleichsam ein Fahrlässigkeitsvorwurf inhärent ist, muss auch aus solch einem Vorverhalten eine Garantenstellung aus Ingerenz folgen.

Nach Stein spricht aber auch die Strafzumessung für eine Garantenstellung. So sei der Unrechtsgehalt geringer, wenn der Tod sofort eintritt, als wenn zwischen

\footnotetext{
$584 \mathrm{u}_{1}=$ erste Unterlassung; $\mathrm{u}_{2}=$ zweite Unterlassung.

$585 \mathrm{a}_{1}=$ erste aktive Handlung; $\mathrm{u}_{1}=$ erste Unterlassung; $\mathrm{a}_{2}=$ zweite aktive Handlung; $\mathrm{u}_{2}=$ zweite Unterlassung.

586 Vgl. S. 139 f.; siehe zum anschließenden Unterlassen Freund, NStZ 2004, 326, 327 f.

587 Siehe zur Abgrenzung der Begehungsformen nur Murmann, Grundkurs, \ 29 Rn. 9 ff.

588 RGSt 63, 211; Beispiel auch bei Murmann, Grundkurs, \ 29 Rn. 10.

589 Dies verkennt Tag, JR 1995, 133, 136.

590 Für eine ,vorsätzliche Ingerenz“ Freund, NStZ 2004, 326, 328; anderweitige Garantenstellungen sollen hier außer Betracht bleiben.

591 Vgl. S. 139 f. bzw. nur Stein, JR 1999, 265, 266 f.
} 
aktiver Handlung und Erfolgseintritt eine Rettungsmöglichkeit verbleibt. ${ }^{592}$ „Der durch aktives Tun verwirklichte Handlungsunwert ist gleich, im zweiten Fall kommt ein Unterlassungsunwert durch Verletzung der Garantenpflicht hinzu. Leugnet man hingegen die Existenz einer Garantenpflicht, dann steht damit zwangsläufig fest, daß das Liegenlassen des Opfers nach rechtlicher Wertung allenfalls noch das wesentlich geringere Gewicht hat, das die Verletzung einer allgemeinen Hilfeleistungspflicht (\$323c) ausmacht, und (allenfalls) mit diesem Unwertquantum ist es bei der Strafzumessung anzusetzen. “593 Zusätzlich wirke sich die Ablehnung einer Garantenstellung auch auf die eigentliche Strafbarkeit aus. Treten erst nach der aktiven Handlung im Rahmen des anschließenden Unterlassens Mordmerkmale hinzu, so müssten diese tatbestandlich gänzlich unberücksichtigt bleiben, wenn es an einer Garantenstellung fehlt. ${ }^{594}$ Es käme dem Täter folglich zugute, dass die Bedrohungslage vorsätzlich aktiv herbeigeführt wurde, da in diesem Fall allein wegen Totschlags zu bestrafen wäre, wohingegen in der Fahrlässigkeitsabwandlung eine fahrlässige Tötung und ein Mord durch Unterlassen vorlägen. Aber auch für den Teilnehmer ergebe sich eine positive Wirkung. Stiftet dieser den Täter nach Ausführung der aktiven Handlung an, dem Opfer nicht zu helfen, so habe sich der Teilnehmer mangels Garantenqualitäts des Haupttäters allein wegen Anstiftung zu einer unterlassenen Hilfeleistung strafbar gemacht. ${ }^{595}$ Hierbei fällt wiederum auf, dass die Strafbarkeit sich dann anders darstellen würde, wenn die Unterlassungssituation fahrlässig herbeigeführt wurde. Dann nämlich käme durch das Nichteinschreiten und nunmehr gegebener Garantenstellung ein Totschlag durch Unterlassen und mithin eine Anstiftung zu diesem in Betracht. Abschließend erscheint es Stein auch im Hinblick auf das zu schützende Rechtsgut geboten, die Garantenstellung zu bejahen. Übertritt der Täter die Grenze hin zu einem strafbewehrten Verhalten, so könne an diesem Punkt der Rechtsgüterschutz nicht enden. „Mangels Befolgungsbereitschaft des Täters hat das Handlungsverbot seinen Zweck, eine Gefährdung des Rechtsgutsobjekts zu verhindern, verfehlt; derselbe Zweck ist aber immerhin noch dadurch erreichbar, daß der Täter nunmehr zusätzlich eine Handlung vornimmt, die geeignet erscheint, die Gefahr wieder zu beseitigen. Wegen eben dieser Eignung ist es auch prinzipiell legitim, dem Täter die Vornahme dieser weiteren Handlung zu gebieten. $[\ldots]$ Dies ist $[\ldots]$ durchaus nicht, widersinnig', sondern die Eignung der gebotenen Handlung, die Folgen der vorangegangenen ungeschehen zu machen, begründet im Gegenteil die Legitimation des Handlungsgebots. “596 Diese Feststellung allein determiniere jedoch noch nicht die Garantenpflicht. Dafür spreche aber die Übertretung der Verbotsnorm, wobei die hieraus resultierenden Gefahren eine Belas-

\footnotetext{
592 Stein, JR 1999, 265, 268.

593 Stein, JR 1999, 265, 268.

594 Stein, JR 1999, 265, 268.

595 Stein, JR 1999, 265, 268.

596 Stein, JR 1999, 265, 270; siehe hierzu auch SK-StGB/Stein/Rudolphi, S 323c Rn. 22.
} 
tung für den Rechtsgutsinhaber darstellen, „die er nach Wertungen, die den Handlungsverboten zugrunde liegen, nicht tragen soll; darin liegt der Unterschied zu den Gefahren, die durch ,Naturkausalität' oder aus rechtmäßigem Verhalten anderer drohen. Von daher ist es konsequent, wenn die Rechtsordnung solchen Gefahren nicht nur durch ,allgemeine' Hilfeleistungspflichten, sondern durch intensivere

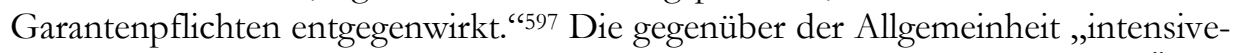
re Pflichtbindung“ resultiere aus dem Umstand, dass der Täter durch das Überschreiten der Rechtsordnung einen rechtswidrigen Vorteil erlange. „[D]ie stärkere Belastung mit einer Garantenpflicht läßt sich mit dem Gedanken der ausgleichenden Gerechtigkeit legitimieren." ${ }^{598}$

\section{(3.) Unzumutbarkeit der Hilfeleistung}

Neben dem sich anschließenden unechten Unterlassungsdelikt ist in demselben Rahmen auch die unterlassene Hilfeleistung tatbestandlich. ${ }^{599}$ Auch hier stellt sich die Frage, ob ein Einschreiten trotz des vorsätzlichen Vorverhaltens zumutbar ist. Die diesbezügliche Argumentation könnte für das unechte Unterlassen fruchtbar gemacht werden. ${ }^{600}$

Wird der Unglücksfall i.S. des \323c StGB vorsätzlich herbeigeführt, so „dürfte es hier regelmäßig schon an der Tatbestandsmäßigkeit fehlen, weil in solchen Fällen die Erfüllung der Hilfeleistungspflicht schlechthin nicht erwartet werden kann und deshalb unzumutbar ist." "601 Auch werde der Zweck des \323c StGB bereits mit der Verbotsnorm erreicht. ${ }^{602}$ „Das aber bedeutet, daß das strafrechtliche Gebot des $\int 323$ c - jedenfalls im Hinblick auf den den Unglücksfall vorsätzlich herbeiführenden Täter - nichts über das Verbot des Begehungsdelikts Hin-

597 Stein, JR 1999, 265, 271.

598 Stein, JR 1999, 265, 271.

599 Im zweiten Beispiel (S. 153) hat der Vater durch das Hineinstoßen des Sohnes jeweils einen Unglücksfall begründet. Selbst wenn der Vater den Jungen im zweiten Akt rettet, kann dies dem dort verwirklichten $₫ 323 \mathrm{c}$ StGB wohl nicht mehr abhelfen. Die sich aus $₫ 323 \mathrm{c}$ StGB ergebene Pflicht verlangt sofortiges Handeln, sodass die Tatbestandsvoraussetzungen des $₫ 323 \mathrm{c}$ StGB aufgrund des Zögerns bereits vorliegen. Aber selbst wenn diesbezüglich §323c StGB abgelehnt wird, so verbleibt die Strafbarkeit wegen unterlassener Hilfeleistung in Bezug auf den ersten Akt; siehe zur anschließenden unterlassenen Hilfeleistung z.B. BGH, NJW 1993, 1871, 1872 m.w.N.: „Wäre die Beteiligung an der Begehungstat festgestellt worden, so hätten die Angekl. zwar zugleich den Tatbestand der unterlassenen Hilfeleistung erfüllt, doch wären sie aus dem Gesichtspunkt der Gesetzeskonkurrenz nur wegen der Begehungstat zu verurteilen gewesen, weil $₫ 323 c$ StGB als subsidiäres Delikt verdrängt worden wäre.“; Fischer, StGB, $₫ 323$ c Rn. 23; MK-StGB/Freund, \323c Rn. 127; Schönke/Schröder/Sternberg-Lieben/Hecker, \323c Rn. 30; vgl. auch Stein, JR 1999, 265, 270.

600 Vgl. Stein, JR 1999, 265, 269 f.

601 Lackner/Kübl, StGB, \323c Rn. 8; siehe auch Oebler, JuS 1961, 154 f.: „Würde der Täter wegen versuchter oder vollendeter vorsätzlicher Tötung verurteilt werden, könnte er nicht außerdem noch wegen unterlassener Hilfeleistung (\$ 330c StGB) bestraft werden. Der Vorsatz der Tötung schließt bereits die Zumutbarkeit als Tatbestandsmerkmal der unterlassenen Hilfeleistung aus." 
ausgehendes zu bewirken vermag. Der Straftäter ist damit in dieser Konstellation nicht Adressat von \323 c StGB.“603 Ebenso bestehen Bedenken in Bezug auf den nemo-tenetur-Grundsatz. „Die Rechtsordnung kann von demjenigen, der sich strafbar gemacht hat oder in den unauslöschlichen Verdacht der Tatbeteiligung geraten ist, keine Handlungen verlangen bzw. erwarten, die ihn u. U. als an der Vortat Beteiligten qualifizieren." 604

In Bezug auf die ersten beiden Einwände lässt sich mit Stein sagen, dass der Rechtsgüterschutz dann nicht endet, wenn der Täter sich deliktisch verhält. Zwar hat die Verbotsnorm versagt, ihr Zweck lässt sich aber noch erreichen, indem der Täter einschreitet und die Rechtsgutsgefährdung beendet. Dies legitimiert die Handlungspflicht. ${ }^{605}$ Stein und Rudolphi weisen zudem darauf hin, dass ,[...] es keine sinnlose Zumutung, sondern eine Selbstverständlichkeit [ist], von jemandem die Beseitigung der Gefahr zu verlangen, die er selbst vorsätzlich herbeigeführt hat; eine solche Pflicht ist auch nicht im Hinblick auf das Verbot der Gefahrherbeiführung überflüssig, denn es geht gerade um diejenigen Situationen, in denen die Gefahr verbotswidrig herbeigeführt worden ist, jenes Verbot also offensichtlich nicht hinreichend war."606

Des Weiteren erscheint zweifelhaft, ob tatsächlich eine Kollision mit dem nemo-tenetur-Grundsatz vorliegt, die die Zumutbarkeit entfallen lassen könnte. Augenfällig ist hierbei, dass sich diese Problematik nicht allein im Rahmen eines vorsätzlichen Vorverhaltens stellt, sondern stets präsent ist. So besteht die Gefahr der Preisgabe der eigenen Täterschaft auch dann, wenn der Täter zuvor allein fahrlässig gehandelt hat. ${ }^{607}$ Unabhängig hiervon könnte ein Verstoß gegen den nemo-tenetur-Grundsatz jedoch ausscheiden, da die ,[...] Handlungspflicht ausschließlich auf ihre Eignung gegründet werden soll, andere Interessen (beispielsweise Leben oder Gesundheit Dritter) zu wahren“ und somit „,[...] von einer menschenwürdewidrigen ,Instrumentalisierung ${ }^{\star}$ nicht mehr die Rede sein [kann].“608 Die Überzeugungskraft dieses Einwands hänge allerdings davon ab, welche Reichweite man dem nemo-tenetur-Grundsatz zubilligt ${ }^{609}$, weswegen dieses Argument diesem Streitentscheid unterworfen ist und somit nur bedingt trägt. Viel überzeugender und allgemeingültig ist hingegen die Feststellung Steins, dass der nemo-teneturGrundsatz nicht pauschal verletzt ist, wenn dem Täter eine zeitlich nachgeordnete Handlungspflicht auferlegt wird. Die Grenze des nemo-tenetur-Grundsatzes kann nur dort greifen, wo eine Selbstbelastung droht, sodass dem Täter zumindest Ret-

\footnotetext{
603 Tag, JR 1995, 133, 136.

604 Tag, JR 1995, 133, 136.

605 Stein, JR 1999, 265, 270.

606 SK-StGB/Stein/Rudolphi, S 323c Rn. 22.

607 Stein, JR 1999, 265, 272.

608 Stein, JR 1999, 265, 272 f.

609 Siehe Stein, JR 1999, 265, 272 f.
} 
tungshandlungen abverlangt werden können, bei denen er sich dem Risiko einer Entdeckung nicht aussetzt. ${ }^{610}$

Somit wird es dem Täter auch unter Berücksichtigung des nemo-teneturGrundsatzes in den allermeisten Fällen möglich sein, adäquate Hilfe zu leisten, sodass eine Pflichtenauferlegung grundsätzlich zumutbar ist.

\section{bb. Zwischenergebnis}

Immer dann, wenn der Erfolg nicht sofort durch das aktive Tun eintritt, verbleibt Raum für ein Unterlassen. Die Frage nach dem Schwerpunkt des strafrechtlichen Verhaltens kann hierbei nicht zu einer Unbeachtlichkeit des Nichteinschreitens führen, da das Unterlassen einen eigenständigen temporal nachgeordneten Anknüpfungspunkt bildet.

In Bezug auf das Bestehen einer Garantenstellung zeigt der Vergleich mit einem fahrlässigen Vorverhalten und die aus einer Negation der Unterlassungsexistenz resultierenden unberechtigten Privilegierungen, dass auch ein vorsätzliches Vorverhalten eine Garantenstellung begründen muss, was zudem durch den gebotenen Rechtsgüterschutz und die durch das Übertreten der rechtlichen Grenzen gesteigerte Verpflichtung des Täters gestützt wird.

Einwände in Bezug auf die Unzumutbarkeit eines entgegengesetzten Verhaltens tragen hingegen nicht, da dem Täter zumindest Maßnahmen abverlangt werden können, bei denen er nicht als Täter in Erscheinung tritt.

\section{b. Konsequenzen für die Gesamtbetracbtungslehre}

aa. Das verkannte Unterlassen

Es hat sich gezeigt, dass in einem mehraktigen Geschehen neben den Primärhandlungen weitere Verhaltenselemente existieren. So hat der Vater aus dem zweiten Beispiel ${ }^{611}$ neben den zwei aktiven Handlungen auch zwei Unterlassungen verwirklicht, sodass $i h m$ konkret $a_{1}+u_{1}+a_{2}+u_{2}$ vorzuwerfen ist. ${ }^{612}$ Differenziert man im Rahmen des Rücktritts zwischen diesen Verhaltensweisen, so bezieht sich die Wirkung des $\ 24$ Abs. 1 StGB mit der Gesamtbetrachtungslehre unproblematisch auf $\mathrm{a}_{1}$ und $\mathrm{a}_{2}$. Da der Täter sich im Rahmen des zweiten Akts zudem in einem nicht fehlgeschlagenen Unterlassungsversuch befindet, kann er durch das entgegengesetzte Handeln auch hiervon zurücktreten. Nicht erfasst ist jedoch der erste Unterlassungsversuch. Mangels Tatidentität der beiden Unterlassungen han-

610 Stein, JR 1999, 265, 272.

611 S. $153 \mathrm{f}$.

612 Die Unterlassungsstrafbarkeit setzt voraus, dass es sich individuell auf die jeweilige aktive Handlung bezogen um einen beendeten Versuch handelt und es mangels sofort eintretenden Erfolgs zwischenzeitlich möglich ist, die Gefahr abzuwenden. Der Vorsatz des Täters wird durch dessen Vorstellung, alles Erforderliche getan zu haben, impliziert. 
delt es sich hierbei um einen eigenständigen fehlgeschlagenen Unterlassungsversuch, der nicht rücktrittsfähig ist. ${ }^{613}$

Entgegen der Gesamtbetrachtungslehre führt die Erfolgsverhinderung nach einer weiteren Ausführungshandlung nicht zu einer vollständigen Straflosigkeit, sondern es verbleibt ein strafrechtlich relevantes Unterlassen.

\section{bb. Weitere Konsequenzen}

Aus der verkannten Unterlassungsstrafbarkeit könnten sich abseits ihrer bloßen Existenz noch weitere Konsequenzen für die Gesamtbetrachtungslehre ergeben.

Freund erkennt, dass der Streit um die Reichweite der Tat nicht nur im Rahmen des unbeendeten Versuchs Relevanz besitzt, sondern ,[...] auch Konstellationen des beendeten Versuchs und damit auch Fälle des versuchten Unterlassungsdelikts die Frage nach der rücktrittsfähigen Versuchstat auf[werfen]. Dabei dürfte gar nicht selten eine Überschneidung dahingehend zu verzeichnen sein, dass sich der Versuchstäter des beendeten Begehungsversuchs zugleich in der Situation des kraft Ingerenz für die Gefahrenabwendung Sonderverantwortlichen und damit in der Situation des Unterlassungsversuchs befindet: Wer sein Opfer mit Tötungsvorsatz lebensgefährlich verletzt hat, muss im Rahmen des ihm Möglichen und Zumutbaren die von ihm geschaffene Lebensgefahr kraft einer qualifizierten (Garanten-)Rechtspflicht abwenden - also im Grunde genau das tun, was den Erfordernissen der Rücktrittsvorschrift entspricht. "614

Konkretisiert bedeutet dies, dass sich das Rücktrittsverhalten und das gebotene entgegengesetzte Verhalten im Rahmen des Unterlassens entsprechen. Stößt der Vater seinen Sohn ins Wasser, so erlangt er Straffreiheit, wenn er den Jungen rettet, wobei hierdurch zugleich der objektive Tatbestand des Unterlassungsdelikts entfallen würde. Dies besagt für sich genommen jedoch nichts über das Verhältnis zur sich ebenfalls anschließenden versuchten Unterlassungsstrafbarkeit. Diesbezüglich ist zu erkennen, dass ein entgegengesetztes Handeln im Rahmen des aktiven Versuchs auf die Tatbestandsvoraussetzungen des versuchten Unterlassens keine Auswirkungen hat. Fasst der Täter einmal den Unterlassungstatentschluss, so kann er beim Vorliegen der übrigen Voraussetzungen nur durch einen Rücktritt straffrei werden. Hierbei ist allerdings festzustellen, dass die Anforderungen an den Rücktritt bei beiden Begehungsformen identisch sind. Sowohl der beendete aktive Versuch, bei dem allein es zu einer sich anschließenden Unterlassungsstrafbarkeit kommen kann, als auch das versuchte Unterlassen erfordern ein entgegengesetztes Handeln. Diese Identität führt dazu, dass eine Ergebnisgleichschaltung vorliegt. Wird bspw. eine Strafbarkeit wegen des sich anschließenden versuchten Unterlassens bejaht, so muss zugleich der Rücktritt vom aktiven Versuch ausgeschlossen sein.

613 Siehe hierzu S. $147 \mathrm{ff}$.

614 Freund, NStZ 2004, 326, 327 und 328 (meine Unterstreichung). 
Wird diese Erkenntnis nunmehr mit der verkannten Unterlassungsstrafbarkeit in einem mehraktigen Geschehen zusammengeführt, so ergeben sich weitere Konsequenzen für die Gesamtbetrachtungslehre. Bleibt bei einem mehraktigen Versuch das erste versuchte Unterlassen $\left(\mathrm{u}_{1}\right)$ trotz eines Rücktritts im Rahmen des zweiten Handlungskomplexes bestehen, so zeigt diese Strafbarkeit, dass der Täter durch sein Verhalten dem Rücktrittserfordernis im Rahmen dieses versuchten Unterlassens nicht nachgekommen ist. Aufgrund der festgestellten Rücktrittsidentität bedeutet dies zugleich, dass auch den Rücktrittsanforderungen in Bezug auf die erste versuchte aktive Handlung nicht entsprochen wurde, sodass ein Rücktritt auch diesbezüglich ausscheiden muss.

Folglich kann der Täter durch das spätere entgegengesetzte Handeln im Rahmen des zweiten Akts allein dahingehend straffrei werden. Der Unrechtsmoment, der durch den ersten Akt realisiert wurde, bleibt trotz des weiteren Verlaufs bestehen.

Aber nicht nur bei einem Rücktritt nach bestehender Mehraktigkeit, sondern auch bei einem einaktigen Versuch ergibt sich die benannte Problematik. Stößt der Vater seinen Sohn ins Wasser, damit dieser ertrinkt und rettet sich der Junge sodann selbst, so könnte der Vater mit der Gesamtbetrachtungslehre Straffreiheit erlangen, indem er eine Fortsetzungsmöglichkeit erkennt, diese aber nicht ausführt. Hierdurch bliebe allerdings ebenso unberücksichtigt, dass nach dem aktiven Tun ein Unterlassungsmoment hinzutritt. Führt das aktive Tun nicht sofort zum Erfolg und geht der Täter davon aus, alles Erforderliche getan zu haben, so entsteht gleichsam eine Tatphase, in der das Nichteinschreiten eine eigenständige rechtliche Relevanz besitzt. Abstrahiert bedeutet dies, dass dem Täter a + u vorzuwerfen ist. Auf den aktiven Teil bezogen könnte mit der Gesamtbetrachtungslehre anscheinend ein Fehlschlag abgewendet werden. In Bezug auf das Unterlassen steht jedoch fest, dass der Unterlassungsversuch mangels einer konkret möglichen Mehraktigkeit endgültig gescheitert ist. ${ }^{615}$ Dies bedeutet, dass sich der Täter der Strafbarkeit aufgrund des verbleibenden deliktischen Unterlassens durch bloBes Ablassen von weiteren aktiven Handlungen nicht insgesamt entziehen kann. Im Weiteren zeigt die Strafbarkeit des versuchten Unterlassens, aufgrund der Deckungsgleichheit der erforderlichen Rücktrittsverhalten von Unterlassungsversuch und aktivem Versuch, dass der Täter durch sein Verhalten dem Rücktritterfordernis im Rahmen des aktiven Versuchs nicht entsprochen hat, da anderenfalls auch die Unterlassungsstrafbarkeit entfallen wäre. Folglich ist der Täter entgegen der Gesamtbetrachtungslehre auch nicht vom aktiven Versuch zurückgetreten.

615 S.h. S. 148 ff.; zudem könnte $\int 323$ c StGB bereits vollendet sein. 
dd. Modifikation der Gesamtbetrachtungslehre

Die Gesamtbetrachtungslehre kann nicht über die in einem Geschehensablauf existierenden Unterlassungsstrafbarkeiten hinweghelfen. Aus ihnen folgt, dass ein Rücktritt im Rahmen eines weiteren Ausführungsakts keine Auswirkungen auf das vorangegangene Geschehen besitzt und zudem, dass der Täter durch das bloße Erkennen und Nichtausführen einer weiteren Handlungsmöglichkeit nicht zurücktreten kann.

Das Unterlassen liegt jedoch allein dann vor, wenn nach dem aktiven Tun eine Zeitspanne verbleibt, in der der Täter davon ausgeht, alles Erforderliche getan zu haben, um den tatbestandlichen Erfolg herbeizuführen.

Für die Grenzen der Gesamtbetrachtungslehre bedeutet dies nunmehr, dass eine einheitliche Tat dann nicht mehr fortbestehen kann, wenn der Täter sich nach der aktiven Handlung in einem beendeten Versuch befindet. In diesem Zeitpunkt besitzt der Täter Tatentschluss in Bezug auf das Unterlassen und die Tat findet in diesem Geschehen ihren Abschluss. Der Versuch ist folglich immer dann endgültig fehlgeschlagen, wenn die auf dem aktiven Handeln beruhende Unterlassungssituation den Erfolg nicht herbeiführen konnte. Durch diese Strafbarkeit wird berücksichtigt, dass der Täter dem von ihm abverlangten konkreten Rücktrittgebot nicht nachgekommen ist.

Invers formuliert folgt aus diesem Verständnis zugleich, dass die einheitliche Tat solange gewahrt ist, wie der Täter durch seine aktiven Handlungen eine Unterlassungssituation noch nicht begründet hat. Verfehlt der Täter das Opfer mit dem abgegebenen Schuss, so wäre ein Rücktritt mangels bestehender Unterlassungsmöglichkeit durch das einfache Ablassen von weiteren Schüssen möglich.

Faktisch würde dies zu einer Privilegierung des Täters führen, der auf das Rechtsgut zwar konkret gefährdend eingewirkt hat, sich diese Gefährdung zwischenzeitlich aber nicht im Sinne eines beendeten Versuchs realisiert. Insoweit ist jedoch zu erkennen, dass die Handlungsfolgen in diesem Fall ein viel geringeres Ausmaß besitzen, als wenn der Täter davon ausgeht, alles Erforderliche zur Erfolgsherbeiführung getan zu haben. Besteht in der einen Ausgestaltung über die konkrete Handlung hinaus ein Risiko, so hat sich der Zustand des Opfers in der anderen Konstellation nicht verändert, wobei die konkrete Handlungsgefahr mit dem partiellen Scheitern endet. Hierdurch ist es geboten, dem Täter unterschiedliche Rücktrittsmöglichkeiten einzuräumen. Die Gesamtbetrachtungslehre in ihrem originären Sinne determiniert folglich ein zu extensives Tatverständnis. Dieselbe Tat i.S. des $₫ 24$ Abs. 1 StGB muss spätestens dann enden, wenn durch die aktiven Ausführungshandlungen des Täters eine konkrete Rechtsgutsgefährdung im Sinne eines beendeten Versuchs begründet wurde. 
ee. Folgen für die begehungsformübergreifende Mehraktigkeit

Wird die reichweitenbegrenzte Gesamtbetrachtungslehre auf den Begehungsformwechsel angewendet, so kann sich die Problematik in dieser Form nicht mehr stellen. Der Unterlassungstäter befindet sich in derselben Lage wie der Täter, der die Unterlassungssituation aktiv herbeigeführt hat und von der Erfolgstauglichkeit seiner Handlung ausgeht. Beide Täter stellen sich vor, dass durch bloßes Zuwarten der tatbestandliche Erfolg eintreten wird, womit ein beendeter Versuch vorliegt. Aufgrund dieser Identität gilt für die begehungsformübergreifende Mehraktigkeit Entsprechendes. Immer dann, wenn das Unterlassen nicht mehr erfolgstauglich ist, scheitert der Unterlassungsversuch endgültig, unabhängig davon, ob dem Täter noch weitere Realisierungsmöglichkeiten zur Seite stehen.

\section{Gesamtergebnis}

Obschon die Gesamtbetrachtungslehre das wohl etablierteste Tatverständnis im Rahmen des $\ 24$ Abs. 1 StGB ist, wird die Wissenschaft von dem Dogma geprägt, dass der Täter stets entgegengesetzt handeln muss, um bzgl. eines versuchten Unterlassens Straffreiheit zu erlangen. Isoliert im Rahmen des Nichteinschreitens ist dies stringent, da das Verhalten, das die Strafbarkeit des Täters begründet, nicht zugleich zu dessen Straflosigkeit führen kann. Unberücksichtigt bleibt in diesem Zusammenhang jedoch die durch eine Gesamtbetrachtung ermöglichte Mehraktigkeit des Geschehens. Kann der Täter im Rahmen der aktiven Begehung von einem Versuch zurücktreten, indem er von einer weiteren Handlung ablässt, so muss diese Möglichkeit im Fall eines Rücktritts vom versuchten Unterlassen gleichsam angedacht werden. Hier zeigt sich, dass das Ablassen von einer weiteren aktiven Handlung für den Unterlassungsversuch allein dann Relevanz besitzen könnte, wenn einem weiten Tatverständnis im Sinne der Gesamtbetrachtungslehre gefolgt wird.

Wird die Gesamtbetrachtungslehre sodann als Bewertungsmaßstab für den Tatbegriff im Sinne des $\int 24$ Abs. 1 StGB zugrunde gelegt, so folgt hierdurch jedoch nicht zwangsläufig die Möglichkeit eines Rücktritts von einem Unterlassungsversuch durch weiteres Unterlassen. Es bleibt weiterhin fraglich, ob aus dem Begehungsformwechsel eine Zäsur resultiert, die die Einheitlichkeit des Geschehens aufspaltet.

Diesbezüglich war zu erkennen, dass eine Tatmitteländerung die Tat nicht trennt und somit Rückschlüsse auf den Begehungsformwechsel nicht möglich sind. Gleiches musste auch in Bezug auf einen Unrechtswechsel festgestellt werden, da die Änderung des Unwerts das Fortbestehen derselben Tat nicht beeinträchtigt. Allein wenn die Unrechtsabweichung so groß ist, dass ein anderer Tatbestand verwirklicht ist, erscheint eine Zäsur möglich. 
An dieses Ergebnis schloss sich die Frage an, ob trotz eines Tatbestandswechsels dieselbe Tat im Sinne des $\int 24$ Abs. 1 StGB fortbestehen kann, wobei dies für den Begehungsformwechsel dann Relevanz besitzt, wenn das Unterlassen gegenüber der aktiven Begehung ein eigenständiges Delikt darstellt. Tatsächlich ist es zutreffend, dass die Rücktrittseinheit spätestens dann endet, wenn der Täter im Fall einer fortgesetzten aktiven Begehung zur Verwirklichung eines anderen Tatbestands ansetzt. In Kombination mit der Feststellung, dass eine entsprechende deliktische Eigenständigkeit besteht, ergibt sich, dass dieselbe Tat im Sinne des $\int 24$ Abs. 1 StGB dann enden muss, wenn der Täter von einem Unterlassen zu einem Tun wechselt.

Gleichsam deutet auch der Umstand, dass eine begehungsformübergreifende iterative bzw. sukzessive Tatbestandsrealisierung regelmäßig keine Beachtung findet, darauf hin, dass ein Unterlassen einer aktiven Begehung nicht entspricht.

Hingegen konnte der Hinweis auf eine mangelnde Distanzierung von der Unterlassung für die Bewertung der Rücktrittsreichweite nicht herangezogen werden. Gleiches gilt für den Opferschutzaspekt, da aus dieser Überlegung kein absoluter Rückschluss möglich ist.

Im Folgenden musste festgestellt werden, dass $\int 13$ StGB kein Schlechterstellungsverbot umfasst, sodass hierdurch eine begehungsformübergreifende Mehraktigkeit nicht begründet werden kann. Bei dieser Prüfung ergab sich allerdings ein weiterer Anknüpfungspunkt, der in Kombination mit einer zuvor gewonnenen Erkenntnis die Gesamtbetrachtungslehre an sich und somit auch die Möglichkeit einer begehungsformübergreifenden Mehraktigkeit betrifft. So zeigte sich, dass bei einem mehraktigen Geschehen auf das aktive Tun ein Unterlassen folgt, wenn handlungsspezifisch ein beendeter aktiver Versuch vorliegt. Tritt der Täter sodann im Rahmen eines weiteren Akts zurück, so verbleibt zumindest die Strafbarkeit hinsichtlich des ersten versuchten Unterlassens. Aufgrund des Umstands, dass die begehungsformspezifischen Rücktrittsverhalten deckungsgleich sind, zeigt die Existenz des Unterlassens zugleich, dass auch den Anforderungen in Bezug auf den Rücktritt von der ersten aktiven Handlung nicht entsprochen wurde. Gleiches gilt für den Fall, in dem der Täter durch das Nichtausführen einer weiteren Handlungsmöglichkeit von dem zunächst für tauglich gehaltenen aktiven Versuch straffrei werden soll. Auch hier verdeutlicht die bestehende Strafbarkeit des versuchten Unterlassens, dass das Verhalten des Täters keinen Rücktritt von der aktiven Handlung darstellt.

Für die Gesamtbetrachtungslehre insgesamt bedeutet dies, dass eine Mehraktigkeit dann ausscheiden muss, wenn der Täter sich nach der aktiven Handlung in einem beendeten Versuch befindet. Wird diese reichweitenbegrenzte Gesamtbetrachtungslehre zugrunde gelegt, so scheidet die begehungsformübergreifende Mehraktigkeit schon von vornherein aus.

Zusammenfassend lässt sich erkennen, dass auch im Rahmen der Gesamtbetrachtungslehre beide Begehungsformen nicht Teil derselben Tat i.S. des $\int 24$ 
Abs. 1 StGB sein können. Für die Frage, ob der Vater strafbefreiend zurücktreten kann, wenn er nach einem gescheiterten Unterlassungsversuch davon absieht, das Kind aktiv zu töten, bedeutet dies somit, dass die weitere mögliche aktive Handlung nicht Teil derselben Tat ist. Der Versuch schlägt mit dem Scheitern des Unterlassens fehl und ein Rücktritt scheidet aus.

Das Dogma, dass der Täter im Rahmen des versuchten Unterlassens für den Rücktritt stets entgegengesetzt handeln muss, trifft folglich zu. 


\section{Literaturverzeichnis}

Ahmed, Adam

Rücktritt vom versuchten unechten Unterlassungsdelikt, Diss. Jur. Regensburg 2006, Hamburg 2007.

Androulakis, Nikolaos K. Studien zur Problematik der unechten Unterlassungsdelikte, Diss. Jur. München 1961, Berlin 1963.

Arloth, Frank/Tilch, Horst Deutsches Rechts-Lexikon, Band 1 und 2, (Hrsg.)

3. Auflage, München 2001.

Bacher, Andreas

Versuch und Rücktritt vom Versuch beim erfolgsqualifizierten Delikt - zugleich ein Beitrag zum Begriff der Tat, Diss. Jur. München 1999, München 1999.

Bärwinkel, Richard

Zur Struktur der Garantieverhältnisse bei den unechten Unterlassungsdelikten, Diss. Jur. Hamburg 1968, Berlin 1968.

Bauer, Wolfram

Der strafbefreiende Rücktritt vom unbeendeten Versuch - ein Problem der subjektiven "Geschäftsgrundlage" (Tatgrundlage), Vom fehlgeschlagenen zum sinnlosen Versuch, wistra 1992, 201-208.

Baumann, Jürgen

Strafrecht Allgemeiner Teil, 5. Auflage, Bielefeld 1968.

Zitat: Baumann, AT, 5. Aufl. 1968 
Baumann, Jürgen/Weber, Strafrecht Allgemeiner Teil, Lehrbuch, Ulrich/Mitsch, Wolfgang 11. Auflage, Bielefeld 2003.

Zitat: Baumann/Weber/Mitsch, AT

Bergmann, Matthias

Einzelakts- oder Gesamtbetrachtung beim Rücktritt vom Versuch?, ZStW 100 (1988), 329-358.

Berner, Albert Friedrich Lehrbuch des Deutschen Strafrechts, 18. Auflage, Leipzig 1898.

Böhm, Alexander

„Korreferat“", JuS 1961, 177-181.

Bottke, Wilfried

Strafrechtswissenschaftliche Methodik und Systematik bei der Lehre vom strafbefreienden und strafmildernden Täterverhalten, Ebelsbach am Main 1979.

Burkhardt, Björn

Der „Rücktritt“ als Rechtsfolgenbestimmung, in: Strafrechtliche Abhandlungen Bd. 23, Berlin 1975.

Busch, Richard

Zur gesetzlichen Begründung der Strafbarkeit unechten Unterlassens, in: Welzel, Hans/Conrad, Hermann/Kaufmann, Armin/Kaufmann, Hilde (Hrsg.), Festschrift für Hellmuth von Weber zum 70. Geburtstag, Bonn 1963, S. 192-206.

Dalcke, Albert/Fuhrmann, Strafrecht und Strafverfahren Kommentar, Ernst/Schäfer, Karl Berlin 1961.

Zitat: Dalcke/Fubrmann/Schäfer, StGB, 37. Aufl. 1961

Dölling, Dieter/Duttge, Gesamtes Strafrecht, StGB, StPO, Gunnar/Rössner, Dieter Nebengesetze, Handkommentar, 3. Auflage, (Hrsg.) Baden-Baden 2013.

Zitat: HK-GS/Bearbeiter 
Dreher, Eduard

Engisch, Karl

Engländer, Armin

Fahrenhorst, Irene

Feltes, Thomas

Fischer, Thomas

Freund, Georg
Strafgesetzbuch Kommentar, 34. Auflage, München 1974.

Zitat: Dreher, StGB, 34. Aufl. 1974

Anmerkung zu Urteil des BGH 5. StS v. 11. 6. 68 - 5 StR 192/68, JR 1969, 105-107.

Besprechung „Die Dogmatik der Unterlassungsdelikte“ v. Armin Kaufmann, JZ 1962, 189-192.

$\begin{array}{lcr}\text { Der Rücktritt } & \text { vom } & \text { versuchten } \\ \text { Unterlassungsdelikt } & \text { durch } & \text { bloßes } \\ \text { Untätigbleiben, JZ } & 2012, \text { 130-133. } & \end{array}$

Fehlschlag des Versuchs bei weiterer Handlungsmöglichkeit?, Jura 1987, 291-294.

Der (vorläufig) fehlgeschlagene Versuch, Zur Abgrenzung von fehlgeschlagenem, beendetem und unbeendetem Versuch, GA 1992, 395-426.

Strafgesetzbuch mit Nebengesetzen, 62. Auflage, München 2015.

Zitat: Fischer, StGB

Strafrecht Allgemeiner Teil, Personale Straflehre, 2. Auflage, Berlin/Heidelberg 2009.

Zitat: Freund, AT

Zum Rücktritt vom Versuch bei einem mehraktigen Unterlassungsdelikt, NStZ 2004, 326-328. 
Fuhrmann, Hans

Geilen, Gerd

Grünwald, Gerald
Der Irrtum über die Garantenpflichten bei den unechten Unterlassungsdelikten, GA 1962, 161-176.

Zur Abgrenzung zwischen beendetem und unbeendetem Versuch, JZ 1972, 335-343.

Zum Rücktritt des Tatbeteiligten im künftigen Recht, in: Stratenwerth, Günther/Kaufmann, Armin/Schreiber, Hans-Ludwig/Jakobs，Günther/Loos，Fritz (Hrsg.), Festschrift für Hans Welzel zum 70. Geburtstag, Berlin/New York 1974, S. 702718.

Zur gesetzlichen Regelung der unechten Unterlassungsdelikte, ZStW 70 (1958), 412432.

Das unechte Unterlassungsdelikt, Diss. Jur. Göttingen 1956.

Güntge, Georg-Friedrich Untreueverhalten durch Unterlassen, wistra 1996, 84-89.

Günther, Hans-Ludwig Partieller Rücktritt vom Versuch und Deliktswechsel, in: Dornseifer, Gerhard/Horn, Eckhard/Schilling, Georg/Schöne, Wolfgang/Struensee, Eberhard/Zielinski, Diethart (Hrsg.), Gedächtnisschrift für Armin Kaufmann, Köln Berlin Bonn München 1989, S. 541554.

Haft, Fritjof

Der Rücktritt des Beteiligten bei Vollendung der Straftat, JA 1979, 306-313. 
Heckler, Andreas

Heinrich, Bernd

Herzberg, Rolf Dietrich

Hillenkamp, Thomas

Jäger, Christian
Die Ermittlung der beim Rücktritt vom Versuch erforderlichen Rücktrittsleistung anhand der objektiven Vollendungsgefahr, 1. Auflage, Baden-Baden 2002.

Zitat: Heckler, Rücktrittsleistung

Strafrecht, Allgemeiner Teil, 4. Auflage, Stuttgart 2014.

Zitat: Heinrich, AT

Der Rücktritt mit Deliktsvorbehalt, in: Hirsch, Hans Joachim/Kaiser, Günther/Marquardt, Helmut (Hrsg.), Gedächtnisschrift für Hilde Kaufmann, Berlin New York 1986, S. 709-735.

Der Rücktritt durch Aufgeben der weiteren Tatausführung, in: Schwind, HansDieter/Berz, Ulrich (Hrsg.), Festschrift für Günter Blau zum 70. Geburtstag, Berlin 1985, S. 97-121.

32 Probleme aus dem Strafrecht, Allgemeiner Teil, 14. Auflage, München 2012.

Zitat: Hillenkamp, Probleme aus dem Strafrecht

Der Rücktritt vom erfolgsqualifizierten Versuch Entwurf einer Struktursynthese aus Rücktritt als Gefährdungsumkehr und Erfolgsqualifikation als Gefährdungserfolg, NStZ 1998, 161-164. 
Jakobs, Günther

Jescheck, Hans-Heinrich
Strafrecht, Allgemeiner Teil, Die Grundlagen und die Zurechnungslehre, Lehrbuch, 2. Auflage, Berlin/New York 1991.

Zitat: Jakobs, AT

Die Bedeutung des Versuchsstadiums für die Voraussetzung eines strafbefreienden Rücktritts - BGH, NJW 1980, 195, JuS 1980, 714-718.

Lehrbuch des Strafrechts, Allgemeiner Teil, 2. Auflage, Berlin 1972.

Zitat: Jescheck, AT, 2. Aufl. 1972

Lehrbuch des Strafrechts, Allgemeiner Teil, Berlin 1969.

Zitat: Jescheck, AT, 1969

Jescheck, Hans-

Lehrbuch des Strafrechts, Allgemeiner Teil, Heinrich/Weigend, Thomas 5. Auflage, Berlin 1996.

Zitat: Jescheck/Weigend, AT

Joecks, Wolfgang

Strafgesetzbuch, 11. Auflage, München 2014.

Zitat: Joecks, StGB

Kaufmann, Armin

Die Dogmatik der Unterlassungsdelikte, 2. Auflage, Göttingen 1988.

Zitat: Armin Kaufmann, Dogmatik

Methodische Probleme der Gleichstellung des Unterlassens mit der Begehung, JuS 1961, 173-177.

Kindhäuser, Urs
Strafrecht, Allgemeiner Teil, 7. Auflage, Baden-Baden 2015.

Zitat: Kindhäuser, AT 
Kindhäuser, Urs/Neumann Nomos-Kommentar zum Strafgesetzbuch, Ulfrid/ Paeffgen, Hans- $\quad$ Band 1, 4. Auflage, Baden-Baden 2013.

Ullrich (Hrsg.) Zitat: NK-StGB/Bearbeiter

Kohlrausch, Eduard/Lange, Strafgesetzbuch mit Erläuterungen und Richard

Nebengesetzen, 43. Auflage, Berlin 1961.

Zitat: Kohlrausch-Lange, StGB, 43. Aufl. 1961

Krey, Volker/Esser, Robert Deutsches Strafrecht Allgemeiner Teil, 5. Auflage, Stuttgart 2012.

Zitat: Krey/Esser, AT

Kudlich, Hans

Anmerkung $\mathrm{zu}$ Beschl. des BGH v. 29.10.2002 - 4 StR 281/02 (= BGH, NStZ 2003, 252f.), JR 2003, 379-382.

Kudlich, Hans/Hannich, Anmerkung zu BGH, Urteil vom 15.05.1997 Kai A.

- 5 StR 127/97 - LG Braunschweig, StV 1998, 369-372.

Kühl, Kristian

Strafrecht Allgemeiner Teil, 7. Auflage, München 2012.

Zitat: Kühl, AT

Grundfälle zu Vorbereitung, Versuch, Vollendung und Beendigung, JuS 1981, 193196.

Küper, Wilfried

Der Rücktritt vom Versuch des unechten Unterlassungsdelikts, ZStW 2000, 1-43.

Versuchs- und Rücktrittsprobleme bei mehreren Tatbeteiligten

Zugleich ein Beitrag zur Struktur der Mittäterschaft, JZ 1979, 779-787. 
Lackner, Karl/Kühl, Kristian

Lackner, Karl/Maassen, Hermann

Leipziger Kommentar
Strafgesetzbuch Kommentar, 28. Auflage, München 2014.

Zitat: Lackner/Kühl, StGB

Strafgesetzbuch Kommentar, 8. Auflage, München 1974.

Zitat: Lackner/Maassen, StGB, 8. Aufl. 1974

Strafgesetzbuch, Leipziger Kommentar, Bd. 1, 12. Auflage, Berlin 2007, Laufhütte, Heinrich Wilhelm/Rissing-van Saan, Ruth/Tiedemann, Klaus (Hrsg.).

Zitat: LK-StGB/Bearbeiter

Leipziger Kommentar, Strafgesetzbuch, Bd. 1, 11. Auflage, Berlin 2003, Jähnke, Burkhard/Laufhütte, Heinrich Wilhelm/ Odersky, Walter.

Zitat: LK-StGB/Bearbeiter, 11. Aufl. 2003

Leipziger Kommentar, Strafgesetzbuch, Bd. 1, 10. Auflage, Berlin/New York 1985, Jescheck, Hans-Heinrich/Ruß, Wolfgang/Willms, Günther (Hrsg.).

Zitat: LK-StGB/Bearbeiter, 10. Aufl. 1985

Leipziger Kommentar, Strafgesetzbuch, 8. Auflage, Bd. 1, Berlin 1957, Jagusch, Heinrich/Mezger, Edmund/Schaefer, August/Werner, Wolfhart (Hrsg.).

Zitat: LK-StGB/Bearbeiter, 8. Aufl. 1957

Leipziger Kommentar, Strafgesetzbuch, Bd. I, 7. Auflage Berlin 1954, Nagler, Johannes/Jagusch, Heinrich/Mezger, Edmund u.a. (Hrsg.).

Zitat: LK-StGB/Bearbeiter, 7. Aufl. 1954, Bd. 1 
Leipziger Kommentar, Strafgesetzbuch, Bd. 2, 6/7. Auflage, Berlin 1951, Nagler, Johannes/Mezger, Edmund/Rohde, Hans/Schinnerer, Erich u.a. (Hrsg.).

Zitat: LK-StGB/Bearbeiter, 6/7. Aufl. 1951, Bd. 2

Lenckner, Theodor

Probleme beim Rücktritt des Beteiligten, in: Lackner, Karl/Leferenz, Heinz/Schmidt, Eberhard/Welp, Jürgen/Wolff, Ernst Amadeus (Hrsg.), Festschrift für Wilhelm Gallas zum 70. Geburtstag, Berlin New York 1973, S. 281-306.

Linke, Laura

Der Rücktritt vom Versuch bei mehreren Tatbeteiligten gemäß \24 Absatz 2 StGB, Diss. Jur. Erlangen/Nürnberg 2008, Regensburg 2010.

Zitat: Linke, Rücktritt

Maurach, Reinhart

Deutsches Strafrecht, Allgemeiner Teil, 4. Auflage, Karlsruhe 1971.

Zitat: Maurach, AT, 4. Aufl. 1971

Deutsches Strafrecht, Besonderer Teil, 5. Auflage, Karlsruhe 1969.

Zitat: Maurach, BT, 5. Aufl. 1969

Deutsches Strafrecht, Allgemeiner Teil, 3. Auflage, Karlsruhe 1965.

Zitat: Maurach, AT, 3. Aufl. 1965

Maurach, Reinhart/Gössel, Strafrecht Allgemeiner Teil, Teilband 2, Karl Heinz/Zipf, Heinz Erscheinungsformen des Verbrechens und Rechtsfolgen der Tat, Ein Lehrbuch, 7. Auflage, Heidelberg 1989.

Zitat: Maurach/Gössel, AT, 7. Aufl. 1989 
Mayer, Hans-Walter

Mayer, Hellmuth

Metzen, Peter Matthias
Zur Frage des Rücktritts vom unbeendeten Versuch - BGH, MDR 1983, 328 - ein Schritt in die richtige Richtung, MDR 1984, 187-190.

Strafrecht Allgemeiner Teil, Stuttgart u.a. 1967.

Zitat: Mayer,AT, 1967

Strafrecht Allgemeiner Teil, Stuttgart u.a. 1953.

Zitat: Mayer, AT, 1953

Die Problematik und Funktion der fakultativen Strafmilderung für die Begehung durch Unterlassen ( $\$ 13$ Abs. 2 StGB 1975), Diss. Jur. Köln, 1977, S. 131.

Zitat: Metzen, Strafmilderung

Meyer-Bahlburg, Hartwig Die Garantenstellungen bei den Unterlassungsdelikten, GA 1966, 203-207.

Beitrag zur Erörterung der Unterlassungsdelikte. Um echte und unechte Unterlassungsdelikte, Diss. Jur. Hamburg 1963.

Mezger, Edmund/Blei, Hermann

Moser, Karl
Strafrecht, I. Allgemeiner Teil, Studienbuch, 14. Auflage, München 1970.

Zitat: Mezger/Blei, Strafrecht AT, 14. Aufl. 1970

Allgemeiner Teil des Strafgesetzbuchs, 2. Auflage, Augsburg 1953.

Zitat: Moser, AT, 2. Aufl. 1953 
Münchener Kommentar Joecks, Wolfgang/Miebach, Klaus (Hrsg.)

Münchener $\quad \begin{aligned} & \text { Kommentar } \\ & \text { Strafgesetzbuch, }\end{aligned}$ Band 5,
München 2014. Auflage,
Zitat: MK-StGB/Bearbeiter

Münchener Kommentar zum

Strafgesetzbuch, Band 4, 2. Auflage,

München 2012.

Zitat: MK-StGB/Bearbeiter

Münchener Kommentar zum

Strafgesetzbuch, Band 1, 2. Auflage,

München 2011.

Zitat: MK-StGB/Bearbeiter

Münchener Kommentar zum

Strafgesetzbuch, Band 1, 1. Auflage,

München 2003.

Zitat: MK-StGB/Bearbeiter, 2003

Murmann, Uwe

Grundkurs Strafrecht, 3. Auflage, München 2015.

Rücktritt vom Versuch des Unterlassungsdelikts durch Verzicht auf aktive Erfolgsherbeiführung, GA 2012, 711721.

Versuchsunrecht und Rücktritt, Heidelberg, 1999.

Nagler, Johannes

Die Problematik der Begehung durch Unterlassung, GerS 111, 1-121. 
Nickel, Egbert

Oehler, Dietrich

Otto, Harro

Die Problematik der unechten Unterlassungsdelikte im Hinblick auf den Grundsatz ,nullum crimen sine lege' (Art. 103 Abs. 2 GG), Diss. Jur. München 1971, Berlin 1972.

Zitat: Nickel, Die Problematik der unechten Unterlassungsdelikte

Konkurrenz von unechtem und echtem Unterlassungsdelikt - BGHSt 14, 282, JuS 1961, 154-156.

Grundkurs Strafrecht, Allgemeine Strafrechtslehre, 7. Auflage, Berlin 2004.

Zitat: Otto, GK

Versuch und Rücktritt bei mehreren Tatbeteiligten (2. Teil), JA 1980, 707-712.

Fehlgeschlagener Versuch und Rücktritt, GA 1967, 144-153.

Paeffgen, Hans-Ulrich Rücktrittshorizont vs. fehlgeschlagener Versuch, in: Paeffgen, Hans-Ulrich/Böse, Martin/Kindhäuser, Urs/Stübinger, Stephan/ Verrel, Torsten/Zaczyk, Rainer (Hrsg.), Festschrift für Ingeborg Puppe zum 70. Geburtstag, Berlin 2011, S. 791-818.

Petters, Walter/Preisendanz, Strafgesetzbuch Lehrkommentar, Holger 28. Auflage, Berlin 1974.

Zitat: Petters/Preisendan₹, StGB, 28. Aufl. 1974

Pfeiffer, Gerd/Maul, Strafgesetzbuch Kommentar, München 1969. Heinrich/Schulte, Benno Zitat: Pfeiffer/Maul/Schulte, StGB, 1969

Preisendanz, Holger

Strafgesetzbuch Lehrkommentar, 29. Auflage, Berlin 1975.

Zitat: Preisendan₹, StGB, 29. Aufl. 1975 
Puppe, Ingeborg

Radbruch, Gustav

Ranft, Otfried

Rengier, Rudolf
Zur Unterscheidung von unbeendetem und beendetem Versuch beim Rücktritt Zugleich eine Besprechung der Entscheidung des BGH vom 22. 8. 1985 - 4 StR 326/85 NstZ 1986, 25, NStZ 1986, 14-18.

Der Handlungsbegriff in seiner Bedeutung für das Strafrechtssytem. Zugleich ein Beitrag zur Lehre von der rechtswissenschaftlichen Systematik, Berlin 1903.

Zitat: Radbruch, Der Handlungsbegriff

Zur Abgrenzung von unbeendetem und fehlgeschlagenem Versuch bei erneuter Ausführungshandlung, Jura 1987, 527-534.

Strafrecht Allgemeiner Teil, 7. Auflage, München 2015.

Zitat: Rengier, AT

Anmerkung zu BGH Urteil v. 12.11.1987 - 4 StR 541/87 (LG Dortmund), JZ 1988, 930933.

Strafrecht, Allgemeiner Teil, Bd. II, Besondere Erscheinungsformen der Straftaten, München 2003.

Zitat: Roxin, AT II

Anmerkung Urteil des BGH v. 5. 12. 1985 - 4 StR 593/85, JR 1986, 424-427.

Der fehlgeschlagene Versuch, Zugleich ein Beitrag zum Problem der wiederholten Ausführungshandlung, JuS 1981, 1-9. 
Satzger, Helmut/

Schluckebier, Wilhelm/

Widmaier, Gunter (Hrsg.)

Sauer, Wilhelm

Sax, Walter

Schaffstein, Friedrich

Scheinfeld, Jörg

Schlüchter, Ellen

Schmidhäuser, Eberhard
Strafgesetzbuch Kommentar, 2. Auflage, Köln 2014.

Zitat: SSW-StGB/Bearbeiter

Das Unterlassungsdelikt, Seine Stellung im Gefährdungs- und im Willensstrafrecht, GerS 114, 279-321.

Grundsätze der Strafrechtspflege, S. 909 1014, in: Bettermann, Karl August/Nipperdey, Hans Carl/Scheuner, Ulrich (Hrsg.), Die Grundrechte Handbuch der Theorie und Praxis der Grundrechte, Berlin 1959.

Zitat: Bearbeiter, in: Die Grundrechte

Die unechten Unterlassungsdelikte im System des neuen Strafrechts, in: Dahm, Georg/Gallas, Wilhelm/Schaffstein Friedrich u.a. (Hrsg.), Gegenwartsfragen der Strafrechtswissenschaft, Festschrift für Graf W. Gleispach, Berlin und Leipzig 1936, S. 70 114.

Der Tatbegriff des $\int 24$, Diss. Jur. Bochum 2005, Holzkirchen/Obb. 2006.

Zitat: Scheinfeld, Tatbegriff

Normkonkretisierung am Beispiel des Rücktrittshorizonts, in: Arzt, Gunther/Fezer, Gerhard/Weber, Ulrich/Schlüchter, Ellen/ Rössner, Dieter (Hrsg.), Festschrift für Jürgen Baumann zum 70. Geburtstag, Bielefeld 1992, S. 71-87.

Strafrecht Allgemeiner Teil, Lehrbuch, 2. Auflage, Tübingen 1975.

Zitat: Schmidhäuser, AT, Lehrbuch 
Schönke, Adolf/Schröder, Strafgesetzbuch Kommentar, 29. Auflage, Horst München 2014.

Zitat: Schönke/Schröder/Bearbeiter

Strafgesetzbuch Kommentar, 28. Auflage, München 2010.

Zitat: Schönke/Schröder/Bearbeiter, 28. Aufl. 2010

Strafgesetzbuch Kommentar, 17. Auflage, München 1974.

Zitat: Schönke/Schröder, 17. Aufl. 1974

Schünemann, Bernd

Grund und Grenzen der unechten Unterlassungsdelikte, Göttingen 1971.

Sommer, Ulrich

Lücken im Strafrechtsschutz des $\ 240 \mathrm{StGB}$ ?

- Zum Verhältnis von Gewalt und Drohung bei der Nötigung, NJW 1985, 769-773.

Stein, Ulrich

Garantenpflichten aufgrund vorsätzlichpflichtwidriger Ingerenz - Zugleich Besprechung des Urteils des BGH vom 24.10.1995 - 1 StR 465/95 -, JR 1999, 265273.

Stratenwerth, Günther/ Kuhlen, Lothar

Streng, Franz
Strafrecht Allgemeiner Teil I, 6. Auflage, München 2011.

Rücktritt vom erfolgsqualifizierten Versuch? Die aufzugebende „Tat“ i. S. v. $\ 24$ Abs. 1 StGB und das Analogieverbot, in: Hettinger, Michael/Zopfs, Jan u.a. (Hrsg.), Festschrift für Wilfried Küper zum 70. Geburtstag, Heidelberg 2007, S. 629-644. 
Handlungsziel, Vollendungsneigung und „Rücktrittshorizont“ - Anmerkung zum Vorlagebeschluß des 1. Strafsenats des BGH vom 27. 10. 1992 - 1 StR 273/92, NStZ 1993, 280 - NStZ 1993, 257-262.

Anmerkung zu BGH, Urt. v. 13.2.1985 - 3 StR 481/84 (LG Mannheim), NStZ 1985, 358-361.

Tatbegriff und Teilrücktritt - Zugleich eine Besprechung zum Urteil des BGH vom 23.08.1983 - 5 StR 408/83 -, JZ 1984, 652-656.

Tag, Brigitte

Nichtanzeige geplanter Straftaten, unterlassene Hilfeleistung oder Freispruch?, JZ 1995, 133-136.

von Mangoldt, Hermann/ Klein, Friedrich/ Starck, Christian (Hrsg.)

Walter, Michael

Weinhold, Ina Elisabeth
Kommentar zum Grundgesetz, Band 3: Artikel 83 bis 146, 6. Auflage, München 2010.

Zitat: Bearbeiter, in: v. Mangoldt/ Klein/Starck, GG III, 6. Aufl. 2010

Der Rücktritt vom Versuch als Ausdruck des Bewährungsgedankens im zurechnenden Strafrecht, Göttingen 1980.

Rettungsverhalten und Rettungsvorsatz beim Rücktritt vom Versuch, Diss. Jur. Bonn 1990, Baden-Baden 1990.

Zitat: Weinhold, Rettungsverhalten und Rettungsvorsatz

Vorangegangenes Tun als Grundlage einer Handlungsäquivalenz der Unterlassung, Berlin 1968.

Zitat: Welp, Vorangegangenes Tun 
Welzel, Hans

Wessels, Johannes
Das Deutsche Strafrecht, 11. Auflage, Berlin 1969.

Zitat: Welzel, Strafrecht, 11. Aufl. 1969

Das Deutsche Strafrecht, 5. Auflage, Berlin 1956.

Zitat: Welzel, Strafrecht, 5. Aufl. 1956

Strafrecht Allgemeiner Teil, 15. Auflage, Heidelberg 1985.

Zitat: Wessels, AT, 15. Aufl. 1985

Strafrecht Allgemeiner Teil, 14. Auflage, Heidelberg 1984.

Zitat: Wessels, AT, 14. Aufl. 1984

Strafrecht Allgemeiner Teil, 1. Auflage, Karlsruhe 1970.

Zitat: Wessels, AT, 1. Aufl. 1970

Wessels, Johannes/Beulke, Strafrecht Allgemeiner Teil, 45. Auflage, Werner/Satzger, Helmut Heidelberg 2015.

Zitat: Wessels/Beulke/Satzger, AT

Wolter, Jürgen (Hrsg)

Systematischer Kommentar, Loseblattausgabe, 8. Auflage, Köln 2013. (Rudolphi: 20. Lfg., [April 1993]; Stein/Rudolphi: 136. Lfg. [Oktober 2012]). Zitat: SK-StGB/Bearbeiter 
Wendet sich ein Unterlassungstäter von seinem Vorhaben ab, so sind die Anforderungen, die an das Rücktrittsverhalten gestellt werden, vermeintlich eindeutig. Unkritisch wird hierbei stets ein entgegengesetztes Handeln gefordert. $\mathrm{Zu}$ beachten ist allerdings, dass diese Frage meist nur im Rahmen der Unterlassung an sich erörtert wird. Der Vater, der seine Tochter ertrinken sieht und vorsätzlich nicht eingreift, kann in diesem Rahmen durch bloßes Zuwarten freilich nicht zurücktreten. Anders könnte es sich aber dann darstellen, wenn die Tochter sich selbst rettet und der Vater die Möglichkeit erkennt, die Tochter wieder zurück ins Wasser zu stoßen, dies jedoch unterlässt. Fraglich erscheint dann, ob das Ablassen von einer weiteren aktiven Ausführungsmodalität tauglich ist, um insgesamt zurückzutreten. 